\title{
Constraints on reproductive success of northern fulmars in the Canadian High Arctic
}

\author{
by \\ Mark Laurence Mallory \\ A thesis submitted to the Faculty of Graduate Studies and Research in partial \\ fulfillment of the requirements for the degree of Doctor of Philosophy \\ Department of Biology \\ Carleton University \\ Ottawa, Ontario \\ November 2008 \\ (C) 2008, Mark Mallory
}




$\begin{array}{ll}\begin{array}{l}\text { Library and } \\ \text { Archives Canada }\end{array} & \begin{array}{l}\text { Bibliothèque et } \\ \text { Archives Canada }\end{array} \\ \begin{array}{l}\text { Published Heritage } \\ \text { Branch }\end{array} & \begin{array}{l}\text { Direction du } \\ \text { Patrimoine de l'édition }\end{array} \\ \begin{array}{l}\text { 395 Wellington Street } \\ \text { Ottawa ON K1A 0N4 } \\ \text { Canada }\end{array} & \begin{array}{l}\text { 395, rue Wellington } \\ \text { Ottawa ON K1A 0N4 } \\ \text { Canada }\end{array}\end{array}$

Your file Votre référence ISBN: 978-0-494-47484-6 Our file Notre référence ISBN: 978-0-494-47484-6

NOTICE:

The author has granted a nonexclusive license allowing Library and Archives Canada to reproduce, publish, archive, preserve, conserve, communicate to the public by telecommunication or on the Internet, loan, distribute and sell theses worldwide, for commercial or noncommercial purposes, in microform, paper, electronic and/or any other formats.

The author retains copyright ownership and moral rights in this thesis. Neither the thesis nor substantial extracts from it may be printed or otherwise reproduced without the author's permission.
AVIS:

L'auteur a accordé une licence non exclusive permettant à la Bibliothèque et Archives Canada de reproduire, publier, archiver, sauvegarder, conserver, transmettre au public par télécommunication ou par l'Internet, prêter, distribuer et vendre des thèses partout dans le monde, à des fins commerciales ou autres, sur support microforme, papier, électronique et/ou autres formats.

L'auteur conserve la propriété du droit d'auteur et des droits moraux qui protège cette thèse. $\mathrm{Ni}$ la thèse ni des extraits substantiels de celle-ci ne doivent être imprimés ou autrement reproduits sans son autorisation.
In compliance with the Canadian Privacy Act some supporting forms may have been removed from this thesis.

While these forms may be included in the document page count, their removal does not represent any loss of content from the thesis.
Conformément à la loi canadienne sur la protection de la vie privée, quelques formulaires secondaires ont été enlevés de cette thèse.

Bien que ces formulaires aient inclus dans la pagination, il n'y aura aucun contenu manquant.

\section{Canada}




\title{
Constraints on reproductive success of northern fulmars in the Canadian High Arctic
}

\author{
by \\ Mark Laurence Mallory \\ A thesis submitted to the Faculty of Graduate Studies and Research in partial \\ fulfillment of the requirements for the degree of Doctor of Philosophy \\ Department of Biology \\ Carleton University \\ Ottawa, Ontario \\ November 2008 \\ (C) 2008, Mark Mallory
}




\section{Abstract}

The main goal of my thesis was to explore variation in breeding schedules and reproductive success of a seabird, the northern fulmar (Fulmarus glacialis), as a guide to understanding constraints and adaptation of this species for breeding in the Canadian High Arctic. Seabirds occupy top-level trophic positions and are common over much of the marine area of Arctic Canada. Such species should be sensitive to environmental change which is predicted to be considerable and rapid in the Arctic. However, we lack even basic information to predict how environmental changes may affect these birds and other Arctic wildlife.

The key physical factor influencing the breeding ecology of High Arctic fulmars is the extent and timing of break-up of sea ice, which influences timing of peak marine food availability. Fulmars breeding in the Canadian High Arctic might benefit from an earlier break-up of sea ice, as predicted by many climate change models. Compared to fulmars nesting farther south at colonies across the North Atlantic or in Alaska, fulmars in the Canadian High Arctic initiated breeding later and had a relatively compressed and synchronized breeding schedule. Furthermore, they arrived at the colony with larger endogenous nutrient reserves, had a longer exodus from the colony prior to egg-laying, took longer incubation shifts, and had lower reproductive success compared to fulmars breeding at southern colonies. High Arctic fulmars also entered primary molt after breeding was completed (or had failed), 
presumably because they needed to offset the High energetic demands of molting and breeding in the Arctic.

Despite my finding obvious constraints on Arctic breeding by fulmars, there was still considerable phenotypic variation in sizes of breeding birds and in reproductive behaviours at High Arctic colonies, which seemed somewhat paradoxical. Future work should address how ocean climate change influences the timing of available marine food resources relative to traditional breeding times, as this will likely provide selection against that variation. 


\section{Acknowledgements}

I submitted my M.Sc. thesis when my son was only a few months old, literally typing up chapters with one hand on an old " 386 ", while holding him with the other hand. It took a long time before I entertained thoughts of doing another degree, but here I sit, 17 years later, completing and submitting my Ph.D. thesis, just prior to my son entering university. Needless to say, this dissertation was a long time in the making, and I have many people to thank for their patience and support in allowing me to finally achieve this goal.

First, I thank my supervisor and friend Mark Forbes, who has been patient, supportive and insightful throughout this study. This is actually the second permutation of a doctoral project that I started with Mark, who understood my changing employment situation and allowed me to switch projects along the way. His infectious enthusiasm and stream-of-consciousness teleconferences guided this project into important areas that I had not envisioned at the start. Given that Mark now has four students affiliated with Arctic projects, I think I have almost convinced him to refocus his entire research program to Arctic issues ... almost. Mark, my sincere thanks for everything.

I conducted this study while an employee of the Canadian Wildlife Service, and I owe a huge debt of thanks to four people in particular who went to bat for me to get and keep this project going, at a time of uncertain funding for government environmental research. Kevin McCormick, Chief of the Northern Conservation 
Division (now retired), knew that I wanted to do a Ph.D. when he hired me in 1999, and it was his casual reference during my second annual appraisal that actually prodded me into this work. Kevin asked, "Weren't you thinking of doing a Ph.D. before you moved to the Arctic?" Somewhat dumbfounded (as I had never spoken with him about this), I responded with a very professional sounding, "Um, yeah", and he quickly added "Well, why isn't that one of the goals on your appraisal?" I had not encountered this sort of strong, forward-thinking managerial support previously. Once I climbed back into my chair, the project(s) began to take shape. Appropriately, Kevin required sound scientific justification for the research, which I provided, and then Gerry McKeating (retired Director, Prairie and Northern Region) and his successor Bill Gummer (also now retired), both provided the necessary approvals. Finally, Siu-Ling Han (not retired!), Head of the Eastern Arctic Section, became my supervisor part-way through the study, and she has continued the friendship and stalwart support for this work that was exhibited by Kevin, Gerry and Bill. Regrettably, the times are a-changing at Environment Canada and I'm not sure that a project like this could be undertaken now, but I remain unwaveringly thankful for these four managers (and friends) who cleared the path for me to conduct this study.

I wish I had a brilliant, theoretical, scientific explanation for why I initiated a study on northern fulmars at a remote and relatively hostile site in the Canadian High Arctic. But, in fact, the real reason is much simpler. In 2002, when I was starting to focus on seabirds in my job, I was working with Grant Gilchrist conducting ivory gull 
surveys on Ellesmere Island. We were ahead of schedule, and decided to get dropped off for a couple of beautiful, bright, 24-hr sunlit days at a location neither of us had ever been, above the cliffs at Cape Vera, Devon Island, to scope out the fulmar colony and check for eiders (Grant's main research beasties). Grant and I had discussed what we thought were the biggest priority knowledge gaps for Canadian Arctic seabirds, and it was down to two candidates: anything to do with black-legged kittiwakes, or anything to do with northern fulmars, both of which were largely unstudied in Canada. While fulmars have the annoying habit of projectile vomiting, we both agreed that the whining calls of kittiwakes were probably intolerable for a full field season. As we sat on the fractured sedimentary cobble of the polar desert above the Cape Vera cliffs, having instant coffee and smoked oysters at about 11 p.m. on that July night, and looking down on thousands of fulmars, I think the decision was made in my mind. Little did I know how the weather could change ...

Conducting fieldwork at Cape Vera was pretty challenging. Over the duration of this study, we had one entire cabin, 2 outhouses, and four large, canvas-walled tents either blow away, or get destroyed by polar bears. Then there was the $330 \mathrm{~m}$ climb from the base camp to the plateau above the cliffs where one needed to observe the fulmars. Then there was the $100 \mathrm{~km} / \mathrm{h}+$ scouring winds and associated flying debris and grit each month. Oh yeah, the crash landing on the sea-ice. And the fog. And the snow. Did I mention the bears? I was also provided data from fulmar observations at an equally appealing site, the oft fog-enshrouded and snowy Prince 
Leopold Island. A flock of wonderful, talented and resilient people worked at these field sites, and each in some way put at least one day into gathering fulmar data that were used in this project. Needless to say, I am indebted to the following people for their friendship and contributions: Jason Akearok, Karel Allard, Jason Berge, Amie Black, Matt Charette, Sarah Chisholm, Jean Michel deVink, Darryl Edwards, Myles Falconer, Chris Ferguson, Alain Fontaine, Josée Galipeau, Tony Gaston, Cindy Gilbert, Grant Gilchrist, Sara Jaward, Debbie Jeffrey, Jonah Kelly, Elaine Lloyd, Rick Ludkin, Carolyn Mallory, Dave Mallory, Kevin Mallory, Kerrith McKay, Alissa Moenting, Mike Netser, Brianna Newton, Norm North, Kieran O'Donovan, Peterloosie Papatsie, Deb Perkins, Heather Priest, Iain Stenhouse, Ilya Storm, Karen Truman, Tracy Utting, Lisa Venier, Mark Wayland, and Kerry Woo. I add a special "shout out" to Jason and Al, my colleagues from the field and office, who experienced most of the logistic and administrative trials we endured keeping this project alive. Additionally, we could not have operated safely at the site without the stellar logistic support of the Polar Continental Shelf Project in Resolute Bay, especially Dave Maloley and Mike Kristjanson, as well as the superb staff at the base (George, Wally, Tim, Helen, Diane, \& Karen), and the pilots from Kenn Borek Air and Universal Helicopters. Finally, for one part of the work, I was able to use data acquired on fulmars breeding in the United Kingdom. I am most grateful to Barbara Cheney, Sue Lewis and Paul Thompson for their contributions to this project. 
In addition to the most excellent hobbits who helped in the field, I also must thank Kerrie Wilcox and the Long Point Waterfowl and Wetlands Research Fund Avian Energetics Laboratory for the superb assistance I received for the molt scoring and analyses of nutrient dynamics. I hope we can continue this great arrangement, as it has been a pleasure working with them.

Funding for this project came from Environment Canada (Canadian Wildlife Service, Northern Ecosystem Initiative, Environmental Damages Fund), Natural Resources Canada (Polar Continental Shelf Project), Indian and Northern Affairs Canada (Northern Contaminants Program, Northern Studies Training Program), the Nunavut Wildlife Management Board (Nunavut Wildlife Research Trust), and Carleton University. Mark Forbes also provided funding from Natural Sciences Engineering Research Council. My sincere appreciation to all. Collections were in accordance with Canadian Council on Animal Care guidelines, and were conducted under the following permits: research (NUN-SCI-03-02, WL000190, WL000714), animal care (2003PNR017, 2004PNR021, 2005PNR021), and land use (59A/7-2-2).

My committee members (Tony Gaston, Grant Gilchrist, Andrew Simons) provided valuable guidance on the project following my oral qualifying exam. In particular, I appreciate very much the insights provided by Tony, who is indisputably one of the world's leading seabird researchers. He shared not only suggestions and experiences from his wealth of knowledge on seabird biology, but he maintains a remarkable openness to sharing data from Prince Leopold Island, an attitude to which 
more researchers should aspire. As well, Grant has been simply exceptional, both for his knowledge of circumpolar seabird issues, and for providing that shot in the arm when I was starting to doubt myself. I look forward to the future joy and trials of Arctic seabird research with these two excellent colleagues. Also, I must thank Birgit Braune for her insights into fulmar health, which helped shape and fund many of the ancillary projects that we investigated while this work was underway.

Finally, in many ways this project has been a family affair (intended or not!). Thanks to my father (Dave) and my brother (Kevin) for coming to the site and helping build the cabins we needed to stay safe and warm, and to my parents (Dave and Maureen) and parents-in-law (Dale and Florence) for their constant support. My remarkably patient and talented wife, Carolyn, helped tremendously in 2005, when we were conducting the detailed (monotonous!) work on incubation and activity patterns, and she experienced being frozen into a cabin due to ice fog, and having to disassemble the door to get out. Most of all, my deepest gratitude and love to Carolyn and my children (Conor, Jessamyn and Olivia), who have been very understanding and supportive when I have spent many weeks away in the field, and then countless nights and weekends scribing away under my candle here at the office trying to complete this, after I had often already put in a full day's work away from them. You guys are everything to me.

... Oh, and thanks for enduring the three months of odoriferous reminders after I dissected those ridiculously smelly fulmars in the downstairs bathroom ... 
"They seem to have a dour, business-like approach to life ... They lack poise and are devoid of decorum ...

If Charles Dickens had written about seabirds, fulmars would have populated the uncouth lower classes of his novels."

- Carl Safina, 2002 


\section{TABLE OF CONTENTS}

Acceptance Sheet

Page

Abstract

ii

Abstract

iii

Acknowledgements

V

Table of Contents xii

List of Tables

$\mathrm{XV}$

List of Figures

$\mathrm{XX}$

CHAPTER ONE General Introduction

CHAPTER TWO Does sea ice constrain the breeding schedule of High

Arctic northern fulmars?

Abstract

Introduction

Materials and Methods

Results

Discussion

CHAPTER THREE Nutrient dynamics and constraints on the pre-laying exodus of High Arctic northern fulmars

Abstract

Introduction

Materials and Methods

Results

Discussion 


\section{TABLE OF CONTENTS Cont'd}

CHAPTER FOUR Costly pre-laying behavioral and physiological expenditures in northern fulmars in the Canadian High Arctic

Abstract

Introduction

Materials and Methods

Results

Discussion

CHAPTER FIVE Flexible incubation rhythms in northern fulmars: a

Abstract

Introduction

Materials and Methods

Results

Discussion

Abstract

Introduction

Materials and Methods

Results

Discussion 


\section{TABLE OF CONTENTS Cont'd}

CHAPTER SEVEN Predation, nest shelter and nesting behaviour: are they 152 correlated in High Arctic northern fulmars?

Abstract

Introduction

Materials and Methods

Results

Discussion

CHAPTER EIGHT Influence of weather on reproductive success of northern fulmars in the Canadian High Arctic

Abstract

Introduction

Materials and Methods

Results

Discussion

CHAPTER NINE Prebasic moult initiation and progress in northern fulmars of the High Arctic: do moult and breeding overlap?

Abstract

Introduction

Materials and Methods

Results

Discussion

CHAPTER TEN General Discussion 


\section{LIST OF TABLES}

\section{Table}

Title

Page

1.1 Operational definitions of terms bolded in the text

2.1 Comparison of key dates and time spent at the Cape Vera colony by paired male and female fulmars during the during the 2005 breeding season (paired $t$-tests; all $\mathrm{t} \geq 6.7$, all $P<0.001$ ). The breeding season was divided into three stages as follows: stage $1=$ pre-exodus, 40 to 21 days before egg-laying; stage 2 = prelaying, 20 to 1 day before egg-laying; stage 3 = incubation, 0 to 62 days after egg-laying. Calculations of the percentage of time spent at the colony used only pairs that had nests where incubation was completed, a chick was observed, and the identity of each member of the breeding pair was ascertained reliably.

2.2 Values of colony attendance parameters (mean $\pm \mathrm{SE}$ ) for successful, failed, and nonbreeding northern fulmars nesting in the Cape Vera colony in 2005. The breeding season was divided into three stages as follows: stage $1=$ pre-exodus, 40 to 21 days before egg-laying; stage 2 = prelaying, 20 to 1 day before egg-laying; and stage $3=$ incubation, 0 to 62 days after egg-laying. For failed breeding adults, date of hatching was calculated as 49 days from the laying date. For nonbreeding adults, the overall mean egglaying date, mean date of hatching, and end of observations during chick-rearing were used to calculate proportions of time spent at the colony during stage 3 . 


\section{LIST OF TABLES Cont'd}

2.3 Locations, sea ice presence, and reported breeding phenology of northern fulmar colonies in Alaska and across the North Atlantic Ocean. Parameters reported include: date of first landing (when fulmars are first observed attending the colony after the previous breeding season); M:F exodus (the length of the male and female prelaying exodus from the colony); date of the earliest reported egg-laying (first egg), mean date of egg-laying, and mean date of hatching, as well as the length of the incubation period.

3.1 Mean measurements of body composition for breeding male and female fulmars before and after the pre-laying exodus (LDW = lean dry weight). $F$ values are in bold from stepwise general linear model analyses on $\log _{\mathrm{e}}$-transformed values, where $\mathrm{PC1}$ scores (an index of structural body size) also entered the comparison significantly; otherwise, comparisons were made with $t$-tests (one-tailed) on $\log _{\mathrm{e}}$-transformed values.

3.2 Composition ( $\mathrm{g}$ ) and energy content of northern fulmar eggs $(n=24)$ collected in 2003-2005. The mass values in brackets represent calculations for only the seven fresh eggs.

4.1 Mean body composition characteristics of northern fulmars by breeding stage. Body mass measures were values for plucked carcasses. 


\section{LIST OF TABLES Cont'd}

4.2 Akaike Information Criterion $\left(\mathrm{AIC}_{\mathrm{c}}\right)$ values for representative models explaining variation in male northern fulmar $(n=44)$ plucked body mass $(\mathrm{g})$, as well as fat, protein, mineral and gizzard mass ( $\mathrm{g}$ ), and small intestine length (mm) at Cape Vera, 20032005. Models incorporated parameters of breeding stage (stage), body size (PC1) and two-way interaction (stage*PC1). Only candidate models of the $90 \%$ confidence set (sum of $w_{i} \geq 0.90$ ) are presented.

4.3 Model-averaged PC1 estimates ( $\theta)$, standard errors, and 95\% confidence intervals derived from the $90 \%$ confidence set of candidate models for body mass, fat, protein, ash, water, gizzard, and small intestine length of male $(n=44)$ and female $(n=40)$ northern fulmars at Cape Vera, Nunavut, 2003-2005.

4.4 Akaike Information Criterion $\left(\mathrm{AIC}_{\mathrm{c}}\right)$ values for representative 103 models explaining variation in female northern fulmar $(n=40)$ plucked body mass ( $\mathrm{g}$ ), as well as fat, protein, and mineral mass (g), at Cape Vera, 2003-2005. Models incorporated parameters of breeding stage (stage), body size (PC1) and two-way interaction (stage* $\mathrm{PC} 1$ ). Only candidate models of the $90 \%$ confidence set (sum of $w_{i} \geq 0.90$ ) are presented.

5.1 Characteristics of incubation shifts reported for northern fulmars in relation to colony location and oceanographic zone. "HA" refers to High Arctic and "B" refers to Boreal for oceanographic zones. 


\section{LIST OF TABLES Cont'd}

6.1 Duration of incubation shifts (days) by northern fulmars breeding at Cape Vera, Nunavut, Canada in 2005, compared to previously reported values from other studies. $P$-values followed by (ns) are considered non-significant after applying sequential Bonferonni corrections for the number of tests, and $n$ refers to the number of pairs.

7.1 Comparison of breeding success (\%), laying date (mean $\pm \mathrm{SE}$ ), incubation shift (median days, range) and incubation period (mean \pm SE days) of northern fulmars (Fulmarus glacialis) in 2003-2005 nesting in parts of the cliff which varied in their protection from weather and predators.

7.2 A comparison of predation rates on white eggs placed or observed exposed at various northern fulmar (Fulmarus glacialis) nest locations around the Cape Vera fulmar colony between 20032005.

7.3 Comparison of time spent in each activity by incubating northern fulmars (Fulmarus glacialis) nesting in different microhabitats on the cliffs in 2003 (sample sizes are number of observation periods of individual birds nesting in each habitat type). 


\section{LIST OF TABLES Cont'd}

8.1 Measures of reproductive performance of northern fulmars from Prince Leopold Island (PLI) and Cape Vera (CV) in the Canadian High Arctic, 2001-2005. AOS refers to apparently occupied sites. Estimates of maximum fledging success and productivity assume that all chicks reaching the post-guard stage survived to fledge.

8.2 A comparison of reproductive performance of northern fulmars

from various colonies in the species' range. AOS refers to apparently occupied sites. Marine oceanographic zones refer to High Arctic (HA) or Boreal (B).

9.1 Mean (SE) percentage of molt intensity of 20 feather regions from northern fulmars collected during the breeding seasons of 20032005 at Cape Vera, Nunavut, Canada. Only birds with complete data for all feather regions are included. Note: Inferences should not be drawn from comparisons between breeders and non- or failed breeders. 


\section{LIST OF FIGURES}

Figure

Title

Page

1.1 Two pairs of northern fulmars Fulmarus glacialis at nearby nest sites on the cliffs of Cape Vera, Devon Island, Nunavut. Both members of the pair in the top part of the photo are "DD" colour morphs, whereas the lower pair are both "LL".

2.1 The location of the Cape Vera study site on northern Devon Island, Nunavut, Canada.

2.2 Total counts of northern fulmars in eight study plots at Cape Vera in 2004 and 2005, showing the early season peak in attendance, the virtual desertion of the colony following the peak, and the fluctuating attendance during incubation and early chick-rearing.

2.3 The breeding phenology of selected northern fulmar colonies in the North Atlantic Ocean, demonstrating earlier colony attendance, egg-laying, and hatching for birds breeding at lower latitudes. (a) First arrival by fulmars at the colony in relation to colony latitude. (b) Mean date of egg-laying (circles) and mean date of hatching (squares) for fulmar colonies in the Arctic (unfilled) and boreal (filled) oceanographic zones. In both panels, data from a colony in Alaska are shown by triangles. 


\section{LIST OF FIGURES Cont'd}

3.1 The location of the Cape Vera study site on Devon Island,

Nunavut, in the Canadian High Arctic, in relation to features of the marine environment in May 2005. Gray patches on land represent glaciers and ice caps. Solid black areas in the inset or east of Ellesmere Island in the main figure represent the only open water ( $<10 \%$ ice cover) on 15 May. Areas A (mouth of Jones Sound) and B (North Water Polynya) had some open water $(\sim 70 \%$ ice covered), and otherwise all marine areas (light gray) were icecovered. Unfilled circles are locations where fulmars were foraging in June and July, as determined by satellite telemetry (Mallory et al. 2008).

3.2 Mean ( \pm SD) total body water (A), body fat (B) and lean dry mass (C; protein + ash) in male (dark square) and female (light circle) fulmars at Cape Vera, pre- and post-exodus.

4.1 Changes in male (solid circle) and female (open circle) body mass \pm SE from arrival at the colony through late incubation.

4.2 Changes in male (solid circle) and female (open circle) body composition $\pm \mathrm{SE}$ (water, fat, protein, mineral) from arrival at the colony through late incubation. 


\section{LIST OF FIGURES Cont'd}

4.3 Time allocation (\%) by northern fulmars (both sexes) to resting, agonistic interactions, pair bonding, and housekeeping at the nest, from arrival at the colony through late incubation.

5.1 The three northern fulmar colonies examined in this study were located in Arctic Canada (Cape Vera, Prince Leopold Island) and the United Kingdom (Eynhallow). Thick lines separate the High Arctic, Low Arctic and Boreal oceanographic zones (after Salomonsen 1965). In Arctic Canada, the North Water Polynya is indicated by " 1 " and Lancaster Sound is shown by "2".

5.2 The distribution of incubation shift durations differed among years and colonies at Cape Vera (CV05), Prince Leopold Island (PLI01, PLI02, PLI03) and Eynhallow (EYN04).

5.3 In Arctic Canada, body masses ( $\mathrm{g}$ ) of incubating male (black circle) and female (gray square) fulmars differed among colonyyears at Cape Vera (CV 03, CV04) and Prince Leopold Island (PLI01, PLI02, PLI03).

6.1 The distribution of incubation shifts in northern fulmars at Cape Vera, showing (a) the frequency of incubation shifts of different duration (days; arrow represents mean), and (b) the frequency of the required number of shifts to complete incubation (arrow represents median). 


\section{LIST OF FIGURES Cont'd}

7.1 Different types of nesting locations of northern fulmars (Fulmarus glacialis) used in this study. In the upper panel, "cave" sites are noted by arrows, whereas other fulmar nests are on "narrow ledges". In the lower panel, all sites were on a "broad ledge".

7.2 Records of temperatures at nest sites on the Cape Vera cliffs in 2004. (a) Hourly temperature records for thermistors set at a nest site on a broad, exposed ledge (open circles) and a cave (filled circles) on 15 - 16 June, 2004. (b) Daily maximum temperate records for thermistors set on the broad ledge (open circles), the cave (filled circle), and mean daily ambient air temperatures (filled squares).

8.1 Mean ( \pm SE) daily temperature at (a) Cape Vera, Devon Island, 2003-2005, and (b) Prince Leopold Island, 2002, 2003, 2005. Lines above the temperature graph indicate the periods of arrival at the colony by fulmars (A), laying (L) and hatching (H) at Cape Vera, which are similar at Prince Leopold Island.

8.2 Cumulative mortality of fulmar eggs or chicks at Prince Leopold Island in 2003 (PLI03) and Cape Vera in 2005 (CV05). The upper panel (a) depicts the timing of egg losses, with pulses of mortality noted by arrows. In the lower panel (b), the thin line is maximum daily wind speed at Cape Vera, the thick lines are cumulative egg (left) or chick (right) loss, and arrows represent storms with easterly wind gusts $>70 \mathrm{~km} / \mathrm{h}$. 


\section{LIST OF FIGURES Cont'd}

8.3 Mean (SE) daily fulmar chick survival rates at Cape Vera, pooled

for 2004 and 2005. The open circle on day 1 corresponds to day of hatching, and was $100 \%$ survival because we could not account for chicks that may have been lost on that day before our observations. Daily sample sizes (open squares, right hand Y axis) declined with increasing age, due both to mortality, or the end of our observation period.

9.1 Sampled proportions of 11,500 individuals in flight exhibiting primary molt. Each point represents a sample of 100 birds observed from either a colony or shoreline position. Points differ by year and location as follows: (1) Cape Vera 2003 (filled circles), 2004 (filled triangles; black are counts made from the cliffs), 2005 (filled diamonds), 2006 (filled squares); (2) Prince Leopold Island 2005 (open circles).

9.2 Mean (SE) primary molt score of individual primary feathers using the Ashmole (1962) method, for the left and right wings of 29 northern fulmars exhibiting primary molt. Molt initiation was never observed for feathers P6-P10 in any birds at the colony.

9.3 Total primary molt scores for left (circle) and right (square) wings of failed and non-breeding fulmars. 


\section{LIST OF FIGURES Cont'd}

10.1 Annual means of daily plot counts of northern fulmars attending

the breeding plots at Prince Leopold Island, 1976 - 2005.

Methodologies for counts are described in Chapters 2 and 8. Data

on Arctic Oscillation Index values came from

http://www.cgd.ucar.edu/cas/jhurrell/indices.html. 


\section{CHAPTER ONE}

\section{General Introduction}

This chapter formed the basis for the following publication:

Mallory, M. 2006. The northern fulmar (Fulmarus glacialis) in Arctic Canada: ecology, threats, and what it tells us about marine environmental conditions. Environmental Reviews 14: 187-216. 
A fundamental premise of Darwin's (1859) theory of natural selection is that there is phenotypic variation within populations. Natural selection acts on individuals, and those individuals with phenotypic traits that allow for higher survival and/or reproduction should contribute more offspring to future generations (Darwin 1859, Endler 1986). Evolutionary ecologists are interested in factors that influence the number of offspring individuals successfully rear (or lifetime reproductive success). These factors can provide underpinnings of population demography, help elucidate the magnitude and direction of selection (if different phenotypes reflect different genotypes) and help researchers explore adaptation within species (Clutton-Brock 1988).

That variation in phenotypes and reproductive success exists within animal populations is well-known (reviewed in Clutton-Brock 1988). However, we have much less understanding of how these different suites of individual traits are maintained for animals within certain environments, and how this relates to local adaptation within species (Wilson 1998). Phenotypic traits, be they physical or behavioural, usually represent a tradeoff between competing demands on an organism. For example, heavier organisms may be able to allocate more energy to egg production or territorial defense (a reproductive benefit), but this may reduce efficient and rapid mobility required to evade predators (a cost to survival).

Similarly, more aggressive or brighter organisms may attract more mates, but they may be more conspicuous to predators (e.g., Réale et al. 2000). We are currently concerned about the variation that exists within populations, because questions arise 
on how composition of wild populations may change at a time of environmental change (Sih et al. 2004). Do populations support variants suited to new situations, and are phenotypic traits flexible enough to cope with rapid changes?

Seabirds (birds that breed on land but forage in the marine environment) form one group of organisms ideally suited to examine the consequences of phenotypic variation. In particular, the petrels (Order Procellariiformes), possess a unique suite of ecological characteristics which include colonial breeding, small clutch size, long incubation and chick-rearing periods, slow growth rates, delayed maturity, long lifespan, marine diet, and exceptional flying and soaring ability (Warham 1990). These life history traits are thought to be adaptive evolutionary responses to breeding on land but feeding on the unpredictable sea (Hamer et al. 2002). As such, seabirds have played a central role in the development and evaluation of important evolutionary and behavioural theories (e.g., life history theory, Lack 1966, 1968; parental investment theory, Trivers 1972). More recently, these same ecological traits have made this group particularly well-suited to examining the effects of marine ecosystem perturbations (Schreiber 2002).

Canada supports internationally important populations of seabirds, many of which inhabit the Canadian Arctic (Brown et al. 1975, Gaston and Jones 1998, Mallory and Fontaine 2004). Seabirds of this region are generally distributed in a few, very large colonies, each of which may face different environmental conditions in any year. Some of these birds or colonies have been well-studied (e.g., murres; reviewed in Gaston and Jones 1998), while others have received much less attention 
(e.g., northern fulmars, Fulmarus glacialis; reviewed in Hatch and Nettleship 1998).

Consequently, there is a paucity of data for many species on reproduction in relation to local environmental conditions. Filling in these knowledge gaps will be fundamental for future management of these species in times of environmental change (Brown 1991).

The main goal of my thesis research was to test hypotheses concerning adaptations and constraints on breeding marine birds using High Arctic fulmars as a case study. I focus on the causes and consequences of variation in phenotypic and behavioural traits, and how these relate to annual reproductive success.

Prior to outlining my approach for this study, it is useful to review aspects of the marine environment in the Canadian High Arctic, as well as the natural history of the northern fulmar.

\section{Fulmars in the High Arctic marine environment}

The marine environment of the Canadian High Arctic exhibits markedly different physical and biological characteristics than marine waters of temperate and tropical regions (Hunt 1991). Perhaps the most obvious difference is that polar marine regions are covered by extensive sea ice for much of the year $(>6$ months in the High Arctic). This sea ice is a physical barrier precluding access to open water for foraging seabirds (Brown and Nettleship 1981), and it also reduces light penetration into the water column. One biological effect of this physical cover is that it decreases or delays marine biological production at lower trophic levels (Welch et al. 1992). At 
the same time, algae living on the bottom surface of the ice form the basis of local food webs, and consequently locations where platforms of sea ice meet open water (such as the floe edge or polynyas) become local hotspots of biological productivity (Brown and Nettleship 1981, Stirling 1997). Polar marine waters are also cold and relatively rich in nutrients, and thus when sea ice breaks up, light penetration increases, and surface waters warm slightly, a rapid pulse of marine biological production is initiated (Raymont 1976, Lewis et al. 1996). Collectively, sea ice cover and its related effects on marine production impose the following constraints on Arctic seabirds: the need to migrate, a short season for breeding, and spatially and temporally concentrated food supplies (Hamer et al. 2002).

Marine birds have proven to be sensitive and effective indicators of the health or condition of marine ecosystems for a suite of measures (Furness 1993, Nettleship and Duffy 1993, Nisbet 1994, Furness and Camphuysen 1997, Burger and Gochfield 2002, Schreiber 2002). Marine birds are a ubiquitous feature of polar environments, typically feeding at the upper trophic levels, and thus they serve as a proxy for the condition of marine ecosystems because they respond to changes in many levels of the marine food web (Nettleship and Duffy 1993). In particular, most polar marine birds forage over considerable geographic areas, and therefore data gathered from these birds integrate the physical and biological factors that influence the distribution, abundance and chemical composition of prey species over these regions (Jenouvrier et al. 2003, Gaston et al. 2005). Many birds also rely on features of sea ice for feeding (edges, polynyas, underside of ice; Stirling 1997), and thus changes in sea ice 
may be detected through effects on marine birds. In years when marine food resources are reduced, aspects of marine bird reproduction are concordantly reduced (e.g., Barbraud and Weimerskirch 2001). Marine birds also offer the advantage of typically being colonial, so multiple samples can be collected at one location, and the geographic area represented by those samples can usually be defined.

The northern fulmar is a common marine bird of the Canadian Arctic, and is the only petrel (Procellariiformes: Procellariidae) that breeds in the Boreal, Low Arctic and High Arctic oceanographic zones (Salomonsen 1965). Because it breeds across such a broad geographic range, where there are inherent differences in the physical and biological characteristics of the marine zone (above), we should expect to observe geographic variation in fulmar breeding behaviour, particularly for those birds nesting near the northern limit of the species' range. While the ecology of fulmars has been well-studied in the Boreal oceanographic zone, the main part of its breeding range (Fisher 1952, Ollason and Dunnet 1978, 1980, 1986, 1988, Hatch and Nettleship 1998, Thompson and Ollason 2001), only a few studies have looked at fulmars breeding in the Arctic (Salomonsen 1961, 1979, Falk and Møller 1997, Hatch and Nettleship 1998).

\section{Natural history of the northern fulmar}

Northern fulmars are ubiquitous seabirds found across the North Atlantic. They spend most of their time out of sight of land, foraging hundreds of kilometres away from their nest site during the breeding season (Falk and Møller 1995), and 
overwintering on the open ocean (Hatch and Nettleship 1998). Travelling vast distances to feed is made possible by their low wing-loading (ratio of body mass: wing area), which makes them efficient fliers that operate effectively even in windy conditions (Warham 1990, 1996, Furness and Bryant 1996). With such efficient travel capabilities, fulmars can forage over a much broader area than sympatric seabirds (alcids, gulls, eiders), and this may make them less sensitive to environmental conditions near their colony. Fulmars are omnivorous, generalist feeders, consuming zooplankton, squid, fish, fisheries discards, and whatever carcasses they can find in the marine environment (Furness and Todd 1984, Hobson 1993, Hatch and Nettleship 1998, Phillips et al. 1999, Garthe et al. 2004). They can store food in a large proventriculus, and oils from consumed prey are converted to a high-energy stomach oil which may be fed to chicks (along with regurgitated, partially digested prey), or used as fuel for self-maintenance. The walls of the proventriculus are muscular, and this adaptation allows fulmars to projectile vomit stomach oil as a defense mechanism against key predators like common ravens (Corvus corax) and glaucous gulls (Larus hyperboreus).

Like all petrels, fulmars are long-lived seabirds with delayed breeding maturation (Warham 1990). They do not begin breeding until they are 8-12 years old, adult survival is high ( $>0.96$ per year; Buckland 1982), and some European fulmars are known to live 30-50 years (Ollason and Dunnet 1988, Dunnet 1991). Fulmars superficially resemble gulls, having gray plumage with lighter feathers on the head. However, in the Canadian Arctic, fulmars have an array of plumage colouration from 
very dark to very light, which is typically classified into four morphs: DD, D, L, and LL, referring to increasing amounts of white on the breast, neck and head of birds (Fisher 1952, van Franeker 1986, Hatch and Nettleship 1998). Fulmars of the Canadian Arctic are mostly intermediate birds (L and D), while Pacific fulmars are very dark (DD), and European fulmars are principally light morphs (LL). Plumage differences and distinct markings on the bill allow experienced observers to distinguish members of a pair that are different morphs at nest sites.

In the Arctic, northern fulmars first return to their breeding colonies around the start of May. Nest sites are typically located on precipitous, eroding cliffs at heights of 200-400 m, and are usually confined to cliff ledges that are inaccessible to mammalian predators like Arctic foxes (Alopex lagopus). Depending on the pattern of snow accumulation over the winter, nest sites may be buried under drifts when the birds return, and fulmars will dig through drifts to get to their site (Hatch and Nettleship 1998). The nest cups are simple scrapes in loose gravel or on rock, occasionally lined by small pebbles, but at well-established nest sites, long-term nutrient enrichment from guano has led to the development of some graminoid vegetation between scrapes. Wynne-Edwards (1939) suggested that fulmars occasionally skip breeding, but this has since been deemed to be quite uncommon (Lack 1968, Warham 1990). Carrick and Dunnet (1954) found that fulmars breeding at Eynhallow, Orkney, could breed in successive years whether or not they were successful in the previous year, and this result has been repeated elsewhere (e.g., Hatch 1990a,c, Hatch and Nettleship 1998). 


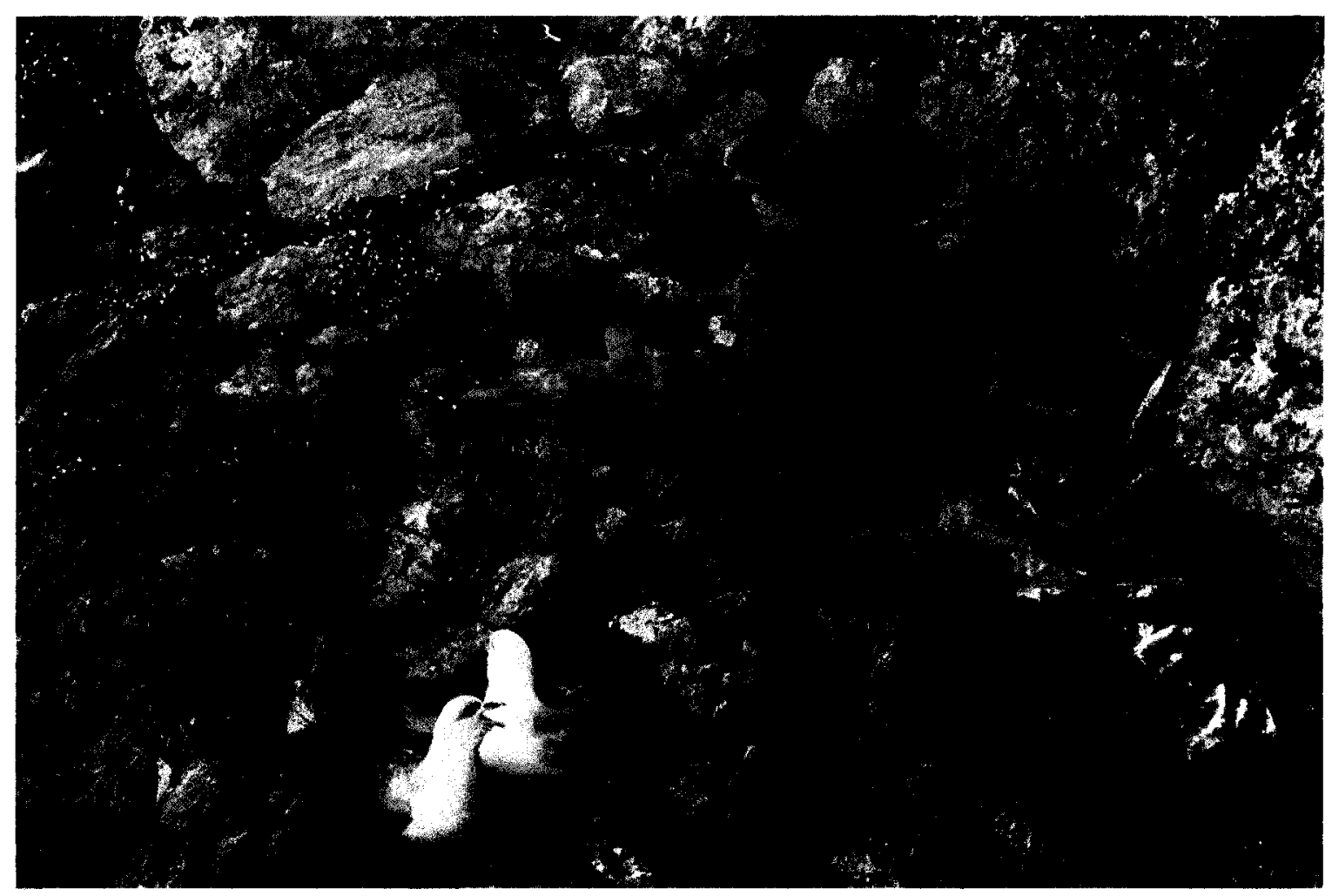

Figure 1.1. Two pairs of northern fulmars Fulmarus glacialis at nearby nest sites on the cliffs of Cape Vera, Devon Island, Nunavut. Both members of the pair in the top part of the photo are "DD" colour morphs, whereas the lower pair are both "LL". 
Nest site and mate fidelity are high in fulmars ( $>90 \%$; Ollason and Dunnet 1978), which exhibit biparental incubation and chick-rearing. After returning to the colony, mates spend approximately $2-3$ weeks presumably re-establishing their pair bond and selecting or defending nest sites (Hatch and Nettleship 1998). Many nonbreeding fulmars also attend the colony, prospecting for future nest sites and gaining experience with conditions on land. A unique feature of procellariid breeding biology is the "pre-laying exodus" or "honeymoon" from the colony (Warham 1990). Following their pair bonding period at the nest, the majority of fulmars depart the breeding colony for 1-2 weeks (Dunnet et al. 1963, Hatch 1990a, Hatch and Nettleship 1998). Prior to this exodus, fulmar pairs mate and females can store sperm in glands, which allows males and females to forage independently during the exodus (Hatch 1983). After the exodus, the male usually returns to the nest site first, followed by the female who lays the egg and departs within $24 \mathrm{hr}$. Fulmars lay a single, yolk- and energy-rich egg (Warham 1990), and if that egg is lost, they do not relay that year (Hatch and Nettleship 1998). The male incubates the egg for the first shift, which may take up to 16 days (Hatch 1990c), after which the male and female take turns incubating or foraging away from the colony, with incubation shifts averaging 4-6 days. After 47-50 days, the chick hatches, and is brooded in shifts by parents for another 10-16 days, before both parents depart on provisioning trips. Chicks fledge at 50-53 days old, with minimal provisioning by parents in the last 5 days. 
Fulmars depart colonies in Arctic Canada in September and October, and migrate south through Baffin Bay and the Davis Strait, to overwinter east of Newfoundland and Labrador (Mallory et al. 2008).

\section{Causes and consequences of variation in phenotypic and behavioural traits}

Seabirds often exhibit marked annual variation in reproductive behaviour and breeding success, in response to both intrinsic (e.g., age, breeding experience; Hamer et al. 2002) and extrinsic factors or constraints (e.g., food supply, weather; Schreiber 2002). As colonial breeders, competition for nest sites and predation pressure can be intense, and food supplies are typically distant from the colony. Patterns in the allocation of time and energy to both resource acquisition (off nest) and breeding activities (on nest) should be paramount for fulmars to successfully reproduce, and this should be particularly true in the Arctic, where feeding areas are covered by extensive sea ice, and consequently have low marine food production, early in the breeding season (Raymont 1976, Welch et al. 1992).

My research tested several fundamental questions related to the variation among individuals or between colonies in the factors that influence annual reproductive success in High Arctic northern fulmars. In particular, I was interested in patterns of the allocation of energetic reserves and corresponding behaviours for the maintenance of these reserves, and how these related to reproductive success. I sought insight to these patterns by addressing the following questions: 
1. How do fulmars breeding in the High Arctic time their reproduction in relation to sea ice breakup, and are they required to adjust aspects of their breeding schedule compared to fulmars breeding farther south? (Chapter 2)

2. What is the sex-specific function of the pre-laying colony exodus for High Arctic fulmars? (Chapter 3)

3. How do fulmars manage their energetic reserves at the start of the breeding season, when energy is required to fuel activities at the nest site, but food supplies are few and distant? (Chapter 4)

4. Does successful incubation of their clutch by High Arctic fulmars require an adjustment to the typical incubation schedule observed by fulmars in more southern waters? (Chapter 5)

5. Are there specific stages of the incubation schedule that are more critical for successful reproduction in High Arctic fulmars than others? (Chapter 6)

6. Does reproductive behaviour and success vary with the characteristics of the nest site? (Chapter 7)

7. What influence does the extreme weather of the Arctic have on reproductive success? (Chapter 8)

8. Can High Arctic fulmars initiate wing moult while breeding, as fulmars might do in the southern part of their range? (Chapter 9)

Below I summarize how each study/chapter was designed to address the preceding questions. 


\section{Chapter 2:}

Many broadly-distributed species exhibit geographical variation of various physical or behavioural traits, presumably an evolutionary response to changing gradients (e.g., climate) across the species' range (Newton 2003). For birds, the timing of nesting will be influenced by the food supply and how that relates to their energetic needs for reproduction, all balanced against self-maintenance requirements to survive and reproduce in the future (Lack 1954, Perrins 1970, Trivers 1972, Brooke 1978). For marine birds, the timing of reproduction is also strongly influenced by annual patterns of marine productivity (Cairns 1987).

In Chapter 2, I examine the timing of breeding by High Arctic fulmars. I expected breeding to commence later in the year than for fulmars at southern colonies because Arctic fulmars had to migrate farther north, and sea ice still covered much of the Arctic ocean at a time when Boreal fulmars could initiate nesting (Hatch 1990b). However, High Arctic fulmars experience a short ice-free period in which to produce and rear young that must fledge before ice once again forms over their marine habitat. Fulmars have a long breeding season compared to other Arctic seabirds (Hatch and Nettleship 1998), and some aspects of their reproductive biology are probably physiologically inflexible, like the time required to form (Astheimer and Grau 1990) or incubate an egg (Hatch and Nettleship 1998). Thus, I also predicted that High Arctic fulmars must adjust certain phases of their breeding schedule (pre-laying, incubation scheduling, chick-rearing) to accommodate the biophysical constraints imposed by annual ice-covered waters. 


\section{Chapter 3:}

Petrels are considered to be "income" breeders (Warham 1990, Meijer and Drent 1999), whereby females must leave their nest site to acquire resources for egg production, and then return to lay their egg. Among the petrels this process is specialized with a pre-laying colony exodus, during which females and males depart the colony, ostensibly to feed heavily and form their egg (for females) or store resources for early incubation (males). Despite its ubiquitous occurrence in this diverse seabird group, no one has ever conducted an empirical test of this accepted explanation for the function of the exodus (Warham 1990, 1996).

In Chapter 3, I examine the nutrient dynamics and sex-specific changes in endogenous body reserves of fulmars pre- and post-exodus. I evaluate whether females must depart for an exodus to gather sufficient resources to form an egg, and whether males must also depart to store reserves for sustaining their first, long incubation shift. I then undertake some energetic modeling to assess how the nutrient dynamics and behaviour of the fulmars might be linked to the timing and availability of open water in the High Arctic.

\section{Chapter 4:}

As a natural progression from the previous chapters, I then investigate the behavioural and energetic responses of High Arctic fulmars to the physical conditions of their nest site and feeding areas when they first arrive at their colony. It is not surprising that fulmars from different colonies face markedly different environmental conditions on return to their colony each year to breed, given that their breeding range 
extends from southern, warmer waters around coastal Europe to the ice-encrusted coasts of the Canadian High Arctic, Like all fulmars, High Arctic fulmars arrive at the colony and must acquire and defend their nest site from conspecifics, and engage in pair bonding activities and copulation (Hatch and Nettleship 1998). However, at this time of year, High Arctic fulmars face colder conditions than fulmars at southern colonies (hence higher thermoregulatory costs; Gabrielsen et al. 1988), must excavate snow to reach their nests (hence higher energetic costs; Ellis and Gabrielsen 2002), and lack the opportunity for short feeding trips to refuel, because ice still covers their feeding areas. Intuitively, High Arctic fulmars must experience great energetic stress at the start of the breeding season.

\section{Chapter 5:}

After considering the effects of extensive sea ice on the timing and energetics of returning to their colony, acquiring their nest site and laying their egg, I turn my attention to questions on how High Arctic fulmars undertake incubation while their surrounding marine feeding areas are still ice covered. Herein, I use data gathered at two High Arctic colonies in Canada and a Boreal colony in the United Kingdom in an inter-colony comparison of incubation scheduling. Such types of analyses have shed much light on our understanding of inter-colony differences in annual reproductive success and population dynamics (e.g., Birkhead and Nettleship 1981, Lewis et al. 2001). Because High Arctic fulmars have no choice but to commute farther distances to feed (as areas near their colonies are ice-covered), I hypothesize that fulmars at these colonies should engage in longer incubation shifts than fulmars at the Boreal 
colony. These longer incubation shifts could be attributable either to increased time and energy expended because of longer distances traveled, or more time and energy required to find sufficient food resources early in the season, when marine production in the Arctic is still relatively low (Raymont 1976, Welch et al. 1992, Gaston et al. 2005).

\section{Chapter 6:}

In Chapter 6, I extend the analysis of fulmar incubation scheduling from Chapter 5, by focusing on the specific pattern of shifts at the Cape Vera colony. As discussed above, fulmars have little flexibility in how long they must incubate an egg (Hatch and Nettleship 1998), but there is considerable variation among pairs in how males and females schedule incubation to ensure protection and warmth for the egg, while the energetic needs of the parents are met (Hatch 1990a,c). However, our understanding of fulmar incubation comes principally from studies where birds have open water adjacent to their colony, and thus abundant potential feeding areas which could support high variation in incubation scheduling strategies (Williamson 1952, Mougin 1967, Hatch 1990c).

Male fulmars take the first incubation shift which is often long (Hatch 1990c), and which is thought to necessitate the male's pre-laying exodus. If the search for food requires longer travel distances and more time early in the season in the High Arctic, then female fulmars should require a relatively long time to recoup energetic reserves after forming an egg. Consequently, I predict that the early incubation shift 
by the male is longer than at southern colonies, and is most critical for successful reproduction in High Arctic fulmars.

\section{Chapter 7:}

Like many seabirds, fulmars are colonial breeders and may experience intense competition for nest sites at a breeding colony (Coulson 2002). Researchers expect that not all nest sites are created equal. There can be considerable variation in the biophysical characteristics of different breeding locations within the same seabird colony (Gaston and Nettleship 1981). Accordingly, variation in nest site characteristics can influence the susceptibility of breeding pairs to predation, to inclement weather, or to agonistic interactions with conspecifics. These factors can affect the time and energy birds must devote to different behaviours, as well as to reproduction (Gilchrist 1999, Hamer et al. 2002, Kim and Monaghan 2005a,b).

There have been no investigations on the role of nest site characteristics on fulmar reproductive success or behaviour. However, falling snow and ice, rockfall, nest density, and predators are all known to have a strong influence on the success of other cliff-nesting Arctic breeding birds (Gaston and Nettleship 1981). In Chapter 7, I test predictions from the hypothesis that nest shelter confers behavioural and energetic advantages to breeding fulmars, which result in higher reproductive success.

\section{Chapter 8:}

In Chapter 8, I progress from the investigation of local nest site characteristics, behaviour, and hatching success in Chapter 7 to an intercolony comparison of reproductive success in High Arctic fulmars. Phenotypic plasticity in 
life history characteristics has been documented in many birds (Welty and Baptista 1988), and might be expected in a broadly distributed species that breeds across a strong environmental gradient like the fulmar (Hatch and Nettleship 1998). In this chapter, I test whether life history traits (hatching success, fledging success, productivity) differ between High Arctic and Boreal fulmars, and which extrinsic factors exert the greatest influence on these traits in the High Arctic. Given that High Arctic fulmars experience a harsher climate than fulmars in the Boreal oceanographic zone, I develop a hypothesis on how early season costs to breeding in this region may be offset by benefits accrued during chick-rearing.

Chapter 9:

Reproduction is not the only energetically-expensive activity that fulmars must undertake during the productive Arctic summer, they must also moult their feathers prior to fall migration and the winter (Hatch and Nettleship 1998). Moult of wing feathers reduces flight efficiency (Swaddle and Witter 1997), an important element of successful foraging by fulmars (Warham 1990, Furness and Bryant 1996). Moreover, because reproduction and moult both require considerable use and management of energetic reserves (King and Murphy 1985), the timing of moult (especially flight feathers) tends to be segregated in most birds from the timing of reproduction, although both generally occur during periods of food abundance (Ricklefs 1974). This poses a potential problem for fulmars in the High Arctic, where there is only a short pulse of abundant, seasonal food supplies (Welch et al. 1992). In some species or locations where environmental conditions constrain life history 
processes (e.g., migration), or where food supplies are superabundant, moult and breeding may overlap in seabirds (Bridge 2006).

In Chapter 9, I examine the timing of moult in High Arctic fulmars as it compares to the timing of breeding. In the Southern Ocean, Barbraud and Chastel (1998) found that moult of flight feathers and breeding overlapped in the closelyrelated southern fulmar (Fulmarus glacialoides). Similarly, breeding fulmars have been observed initiating primary moult while attending nest sites in Alaska. The environmental conditions appear to be substantially different in the High Arctic, as I argue in previous chapters, and fulmars are flying long distances to acquire food. Given these constraints, I predict that High Arctic fulmars cannot initiate moult of primary feathers until reproduction has either failed, or until chick-rearing when marine food resources are abundant.

\section{Thesis synopsis}

This thesis investigates the environmental constraints on a marine bird species nesting at the northern limit of its breeding range (Chapters Two through Nine), and examines the causes and consequences of behavioural variation within a colony and across the breeding range. Although not included in the thesis, I also tested for potential effects of parasites, contaminants and particulate pollution as additional constraints on fulmar reproduction. While novel results were found and published (Mallory 2008, Mallory et al. 2006a, b, 2007), I concluded that the evidence did not place these issues as constraints on High Arctic fulmars, although they are probably 
additive stresses during the breeding season. Finally, I also examined reproductive performance in relation to presumed prior breeding experience (an important factor for other fulmars; Ollason and Dunnet 1978). However, with only three years of observations on these long-lived birds, I considered the results to be equivocal, particularly in the absence of a marked population, and thus they were not included in the thesis.

I end my thesis with a general discussion that places my findings in the body of what is known about constraints on breeding in birds generally, and in fulmars specifically, and why such constraints are important to study. I then highlight other avenues of research that are likely to be important (e.g., how seabird reproduction relates to the North Atlantic Oscillation) in terms of our monitoring of seabird reproduction and projected climate change scenarios. 
Table 1.1. Operational definitions of terms bolded in the text.

\begin{tabular}{|l|l|}
\hline Term & Definition \\
\hline Energetic reserves & $\begin{array}{l}\text { Storage of nutrients (fat, protein) in somatic tissue to } \\
\text { circumvent daily needs of foraging to acquire } \\
\text { energy; sources of nutrients may be endogenous } \\
\text { (acquired and stored before arrival at the breeding } \\
\text { colony) or exogenous (acquired locally after arrival } \\
\text { at the breeding colony; Alisauskas and Ankney } \\
1992 \text { ) }\end{array}$ \\
\hline Extrinsic factors & $\begin{array}{l}\text { Environmental or ecological constraints that } \\
\text { influence reproductive success of an individual (e.g., } \\
\text { food supply, predators; Roff 1992) }\end{array}$ \\
\hline Intrinsic factors & $\begin{array}{l}\text { Internal constraints that influence reproductive } \\
\text { success of an individual (e.g., age, breeding } \\
\text { experience, phylogeny; Roff 1992) }\end{array}$ \\
\hline Life history traits & $\begin{array}{l}\text { Prime determinants of reproductive contribution to } \\
\text { the next generation; set of rules and choices } \\
\text { pertaining to an individual's schedule of } \\
\text { reproduction, survival and survival of offspring (e.g., } \\
\text { development time, body size and fecundity; Roff } \\
\text { 1992). }\end{array}$ \\
\hline Marine biological production & $\begin{array}{l}\text { Strictly defined as the amount of carbon fixed in the } \\
\text { ocean per m }{ }^{2} \text { or m } \text { m }^{3} \text { per unit of time; in terms of } \\
\text { marine bird foraging, more generally considered as } \\
\text { the amount of food (phytoplankton, zooplankton, } \\
\text { fish) produced in the marine food web per unit } \\
\text { volume per unit time (Raymont 1976) }\end{array}$ \\
\hline Pre-laying exodus & $\begin{array}{l}\text { Geographic divisions of the surface waters of the } \\
\text { North Atlantic and Arctic Ocean system based on } \\
\text { currents, temperature, salinity, and distribution of } \\
\text { marine invertebrates (Nettleship and Evans 1985) }\end{array}$ \\
\hline Phenotypic traits & $\begin{array}{l}\text { Observable characteristics of an organism (e.g., } \\
\text { morphology, behaviour; Roff 1992) }\end{array}$ \\
\hline $\begin{array}{l}\text { Patches of mostly year-round open water, } \\
\text { surrounded by sea ice, which occur due to current, } \\
\text { tidal or upwelling activities, and which tend to have } \\
\text { higher marine production (Smith and Rigby 1981) }\end{array}$ \\
\hline $\begin{array}{l}\text { For petrels, also known as the "honeymoon"; the } \\
\text { time period after copulation at the colony when } \\
\text { some or all established breeding petrels go to sea }\end{array}$ \\
\hline
\end{tabular}




\begin{tabular}{|l|l|}
\hline & $\begin{array}{l}\text { while the egg is formed, before returning to the } \\
\text { colony at which time the female immediately lays } \\
\text { the egg (Warham 1990) }\end{array}$ \\
\hline Trophic levels & $\begin{array}{l}\text { Steps in a food chain; in marine environments, } \\
\text { phytoplankton are primary producers and form the } \\
\text { first trophic level, while seabirds may be second or } \\
\text { third order carnivores at upper trophic levels (Smith } \\
1980)\end{array}$ \\
\hline
\end{tabular}




\section{CHAPTER TWO}

Does sea ice constrain the breeding schedules of high Arctic northern fulmars?

This chapter formed the basis for the following publication:

Mallory, M. L., and M. R. Forbes. 2007. Does sea ice constrain the breeding schedules of High Arctic northern fulmars? Condor 109 894-906. 


\begin{abstract}
The Northern fulmar (Fulmarus glacialis) is a pelagic seabird that breeds across $25^{\circ}$ of latitude, from the Boreal to the High Arctic oceanographic zones. I examined the breeding schedule of fulmars in the remote Cape Vera colony in the Canadian High Arctic, a marine region covered by sea ice much of the year, to determine if the timing of breeding and colony attendance patterns of birds differed from the breeding phenology of fulmars in colonies farther south. Cape Vera fulmars arrived at the colony later in the year, spent less time at the colony before egg-laying, and took a significantly longer prelaying exodus from the colony compared to fulmars nesting in more southerly colonies. After egg-laying, however, patterns of colony attendance by fulmars in the High Arctic were similar to patterns for fulmars in southern colonies; this part of the fulmar breeding schedule may be inflexible. The differences in breeding schedules across the species' range might reflect behavioural adaptations by arctic-nesting birds to accommodate the physical and biological limitations imposed by extensive sea ice near arctic colonies, particularly early in the breeding season. Given that climate warming and corresponding reductions in sea ice are taking place in the Arctic, it remains to be determined whether fulmars in the High Arctic have the behavioural flexibility in their breeding phenology to compensate for rapidly occurring changes in their environment.
\end{abstract}




\section{Introduction}

The timing of breeding by birds has received considerable attention. Timing of nesting might relate to the ability of the female to gather sufficient food for egg production (Perrins 1970), the parents' abilities to gather resources for selfmaintenance during incubation (Brooke 1978), or the parents' abilities to find sufficient food to provision young while maintaining their own body condition (Lack 1954, Gaston and Hipfner 1998). Recent studies have identified connections between breeding phenology and large-scale effects of climate change on marine ecosystems (Montevecchi and Myers 1997, Ainley 2002). Among seabirds, timing of reproduction typically reflects annual patterns of marine productivity (Cairns 1987, Abraham and Sydeman 2004). In years when marine production is low, often a result of major climatic factors, marine birds may nest later (Schreiber 2002, Gaston et al. 2005).

For seabirds nesting in polar regions, breeding phenology may be particularly affected by marine conditions (Hunt 1991), because sea-ice cover creates a physical barrier to open water access (Brown and Nettleship 1981) and also reduces light penetration, thereby reducing or delaying productivity at lower trophic levels (Raymont 1976, Welch et al. 1992). In years when sea-ice cover is extensive or persists longer into the breeding season, marine birds should experience higher foraging costs, because they have to travel farther to find food, as well as reduced food availability, because marine production is adversely affected. Both of these factors could influence reproductive decisions by breeding birds. Indeed, several 
studies of polar seabirds have found delayed egg-laying and reduced reproductive success in years with more severe sea-ice conditions (Ainley et al. 1983, Gaston and Hipfner 1998, Gaston et al. 2005).

Another approach for addressing the importance of ice conditions for seabird reproduction is to compare timing and duration of key breeding events within species across a range of latitudes. This reduces the contribution of interannual variation in other factors that may relate to annual variation in sea-ice cover during the breeding season. Specifically, if sea-ice cover acts as an important constraint on seabird breeding as inferred, then we would expect to find consistent differences in breeding phenology between northern (High Arctic) and southern populations of widespread species. Using published information, such a study requires comparing birds at different colonies in different years, necessitates accounting for various study designs, and assumes that breeding metrics for each colony were derived during typical annual environmental conditions.

The northern fulmar (Fulmarus glacialis) is ideal for such comparisons: it is a fulmarine petrel with a circumpolar distribution, and it breeds between $55^{\circ}$ and $80^{\circ} \mathrm{N}$ in the North Atlantic Ocean (Hatch and Nettleship 1998). The northern fulmar is long-lived, lays one egg per clutch, and does not relay following breeding failure (Dunnet et al. 1963, Ollason and Dunnet 1978). Like all petrels, this fulmar undertakes an exodus (a key breeding event) from the breeding colony prior to egglaying, which allows the female to gather nutrients to form her single, relatively large, energy-rich egg (Warham 1990, 1996). Additionally, breeding at fulmar colonies 
appears to be relatively synchronized annually, and shows little variation in mean laying dates across years (Hatch and Hatch 1990), similar to many other petrels including sooty shearwaters (Puffinus griseus; Richdale 1963), short-tailed shearwaters (P. tenuirostris; Serventy 1963), Manx shearwaters (P. puffinus; Brooke 1978), Antarctic fulmars (Fulmarus glacialoides), Antarctic petrels (Thalassoica antarctica), cape petrels (Daption capense), and snow petrels (Pagodroma nivea; Hodum 2002).

In his seminal work on the species, Fisher (1952) deduced that northern fulmars throughout the boreal oceanographic zone had a similar breeding schedule, but suggested that this schedule might be different for arctic colonies. In the Boreal Zone of the Atlantic, fulmars typically begin to attend their breeding colony intermittently in the autumn preceding the breeding season, and lay eggs in mid- to late May, with egg hatching occurring in early to mid-July (Fisher 1952, Dunnet et al. 1963, Coulson and Horobin 1972, MacDonald 1977, 1980). Several authors have provided some evidence that fulmars in the Arctic do indeed nest later than fulmars in the Boreal Zone (Freuchen and Salomonsen 1958, Falk and Møller 1997, Hatch and Nettleship 1998), but no studies to date have provided details of the first arrival of the birds at these colonies, nor measures of the duration of the prelaying exodus. These two key features of fulmar breeding should be most affected by sea ice or climatic conditions, because sea-ice extent should be greatest and pelagic marine productivity lowest early in the year.

I studied the breeding phenology of northern fulmars in the remote Cape Vera 
colony in the Canadian High Arctic. At this site, fulmars have to fly over extensive sea ice in Baffin Bay and Jones Sound for over half of their breeding season (first arrival at the colony to date of hatching), a constraint experienced by only a few fulmar colonies across the High Arctic (Falk and Møller 1997, Hatch and Nettleship 1998). Because of this sea-ice cover, I predicted that birds would arrive at the colony later, would have a shorter prelaying period at the colony, and would take a longer prelaying exodus than fulmars nesting in the boreal oceanographic zone. I tested these expectations, while also comparing differences in breeding phenology related to gender or breeding status as other studies have done. This study thereby provides baseline data on timing and duration of key breeding events of fulmars nesting at this colony.

\section{Materials and Methods}

I conducted fieldwork between 14 May and 9 August 2004 and from 20 April to 10 August 2005 at the "Cape Vera" fulmar colony $\left(76^{\circ} 15^{\prime} \mathrm{N}, 89^{\circ} 15^{\prime} \mathrm{W}\right)$ on northern Devon Island, beside the Hell Gate-Cardigan Strait polynya (Fig. 2.1). This marine area is located in the High Arctic oceanographic zone (Salomonsen 1965), and nearby Jones Sound remains ice-covered from October through July (except for the open water near the polynya; Mallory and Fontaine 2004). I obtained data on the ice conditions of Jones Sound and Baffin Bay from the Environment Canada - Canadian Ice Service climate archives (available at $<$ http://ice-glaces.ec.gc.ca>). Typical conditions for maximum, circumpolar extent of arctic sea ice were taken from 


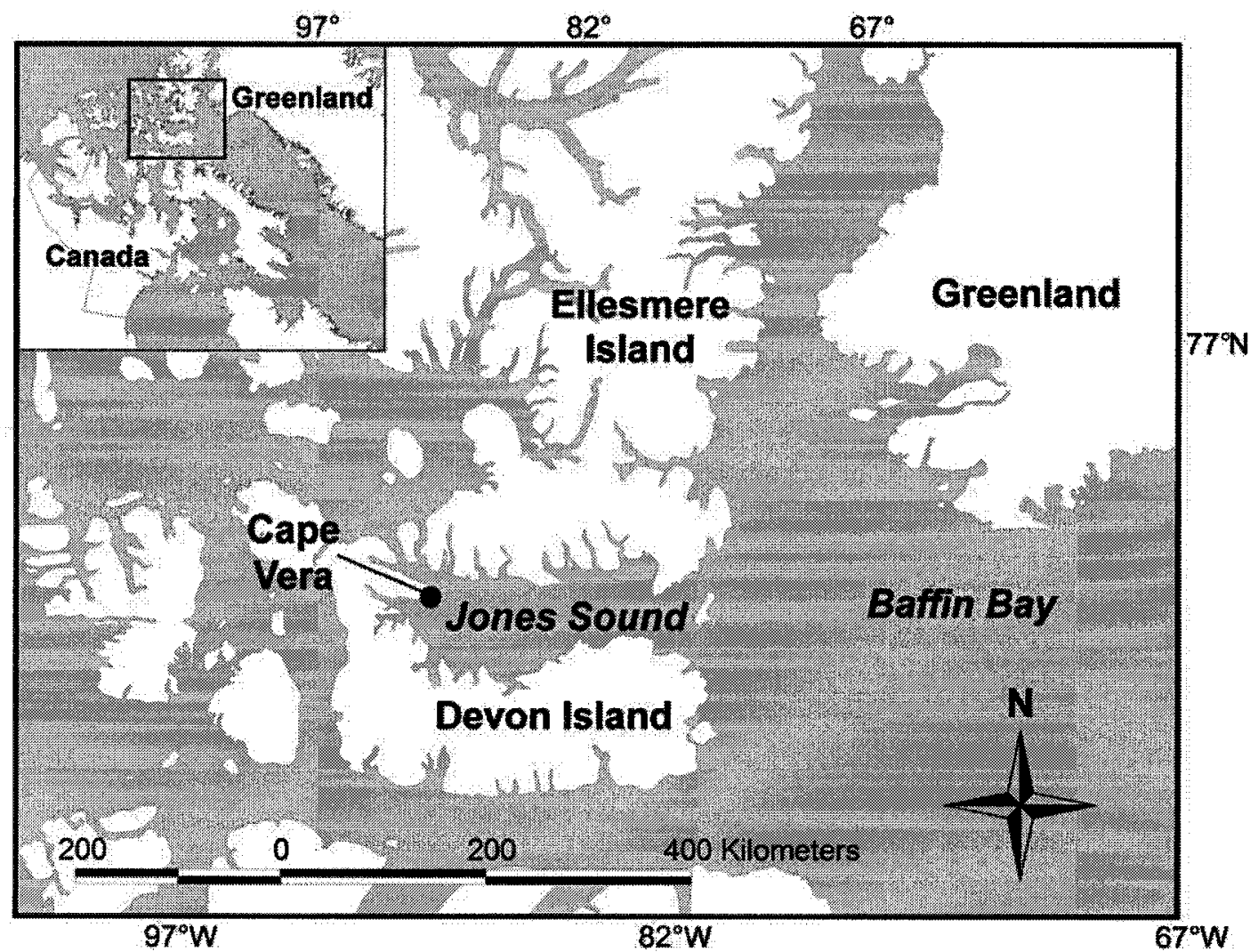

Figure 2.1. The location of the Cape Vera study site on northern Devon Island, Nunavut, Canada. 
satellite imagery (National Snow and Ice Data Center 2007).

The Cape Vera colony is the most northerly and remote fulmar colony in North America (Hatch and Nettleship 1998). The coastline at Cape Vera features prominent cliffs that rise $245-313 \mathrm{~m}$ above sea level, and approximately 11000 pairs of fulmars occupy nest sites along $6.4 \mathrm{~km}$ of deeply incised cliffs (Gaston et al. 2006). Breeding fulmars do not appear to feed in the Hell Gate polynya, and instead fly east to forage between Ellesmere Island and Greenland (Mallory et al. 2008).

I established eight long-term monitoring plots along the breeding cliffs at Cape Vera, with each plot supporting 25-300 nest sites (Mallory and Gaston 2005). Nest sites and attending birds could be easily viewed using $10 \times 42$ binoculars or a $60 \times$ spotting scope from vantage points $30-300 \mathrm{~m}$ distant along the cliff top, meaning that birds were not disturbed during counting. Cape Vera is highly susceptible to fog and high winds, and these weather conditions meant that data on all plots were collected on only 34 of 87 (39\%) days in 2004 . One plot was particularly problematic, and this plot was replaced in 2005 (accounting for some of the total count differences between years). In 2005, data on all plots were collected on 93 of $107(87 \%)$ days, and data were collected on some of the plots on days when other plots were obscured. In 2005, I also used a Canon ${ }^{\circledR} 20 \mathrm{D}$ digital camera with a 400 $\mathrm{mm}$ lens to produce an 8 megapixel photograph of each plot each day. These were downloaded to field computers, and counts could be conducted or confirmed in camp from these photos during poor weather. In situations where a nest could not be observed on day $x$, but I identified the same bird at the nest on day $x-1$ and day $x+$ 
1, I assumed the bird was on the nest during day $x$. If the other pair member appeared on day $x+1$, I assumed that the new bird arrived that day, and attributed the missed observation to the bird observed on day $x-1$.

To determine which member of the pair was in attendance, I relied on several types of information. Northern fulmars range in plumage color from very dark (DD) to intermediate (D or $\mathrm{L}$ ) to very light $(\mathrm{LL})$, which refers to increasing amounts of white on the breast, neck, and head of birds (Fisher 1952, Hatch and Nettleship 1998). Fulmars of the Canadian Arctic are mostly intermediate birds (L and D), with numerous very light morphs (LL), and relatively few very dark birds (DD). Plumage differences, along with distinct markings on the bill, allow experienced observers to distinguish members of a pair based on these characteristics. Live fulmars cannot be sexed unless measured (Mallory and Forbes 2005), or unless the position of birds during copulation is noted (Hatch 1990a). However, males are usually first to arrive at the colony (as with many other seabirds; Ainley et al. 1983), last to leave and first to return from the exodus, and they take the first long incubation shift (Fisher 1952, Hatch 1990a, b, c).

It is not easy to determine if a fulmar is on an egg, as nonbreeders often appear to be incubating for periods of hours, but then leave the nest site (Fisher 1952, Gaston et al. 2006). In preliminary work in 2003, I estimated that approximately onethird of the time I incorrectly assumed that observed birds at nest sites were breeding adults and then saw them fly off with no egg or chick at the site. To reduce this error, I determined that repeated observations of the same individuals for several hours each 
day were required.

On five of the study plots in 2004 and 2005, I conducted detailed, daily observations for $1-4$ hours on selected nest sites to determine which pair member was attending the nest, and to identify whether an egg or chick was in the nest. In some cases I recorded whether the bird exhibited "egg behaviour" and confirmed the status of the nest at a later date when the egg was subsequently observed. Repeated observations of the same plots by the same personnel meant that observers became familiar with the individual birds' behaviours. Thus, for these well-studied plots, "egg behaviour" was incorrectly ascribed to only $1 \%$ of birds for which I later confirmed that there was no egg present. I defined the following three categories of birds: successful breeders (fulmars at nests that produced a chick which was still alive by 10 August); failed breeders (fulmars at nests that produced an egg, but either the egg or chick was lost during incubation or brood-rearing); and nonbreeders (fulmars at nests where I never observed an egg). Observing whether these types of birds differ in attendance patterns is important as it might tell us whether inter-colony comparisons have to be made somewhat carefully.

In 2005, I collected six fresh fulmar eggs within one day of laying. I used the staining and yolk ring counting technique of Astheimer and Grau (1985) to determine how many days females spent developing eggs.

I followed the approach of Hatch (1990c) to divide the fulmar breeding season into stages as follows: stage 1 (pre-exodus) -40 to 21 days before egg-laying, covering the period of prelaying colony attendance and the departure for the exodus; 
stage 2 (prelaying) - 20 to 1 days before egg-laying, covering most of the exodus from the colony and the return of fulmars prior to the day the egg was laid; and stage 3 (incubation) -0 to 62 days after egg-laying, covering incubation and the posthatching guard stage where one of the parents broods the chick. I then compared the time the male and female spent at the colony in each of these stages for those fulmars that successfully reached the end of stage 3 . I was not at the colony long enough to cover Hatch's (1990c) stage 4 (chick-rearing), nor to observe young fledge.

To compare breeding schedules of fulmars at Cape Vera to those from colonies elsewhere, I reviewed the literature for published values of key phenological dates (e.g., first landing, start and end of exodus, egg-laying, date of hatching). In situations where studies were conducted over several years, I took the earliest dates from any of the years as my measure for each colony-specific date. Aside from Cape Vera, only fulmar colonies in Canada, Greenland, Spitzbergen (Norway), and Franz Joseph Land (Norway) encounter extensive sea ice at some stage of the breeding season (National Snow and Ice Data Center 2007).

For calculations, all dates were converted to ordinal dates, with 1 January = 001. In situations in which the date of first landing reported in the literature was in the autumn prior to a new breeding season, I subtracted the number of days from 1 January (e.g., 1 December $=-031$ ). Because Cape Vera data were missing for many days in 2004, I refer principally to 2005 data below, but include and describe 2004 data where appropriate. Depending on the distribution of data, I used $t$-tests, ANOVAs, Kruskal-Wallis tests, or Pearson or Spearman rank correlations to compare 
data among years or colonies. I used ANOVAs for comparisons with summary data from other studies, but in all cases the Bartlett's tests suggested significant differences in standard deviations among studies (all $P<0.01$ ). Therefore, statistical differences among studies should be interpreted cautiously. Means are presented \pm SE unless otherwise noted.

\section{Results}

Sea-ice distribution

During April and May, fulmars encountered $>90 \%$ sea-ice cover from Disko Island $\left(69^{\circ} 30^{\prime} \mathrm{N}, 54^{\circ} \mathrm{W}\right)$, Greenland to the Cape Vera breeding colony, a distance of approximately $1200 \mathrm{~km}$. The exception was a recurrent area of open water between Ellesmere Island and Greenland (the North Water Polynya, $76^{\circ} \mathrm{N}, 75^{\circ} \mathrm{W}$ ), which varied annually in size and could be 350-500 km away at this time. Between 1996 and 2005, the mean distance to open water at Cape Vera in the second week of June was $190 \pm 5 \mathrm{~km}$, a distance that was consistent across years (range: $175-225 \mathrm{~km}$, coefficient of variation 9\%). By the third week of July, fulmars still had to cross at least $100 \mathrm{~km}$ of sea ice in 2004 , and $300 \mathrm{~km}$ of ice in 2005 , to reach feeding areas.

\section{Prelaying colony attendance and the exodus}

In 2005 , northern fulmars were not observed in the nearby polynya nor landing on the cliffs before 30 April (two weeks before observations were initiated in 2004). The first birds to appear at known nesting sites in monitoring plots were observed one day 
later, and numbers increased rapidly to a maximum count for the year on 7 May, before declining to $<5$ fulmars by 21 May (Fig. 2.2). In 2005, the colony was effectively deserted for 14 days: only 10 fulmars were observed between 17 and 30 May at 307 nest sites. At 48 nests where I could distinguish pair members, knew the sex of the birds, and tracked attendance to hatching, $35 \%$ of the pairs arrived at the colony on the same day, with the male arriving before the female in all other cases. Thirty-three percent of pairs departed together for the exodus, while the female departed before the male in all but $6 \%$ of the remaining pairs. Collectively, males arrived earlier, spent longer at the colony prior to departing for the exodus, were away from the colony for a shorter exodus, and returned earlier before egg-laying than females (Table 2.1). At 23 days long, the male exodus was five days shorter than the female exodus, with females away from the colony for approximately one month (Table 2.1).

Colony attendance from late prelaying to early incubation (14 May to 23 June) was highly correlated between counts on the same day in 2004 and $2005\left(r_{s}=0.86, P\right.$ $<0.05, n=14$; Fig. 2.2), suggesting that the colony was synchronized across years.

\section{Egg-laying, incubation, date of hatching, and chick-rearing}

There was no variation in counts of yolk rings among fulmar eggs; all six females took 23 days to form their egg. Mean egg-laying day for Cape Vera in 2005 was 


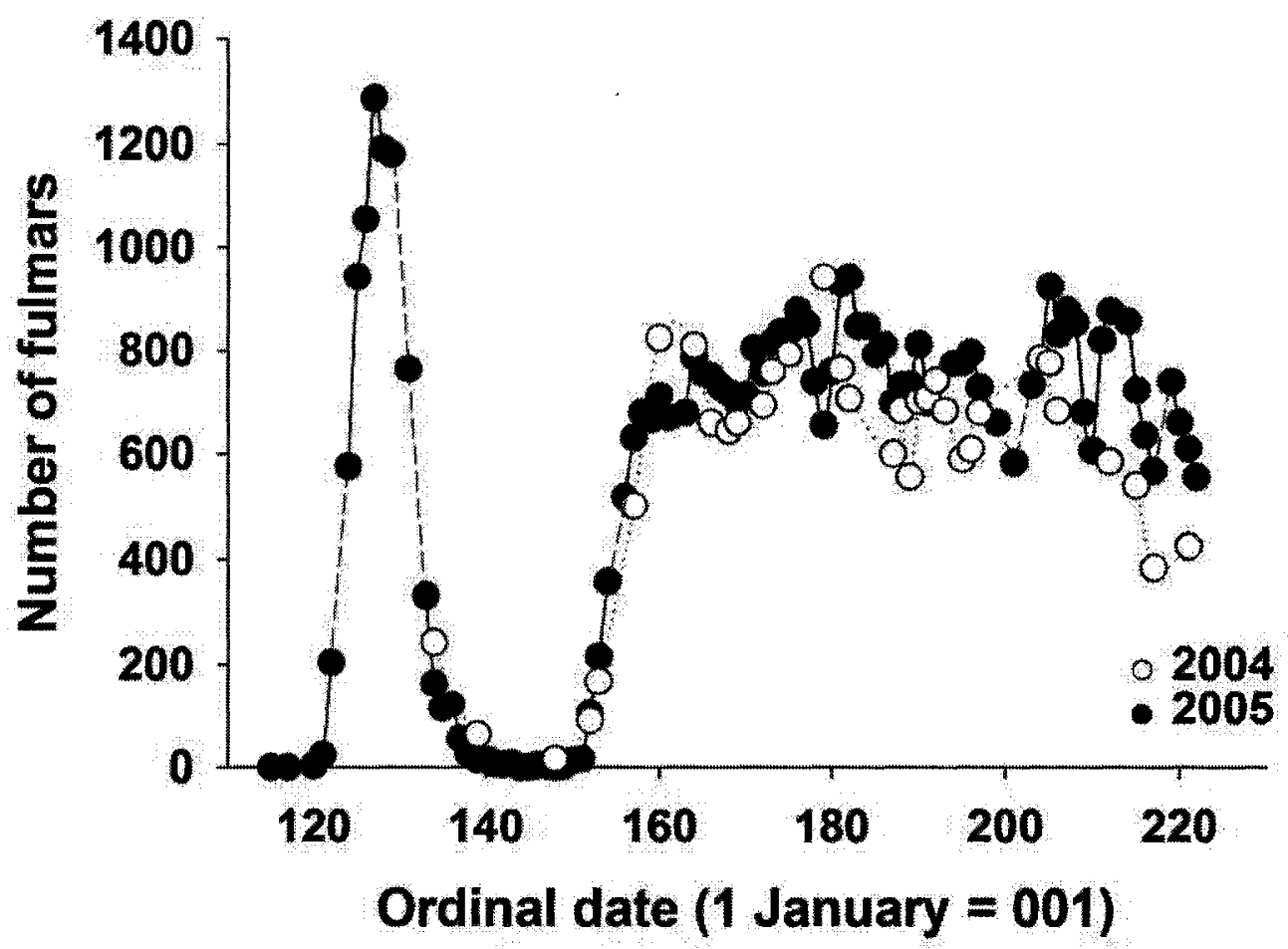

Figure 2.2. Total counts of northern fulmars in eight study plots at Cape Vera in 2004 and 2005 , showing the early season peak in attendance, the virtual desertion of the colony following the peak, and the fluctuating attendance during incubation and early chick-rearing. 


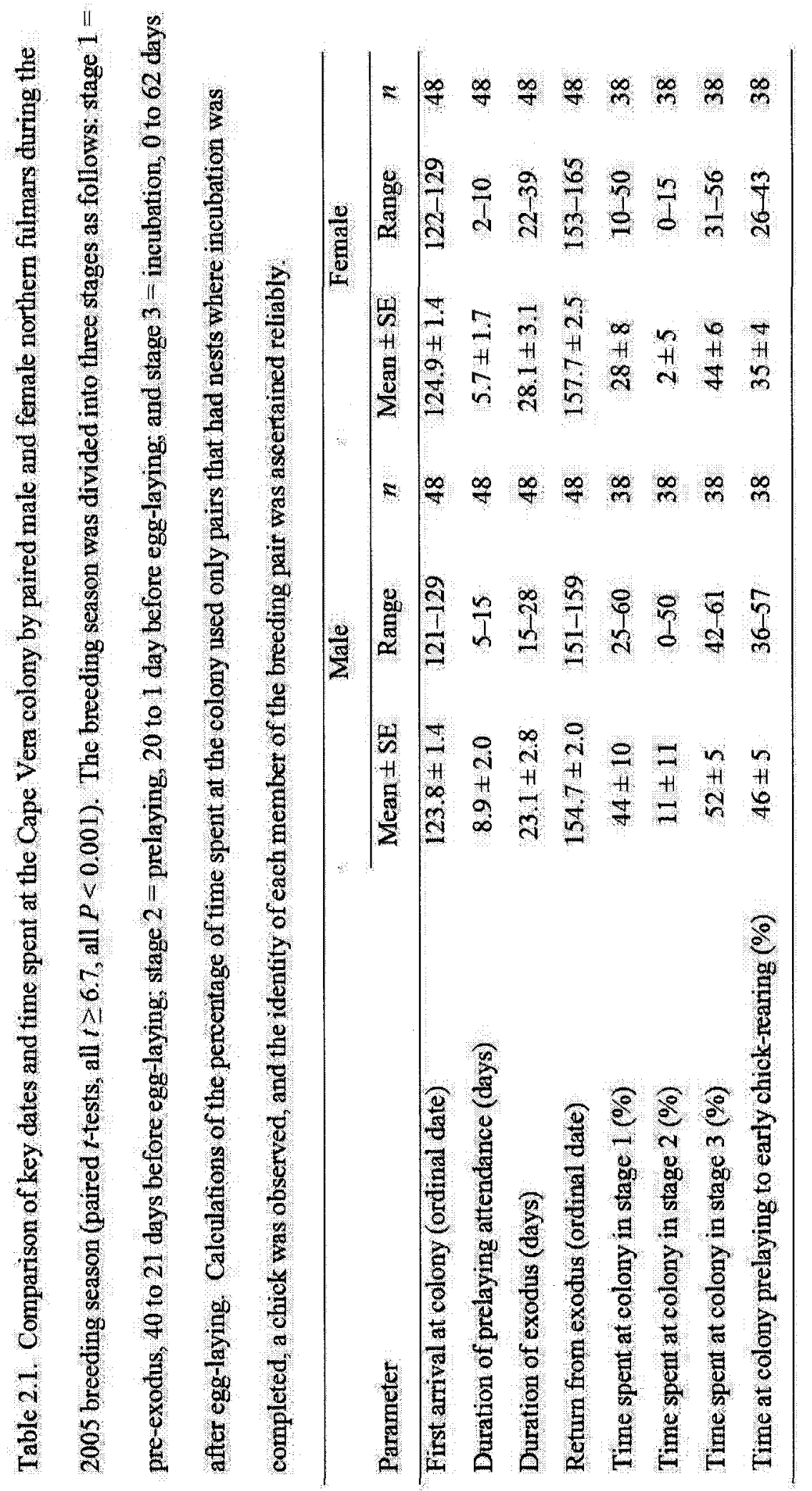


$157.9 \pm 0.2$ ( 6 June, range: $2-16$ June, $n=103$ ), with $80 \%$ of eggs laid between 4 and 9 June. This was similar to 2004, in which the egg-laying day for 16 nests averaged $157.1 \pm 0.6$, and the earliest egg was also observed on 2 June.

The incubation period of fulmars at Cape Vera was $49.0 \pm 0.2$ days (range: $46-52, n=65$ ), and mean day of hatching was $206.1 \pm 0.3$ (25 July, range: $22-31$ July, $n=65$ ). Like egg-laying, date of hatching was highly synchronized, with $80 \%$ of eggs hatching between 23 and 27 July. In 2004, I observed 39 nests hatch between 21 and 31 July (mean day $=205.8 \pm 0.5$ ), and behaviours of birds suggested that hatching occurred at a further nine nests during this period, but I was unable to confirm the presence of a chick at these nests until 3 August. Thus, it seems probable that overall mean dates of hatching in both years were within one day of each other.

For 24 nests where the full chick-guarding stage was observed, at least one parent was with the chick for $14.6 \pm 0.4$ days (range: $12-18$ days). At another 16 nests, an adult was observed still attending the chick 10-19 days after hatching when my observations ended (i.e., before the completion of chick-rearing).

Seasonal pattern of time allocation at the colony

During stage 1 (pre-exodus) of the breeding season, males spent $44 \%$ and females spent $28 \%$ of their time at the colony, although these differences were not statistically significant (Table 2.1). This stage was marked by high synchrony in attendance within pairs, with many pairs arriving and departing on the same day (above). Males spent only $11 \%$ of stage 2 (prelaying) at the colony, but this was significantly more 
than females, who attended the colony for only $2 \%$ of those days. During incubation and early chick-rearing (stage 3 ), males spent slightly more than half of their time at the nest, which was more than females, who attended the colony for $44 \%$ of the period (Table 2.1). Thus, over the entire 103-day breeding period that I observed, males spent $46 \%$ of their time at the nest and females spent $35 \%$ of their time at the nest, for an overall mean of $40 \pm 1 \%(n=38)$. During this period, birds were observed together at the nest $9 \pm 1 \%$ of the time.

\section{Breeding schedules and breeding status}

At Cape Vera, males and females of known sex (above) appeared to have consistent patterns of arrival and departure, so I assumed that the first birds to arrive and the last birds to depart during prelaying were males. Using this approach, I found no significant differences for 133 apparently occupied nest sites among successful, failed, or nonbreeders in any of the following: the synchrony of arrival and departure from the colony; the time the pair spent together during prelaying; the time spent at the colony by males or females during stage 1 ; or the duration of the male or female exodus (Table 2.2). Fulmars attended their nest sites from prelaying to chick-rearing even if they were non- or failed breeders, but over the entire 103-day observation period, nonbreeders were more often observed together at the colony than successful breeders (Table 2.2). In addition, nest sites were left unattended significantly less often during incubation by successful breeders than by failed breeders, and both of these groups were at the nest more often than nonbreeders 
Table 2.2. Values of colony attendance parameters (mean $\pm \mathrm{SE}$ ) for successful, failed, and nonbreeding northern fulmars nesting in the Cape Vera colony in 2005. The breeding season was divided into three stages as follows: stage $1=$ pre-exodus, 40 to 21 days before egg-laying; stage 2 = prelaying, 20 to 1 day before egg-laying; and stage 3 = incubation, 0 to 62 days after egg-laying. For failed breeding adults, date of hatching was calculated as 49 days from the laying date. For nonbreeding adults, the overall mean egg-laying date, mean date of hatching, and end of observations during chick-rearing were used to calculate proportions of time spent at the colony during stage 3 .

\begin{tabular}{|c|c|c|c|c|c|}
\hline \multirow[b]{2}{*}{ Parameter } & \multicolumn{3}{|c|}{ Breeding status $(n)$} & \multicolumn{2}{|c|}{$\begin{array}{l}\text { Statistical } \\
\text { comparison }\end{array}$} \\
\hline & $\begin{array}{c}\text { Successful } \\
(52)\end{array}$ & $\begin{array}{c}\text { Failed } \\
(48)\end{array}$ & $\begin{array}{c}\text { Nonbreeding } \\
\text { (33) }\end{array}$ & $\begin{array}{l}F \text { or } \\
K-W\end{array}$ & $P$ \\
\hline \multicolumn{6}{|c|}{ Synchrony of prelaying arrival } \\
\hline$(\text { days })^{\mathbf{a}}$ & $1.2 \pm 0.2$ & $1.4 \pm 0.2$ & $1.6 \pm 0.3$ & 0.7 & 0.48 \\
\hline \multicolumn{6}{|c|}{ Synchrony of departure for } \\
\hline exodus (days) ${ }^{\mathrm{b}}$ & $2.0 \pm 0.3$ & $1.7 \pm 0.3$ & $1.2 \pm 0.4$ & 1.3 & 0.26 \\
\hline \multicolumn{6}{|c|}{ Proportion of days paired during } \\
\hline prelaying (\%) & $76.8 \pm 3.9$ & $72.8 \pm 4.8$ & $64.1 \pm 5.1$ & 1.3 & 0.28 \\
\hline \multicolumn{6}{|c|}{ Male at colony during stage 1} \\
\hline (days) & $8.8 \pm 0.3$ & $9.0 \pm 0.4$ & $8.7 \pm 0.4$ & 0.2 & 0.84 \\
\hline \multicolumn{6}{|c|}{ Female at colony during stage 1} \\
\hline (days) & $5.5 \pm 0.2$ & $5.7 \pm 0.3$ & $6.0 \pm 0.4$ & 0.7 & 0.50 \\
\hline Male exodus (days) ${ }^{c}$ & $23.2 \pm 0.4$ & $23.8 \pm 0.4$ & $24.6 \pm 0.7$ & 2.0 & 0.14 \\
\hline Female exodus (days) ${ }^{\mathbf{d}}$ & $28.4 \pm 0.4$ & $28.5 \pm 0.4$ & $28.2 \pm 1.0$ & 0.1 & 0.94 \\
\hline \multicolumn{6}{|c|}{ Synchrony of return from exodus } \\
\hline$(\text { days })^{\mathrm{a}}$ & $3.2 \pm 0.4$ & $2.9 \pm 0.4$ & $3.2 \pm 0.6$ & 0.1 & 0.86 \\
\hline \multicolumn{6}{|c|}{ Nest site unattended during } \\
\hline incubation (days) & $0.5 \pm 0.2$ & $3.2 \pm 0.7$ & $12.5 \pm 1.3$ & 64.8 & $<0.001^{\mathrm{e}}$ \\
\hline
\end{tabular}




\begin{tabular}{lcccccc}
\hline Table 2.2 Continued & \multicolumn{3}{c}{ Breeding status $(n)$} & \multicolumn{2}{c}{$\begin{array}{c}\text { Statistical } \\
\text { comparison }\end{array}$} \\
\cline { 2 - 7 } & $\begin{array}{c}\text { Successful } \\
\text { Parameter }\end{array}$ & $\begin{array}{c}\text { Failed } \\
(52)\end{array}$ & $\begin{array}{c}\text { Nonbreeding } \\
(48)\end{array}$ & $\begin{array}{c}F \text { or } \\
\text { (33) }\end{array}$ & $K-W$ & $P$ \\
\hline $\begin{array}{l}\text { Days pair together during stage 3 } \\
\text { (days) }\end{array}$ & $4.7 \pm 0.4$ & $8.7 \pm 0.6$ & $11.6 \pm 1.0$ & 40.7 & $<0.001^{\mathrm{f}}$ \\
$\begin{array}{l}\text { Days pair together from prelaying } \\
\text { to early chick-rearing (\%) }\end{array}$ & $9 \pm 1$ & $13 \pm 1$ & $14 \pm 1$ & 20.3 & $<0.001^{\mathrm{f}}$ \\
\hline
\end{tabular}

${ }^{a}$ Calculated as date of first arrival - date of second arrival.

${ }^{\mathrm{b}}$ Calculated as date of last to depart - date of first to depart.

${ }^{\mathrm{c}}$ Assumes male is last to depart and first to arrive back from exodus.

${ }^{\mathrm{d}}$ Assumes female is first to depart and last to arrive back from exodus.

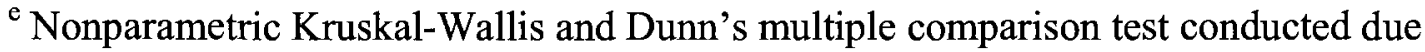
to significant difference in variation of each group; each group significantly different from the others (three groups tested).

${ }^{f}$ Nonparametric Kruskal-Wallis and Dunn's multiple comparison test conducted due to significant difference in variation of each group; successful lower than failed or nonbreeding. 
(Table 2.2; Kruskal-Wallis tests, all $P<0.03$ ). Thus, prior to egg-laying, fulmars exhibited similar breeding schedules irrespective of breeding status, but during incubation, nonbreeders and failed breeders spent more time away from the nest site.

\section{Comparisons with breeding schedules of North Atlantic fulmars}

For 16 fulmar colonies located across the North Atlantic and Arctic Oceans, the first landing of fulmars at the colony was significantly later at higher latitudes $\left(r_{s}=0.68, P\right.$ $=0.004$; Table 2.3, Fig. $2.3 \mathrm{a}$ ). This same pattern held when the analysis was restricted to seven colonies situated around Baffin Bay $\left(r_{s}=0.68, P=0.11\right)$, although the trend was not significant due to the small sample size. First egg dates $\left(r_{s}=0.74\right.$, $P=0.04, n=8)$, mean egg dates $\left(r_{s}=0.64, P=0.01, n=8\right)$, and first observed hatching dates $\left(r_{s}=0.78, P=0.01, n=10\right.$; Table 2.3, Fig. $\left.2.3 \mathrm{~b}\right)$ also were later for fulmar colonies at higher latitudes.

Fulmars breeding at Cape Vera departed the colony for a prelaying exodus that averaged more than one week longer than fulmars at colonies farther south (Table 2.3). Both males (ANOVA on summary data: $F_{2,790}=159.2, P<0.001$ ) and females $\left(F_{2,779}=113.6, P<0.001\right)$ spent significantly longer periods away from the colony, and differences among the Cape Vera, Semidi Islands, and Sands of Forvie colonies were all significant (Tukey-Kramer multiple comparisons tests, all $P<0.05$ ).

The incubation period for fulmars at Cape Vera (49.0 days, $n=65)$ was slightly longer than for fulmars in Alaska ( $48.4 \pm 0.1$ days, $n=52$; Hatch 1990a) or Prince Leopold Island (47.7 \pm 0.2 days, $n=30$; Hatch and Nettleship 1998; ANOVA 
Table 2.3. Locations, sea ice presence, and reported breeding phenology of northern fulmar colonies in Alaska and across the North Atlantic Ocean. Parameters reported include: date of first landing (when fulmars are first observed attending the colony after the previous breeding season); M:F exodus (the length of the male and female prelaying exodus from the colony); date of the earliest reported egg-laying (first egg), mean date of egg-laying, and mean date of hatching, as well as the length of the incubation period.

\begin{tabular}{|c|c|c|c|c|c|}
\hline Fulmar colony & Latitude & Longitude & $\begin{array}{c}\text { Sea ice } \\
\text { present? }^{\mathrm{a}}\end{array}$ & $\begin{array}{l}\text { Date of } \\
\text { first } \\
\text { landing }\end{array}$ & $\begin{array}{c}\text { M:F } \\
\text { exodus } \\
\text { (days) }\end{array}$ \\
\hline Alaska (Semidi Islands) & $56^{\circ} \mathrm{N}$ & $156^{\circ} \mathrm{W}$ & No & $11 \mathrm{Apr}$ & $12.2: 17.6$ \\
\hline United Kingdom (Weybourne) & $53^{\circ} \mathrm{N}$ & $1^{\circ} 6^{\prime} \mathrm{E}$ & No & $23 \mathrm{Oct}$ & \\
\hline \multicolumn{6}{|l|}{ United Kingdom (Sands of } \\
\hline Forvie) & $57^{\circ} 18^{\prime} \mathrm{N}$ & $1^{\circ} 56^{\prime} \mathrm{W}$ & No & 22 Oct & $9.3: 19.6$ \\
\hline United Kingdom (St. Kilda) & $57^{\circ} 48^{\prime} \mathrm{N}$ & $8^{\circ} 36^{\prime} \mathrm{W}$ & No & 30 Oct & \\
\hline \multicolumn{6}{|l|}{ United Kingdom (Orkney, } \\
\hline Shetland) & $59^{\circ} 30^{\prime} \mathrm{N}$ & $2^{\circ} \mathrm{W}$ & No & 29 Oct & $14.5: 15.9$ \\
\hline Faeroe Islands & $62^{\circ} 30^{\prime} \mathrm{N}$ & $7^{\circ} 30^{\prime} \mathrm{W}$ & No & 30 Oct & \\
\hline Iceland & $65^{\circ} 30^{\prime} \mathrm{N}$ & $22^{\circ} 30^{\prime} \mathrm{W}$ & No & 20 Oct & \\
\hline Greenland (Disko) & $69^{\circ} \mathrm{N}$ & $54^{\circ} \mathrm{W}$ & No & $8 \mathrm{Apr}$ & \\
\hline Greenland (Umanaq) & $71^{\circ} \mathrm{N}$ & $52^{\circ} \mathrm{W}$ & Yes & 12 Apr & \\
\hline Norway (Jan Mayen) & $71^{\circ} \mathrm{N}$ & $9^{\circ} \mathrm{W}$ & No & $19 \mathrm{Dec}$ & \\
\hline Canada (Baillarge Bay) & $73^{\circ} 24^{\prime} \mathrm{N}$ & $84^{\circ} 30^{\prime} \mathrm{W}$ & Yes & $23 \mathrm{Apr}$ & \\
\hline Canada (Prince Leopold Island) & $74^{\circ} \mathrm{N}$ & $90^{\circ} \mathrm{W}$ & Yes & 2 May & \\
\hline Canada (Cape Liddon) & $74^{\circ} 36^{\prime} \mathrm{N}$ & $91^{\circ} 12^{\prime} \mathrm{W}$ & Yes & $26 \mathrm{Apr}$ & \\
\hline Norway (Bjornoya) & $74^{\circ} 30^{\prime} \mathrm{N}$ & $19^{\circ} \mathrm{E}$ & No & Dec & \\
\hline Canada (Cape Vera) & $76^{\circ} 12^{\prime} \mathrm{N}$ & $89^{\circ} 12^{\prime} \mathrm{W}$ & Yes & $30 \mathrm{Apr}$ & $23.2: 28.2$ \\
\hline Norway (Spitzbergen) & $77^{\circ} 30^{\prime} \mathrm{N}$ & $15^{\circ} \mathrm{E}$ & No & 22 Jan & \\
\hline Norway (Franz Joseph Land) & $81^{\circ} \mathrm{N}$ & $50^{\circ} \mathrm{E}$ & Yes & $13 \mathrm{Mar}$ & \\
\hline Greenland (Mallemukfjeld) & $80^{\circ} 12^{\prime} \mathrm{N}$ & $16^{\circ} 36^{\prime} \mathrm{W}$ & Yes & $24 \mathrm{Apr}$ & \\
\hline
\end{tabular}


Table 2.3 continued.

\begin{tabular}{|c|c|c|c|c|c|}
\hline Fulmar colony & $\begin{array}{l}\text { Date of } \\
\text { first egg }\end{array}$ & $\begin{array}{c}\text { Mean egg- } \\
\text { laying } \\
\text { date }\end{array}$ & $\begin{array}{c}\text { Mean } \\
\text { hatching } \\
\text { date }\end{array}$ & $\begin{array}{l}\text { Incubation } \\
\text { period } \\
\text { (days) }\end{array}$ & Reference $^{\mathfrak{c}}$ \\
\hline Alaska (Semidi Islands) & 26 May & 9 Jun & $27 \mathrm{Jul}$ & 48.4 & 1 \\
\hline United Kingdom (Weybourne) & & & & & 2 \\
\hline \multicolumn{6}{|l|}{ United Kingdom (Sands of } \\
\hline Forvie) & 12 May & 21 May & $3 \mathrm{Jul}$ & & 3,4 \\
\hline United Kingdom (St. Kilda) & 5 May & 12 May & 21 Jun & & 5 \\
\hline \multicolumn{6}{|l|}{ United Kingdom (Orkney, } \\
\hline Shetland) & 12 May & 22 May & 24 Jun & & $5,6,7$ \\
\hline Faeroe Islands & 19 May & & $15 \mathrm{Jul}$ & & 5 \\
\hline Iceland & 11 May & 16 May & $7 \mathrm{Jul}$ & & 5 \\
\hline Greenland (Disko) & & & & & 5 \\
\hline Greenland (Umanaq) & 28 May & & & & 5 \\
\hline Norway (Jan Mayen) & & & $14 \mathrm{Jul}^{\mathrm{b}}$ & & 5 \\
\hline Canada (Baillarge Bay) & & & & & 5 \\
\hline Canada (Prince Leopold Island) & $3-5$ Jun & $7 \mathrm{Jun}$ & $25 \mathrm{Jul}$ & 47.7 & 8,9 \\
\hline Canada (Cape Liddon) & & & & & 8 \\
\hline Norway (Bjornoya) & & & $14 \mathrm{Jul}^{\mathrm{b}}$ & & 5 \\
\hline Canada (Cape Vera) & 3 Jun & 8 Jun & $25 \mathrm{Jul}$ & 49.0 & 10 \\
\hline Norway (Spitzbergen) & & 3 Jun & & & 5 \\
\hline Norway (Franz Joseph Land) & & & & & 5 \\
\hline Greenland (Mallemukfjeld) & & 31 May & $19 \mathrm{Jul}$ & & 11 \\
\hline
\end{tabular}

${ }^{a}$ Extensive sea ice typically present during early breeding season (April-May)

${ }^{b}$ Reported hatches almost one month earlier seem highly implausible; given date substantiated by $>1$ study

${ }^{\mathrm{c}} 1$ = Hatch and Hatch (1990); 2 = Slater (1990); 3 = MacDonald (1977); 4 = MacDonald (1980); 5 = Fisher (1952); 6 = Dunnet et al. (1963); 7 = Brooke (2004); 8 = Hatch and Nettleship (1998); $9=$ Gaston et al. (2005); $10=$ this study; $11=$ Falk and Møller (1997) 

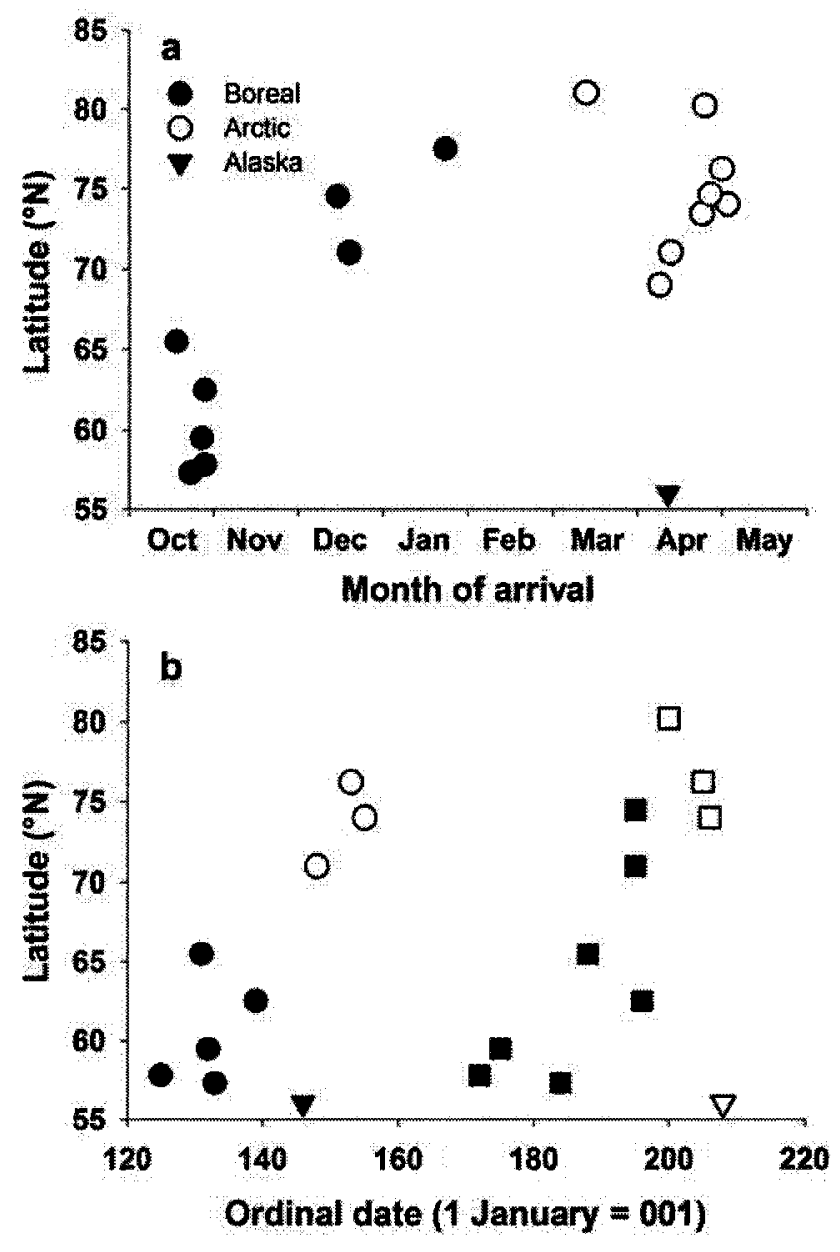

Figure 2.3. The breeding phenology of selected northern fulmar colonies in the North Atlantic Ocean, demonstrating earlier colony attendance, egg-laying, and hatching for birds breeding at lower latitudes. (a) First arrival by fulmars at the colony in relation to colony latitude. (b) Mean date of egg-laying (circles) and mean date of hatching (squares) for fulmar colonies in the arctic (unfilled) and boreal (filled) oceanographic zones. In both panels, data from a colony in Alaska are shown by triangles. 
on summary data: $F_{2,144}=11.3, P<0.001$; Tukey-Kramer multiple comparisons tests, all $P<0.05$ ), although the range of incubation periods was similar.

\section{Discussion}

Hatch and Nettleship (1998) predicted that northern fulmars breeding in the High Arctic might exhibit adaptations to the colder, ice-covered environmental conditions, including a compressed breeding season, compared with boreal fulmars elsewhere in the Pacific and Atlantic Oceans. Results of this study of northern fulmars breeding at Cape Vera were similar in some respects to those of studies of breeding fulmars in the boreal zone, but I also found support for the hypothesis above. As with other fulmars, I found that females at Cape Vera took 23 days to form their eggs (Astheimer and Grau 1985). Moreover, Cape Vera fulmars completed incubation in 46-52 days (Hatch and Nettleship 1998) and guarded the chick for $>14$ days (Hatch 1990c), despite having to fly over extensive sea ice to forage throughout the prelaying and incubation periods. This result is similar to patterns observed by Hodum (2002), where incubation, chick-guarding, and nestling periods of four Antarctic fulmarine petrels varied little for colonies separated by 21 degrees of latitude. However, Cape Vera fulmars were among the last fulmars of the North Atlantic population to begin breeding each year, with the second-latest colony arrival date and the latest mean egglaying date. What consequences does this have for their allocation of time to different stages of their breeding schedule?

Surprisingly, both male and female fulmars breeding at Cape Vera spent about 
the same time at the colony from arrival at the colony through chick-guarding as fulmars in the Semidi Islands in Alaska (46\% and 35\%, respectively; Hatch 1990c), and even similar time together at the nest site. However, time at the nest appeared to be allocated differently between these colonies. Male fulmars at Cape Vera spent proportionally more time at the colony during pre-exodus but less time during prelaying and incubation than Hatch (1990c) observed in any of six years for male fulmars in Alaska. In contrast, female fulmars at Cape Vera spent about $6 \%$ less time at the colony during prelaying, attributable to taking a 10-day longer exodus, but were at the colony for similar proportions of time during pre-exodus and incubation compared to female fulmars in Alaska.

Compressed breeding season, the exodus, and synchronization

Boreal fulmars first attend colonies six or more months prior to the annual breeding season (Fisher 1952, Coulson and Horobin 1972). However, arctic colonies surrounded by extensive sea ice are not visited by fulmars until about one month prior to egg-laying (except, occasionally, Pribilof Island colonies; S. Hatch, Alaska Science Center, pers. comm.). In northern Baffin Bay, there are no published observations of fulmars before 24-26 April (Fisher 1952), thus I suspect that there were no fulmar landings at Cape Vera before our observations on 30 April. Therefore, at Cape Vera, fulmar mates typically arrive within two days of each other and spend only six to nine days together at the colony before departing for the exodus. Unless pairs meet at sea (which is unknown), fulmars breeding in the High Arctic have a shorter period each 
year to choose or check nest sites, re-establish pair bonds, and copulate than fulmars breeding in Boreal or Low Arctic colonies (Hatch and Nettleship 1998).

The prelaying exodus of fulmars at Cape Vera is 9-14 days longer than that reported in other locations, and is characterized by a lack of intermittent, short visits to the colony which may be observed at southern colonies (Hatch 1990c). Fulmars can travel several hundred kilometers to feed (Weimerskirch et al. 2001, Mallory et al. 2008), and surveys by McLaren (1982) suggested that fulmars may leave the High Arctic completely during the exodus, perhaps to feed near southwestern Greenland or southern Davis Strait. I suspect that marine production is still too low early in the season to support the energetic needs of fulmars at this time (Welch et al. 1992, Lewis et al. 1996), thus the birds appear to move to distant, more productive waters.

If the physical and biological effects of sea ice constrain the breeding schedule of arctic fulmars (Fisher 1952, Falk and Møller 1997, Hatch and Nettleship 1998), it follows that polar colonies should be more synchronized in their schedules than southern colonies. Indeed, the range of egg-laying dates in the Canadian High Arctic (11-19 days) was shorter than the range in northeastern Greenland (24 days; Falk and Møller 1997), Alaska (18-34 days; Hatch and Hatch 1990), or the eastern North Atlantic ( $\sim 30$ days; Fisher 1952). Falk and Møller (1997) demonstrated how the phenology of fulmar reproduction in northeastern Greenland matched the sea ice cycle of the nearby polynya, a pattern also found by Hodum (2002) for four species of fulmarine petrels near Antarctica. Thus, fulmars nesting in the most ice-constrained sites appear to have higher synchronization of egg-laying than fulmars breeding at 
colonies surrounded by open water year-round.

\section{Compressed breeding schedule and extra-pair copulations}

While overall time spent at the colony from arrival through chick-guarding was similar between fulmars at Cape Vera and Alaska, fulmars breeding in Alaskan colonies may begin attending breeding cliffs up to 47 days before egg-laying, compared to 40 days for fulmars at Cape Vera (Hatch 1989). Pairs also may be observed copulating at Alaskan colonies over a 30-day period, up to 10 days before egg-laying (Hatch 1987), because the prelaying exodus is shorter in Alaska. At Cape Vera, no pairs that attempted to breed were observed at the colony after 14 May, and those same pairs laid eggs starting 5 June, meaning that no copulations occurred $<22$ days before egg-laying. This timing is similar to the length of the egg formation period ( 23 days), and the time at which copulation frequencies begin to decline at Boreal colonies (20 days before egg-laying; Hunter 1998), both of which suggest that females at Cape Vera have already decided whether to breed and have secured sperm from their mates potentially much earlier than at other colonies (Hunter 1998).

During the pre-exodus period, male fulmars always arrived at the Cape Vera colony before or with their mate, and males spent $8 \%$ more time at the colony than males in Alaska (Hatch 1990c). This increased attendance may reflect a behavioural adaptation of male fulmars to the short breeding season in the High Arctic to enhance opportunities to copulate with the female, to secure extra-pair copulations, or to guard the female from extra-pair copulation attempts by other males (Hatch 1987, Hunter 
1998). If this interpretation is correct, I make the following predictions: (1) levels of extra-pair copulations by fulmars in High Arctic colonies will be more highly correlated with proportional male attendance during prelaying than is found in low Arctic or boreal colonies; (2) High Arctic fulmars will have lower egg hatchability, because there will be fewer fertilizations due to absent males during the sole opportunity to mate, and females may use older, degraded, stored sperm.

\section{Scheduling differences between breeding and nonbreeding fulmars}

Nonbreeding fulmars attend colonies throughout the breeding season (Fisher 1952, Coulson and Horobin 1972, Falk and Møller 1997), presumably to gain experience with potential nest sites, timing of movements, and locations of feeding areas (Warham 1990, 1996), which are critical for successful reproduction (Ollason and Dunnet 1978). At Cape Vera, nonbreeding fulmar pairs exhibited similar levels of synchrony in colony attendance as breeding birds, and spent similar time at the colony prior to the exodus, unlike nonbreeding fulmars in Alaska, which spent less time at the colony than breeding adults. With little food and extensive ice nearby, there is probably an energetic disadvantage for nonbreeders at Cape Vera to leave the breeding cliffs early in the season, whereas those in Alaska may be able to make brief foraging trips at this time.

The differences in attendance patterns between breeding and nonbreeding adult fulmars were most evident during incubation. Nonbreeders were observed either absent from the nest or with their mate at the nest site much more than 
breeders, a result undoubtedly attributable to the greater energetic limitations placed on breeding birds. At least one member of a breeding pair must remain at the nest to incubate the egg and protect it from inclement weather or predation. In contrast, the value of colony attendance by failed or nonbreeders declines as the season progresses, for two reasons. First, it is too late in the season for nonbreeders to initiate a nest, and failed breeders do not renest (Hatch and Nettleship 1998). Second, the high energetic costs of replacing feathers during moult, particularly primary moult, are deferred by breeding birds until late in chick-rearing, but nonbreeders initiate moult shortly after mean egg-laying dates for the colony, and failed breeders enter moult shortly after losing their egg or chick (Fisher 1952, Hatch 1990c, Hatch and Nettleship 1998).

Collectively, the data from Cape Vera and studies of other fulmar colonies affected by sea ice indicate that High Arctic fulmars have a compressed and substantially adjusted breeding schedule compared to fulmars breeding in the Boreal oceanographic zone. These scheduling adaptations occur during prelaying; egg development and attendance during incubation and chick-rearing appear to be similar across the species' range.

With climate change already contributing to reductions in arctic sea ice (McBean 2004), fulmars may be less constrained in scheduling early season breeding activities near their colonies in the future. However, it is unclear whether fulmars adapted to High Arctic conditions are flexible enough to adopt a more Boreal breeding schedule, or whether they can maintain a typical High Arctic breeding schedule but shift it earlier into the season. Barbraud and Weimerskirch (2006) 
showed that several species of Antarctic seabirds have begun arriving at colonies and laying eggs later over the past 55 years. The authors noted that the birds apparently have the behavioural plasticity to accommodate the resultant shorter breeding period, perhaps by decreasing the time required for activities in the prelaying period, similar to phenology at Cape Vera. However, some studies have suggested that climatemediated earlier production of prey items has led to a mismatch of avian breeding phenology and prey abundance (Stenseth and Mysterud 2002), which could have detrimental long-term effects if behavioural adaptations of fulmars cannot occur as rapidly as changing food supplies. 


\section{CHAPTER THREE}

\section{Nutrient dynamics and constraints on the pre-laying exodus of High Arctic northern fulmars}

This chapter formed the basis for the following publication:

Mallory, M. L., M. R. Forbes, C. D. Ankney, and R. T. Alisauskas. 2008. Nutrient dynamics and constraints on the pre-laying exodus of High Arctic northern fulmars. Aquatic Biology, in press. 


\section{Abstract}

Many aspects of the reproductive ecology of seabirds are linked to the phenology, quantity and accessibility of marine food supplies. In polar regions, annual sea ice constrains these aspects of marine productivity, and thus seabirds breeding at high latitudes may exhibit adaptations to accommodate these constraints. Like most petrels, northern fulmars (Fulmarus glacialis) undertake an exodus from their breeding colony just before egg-laying. To assess whether this exodus was related to energetic needs and stored nutrient reserves, I studied changes in body mass and composition of male and female fulmars breeding in the Canadian High Arctic, by comparing birds collected just before and just after the pre-laying exodus. Males gained body mass over this period, accumulating water, fat, and protein, whereas females lost body mass, particularly protein and fat. Declines in female fat and protein approximated the amount contributed to eggs, but water and mineral reserves in pre-exodus females appeared insufficient for egg production. I predict that female fulmars leave the colony before egg-laying to meet mineral demands for egg production, possibly focusing on calcium-rich prey. In contrast, I predict that males use a different strategy for resource acquisition and allocation which seeks to maximize fat and protein accumulation to meet forthcoming incubation demands. Differences in typical marine environmental conditions at breeding colonies across the species' range probably account for observed behavioural variation in breeding schedules, and may also result in different nutrient dynamics. 


\section{Introduction}

Annual and long-term variation in the biophysical characteristics of the marine environment can have dramatic effects on marine food webs (Aebischer et al. 1990, Frederiksen et al. 2006). As top predators in the oceans, fluctuations in marine productivity or specific food supplies can affect seabird behaviour, reproductive success, or survival (e.g., Cairns 1987, Frederiksen et al. 2007). Thus, seabird ecology is tightly linked to the health and condition of marine ecosystems (reviewed in Boyd et al. 2006). This relationship should be pronounced in polar regions, because extreme winter climates and extensive sea ice cover over feeding areas impose three significant energetic constraints on seabirds: (1) the need for birds to migrate from these regions for the winter; (2) shortened seasonal opportunities for reproduction; and (3) spatially and temporally concentrated food resources (Raymont 1976, Hamer et al. 2002). In this chapter, I examine how aspects of the behaviour and physiology of a broadly distributed seabird are adapted to accommodate the constraints imposed by the High Arctic marine environment (Salomonsen 1965).

For many birds, body mass and composition (lipid, protein, mineral) of breeding individuals varies through the breeding cycle (Baldwin and Kendeigh 1938, Ankney and MacInnes 1978, Warham 1996). These changes are required to meet the energetic and nutritional demands of producing and incubating eggs while still meeting self-maintenance needs (Drent and Daan 1980). Lipid is the primary stored (endogenous) reserve of most birds (Griminger 1986, Cherel et al. 1994a,b), and is the main fuel used for incubation (Ricklefs et al. 1986), although protein is also 
metabolized (Blem 1990). The amount to which breeding birds rely on endogenous (capital) versus exogenous (income) sources of nutrients to meet their nutritional requirements of breeding varies markedly by species and breeding strategy, and influences patterns of change in body mass and composition (Meijer and Drent 1999). Although body mass change and nutrient dynamics have been well-studied for some birds, notably waterfowl (Alisauskas and Ankney 1992) and penguins (e.g., Cherel et al. 1993, 1994a, b), this has received minimal attention in pelagic seabird research. These birds may chronically experience marginal food supplies (Lack 1968), because marine prey distributions may be ephemeral, patchy, difficult to find, or distant from the colony, often because suitable breeding sites are remote from suitable foraging areas (Warham 1990). Consequently, Grau (1984) suggested that nutrition for egg production by pelagic seabirds may be critical.

The Procellariiformes (hereafter petrels) are a group of mostly pelagic seabirds that share two reproductive characteristics: (1) all petrels lay a single, large, energy-rich egg (Warham 1983); and (2) breeding female petrels (and most males) undertake an exodus from their colony just before their egg-laying date (Warham 1990, 1996). The prevailing hypothesis has been that, upon arrival at the colony, petrels require time to re-establish the pair bond, assess the condition of their nest site and their mate, and defend that site from conspecifics before egg-laying (Warham 1990). Following these activities, pairs may lack sufficient nutrient reserves to form an egg (female) or initiate incubation (male), and thus they depart temporarily to meet this need (Warham 1990, 1996). 
Given these observations, and the ubiquitous acceptance of income breeding as the explanation for pre-laying exodus by petrels, it is surprising that there have been few empirical attempts to verify this hypothesis (for any petrel; Lack 1968, Warham 1990, Whittow 2002). Marshall and Serventy (1956) showed that female short-tailed shearwaters (Puffinus tenuirostris) had relatively small fat reserves at egg-laying, while male fat reserves were large (hence female nutrients were likely shunted towards egg production). Otherwise, most evidence has come by inference, based on body mass changes (Hatch 1990a,b, Warham 1990), and evidence of energetic limitations on reproductive performance later in the breeding season (Pinaud and Weimerskirch 2002).

I studied the functional significance of the pre-laying exodus in the northern fulmar (Fulmarus glacialis). This is the only petrel with a northern, circumpolar distribution, and is a species for which information on nutrition and energetics was limited (Bryant and Furness 1995, Furness and Bryant 1996), and absent for Arctic colonies (Hatch and Nettleship 1998). Both sexes of fulmars leave the colony, but the exodus by males is shorter than that by females (Chapter 2). Females usually lay an egg within one day of their return, then depart while males begin the first incubation shift which may last two weeks (Hatch 1990b). Although most of the North Atlantic fulmar population breeds in the Boreal or Low Arctic oceanographic zone (Hatch and Nettleship 1998), this study site was at a remote colony in the High Arctic zone (Salomonsen 1965), where cold temperatures, snow-covered breeding ledges and extensive sea ice meant that pairs had only a brief period between arrival at the 
colony and departure for the pre-laying exodus in which to pair bond, prepare their nest, and copulate (Chapter 2). I examined body composition of breeding northern fulmars collected just before departure and immediately upon return to examine potential links between the pre-laying exodus and the pair's energetic needs. If female fulmars must leave to gather nutrients for egg production (i.e., income breeding), I predicted that pre-exodus females would lack sufficient endogenous reserves to produce an egg and still fly to their feeding grounds. Similarly, if male fulmars depart on the exodus to store energetic reserves for incubation, I predicted that pre-exodus males would lack sufficient fat to complete the first incubation shift. Finally, I evaluated the duration of the fulmar exodus and the corresponding nutrient dynamics of the birds during this period as they related to the annual phenology of sea ice cover and marine productivity in the Arctic.

\section{Materials and methods}

\section{Study area and marine environment}

Studies of nutrient dynamics of fulmars at Cape Vera were conducted in four field seasons: 8 May to 15 June, 1983; 26 May to 22 August, 2003; 14 May to 9 August 2004; 20 April to 10 August 2005. The distribution of sea ice at the time of the fulmar exodus was determined from satellite imagery (http://ice-glaces.ec.gc.ca), and is reproduced in Fig. 3.1. Although I did not track movements of fulmars during their exodus, birds equipped with satellite transmitters were followed starting on 12 July 


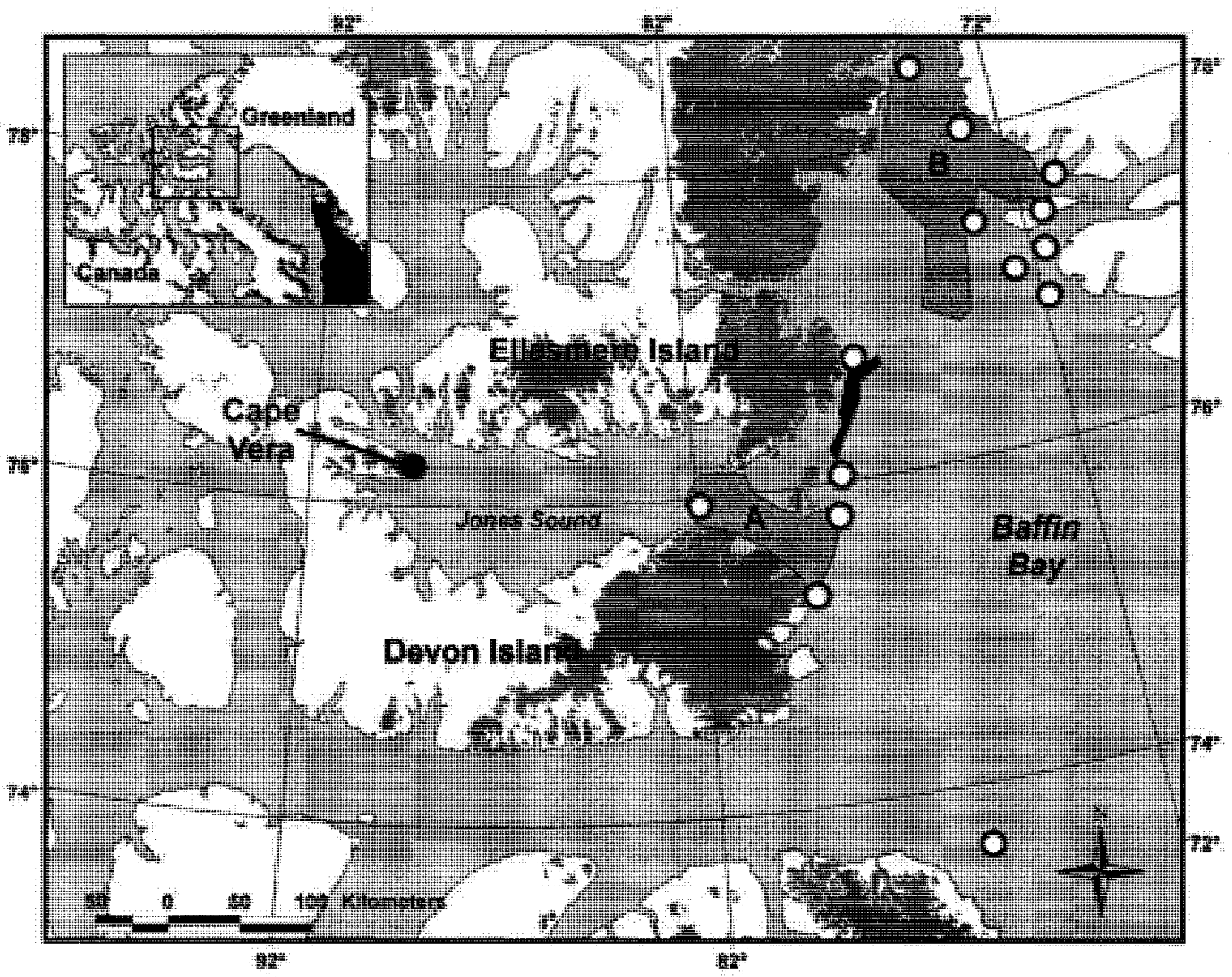

Figure 3.1. The location of the Cape Vera study site on Devon Island, Nunavut, in the Canadian High Arctic, in relation to features of the marine environment in May 2005. Gray patches on land represent glaciers and ice caps. Solid black areas in the inset or east of Ellesmere Island in the main figure represent the only open water ( $<10 \%$ ice cover) on 15 May. Areas A (mouth of Jones Sound) and B (North Water Polynya) had some open water ( $70 \%$ ice covered $)$, and otherwise all marine areas (light gray) were ice-covered. Unfilled circles are locations where fulmars were foraging in June and July, as determined by satellite telemetry (Mallory et al. 2008). 
2004 and 12 June 2005 (approximately one week after the completion of the prelaying exodus; Mallory et al. 2008). The intent here was to show some of the main feeding areas during incubation as they related to the location of the colony and sea ice extent.

\section{Collections}

Breeding schedules of northern fulmars at Cape Vera are highly synchronized within and across years, with the colony almost completely deserted between 20 to 30 May annually, and with colony numbers rapidly building from 1 June through mean egglaying (6 June; Chapter 2). Fulmars were collected just before their departure for the exodus (15-18 May, before egg formation), and immediately upon their return (5-11 June). Fulmar carcasses were used for a variety of studies, including parasites (Mallory et al. 2006a, 2007), morphometrics (Mallory and Forbes 2005), diet and contaminants (Mallory et al. 2006b). In 1983, 44 fulmars were collected with shotguns near the breeding cliffs (males: 11 pre-exodus, 16 post-exodus; females: 11 pre-exodus, 6 post-exodus). On the day of collection, birds were weighed ( $\pm 10 \mathrm{~g})$, and esophageal contents and gonads were removed and stored in ethanol. In 2003 ( $n=6 ; 4$ males post-exodus, 2 females pre-exodus), birds were shot near the breeding cliffs, while in 2004 ( $n=17$; males: 5 pre-exodus, 9 post-exodus; 3 females preexodus) and 2005 ( $n=11$; all post-exodus females), birds were captured on their nest site with noose poles and were immediately decapitated. All post-exodus female 
weights excluded mass of eggs. Fresh eggs $(n=7)$ were collected in nests where pairs were captured, while other eggs $(n=17)$ were collected in the first $10 \mathrm{~d}$ of incubation as part of other studies. Fulmars were weighed $( \pm 10 \mathrm{~g})$ and then they were frozen in air-tight bags, and transported to the laboratory.

\section{Nutrient analyses}

Fulmars were thawed and morphometrics recorded (head length and keel length for all birds, as well as wing cord, tarsus length, culmen length, and skull width for birds collected in 2003-2005, all in mm). All feathers were plucked, except the remiges which were cut with scissors where they emerged from the skin, and the plucked bird was reweighed (plucked body mass, g). The leg and breast muscle from the left side of the body (Alisauskas and Ankney 1985), liver, gizzard, and large and small intestines were removed, and weighed $( \pm 0.1 \mathrm{~g})$ or measured $( \pm 0.5 \mathrm{~cm})$. Intestinal contents were removed and stored in ethanol. In 1983, the ovaries and oviducts of post-exodus females were inspected, and birds were considered as breeders if they had a post-ovulatory follicle and/or an oviducal egg. This approach was repeated in 2003 and 2004, while in 2005, both post-exodus males and females were collected on the nest on the day of laying. Thus, breeding status for post-exodus females was known confidently, as were most post-exodus males. I assumed that pre-exodus birds collected on nest sites or close to the cliffs were principally breeders $(\geq 74 \%$ of birds at apparently occupied sites laid an egg; unpubl. data). Only birds that were presumed to be breeders were included in subsequent analyses. 
For nutrient analyses, the liver, and leg and breast muscles were dried to constant mass at $80-95^{\circ} \mathrm{C}$ (Keer et al. 1982). The intestine and the remainder of the carcass (excluding the half breast, one leg, liver, feathers and gonads/oviduct) were weighed (corrected mass, g), homogenized in a food grinder and oven-dried at $80-95^{\circ}$ $\mathrm{C}$ to constant dry mass. The dried liver, dried breast and leg muscles, and dried carcass homogenate were ground separately with a portable coffee grinder. Lipid (hereafter fat) was extracted from an 8-10 $\mathrm{g}$ subsample of each of the ground body parts, using petroleum ether in a modified Soxhlet apparatus for $8 \mathrm{hr}$ (Dobush et al. 1985). The mass of the resultant lean dry sample was subtracted from the dry mass of the original sample, to obtain the mass of fat in the sample. A subsample of the lean dry residue from each extracted homogenate was placed in a preweighed crucible, and heated in a furnace at $550^{\circ} \mathrm{C}$ for $6 \mathrm{hr}$ (note that this was done only for females in 1983 samples, but for all birds in the other years). The remaining ash was weighed and divided by the mass of the lean dry sample to obtain the percentage of ash in each sample. Total fat in each body part (carcass, liver, breast, leg) was determined by multiplying the dried mass of the body part by the proportion of fat in the subsample of homogenate. Total ash in each body part was similarly determined by multiplying the proportion of ash in the subsample by the lean dry mass of the body part. Ashfree lean dry mass (a measure of protein content) was calculated as the dry mass of the body part minus total fat and ash.

The nutrient composition of eggs was determined by following similar protocols as outlined in Alisauskas and Ankney (1985), except that yolk, albumen and 
membranes were kept together as one tissue for analysis. Eggs were boiled, and the shell was separated and oven-dried for weighing ( $\pm 0.01 \mathrm{~g})$. Egg albumen, yolk and shell membranes were dried to constant mass, and lipid and lean dry mass were determined as above for somatic tissues. Energy content of eggs was estimated by assuming $39.4 \mathrm{~kJ} \cdot \mathrm{g}^{-1}$ in fat and $17.8 \mathrm{~kJ} \cdot \mathrm{g}^{-1}$ in protein (Nagy 1983 , Groscolas et al. 1991).

\section{Estimating energy needs}

The energy required to complete the first incubation shift plus a day to fly from the colony to a feeding site was estimated. Gabrielsen et al. (1988) and Bryant and Furness (1995) reported a basal metabolic rate (BMR) for northern fulmars of 312 $300 \mathrm{~kJ} \cdot \mathrm{d}^{-1}$, and a field metabolic rate (FMR) averaging $1444 \mathrm{~kJ} \cdot \mathrm{d}^{-1}$ (Furness and Bryant 1996). The daily cost of incubation for male fulmars was estimated by deriving an equation from the relationship between incubation metabolic rate (IMR) and BMR presented for 14 petrels in Grant (1984), as follows:

$$
\mathrm{IMR}=14.04+1.21(\mathrm{BMR})\left(r_{14}=0.997, P<0.001\right)
$$

Thus, for fulmars, the IMR is predicted to be between 392 and $414 \mathrm{~kJ} \cdot \mathrm{d}^{-1}$, so I used $400 \mathrm{~kJ} \cdot \mathrm{d}^{-1}$ as my estimate.

I compared the lipid, protein, mineral and water fractions of eggs to female endogenous reserves before the exodus, and assumed 100\% conversion efficiency of endogenous stores to materials deposited in the egg for energetic estimates, acknowledging that this may be liberal (see Krementz and Ankney 1986). 


\section{Statistical analyses}

Only head length $( \pm 0.1 \mathrm{~mm})$ and keel length $( \pm 0.1 \mathrm{~mm})$ were measured consistently for all fulmars across years, and thus we created an index of body size using the first factor (PC1) from a principal component analysis on these measurements. PC1 explained $61.1 \%$ and $65.9 \%$ of body size variation in males and females, respectively. Body mass was positively correlated with PC1 in males $($ Mass $=20.2(\mathrm{PC} 1)+789.1$, $r^{2}=0.14$, df $1,35, P=0.02$ ), and was positively but not significantly correlated with $\mathrm{PC} 1$ in females $\left(\right.$ Mass $=15.1(\mathrm{PC} 1)+634.1, r^{2}=0.10$, df $\left.1,25, P=0.12\right)$.

Depending on the distribution of data, $t$-tests, Mann-Whitney $U$ tests, coefficient of variation (CV), Pearson rank correlations, or stepwise general linear modelling (backward selection) were used to analyse data within sexes, and before and after the exodus (Systat Software Inc. 2002). Collections were targeted to minimize the number of birds killed, and to take advantage of carcasses used in other studies (above). For this reason, there was a bias in sampling between breeding stage and year (e.g., in 2005, post-exodus females but no pre-exodus females were collected). During preliminary analyses, there was a significant stage $\times$ year interaction explaining variation in certain nutrients, which was interpreted as the result of the sampling bias (above) rather than inter-year differences. However, I was confident that any effects of annual variation on body composition were small for three reasons. First, fulmar breeding chronology at the Cape Vera colony is highly synchronized across years, presumably because sea ice features, which dictate marine environmental conditions and food supplies, are driven by the recurrent Northwater 
Polynya which is stable across years at this colony (Chapter 2). Second, in six of six analyses on females that compared nutrient levels at the same stage among years, no significant differences were found (Mann-Whitney or Kruskal-Wallis tests, all $P>$ $0.2)$. The same was true for males in five of six comparisons $(P>0.1)$, but in 1983 , post-exodus males had lower fat levels than post-exodus males in $2004(P=0.01)$. Nonetheless, the patterns of changes in body composition were similar in each year, although sample sizes were small. Thus, data were pooled across years for analyses, but I discuss the possible implications of the significant result for males below.

To evaluate whether male and female fulmars differed in body composition before and after the exodus, I first conducted a single MANOVA on independent body components (i.e., those which were not subcomponents of each other; body fat, water, lean dry mass, liver dry mass, liver fat), using sex and exodus as independent treatments. Significant multivariate main effects were then followed by univariate, two-way, stepwise general linear models (GLMs; backward selection), or $t$-tests (onetailed, unequal variances) if covariates were not significant. By preceding the GLMs with the MANOVA, an overall $\alpha$ (set at 0.1 to reduce Type II error rates due to small sample sizes) was maintained. I did not apply sequential Bonferroni corrections to $p$ values, as my results came from planned comparisons, and they satisfied reasonable and logical expectations (Moran 2003). Means are presented \pm SE unless otherwise noted. 


\section{Results}

\section{Marine environment during the exodus}

On 15 May 2005 (approximately the start of the pre-laying exodus at Cape Vera), a polynya ( $70 \%$ ice covered) extending approximately $3000 \mathrm{~km}^{2}$ was situated $200 \mathrm{~km}$ east of the breeding colony (Fig. 3.1), and $180 \mathrm{~km}$ farther northeast lay the southern boundary of the North Water Polynya $\left(\sim 10,000 \mathrm{~km}^{2}, 70 \%\right.$ ice covered). A small polynya $\left(\sim 750 \mathrm{~km}^{2},<10 \%\right.$ ice covered) was located between the two larger polynyas, and otherwise the nearest region of open water lay $>1000 \mathrm{~km}$ southeast of the colony (Fig. 3.1). This pattern was similar in 2004, except that the North Water Polynya was larger, extended $100 \mathrm{~km}$ farther south, and was mostly open water by 15 May. In 2003, the North Water Polynya occupied a similar extent on 15 May as in 2005, but was $80 \%$ ice covered, and there was no partially open water near the mouth of Jones Sound (i.e., fulmars had to travel $\geq 350 \mathrm{~km}$ to reach partially open water). Conditions in 1983 were similar to 2005 . By the end of the exodus ( $\sim$ June), the polynyas consistently had a higher proportion of open water.

Satellite tracking in 2004 and 2005 suggested during incubation recesses, fulmars traveled to marine areas that were polynyas at the time of the pre-laying exodus (Fig. 3.1; Mallory et al. 2008). 
Differences in body composition pre- and post-exodus

Mean corrected body mass of 76 fulmars was $577.3 \pm 10.3 \mathrm{~g}$, which was $51.6 \%$ water, $26.7 \%$ lean dry mass (protein and ash), and $21.7 \%$ fat. However, body mass and composition of both male and female fulmars differed before and after their breeding exodus (Table 3.1). The index of structural body size (PC1) was significantly correlated to total body mass in male fulmars (see Methods). However, PC1 was positively but not significantly correlated with the amount of body water, fat, or LDW either before or after the exodus in either sex (all $r<0.4$, all $P>0.13$ ), except for post-exodus males, where structurally-larger males tended to have larger fat stores $(r=0.37, n=28, P=0.07)$.

Wilk's Lambda test criterion indicated that fulmar body composition was influenced by $\operatorname{sex}\left(F_{4,71}=31.0, P<0.001\right)$, and by the exodus $\left(F_{4,71}=2.7, P=0.04\right.$; interaction effects, $P>0.25$ ), so I used univariate comparisons to evaluate where this variation occurred (Table 3.1).

Among male fulmars, the structural size of fulmars collected before and after the exodus was similar ( $\mathrm{PC} 1$ scores, $t_{38}=0.7, P=0.4$; Table 3.1 ), but body mass was significantly heavier in post-exodus birds (Table 3.1). Post-exodus males had larger stores of fat (11\%), lean dry mass (6\%) and water $(6 \%)$ than pre-exodus males (Fig. 3.2). After correcting for ash content in a subset of 18 males, ash-free lean dry mass was significantly larger $(9 \%)$ in post-exodus males. As well, both breast fat and breast lean dry mass were heavier in post-exodus males (Table 3.1). In male fulmars, body fat accounted for $17-18 \%$ of total body mass, but amounts of body fat in our 
Table 3.1. Mean measurements of body composition for breeding male and female fulmars before and after the pre-laying exodus (LDW = lean dry weight). $F$ values are in bold from stepwise general linear model analyses on $\log _{\mathrm{e}}$-transformed values, where PC1 scores (an index of structural body size) also entered the comparison significantly; otherwise, comparisons were made with $t$-tests (one-tailed) on $\log _{\mathrm{e}^{-}}$ transformed values.

\begin{tabular}{|c|c|c|c|c|c|c|}
\hline \multirow[b]{3}{*}{ Variable } & \multicolumn{6}{|c|}{ Male } \\
\hline & \multicolumn{2}{|c|}{ Pre-exodus } & \multicolumn{2}{|c|}{ Post-exodus } & \multirow[t]{2}{*}{$F$ or $t$} & \multirow[t]{2}{*}{$P$} \\
\hline & $n$ & Mean (SE) & $n$ & Mean (SE) & & \\
\hline Total body mass (g) & 16 & $767.2(10.1)$ & 28 & $808.4(13.1)$ & 2.5 & 0.008 \\
\hline Corrected body mass $^{a}(\mathrm{~g})$ & 16 & $611.7(9.0)$ & 28 & $655.2(11.9)$ & 2.9 & 0.003 \\
\hline Head length (mm) & 16 & $92.2(0.5)$ & 28 & $92.2(0.2)$ & 0.2 & ns \\
\hline Keel length (mm) & 15 & $57.7(0.5)$ & 25 & $58.4(0.5)$ & 0.9 & $\mathrm{~ns}$ \\
\hline Body fat $(\mathrm{g})$ & 16 & $133.0(5.9)$ & 28 & $147.7(7.9)$ & 1.1 & $\mathrm{~ns}$ \\
\hline Breast fat $(\mathrm{g})$ & 13 & $2.6(0.2)$ & 25 & $3.3(0.2)$ & 2.5 & 0.009 \\
\hline Leg fat $(g)$ & 13 & $1.8(0.1)$ & 27 & $1.9(0.1)$ & 0.4 & ns \\
\hline Liver fat $(\mathrm{g})$ & 16 & $0.55(0.03)$ & 28 & $0.59(0.04)$ & 0.7 & $\mathrm{~ns}$ \\
\hline Body water (g) & 16 & $311.1(6.2)$ & 28 & $329.4(5.1)$ & 2.2 & 0.01 \\
\hline Body LDW (g) & 16 & $165.6(3.3)$ & 28 & $176.2(3.4)$ & 2.3 & 0.02 \\
\hline Breast LDW (g) & 13 & $9.8(0.3)$ & 26 & $10.7(0.3)$ & 2.1 & 0.02 \\
\hline Leg LDW (g) & 13 & $8.0(0.3)$ & 27 & $8.0(0.2)$ & 0.1 & ns \\
\hline Liver LDW (g) & 16 & $3.3(0.2)$ & 28 & $4.2(0.1)$ & 3.8 & $<0.001$ \\
\hline Body ash (g) & 5 & $31.6(1.1)$ & 13 & $32.0(1.1)$ & 0.2 & $\mathrm{~ns}$ \\
\hline Body ash-free LDW (g) & 5 & $103.8(2.3)$ & 13 & $113.2(1.7)$ & 8.6 & 0.01 \\
\hline Testes $(\mathrm{g})$ & 14 & $1.10(0.30)$ & 26 & $0.19(0.03)$ & $31.0^{\mathrm{b}}$ & $<0.001^{\mathrm{b}}$ \\
\hline \multicolumn{7}{|l|}{ Oviduct (g) } \\
\hline Small Intestine (mm) & 14 & $146.0(4.1)$ & 28 & $156.4(2.8)$ & 2.1 & 0.02 \\
\hline Small Intestine (g) & 14 & $10.4(0.8)$ & 27 & $12.9(0.8)$ & 2.2 & 0.02 \\
\hline Gizzard (g) & 16 & $3.4(0.1)$ & 28 & $4.3(0.2)$ & 4.0 & $<0.001$ \\
\hline
\end{tabular}


Table 3.1 continued.

\begin{tabular}{|c|c|c|c|c|c|c|}
\hline \multirow[b]{3}{*}{ Variable } & \multicolumn{6}{|c|}{ Female } \\
\hline & \multicolumn{2}{|c|}{ Pre-exodus } & \multicolumn{2}{|c|}{ Post-exodus } & \multirow[t]{2}{*}{$F$ or $t$} & \multirow[t]{2}{*}{$P$} \\
\hline & $n$ & Mean (SE) & $n$ & Mean (SE) & & \\
\hline Total body mass (g) & 14 & $648.9(13.5)$ & 19 & $631.0(14.5)$ & 1.2 & ns \\
\hline Corrected body mass $^{a}(\mathrm{~g})$ & 14 & $510.8(12.6)$ & 19 & $482.3(8.5)$ & 1.9 & 0.04 \\
\hline Head length (mm) & 13 & $86.2(0.5)$ & 19 & $86.2(0.4)$ & 0.05 & $\mathrm{~ns}$ \\
\hline Keel length (mm) & 9 & $54.0(0.6)$ & 18 & $54.3(0.8)$ & 0.25 & ns \\
\hline Body fat (g) & 14 & $110.7(8.0)$ & 19 & $94.9(3.2)$ & 1.7 & 0.05 \\
\hline Breast fat $(\mathrm{g})$ & 11 & $2.0(0.2)$ & 17 & $2.2(0.1)$ & 0.6 & ns \\
\hline Leg fat $(\mathrm{g})$ & 14 & $1.3(0.1)$ & 19 & $1.2(0.1)$ & 1.3 & ns \\
\hline Liver fat $(\mathrm{g})$ & 14 & $0.58(0.04)$ & 19 & $0.47(0.02)$ & 2.5 & 0.01 \\
\hline Body water (g) & 14 & $263.2(5.5)$ & 19 & $261.8(5.2)$ & 0.2 & ns \\
\hline Body LDW (g) & 14 & $134.8(2.9)$ & 19 & $124.6(3.2)$ & 10.4 & 0.004 \\
\hline Breast LDW (g) & 11 & $8.3(0.3)$ & 17 & $8.7(0.2)$ & 1.1 & ns \\
\hline Leg LDW (g) & 14 & $5.9(0.2)$ & 19 & $6.1(0.1)$ & 0.5 & ns \\
\hline Liver LDW (g) & 14 & $3.5(0.2)$ & 19 & $3.4(0.1)$ & 0.3 & ns \\
\hline Body ash (g) & 14 & $22.9(0.9)$ & 19 & $24.0(1.2)$ & 0.7 & ns \\
\hline Body ash-free LDW (g) & 14 & $96.1(2.5)$ & 19 & $83.4(3.4)$ & 10.7 & 0.003 \\
\hline \multicolumn{7}{|l|}{ Testes (g) } \\
\hline Oviduct (g) & 13 & $0.3(0.1)$ & 19 & $6.7(1.1)$ & $4.0^{\mathrm{b}}$ & $0.001^{b}$ \\
\hline Small Intestine (mm) & 14 & $140.6(4.4)$ & 19 & $137.8(3.5)$ & 0.5 & ns \\
\hline Small Intestine (g) & 14 & $12.4(0.9)$ & 19 & $10.2(0.7)$ & 1.9 & 0.03 \\
\hline Gizzard (g) & 14 & $3.0(0.3)$ & 19 & $3.4(0.2)$ & 1.1 & ns \\
\hline
\end{tabular}

${ }^{a}$ Corrected body mass $=$ plucked body mass $-($ ingesta + reproductive tissue $)$

${ }^{\mathrm{b}}$ Mann-Whitney U test 
sample of post-exodus males were more variable (CV 29\%) than in pre-exodus males $(18 \%)$.

A different pattern was evident for female fulmars. Structural size was also similar in pre- and post-exodus females ( $\mathrm{PC} 1$ scores, $t_{25}=0.3, P=0.8$ ), but breeding females captured shortly after their return from the exodus weighed less than females captured before the exodus (Table 3.1). This was attributable in part to a $14 \%$ decline in body fat and an $8 \%$ decline in lean dry mass (after accounting for body size; Table 3.1, Fig. 3.2). Unlike males, however, there was no difference in body water for preand post-exodus females. Also counter to the pattern observed in males, amounts of body fat in post-exodus females were less variable (CV 15\%) than in pre-exodus females $(27 \%)$, but accounted for a similar proportion of total body mass (15-17\%).

\section{Changes in organs}

Reproductive organs in both sexes changed during the exodus (Table 3.1). Male fulmars experienced a 5.7-fold decrease in the mass of their testes, whereas females underwent a 22 -fold increase in the mass of their oviduct, with oviduct mass changing from 0.05 to $1.0 \%$ of total body mass. Pre-and post-exodus female fulmars had similar intestine length and gizzard mass, but small intestines were $18 \%$ lighter in post-exodus females. Small intestines of post-exodus males were $7 \%$ longer and $24 \%$ heavier, and gizzards were $26 \%$ heavier, compared to pre-exodus males (Table 3.1 ). Post-exodus males also had larger livers than pre-exodus males, notably composed of 

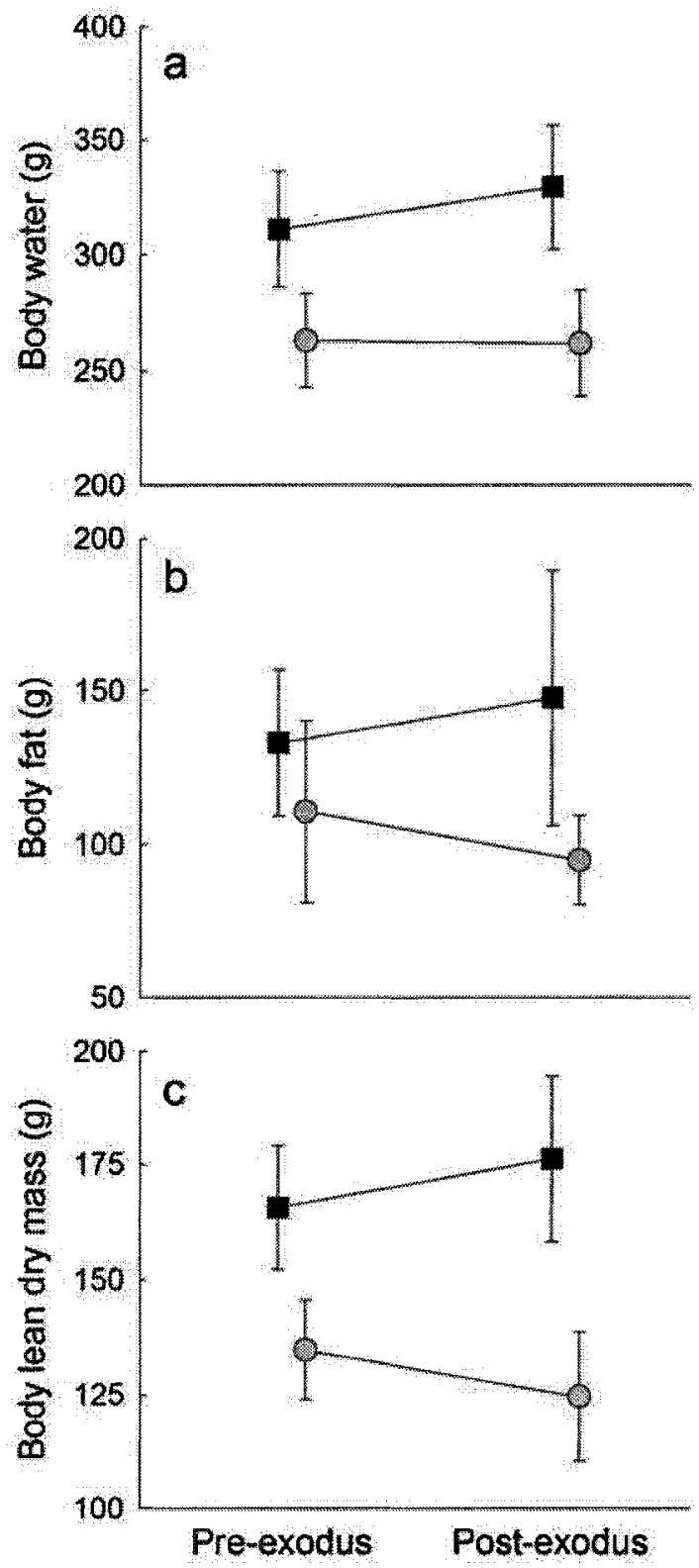

Figure 3.2. Mean ( \pm SD) total body water (A), body fat $(B)$ and lean dry mass $(C$; protein+ash) in male (dark square) and female (light circle) fulmars at Cape Vera, pre- and post-exodus. 
$27 \%$ more lean dry mass. Post-exodus female livers had $19 \%$ less fat than pre-exodus females, but lean dry mass was similar.

\section{Energy needs}

Male fulmars take the first incubation shift immediately after the female lays the egg, and this shift averages $9.3 \mathrm{~d}$ at Cape Vera (Chapter 5). At an IMR of about $400 \mathrm{~kJ} \cdot \mathrm{d}^{-}$ ${ }^{1}$, the average first incubation shift should require $3720 \mathrm{~kJ}$, and would total $5164 \mathrm{~kJ}$ including the average costs of flying $1 \mathrm{~d}$ from the colony to the feeding grounds $(1444 \mathrm{~kJ})$. This represents the energy content of $131 \mathrm{~g}$ of fat. The average male fulmar at Cape Vera had $142 \mathrm{~g}$ of fat stored post-exodus (5618 kJ), an amount capable of supporting $10.5 \mathrm{~d}$ of incubation plus a day of flight to the feeding grounds (not including the energy also available from using stored protein).

Fresh eggs had higher mean water content $(70.0 \pm 1.5 \mathrm{~g})$ than partly incubated eggs $\left(61.6 \pm 2.1 ; t_{20}=3.2, P=0.004\right)$, but fat, mineral and protein content were all similar ( $t$-tests, all $P>0.38$ ), and thus values for all 24 eggs are presented in Table 3.2. Mean energy content of fresh eggs was $5.9 \pm 0.1 \mathrm{~kJ} / \mathrm{g}(535 \mathrm{~kJ})$, and an average, fresh egg represented $14.8 \%$ of the body mass of pre-exodus females. Post-exodus females that laid an egg had about $16 \mathrm{~g}$ less body fat than pre-exodus females, representing twice as much fat as was deposited in the egg (Table 3.2). Similarly, after the exodus, females had $12.7 \mathrm{~g}$ less protein in their bodies, although some of this protein could have been mobilized for oviduct growth. Protein comprised $22-23 \%$ of breast and leg tissue wet mass, respectively, and thus $6.7 \mathrm{~g}$ of oviduct probably 
Table 3.2. Composition (g) and energy content of northern fulmar eggs $(n=24)$ collected in 2003-2005. The mass values in brackets represent calculations for only the seven fresh eggs.

\begin{tabular}{lcc}
\hline Variable & Mean & SE \\
\hline Egg Mass $(\mathrm{g})$ & $91.20(96.17)$ & $2.28(2.36)$ \\
Total Protein $(\mathrm{g})$ & 12.04 & 0.36 \\
Total Fat $(\mathrm{g})$ & 8.13 & 0.26 \\
Total Mineral $(\mathrm{g})$ & 6.78 & 0.17 \\
Energy content $(\mathrm{kJ})$ & 534.6 & 15.5 \\
\hline
\end{tabular}


represents $1.5 \mathrm{~g}$ of protein (I did not analyse oviduct composition directly). Hence, even accounting for use of body protein for oviduct growth, the remaining amount of protein lost by females during the exodus (11.2 g) was roughly equivalent to the amount of protein in the egg $(12.0 \mathrm{~g})$. Eggs required $6.8 \mathrm{~g}$ of mineral to form the shell and $70 \mathrm{~g}$ of water for egg contents, representing $30 \%$ of the mineral (body ash) content and $27 \%$ of the body water of pre-exodus females, respectively. Post-exodus females had similar amounts of ash and water as pre-exodus females (Table 3.1).

\section{Discussion}

Northern fulmars nesting at Cape Vera encounter some annually predictable features in the marine environment surrounding their colony early in their breeding season. For example, by the start of the pre-laying exodus, they must fly a minimum of 200 $\mathrm{km}$ to reach the nearest partially open water, although in some years (e.g., 2004) this may be much farther. The North Water Polynya is partly open each year by mid-May and appears to be an important feeding area for these fulmars during incubation and chick-rearing (Fig. 3.1), presumably due to its proximity to the colony and high productivity (Mallory and Fontaine 2004). However, regional surveys suggest that few fulmars forage in this polynya during the exodus (McLaren 1982), and instead probably move $>1000 \mathrm{~km}$ southeast to the open waters along the west coast of Greenland before returning to their colonies to lay eggs. This suggests that during the pre-laying exodus, fulmars are unlikely to acquire sufficient marine food supplies near their colony, either due to the unpredictability of suitable open water foraging 
areas, or the relatively low marine production early in the season (Raymont 1976, Welch et al. 1992). Predictable feeding sites are located $>1000 \mathrm{~km}$ away.

Why do fulmars breed at Cape Vera under such marine conditions? The benefit to fulmars breeding at this or other High Arctic sites may be that food resource acquisition (a key factor determining seabird reproductive success; Frederiksen et al. 2007) is comparatively easy during the summer pulse of superabundant marine food resources in the Arctic (Welch et al. 1992), compared to fulmars nesting in the Boreal oceanographic zone. The summer coincides with the chick-rearing stage, when breeding marine birds face their greatest energetic challenges (Ricklefs 1983, Whittow 2002). However, finding enough food during the pre-laying exodus is also critical for fulmar reproduction, as they are clearly income breeders (below). To withstand the challenges imposed by extensive ice cover (i.e., distant and/or scarce food resources), High Arctic fulmars exhibit behavioural adjustments to their breeding schedule compared to conspecifics breeding at more southern colonies. These adaptations include a short period at the colony prior to the exodus, and a pre-laying exodus $43-149 \%$ longer than at southern fulmar colonies (Chapter 2). During the exodus, both male and female fulmars undergo substantial changes in body tissues, the size of which appear matched to their sex-specific requirements of egg-laying and incubation at this site. 
Body changes during the exodus

Body mass, egg composition and water content of breeding northern fulmars at the Cape Vera colony were similar to values previously reported for fulmars or other petrels (Warham 1983, 1990, Hatch and Nettleship 1998). In particular, fulmars exhibited high adiposity $(\sim 22 \%)$, similar to great-winged petrels, Pterodroma macroptera (Groscolas et al. 1991) and higher than some long-term fasting penguins (Cherel et al. 1993). However, I found that body mass and nutrient levels of breeding fulmars changed during the pre-laying exodus from the colony in late May, and that changes were in opposite directions for males and females, although both indicate income breeding. Body mass of male fulmars increased, because of protein, fat (notably breast fat) and water accumulation, whereas females lost body mass, particularly protein and fat. In an earlier study in Alaska, Hatch (1990a) showed that body mass of male fulmars also increased from pre-laying to laying, but by $14 \%$, whereas increases at Cape Vera were only $5 \%$. As well, female fulmar body mass appeared to increase marginally (1\%; Fig. 8 in Hatch 1990a), while at Cape Vera, female mass declined by $3 \%$. While these studies confirm that fulmars have similar, sex-specific changes in body mass (and likely composition) during the exodus at each colony, the magnitude of the differences suggests colony-specific responses in nutrient dynamics to accommodate reproduction in response to the type or availability of prey within the foraging range of each colony. 
Female energetics

Based on the differences in females before and after the exodus, and the composition of fulmar eggs, pre-exodus females had similar levels of endogenous fat and protein as was required to form an egg (excluding costs of biosynthesis; Grau 1984). In fact, during the exodus, female fat reserves declined by twice the amount of fat that was deposited in an egg, while declines in protein reserves were approximately equivalent to that found in an egg. However, egg requirements for water and mineral represented more than one quarter of these total constituents in pre-exodus females, which presumably would have placed a severe strain on the female to liberate for egg synthesis, because female birds can only mobilize $\leq 15 \%$ of their skeletal calcium for egg production (Brenninkmeijer et al. 1997). This suggests that the principal function of the exodus is to allow female fulmars to acquire enough minerals to form the eggshell, as well as providing water for albumen production.

The changes I observed in nutrients of breeding female fulmars during the exodus are most consistent with a model of "mineral limitation". I predict that female fulmars use some of their endogenous fat reserves (i.e., pre-exodus stores) to meet the requirements of egg (yolk) synthesis, as well as fueling some of their existence energy and physiological changes while foraging during the exodus (analogous to High Arctic shorebirds; Morrison and Hobson 2004). In support of this prediction, I found that lipophilic contaminants in females that had laid an egg were lower than in non-breeding females or males (Mallory et al. 2006b), suggesting that females had shed some of their contaminants with lipids contributed to egg production. Given the 
decline in protein reserves, despite a month foraging away from the colony, I suggest that much of the protein required for egg synthesis also came from the female's reserves, as observed in several species of waterfowl (Alisauskas and Ankney 1992) and in great black-backed gulls (Larus marinus) (Mawhinney et al. 1999). By using some endogenous reserves to fulfill fat and protein requirements for egg production, I speculate that females forage for more mineral-rich (i.e., calcium-rich) items during the exodus, as found in other pre-laying female birds (e.g., Boersma et al. 2004). They may feed less on squid during the exodus, which are typically an important component of High Arctic fulmar diets (Hatch and Nettleship 1998) but are relatively poor sources of calcium (Clarke and Prince 1980, Cherel and Ridoux 1992, Lawson et al. 1998). Female digestive organs did not increase in size over the exodus, as would be expected if they were foraging more heavily than before the exodus to acquire fat and protein (Ankney 1977, Drobney 1984). If this speculation is correct, I predict that: (a) male and female resource acquisition and allocation should differ during the exodus, which might be detected in isotopic studies; and (b) that females probably switch resource acquisition strategies immediately after the exodus to quickly recoup fat and protein stores.

Why would female reserves decline if the bird was away for one month to feed? Fulmar eggs require $23 \mathrm{~d}$ to form (Chapter 2), so the daily costs of egg synthesis would be relatively low. Nonetheless, during the exodus, fulmars in the High Arctic would be foraging at a time when marine productivity would still be reduced, due to extensive ice-coverage and low sea-surface temperatures (Welch et 
al. 1992). Moreover, at this time fulmars may face high competition with conspecifics and other seabirds for marine prey concentrated at predictable, productive sites such as ice edges (Hunt 1991). If females do forage specifically for mineral-rich prey during the exodus, then locating sufficient prey may be difficult early in the breeding season for fulmars at this latitude, which may explain why fulmars in the High Arctic have a markedly longer exodus than fulmars at lower latitudes (Chapter 2), and why they lose more reserves than required strictly for egg formation (this paper).

\section{Male energetics}

My data support the hypothesis that males undertake the exodus to acquire nutrients for incubation. Pre-exodus males had $133 \mathrm{~g}$ of fat stores, sufficient to fuel the average first incubation shift and a flight to the feeding grounds if that shift started when the exodus started. However, if the female departs to gather nutrients for egg production (above) and the male was to remain at the nest site for $28 \mathrm{~d}$ (the average duration of the female exodus; Chapter 2), then the male would require the equivalent of $282 \mathrm{~g}$ of fat $(11200 \mathrm{~kJ})$, at a resting metabolic rate of $400 \mathrm{~kJ} \cdot \mathrm{d}^{-1}$ (assuming RMR $\approx$ IMR; Grant 1984). Even if these values overestimate energetic use by $100 \%$, preexodus males would still have insufficient reserves to initiate incubation on the female's return, and thus males must also depart to acquire nutrients to enable them to initiate incubation once the female has laid her egg. Thus, the exodus by males may be a required response to the female's energetic requirements. 
Post-exodus males had $142 \mathrm{~g}$ of endogenous fat as well as stored protein. With their high adiposity and reduced metabolic rates fasting during incubation (e.g., Cherel et al. 1993), these stores could support $10.5 \mathrm{~d}$ of incubation, more than was required to fuel the average, first incubation shift at Cape Vera. I also found that post-exodus male fat stores were more variable than in pre-exodus males, which may be attributable to: (1) incorporation of some non-breeding males in the sample (which might have had smaller fat stores); or (2) variation in fat stores to meet different incubation schedules. Given the finding that fat levels were significantly lower in 1983 compared to 2004, post-exodus males (see Methods), and that the 1983 males were shot near the cliffs while the 2004 males were taken from nests, I believe that option (1) fits the data, that is, some non-breeding, post-exodus males were included in the 1983 sample. However, the result of this bias is that I have underestimated the reserves acquired over the exodus, and thus my overall interpretation of patterns remains the same. There is also support for option (2), in that there is considerable variation among fulmar pairs in incubation scheduling (Hatch 1990c, Chapter 6). Given that mate fidelity and breeding experience have a critical influence on fulmar reproductive success (Hatch and Nettleship 1998), pair-specific patterns of incubation scheduling might be reflected in differences in endogenous reserve levels for incubation.

Males also increased the amount of water stored in skeletal muscle during the exodus. This was attributable in part to males increasing their levels of protein during the exodus, because protein and water levels generally change simultaneously in lean 
tissues (Groscolas et al. 1991). While catabolism of fat may be a source of metabolic water (Ricklefs et al. 1978), males may have been storing additional water, perhaps to meet challenges in maintaining water balance for a long, uninterrupted incubation $\operatorname{shift}(\sim 10 \mathrm{~d})$ in an arid environment.

Hatch (1983) found that female fulmars had sperm storage glands, and suggested that this could allow pairs to forage separately over pelagic waters during the exodus, because mating would already be completed. My data support this hypothesis. Unlike post-exodus female fulmars, whose digestive organs showed little difference from pre-exodus females (and appeared to lose mass), male fulmars collected after the exodus had significantly larger digestive organs and livers than pre-exodus males, which suggests that males increased foraging rates during the exodus (Ankney 1977, Drobney 1984). Male and female fulmars also depart and return at different times for their exodus (Hatch 1990b, Chapter 2). Thus, differences in exodus scheduling, digestive organ changes, body composition changes, and mass trajectories all suggest that female and male fulmars have different resource acquisition and allocation strategies during their pre-laying exodus, and these might include foraging in different regions or marine habitats.

\section{Tissue nutrient dynamics}

Fulmar reproductive organs changed predictably in size during the exodus. Male copulation is frequent before the exodus, but there are no mating opportunities following this date (Hatch and Nettleship 1998), so testes size should decline. In 
contrast, females fertilize eggs during the exodus at Cape Vera ( $28 \mathrm{~d}$ exodus, $23 \mathrm{~d}$ egg formation; Chapter 2), using stored sperm (Hatch 1983), after which oviduct growth appears to be rapid.

Unlike geese, gulls and penguins (Ankney and MacInnes 1978, Houston et al. 1983, Cherel et al. 1994b), where the pectoral muscle is the primary source of endogenous protein (Blem 1990), I found no change in either protein or fat content of female fulmar pectoral muscles during the exodus (although males stored reserves in the pectoral region). Fulmars (and other petrels) are highly reliant on efficient flight for foraging (Warham 1990, Furness and Bryant 1996), so declines in the size, strength or efficiency of the pectoral muscles may have a deleterious effect on feeding ability during the exodus. Thus selection may have favored mobilization of nutrients for egg formation from other body tissues. However, it is unclear which tissues might serve as the source of protein for females. The decline in mass of the intestine $(2.2 \mathrm{~g})$ represented only $17 \%$ of the observed decline in body lean dry mass $(12.7 \mathrm{~g})$, and was only $0.5 \mathrm{~g}$ more than the protein required for oviduct growth. I did not see changes in lean dry mass of any other specific tissues examined (breast, leg, liver, gizzard; Table 1), and thus further investigation is required to determine protein dynamics for breeding female fulmars.

Oceanographic zones and the implications for other colonies Nutrient dynamics for fulmars at Cape Vera represent the situation at the extreme northern limit of the breeding range for this species (Hatch and Nettleship 1998), in 
the High Arctic oceanographic zone, where breeding phenology and marine food supplies are largely constrained by the timing and extent of annual marine ice cover. At more southern colonies in the Boreal and Low Arctic oceanographic zones, breeding is initiated earlier in the year, males and females undertake an exodus which may be two weeks shorter and may be punctuated by brief returns to the colony (Hatch 1990a), and many fulmars have alternate food sources to prey upon (Hatch and Nettleship 1998). Importantly, fish and fisheries offal, both presumably excellent sources of minerals, protein and fat, form a higher proportion of the diet in fulmars at more southern colonies. Thus, while mineral limitation may also explain the fulmar exodus at colonies further south, differences in breeding phenology and available food supplies apparently permit females to spend less time away from the colony, and may allow females to more quickly recover fat and protein used for egg production. As well, fulmars may return from wintering grounds to High Arctic colonies with proportionally larger reserves than fulmars at Boreal or Low Arctic colonies to compensate for relatively low, early season marine production in the High Arctic. This hypothesis might account for differences in mass trajectories between our study and those found by Hatch (1990a).

My data clearly are consistent with the hypothesis that insufficient endogenous reserves, particularly of minerals, are an important motivation for the pre-laying exodus by High Arctic northern fulmars. However, I propose that differences in quality and quantity of exogenous nutrient supplies in marine environments contribute to observed behavioural differences in the pre-laying exodus, 
and I predict that substantial differences occur in nutrient dynamics during the exodus across the species' range. 


\section{CHAPTER FOUR}

\section{Costly pre-laying behavioural and physiological expenditures in northern fulmars in the Canadian High Arctic}

This chapter formed the basis for the following publication:

Mallory, M. L., and M. R. Forbes. 2008. Costly pre-laying behavioural and physiological expenditures in northern fulmars in the Canadian High Arctic. Écoscience, accepted. 


\section{Abstract}

Petrels are a group of seabirds that undertake an exodus from their breeding colony just prior to egg-laying, purportedly to allow the female to acquire nutrients for egg synthesis from the local environment. I studied seasonal nutrient dynamics and atnest behaviour of northern fulmars (Fulmarus glacialis), a petrel found in the Canadian High Arctic, to evaluate the importance of pre-laying nutrient reserves to annual breeding in this species. Females and males carried $35-50 \%$ more fat when they first arrived at the colony than when they returned from their pre-laying exodus to lay their egg or initiate incubation. Fulmars spent approximately $70 \%$ of their time at the nest engaged in energetically-expensive behaviours (pair-bonding, digging out and defending their nest site) during the brief period from colony arrival to departure on their pre-laying exodus. In contrast, $70 \%$ of their time at the nest was spent resting during incubation. Both nutrient reserve and behavioural data suggest that High Arctic fulmars require large endogenous reserves prior to egg-laying to fuel their energetically-costly activities during the arrival-to-exodus period. 


\section{Introduction}

Avian body mass and composition changes adaptively throughout the breeding cycle to meet the competing energetic and nutritional demands of reproduction and selfmaintenance (Blem 1990). Drent and Daan (1980) described two principal strategies of how birds manage nutrient reserves for breeding. In migratory birds, capital breeders are those species that lay eggs by relying primarily on endogenous body reserves stored before arrival at the breeding site, whereas income breeders acquire necessary exogenous nutrients from the local breeding environment once they have arrived. More recent research has shown that the distinction between capital versus income breeding is not mutually exclusive (Meijer and Drent 1999, Klaassen et al. 2006; Guillemain et al. 2008), and that most species fall somewhere along a continuum between these extremes (Gauthier et al. 2003).

The role of pre-laying nutrient reserves and energetics has been well-studied in waterfowl (e.g., Alisauskas and Ankney 1992) and passerines (e.g., Sandberg and Moore 1996), but has received much less attention in seabirds (c.f., Mawhinney et al. 1999). Most studies on seabird energetics usually encompass the chick-rearing period, the most energetically-demanding stage for seabirds (Ricklefs 1983). Moreover, these studies have generally used size-corrected body mass as a coarse index of body condition (Ellis and Gabrielsen 2002). However, assessing true nutrient reserves and dynamics is critical to elucidate ecological needs for breeding; for example, among Arctic shorebirds, large pre-laying body mass or endogenous 
reserves are required to meet needs other than egg synthesis (Klaassen et al. 2001), somewhat contrary to the initial theory that these birds were capital breeders.

The Procellariiformes (hereafter petrels) are a diverse group of seabirds, in which breeding pairs undertake an exodus from their colony just prior to egg-laying, ostensibly for the female to gather nutrients to form her egg (i.e., income breeding; Warham 1990). Petrel body condition varies within and among years and individuals (Warham 1990, Chastel et al. 1995), and poor body condition prior to breeding may lead petrels to skip a breeding attempt (e.g., Barbraud and Weimerskirch 2001a). As well, allocation of time and energy to different behaviours through the breeding season varies for petrels, with significant adjustments to both time spent and activities undertaken at the nest (Hatch 1990, Chastel et al. 1995). Prior to laying, petrels spend much time paired at the nest, engaged in pair bonding, copulation, nest building and nest defense (Warham 1990). During incubation and chick-rearing, breeding petrels spend most of their time while at the nest without their mate, relatively motionless while incubating or brooding. These substantial changes in behaviour presumably consume markedly different energetic stores, and thus behavioural patterns at the nest should correlate with nutrient dynamics through the breeding season.

I studied early-season nutrient dynamics and time-activity budgets of breeding northern fulmars (Fulmarus glacialis), the only petrel with a northern, circumpolar distribution. Some aspects of fulmar reproductive energetics have been investigated (Furness and Bryant 1996), but little is known of their nutritional requirements, and 
information on time spent in different activities at the nest is primarily anecdotal (Hatch and Nettleship 1998). My study site was at a remote colony in High Arctic Canada (Cape Vera, Nunavut; Fig. 2.1), where pairs had a brief period between arrival at the colony and departure for the pre-laying exodus in which to pair bond, prepare their nest, and copulate (Chapter 2). Thus, one of my objectives was to quantify the allocation of time to different activities at the nest by breeding fulmars from arrival at the colony through late incubation. I predicted that time allocated to energetically-costly behaviours at the nest would be greater prior to egg-laying than during incubation. Furthermore, because the fulmars appear to fast from arrival at the colony until undertaking the exodus (Chapter 2), I predicted that fulmars must arrive with large endogenous reserves to meet the energetic and nutritional demands of preexodus activities at the nest.

\section{Materials and Methods}

\section{Collections}

Breeding schedules of fulmars at Cape Vera are highly synchronized within and across years, with the colony almost completely deserted between 20 to 30 May annually, and with colony numbers rapidly building from 1 June through mean egglaying (6 June; Chapter 2). I collected fulmars during the first week after arrival at the colony (4-6 May; ARRIVE), prior to the exodus (16-18 May; PRE-LAYING), during or immediately after egg-laying (5-17 June; POST-LAYING), during mid- 
incubation (4-7 July; MID), and during late incubation (15-17 JULY; LATE). The fulmar carcasses were used for a variety of studies (e.g., Mallory and Forbes 2005, Chapter 9). In 2003 ( $n=32$ ), 17 birds were shot near the breeding cliffs, while another 15 were captured with noose poles on their nest site and were immediately decapitated. In 2004 ( $n=31)$ and $2005(n=24)$, all breeding birds were captured on their nest, and then decapitated. Fulmars were weighed $( \pm 10 \mathrm{~g})$ and frozen in airtight bags, and then transported to the laboratory.

Individual breeding birds are capable of adjusting their body condition or reproductive effort, and thus serial sampling of individuals through breeding would best capture body composition dynamics (e.g., Bêty et al. 2003). However, this was not possible with Arctic fulmars, because they often abandon nests after capture (M. L. Mallory, pers. obs.), and because I was interested in examining changes in different body tissues which required sacrificing birds. Thus, the sampling protocol above assumed that I collected fulmars of average size and condition at each stage of breeding. This assumption seemed reasonable (see Statistical analyses), as nesting was highly synchronous (i.e., fulmars had little option to vary lay date in relation to body condition; Chapter 2), clutch size was uniformly one egg (Hatch and Nettleship 1998), and variation in fulmar egg size comes principally from differences in female structural size or breeding experience, and not environmental conditions (Michel et al. 2003). The main potential for bias was in my samples of birds during ARRIVE, where some birds could have been non-breeders. The result of this bias would be that I underestimated the true decline in nutrient stores from arrival to pre-laying. 


\section{Nutrient analyses}

Preparation of fulmars for analysis (measurements, dissections), as well as analytical procedures are identical to those outlined in Chapter 3. All fulmars collected prior to the colony exodus were considered breeders (at least $74 \%$ of birds at apparently occupied sites laid an egg; M. L. Mallory, unpubl. data). After the return from the exodus, most breeding birds were captured on the nest with an egg, confirming their status. However, for female fulmars collected off of the nest site in 2003, birds were considered breeders if they had a post-ovulatory follicle and/or an oviducal egg. Only birds that were presumed to be breeders were included in subsequent analyses.

\section{Time budgets}

Northern fulmar nest sites could be viewed easily using $10 \times 42$ binoculars or a $60 \mathrm{X}$ spotting scope from vantage points $30-300 \mathrm{~m}$ distant along the cliff top, meaning that birds were not disturbed during observations. I recorded $64.7 \mathrm{hr}$ of diurnal activity observations of 50 different breeding fulmars (only one member from any breeding pair) in $2004(52.9 \mathrm{hr})$ and $2005(11.8 \mathrm{hr})$. Duration of observations averaged $1.3 \pm$ $0.1 \mathrm{SE} \mathrm{hr}$ (range $0.4-3.0 \mathrm{hr}$ ). Sampling intensity was distributed across breeding as follows: $7.1 \mathrm{hr}$ on four birds at the time of arrival (two males and two females, based on size differences of paired birds; Mallory and Forbes 2005); 17.8 hours on 13 birds during pre-laying; $9.8 \mathrm{hr}$ on eight birds at egg-laying; $20.8 \mathrm{hr}$ on 17 birds during early to mid-incubation; 9.2 hrs on eight birds during the week of hatch. For observations 
during ARRIVE and PRELAY, I assumed that paired birds were breeders. Observations later in the season were on incubating fulmars.

I used the following categories to describe fulmar behaviour at the nest: resting (sleeping or resting); adjusting (resettling, preening); vigilant (watching nearby activity of conspecifics or avian predators); agonistic (calling at or defending nest from neighbours or visiting non-breeders, reaction to predators); pair bonding (courtship activities with mate); and housekeeping (digging through snow to nest, moving pebbles to nest rim, clearing debris from nest). I could not reliably distinguish between male and female fulmars for activity observations, except for the ARRIVE period, and therefore I assumed that my observations were not biased by any sex-specific allocation of time to different behaviours during incubation. Several hundred hours of preliminary study in 2003 did not suggest any sex bias in activities at the nest, although behaviour may differ for birds nesting in caves versus ledges (Chapter 7). For this reason, I only used observations from birds nesting on open ledges.

\section{Statistical analyses}

Head length, tarsus length and keel length were measured for all fulmars across years, and with these I tested for relationships between structural body size, breeding stage and sex in a multivariate analysis of variance (MANOVA; SAS Institute Inc. 2002). For subsequent modeling, I used these data to create an index of body size using the first factor (PC1) from a principal component analysis on these measurements. 
However, PC1 was highly correlated with $\operatorname{sex}\left(\right.$ mean $P C 1_{\text {male }}=-1.14 \pm 0.11$, mean $\left.P C 1_{\text {female }}=1.40 \pm 0.12 ; t_{124}=15.9, P<0.0001\right)$, so I repeated the procedure but created a PC1 within each sex.

I used a combination of statistical hypothesis testing and information-theoretic approaches to data analyses. To evaluate whether male and female fulmars differed in body composition through breeding, I first conducted a MANOVA on independent body components (i.e., those which were not subcomponents of each other: body fat, water, protein, mineral), using sex and stage as independent treatments. Significant multivariate main effects were then followed by univariate, two-way, generalized linear models (PROC GLM) to evaluate changes in body composition of breeding male and female fulmars (those variables listed above, as well as plucked body mass). I developed seven candidate models involving combinations of the variables breeding stage, structural size index (PC1), and their two-way interaction. I used Akaike's Information Criterion adjusted for small sample sizes $\left(\mathrm{AIC}_{\mathrm{c}}\right.$; Burnham and Anderson 2002) to choose the best approximating models, as well as using model-averaging to derive parameter estimates of continuous variables (denoted as $\theta \pm \mathrm{SE}$ ) and associated variances and confidence limits from a $90 \%$ confidence set of candidate models (Burnham and Anderson 2002). To compare body composition within male and female fulmars, I used Tukey's HSD post hoc tests from the model where $\Delta \mathrm{AIC}_{\mathrm{c}}=0$ (except for water composition in females, where we used the $\mathrm{PC} 1{ }^{*}$ stage model).

I did not include year as a variable in the final set of candidate models. My collections were targeted to minimize the number of birds killed, and to take 
advantage of carcasses used in other studies (above). For this reason, there was a bias in sampling between breeding stage and year (e.g., all ARRIVE and all male POSTLAYING samples were collected in 2005). During preliminary analyses, there was a significant interaction between stage* year in explaining variation in body composition, which I interpreted as the result of the sampling bias (above) rather than inter-year differences. However, I was confident that any effects of annual variation on body composition were small for three reasons. First, fulmar breeding chronology at the Cape Vera colony is highly synchronized across years, presumably because sea-ice features, which dictate marine environmental conditions and food supplies, are driven by a recurrent polynya which is stable across years at this colony (Chapter 2). Thus, samples collected on Ordinal date $x$ in year 1 would be at the same breeding stage as samples collected on the same date in year 2 . Second, in five pairwise tests where four or more fulmars of the same sex and same breeding stage were collected in different years, there was no evidence that stage-specific fulmar body mass differed significantly between years $(t$-tests; $0.2<t<1.7,11<\mathrm{df}<18$, $0.86>P>0.11$ ). Third, seasonal patterns of nutrient dynamics within years were consistent between years, including comparisons to collections made in the $1980 \mathrm{~s}$ (Chapter 3). Thus, I pooled data across years for analyses.

For time budget data, I converted all time spent in each activity category to a percentage of the overall duration of observation, and then transformed these proportions using arcsin square root transformation. Some data still did not approximate normality, and sample sizes were small, so I compared transformed 
proportions of time spent in activities at different breeding stages using nonparametric Kruskal-Wallis analysis of variance tests.

All statistical analyses were conducted with SAS (SAS Institute Inc. 2002). Means are presented \pm SE unless otherwise noted.

\section{Results}

Fulmar body size

Male and female fulmars differ in many aspects of body size (Mallory and Forbes 2005). Wilk's Lambda test criterion indicated that fulmar structural body size (head, tarsus and keel length) was influenced by sex (MANOVA; $F_{3,74}=42.0, P<0.001$ ), but not by breeding stage $\left(F_{15,205}=0.8, P=0.72\right.$; interaction effects, $\left.P>0.25\right)$. In a separate MANOVA, Wilk's Lambda test criterion showed that measures of body composition (fat, protein, mineral) were influenced both by $\operatorname{sex}\left(F_{3,74}=17.1, P<0.001\right)$, as well as breeding stage $\left(F_{15,205}=6.0, P<0.001\right)$, with a significant sex* stage interaction $\left(F_{12,196}=2.0, P=0.03\right)$. Based on both of these analyses, I examined patterns of change in body mass or composition within each sex.

\section{Fulmar body composition}

Among 44 male fulmars, mean plucked body mass was $676 \pm 11 \mathrm{~g}$, which was $48 \%$ water, $27 \%$ fat, $20 \%$ protein, and $5 \%$ mineral. Female fulmars ( $n=43$ ) weighed $20 \%$ less than males, with a mean plucked body mass of $544 \pm 8 \mathrm{~g}$, which was $49 \%$ water, $26 \%$ fat, $20 \%$ protein, and $5 \%$ mineral. Upon arrival at the colony, absolute mass of 
fat in male and female fulmars was similar (Table 4.1; $t_{11}=0.2, P=0.8$ ). However, body mass and composition of both male and female fulmars changed during the breeding season (Table 4.1).

I analysed how male fulmar body composition (plucked body mass, fat, protein, mineral, or water) was influenced by breeding stage, structural size (PC1), and their interactions. In each case, the best-fitting model explaining differences in body composition was one with only breeding stage entered, where this parameter alone explained $16-51 \%$ of the variation (Table 4.2). Other models within the $90 \%$ confidence set included PC1, or stage and PC1 together. However, in each model, the PC1 parameter did not differ statistically from 0 (Table 4.3), which was reflected in the low additional variation explained with the incorporation of this variable (Table 4.2). Hence, for male fulmars, structural size had little effect on the size of endogenous nutrient stores.

On average, male fulmars appeared to be heaviest and had the largest endogenous reserves of water, fat, protein, and mineral when they arrived at the colony (Fig. 4.1). A 13\% decline in body mass occurred during the $14 \mathrm{~d}$ period between arrival at the colony and pre-laying period (i.e., when they departed for the pre-laying exodus), which was manifested as decreases in all body reserves (Fig. 4.2; fat: $-43 \%$; protein: $-11 \%$; water: $-9 \%$; mineral: $-3 \%$ ). In statistical comparisons, fat reserves of males upon arrival were significantly larger than pre- or post-laying males, water reserves in arriving males were larger than for males at any time after 
Table 4.1. Mean body composition characteristics of northern fulmars by breeding stage. Body mass measures were values for plucked carcasses.

\begin{tabular}{|c|c|c|c|c|c|}
\hline \multirow{3}{*}{$\begin{array}{l}\text { Body } \\
\text { Component }\end{array}$} & \multicolumn{5}{|c|}{ Mass \pm SE $(g)$ at breeding stage } \\
\hline & \multirow[b]{2}{*}{ Arrival } & \multirow[b]{2}{*}{ Prelaying } & \multirow[b]{2}{*}{ Post-Laying } & \multicolumn{2}{|c|}{ Incubation } \\
\hline & & & & Mid & Late \\
\hline$N$ (male) & 7 & 5 & 21 & 8 & 3 \\
\hline Body mass & $743(24)$ & $647(14)$ & $674(16)$ & $640(22)$ & $683(39)$ \\
\hline Fat & $212.0(14.2)$ & $121.2(8.7)$ & $136.9(9.0)$ & $159.3(12.3)$ & $164.7(27.3)$ \\
\hline Protein & $117(4)$ & $104(5)$ & $110(2)$ & $105(5)$ & $103(2)$ \\
\hline Mineral & $33(2)$ & $32(1)$ & $32(1)$ & $27(2)$ & $28(3)$ \\
\hline Water & $294(9)$ & $267(3)$ & $262(4)$ & $233(6)$ & $255(15)$ \\
\hline$N$ (female) & 6 & 3 & 15 & 9 & 7 \\
\hline Body mass & $638(15)$ & $542(38)$ & $516(10)$ & $535(11)$ & $540(19)$ \\
\hline Fat & $207.4(11.4)$ & $103.2(13.0)$ & $95.4(4.1)$ & $144(20)$ & $85(9)$ \\
\hline Protein & $92(6)$ & $87(5)$ & $78(2)$ & $89(5)$ & $92(3)$ \\
\hline Mineral & $26(2)$ & $27(1)$ & $26(1)$ & $24(1)$ & $27(3)$ \\
\hline Water & $227(8)$ & $211(13)$ & $202(3)$ & $210(9)$ & $229(9)$ \\
\hline
\end{tabular}


Table 4.2. Akaike Information Criterion $\left(\mathrm{AIC}_{\mathrm{c}}\right)$ values for representative models explaining variation in male northern fulmar $(n=44)$ plucked body mass $(g)$, as well as fat, protein, mineral and gizzard mass $(\mathrm{g})$, and small intestine length $(\mathrm{mm})$ at Cape Vera, 2003-2005. Models incorporated parameters of breeding stage (stage), body size (PC1) and two-way interaction (stage*PC1). Only candidate models of the $90 \%$ confidence set (sum of $w_{i} \geq 0.90$ ) are presented.

\begin{tabular}{|c|c|c|c|c|c|}
\hline Model & RSS & $K$ & $\overline{\Delta \mathrm{AIC}_{\mathrm{c}}}$ & $w_{i}^{c}$ & $R^{2}$ \\
\hline \multicolumn{6}{|c|}{ Plucked Body Mass } \\
\hline Stage & 176462.4 & 6 & 0.00 & 0.58 & 0.21 \\
\hline stage, $\mathrm{PCl}$ & 173107.0 & 7 & 2.00 & 0.21 & 0.22 \\
\hline $\mathrm{PCl}$ & 220983.9 & 3 & 2.23 & 0.19 & 0.01 \\
\hline \multicolumn{6}{|c|}{ Fat } \\
\hline Stage & 57313.9 & 6 & 0.00 & 0.76 & 0.38 \\
\hline stage, PC1 & 56967.0 & 7 & 2.57 & 0.21 & 0.39 \\
\hline \multicolumn{6}{|c|}{ Protein } \\
\hline Stage & 4141.5 & 6 & 0.00 & 0.43 & 0.16 \\
\hline $\mathrm{PCl}$ & 4934.5 & 3 & 0.04 & 0.42 & 0.002 \\
\hline stage, $\mathrm{PCl}$ & 4122.5 & 7 & 2.64 & 0.11 & 0.17 \\
\hline \multicolumn{6}{|c|}{ Mineral } \\
\hline Stage & 603.5 & 6 & 0.00 & 0.70 & 0.24 \\
\hline stage, PC1 & 602.4 & 7 & 2.76 & 0.18 & 0.17 \\
\hline PC1 & 794.2 & 3 & 4.42 & 0.08 & 0.0 \\
\hline \multicolumn{6}{|c|}{ Water } \\
\hline Stage & 13557.1 & 6 & 0.00 & 0.77 & 0.51 \\
\hline stage, PC1 & 13511.0 & 7 & 2.82 & 0.19 & 0.51 \\
\hline
\end{tabular}


Table 4.3. Model-averaged PC1 estimates $(\theta)$, standard errors, and 95\% confidence intervals derived from the $90 \%$ confidence set of candidate models for body mass, fat, protein, ash, water, gizzard, and small intestine length of male $(n=44)$ and female $(\mathrm{n}=40)$ northern fulmars at Cape Vera, Nunavut, 2003-2005.

\begin{tabular}{|c|c|c|c|}
\hline Body Component & $\theta$ & $\mathrm{SE}$ & $95 \% \mathrm{CI}$ \\
\hline \multicolumn{4}{|c|}{ Male } \\
\hline Plucked Body Mass & 7.5 & 10.0 & $-12.4-27.4$ \\
\hline Fat & -2.4 & 5.1 & $-12.6-7.7$ \\
\hline Protein & 0.4 & 1.6 & $-2.7-3.6$ \\
\hline Ash & -0.02 & 0.6 & $-1.2-1.1$ \\
\hline Water & 0.9 & 2.5 & $-4.1-5.9$ \\
\hline \multicolumn{4}{|c|}{ Female } \\
\hline Plucked Body Mass & 8.3 & 5.1 & $-2.0-18.5$ \\
\hline Fat & -3.2 & 4.5 & $-12.2-5.8$ \\
\hline Protein & 1.8 & 1.6 & $-1.4-5.0$ \\
\hline Ash & 0.3 & 0.5 & $-0.6-1.3$ \\
\hline Water & 5.8 & 2.7 & $0.3-11.2$ \\
\hline
\end{tabular}




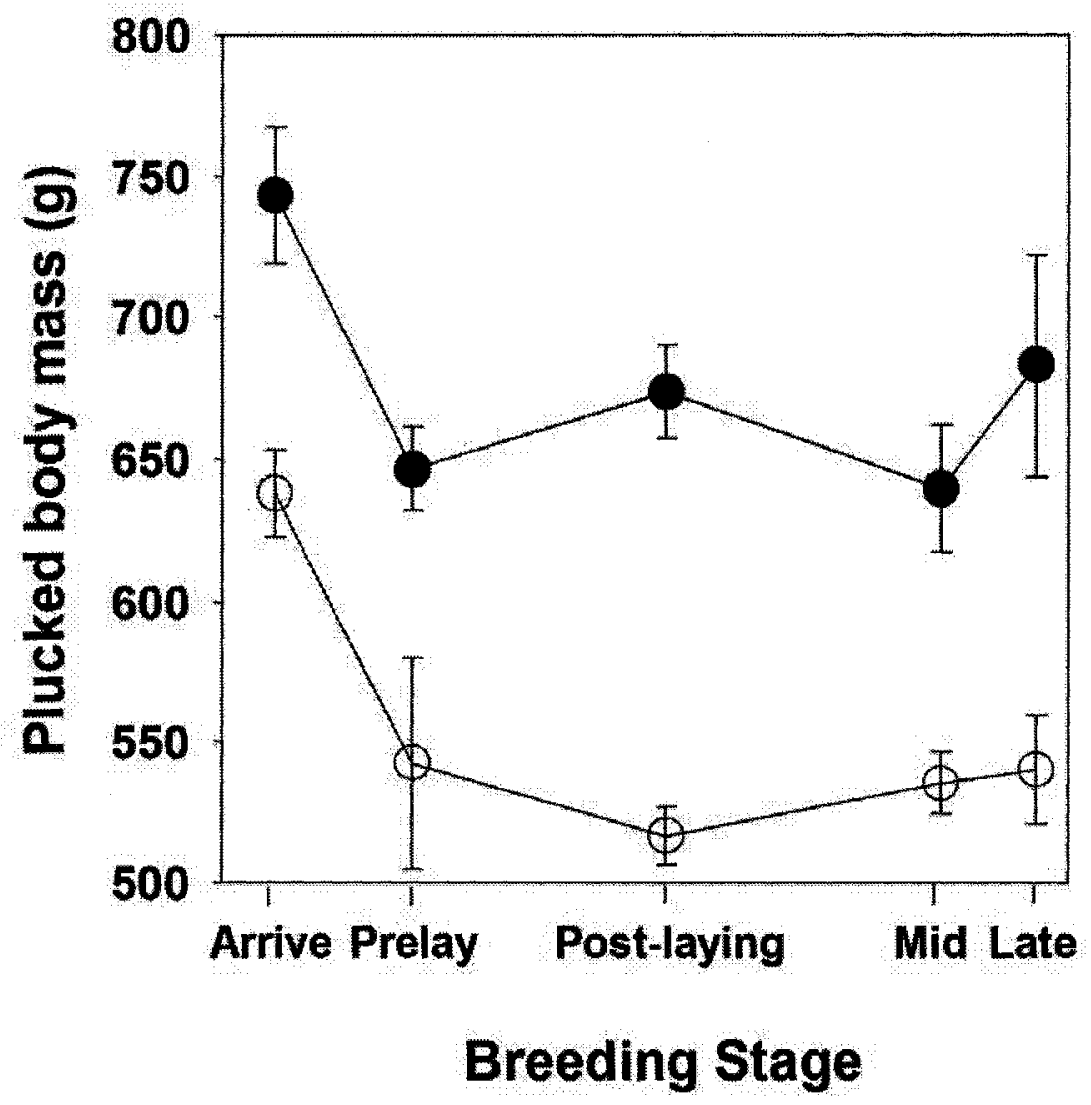

Figure 4.1. Changes in male (solid circle) and female (open circle) body mass $\pm \mathrm{SE}$ from arrival at the colony through late incubation. 

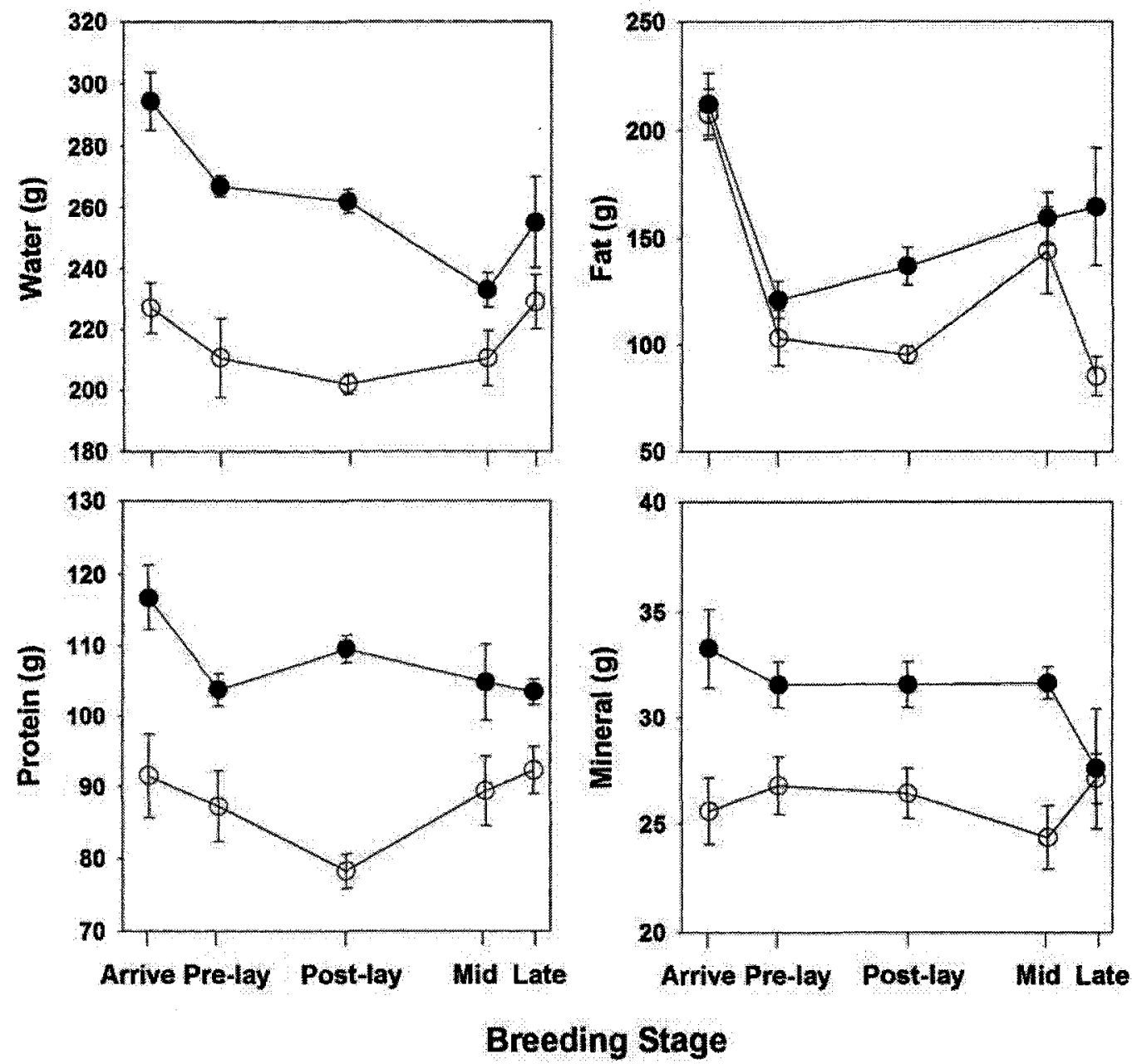

Figure 4.2. Changes in male (solid circle) and female (open circle) fulmar body composition $\pm \mathrm{SE}$ (water, fat, protein, mineral) from arrival at the colony through late incubation. 
egg-laying, and males during mid-incubation had lower body mass and ash than males first arriving at the colony (Tukey HSD tests, all $\underline{P}<0.04$ ).

Slightly different results were found for the influence of structural size and breeding stage on female fulmar body composition (Table 4.4). For body mass, fat, and protein, the best-fitting models were those with only breeding stage entering, where this parameter explained $24-62 \%$ of the variation (Table 4.4). As with males, the PC1 parameter did not differ from 0 in these models (Table 4.3). However, the best-fitting models explaining variation in mineral reserves included PC1, but these models were poor. The PC1 parameter did not differ significantly from 0 (Table 4.3), and variation explained by the models was minimal (Table 4.4). For water reserves, the best-fitting and highest weighted model was one which included only PC1, and in this case, larger females tended to have larger water reserves (Table 4.3).

Female fulmars were heavier and had larger fat reserves upon arrival at the colony than at any other period before their eggs hatched (Figs. 4.1, 4.2; Tukey HSD Tests, all $P<0.02$ ). After arrival, however, females experienced a large decline in average body mass (-19\%) and nutrient reserves to apparent seasonal minima postlaying, approximately $34 \mathrm{~d}$ after arrival (Fig. 4.2; fat: -54\%; protein: -15\%; water: $11 \%$ ), although water and protein levels were not statistically different from that of arriving females $(0.14>P>0.05)$. Mineral reserves changed little through the entire period (Fig. 4.2). 
Table 4.4. Akaike Information Criterion $\left(\mathrm{AIC}_{\mathrm{c}}\right)$ values for representative models explaining variation in female northern fulmar ( $n=40)$ plucked body mass $(g)$, as well as fat, protein, and mineral mass (g), at Cape Vera, 2003-2005. Models incorporated parameters of breeding stage (stage), body size ( $\mathrm{PCl}$ ) and two-way interaction (stage*PC1). Only candidate models of the $90 \%$ confidence set (sum of $w_{i} \geq 0.90$ ) are presented.

\begin{tabular}{|c|c|c|c|c|c|}
\hline Model & RSS & $K$ & $\Delta \mathrm{AIC}_{\mathrm{c}}$ & $w_{i}^{c}$ & $R^{2}$ \\
\hline \multicolumn{6}{|c|}{ Plucked Body Mass } \\
\hline Stage & 62680.5 & 6 & 0.00 & 0.33 & 0.51 \\
\hline stage, PC1 & 58279.5 & 7 & 0.04 & 0.32 & 0.54 \\
\hline stage, stage*PC1 & 45442.2 & 10 & 0.18 & 0.30 & 0.64 \\
\hline \multicolumn{6}{|c|}{ Fat } \\
\hline Stage & 41772.2 & 6 & 0.00 & 0.76 & 0.62 \\
\hline stage, PC1 & 41152.3 & 7 & 2.36 & 0.23 & 0.63 \\
\hline \multicolumn{6}{|c|}{ Protein } \\
\hline stage & 4544.3 & 6 & 0.00 & 0.49 & 0.24 \\
\hline $\mathrm{PC} 1$ & 5682.0 & 3 & 1.06 & 0.29 & 0.06 \\
\hline stage, PC1 & 4478.8 & 7 & 2.37 & 0.15 & 0.26 \\
\hline \multicolumn{6}{|c|}{ Mineral } \\
\hline $\mathrm{PC} 1$ & 616.4 & 3 & 0.00 & 0.87 & 0.01 \\
\hline stage*PC1 & 579.3 & 6 & 5.40 & 0.06 & 0.07 \\
\hline \multicolumn{6}{|c|}{ Water } \\
\hline $\mathrm{PC} 1$ & 16770.7 & 3 & 0.00 & 0.35 & 0.14 \\
\hline stage* $\mathrm{PC} 1$ & 14111.5 & 6 & 0.97 & 0.21 & 0.28 \\
\hline stage, stage*PC1 & 10364.5 & 10 & 1.67 & 0.15 & 0.47 \\
\hline stage & 14539.0 & 6 & 2.17 & 0.12 & 0.25 \\
\hline stage, PC1 & 13592.6 & 7 & 2.43 & 0.10 & 0.30 \\
\hline
\end{tabular}




\section{Time allocation in breeding fulmars}

Breeding fulmars differed in their allocation of time to most activities depending on the stage of the breeding season (Fig. 4.3), though my sample sizes were small. Fulmars spent similar proportions of time adjusting (mean $5 \pm 1 \% ; K W_{50}=2.4, P=0.65$ ) and vigilant $\left(13 \pm 3 \% ; K W_{50}=2.4, P=0.67\right)$ at all stages. However, time spent resting $\left(69 \pm 4 \% ; K W_{50}=12.8, P=0.013\right)$, pair bonding $\left(5 \pm 1 \% ; K W_{50}=20.8, P=0.0003\right)$ housekeeping $\left(2 \pm 1 \% ; K W_{50}=19.5, P=0.0008\right)$ and in agonistic interactions $(5 \pm 1 \%$; $\left.K W_{50}=17.6, P=0.0014\right)$ differed significantly from arrival through to hatching. These differences appeared to be attributable principally to time allocation by fulmars during the ARRIVE stage. Fulmars spent statistically similar amounts of time in each activity during the PRE-LAYING, POST-LAYING, LATE and HATCH stages (Fig. 4.3; Dunn's Multiple Comparison test, $P>0.05$ ). In contrast, they spent more time courting and housekeeping during ARRIVE than during PRE-LAYING or LATE incubation (Dunn's Multiple Comparison Test, all $P<0.05$ ), more time housekeeping during ARRIVE than HATCH $(P<0.05)$, and more time in agonistic interactions during ARRIVE than during PRE-LAYING $(P<0.001)$. Fulmars also spent less time resting during ARRIVE than during PRE-LAYING $(P<0.05)$.

\section{Discussion}

Warham (1990) noted that petrels and penguins were common, sympatric seabirds of the Southern Hemisphere, yet he suggested that penguins were capital breeders, arriving at the colony fat and ready to lay eggs, whereas petrels were income 


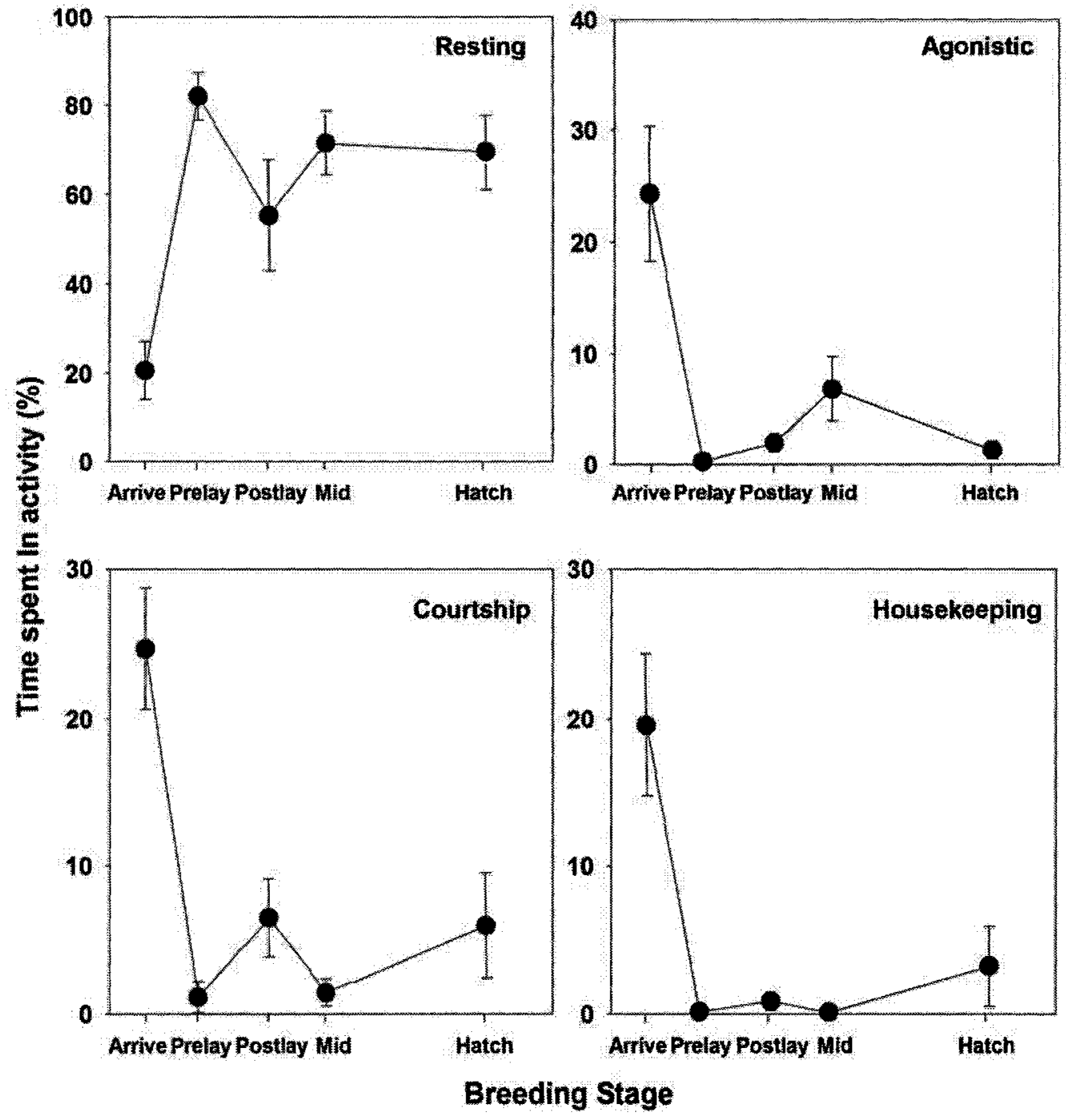

Figure 4.3. Time allocation (\%) by northern fulmars (both sexes) to resting, agonistic interactions, pair bonding, and housekeeping at the nest, from arrival at the colony through late incubation. 
breeders, requiring the pre-laying exodus to gather exogenous resources for egg production and incubation. We now know that most birds employ energetic strategies for breeding somewhere along a continuum between capital and income approaches, as researchers find increasing evidence of mixed capital/income breeding strategies (e.g., Gauthier et al. 2003, Klaassen et al. 2006). I suggest that northern fulmars are not "income breeders", as many petrels have been considered, but that they also reside along this capital/income continuum, at least for some breeding locations. Importantly, fulmars in High Arctic Canada arrived at the colony with the largest fat reserves of the breeding season. Even after returning from the pre-laying exodus, males had 35\% less fat and females had 50\% less fat (including fat deposited in the egg) than when they arrived at the colony a month earlier (Chapter 2). That fulmars returned to lay their egg or initiate incubation in poorer condition than when they first arrived at the colony suggests that energetic strategies are not easily designated for this group of seabirds (as found in Arctic shorebirds; Klaassen et al. 2001).

Even within species, actual strategies of managing energetic reserves may be flexible (e.g., Gauthier et al. 2003, Bêty et al. 2004). For example, fulmars at Cape Vera arrived at the colony fat, heavy, and with stored water supplies, whereas Alaskan fulmars during pre-laying were not as heavy on arrival as during egg-laying and early incubation (Fig. 8 in Hatch 1990; although sample sizes were small in both studies). High Arctic fulmars lack the short, refueling opportunities afforded other fulmar colonies during pre-laying because sea-ice cover remains extensive at this time, resulting in a comparatively short window of breeding opportunity. In the 
period between arrival of both members of the pair and departure of the first member for the exodus (almost always the female), I saw both mates at the nest $93 \%$ of 340 daily nest checks for pairs that subsequently laid an egg (M. L. Mallory, unpubl. data). Indeed, survey data suggest that fulmars probably leave much of the High Arctic altogether during the exodus, perhaps moving more than $1500 \mathrm{~km}$ away to feed (McLaren 1982). Moreover, unlike fulmars at more southern colonies, High Arctic fulmars must dig snow from their nest site (Hatch and Nettleship 1998, this study), possibly to help ensure that the site is snow-free upon their return from the exodus. High Arctic fulmars appear to address these constraints by arriving at the colony with proportionately larger reserves, and then fast, thereby avoiding the need for refueling trips before the exodus.

There are three likely reasons why High Arctic fulmars need large reserves at the time of arrival. First, fulmars spent approximately $70 \%$ of their time aggressively interacting with other birds, pair bonding (including copulating), or digging through the snow while paired at the nest just after arrival. There are no energetic estimates for the cost of these activities for fulmars, but it seems reasonable to assume that using their feet to dig through snow requires considerable energy, as would the activities other than resting (Weathers et al. 1984). Fulmars walk awkwardly on land (Hatch and Nettleship 1998), and walking is energetically-costly in other seabirds (Ellis and Gabrielsen 2002). Chastel et al. (1995) used a similar argument for the importance of early body condition and time allocation during pre-laying in blue petrels Halobaena caeruelea, a species that digs a burrow. I propose that Arctic 
fulmars would need larger energetic reserves than Boreal fulmars to effectively prepare and defend their nest, particularly because Arctic fulmars are constrained by a lack of nearby food supplies.

Second, weather conditions during the arrival and pre-laying periods of Arctic fulmars are cold, ranging between $-18^{\circ} \mathrm{C}$ to $-5^{\circ} \mathrm{C}$ (M. L. Mallory, unpubl. data). Although fulmars are well-adapted to the cold, at these temperatures they use more energy thermoregulating (Gabrielsen et al. 1988) than birds at warmer colonies in the species' range. For example, ambient temperatures at Alaskan colonies average approximately $5^{\circ} \mathrm{C}$ in May (http://www.wunderground.com), and as such fulmars in the High Arctic would use roughly twice as much energy at the same time of year, just staying warm (Fig. 2 in Gabrielsen et al. 1988).

Third, the markedly seasonal production of marine food supplies at high latitudes is low early in the year, until temperatures and ice break-up initiate the pulse of high planktonic production (Welch et al. 1992). With food scarce or distant, fulmars would need more time to acquire sufficient reserves to replenish energy stores. Indeed, the fulmar exodus at Cape Vera is $43-149 \%$ longer than reported for colonies in the North Atlantic or Alaska (Chapter 2). I believe that male and female High Arctic fulmars experience different, sex-specific pressures on their breeding schedule, against which they balance their time allocation and management of endogenous reserves for successful reproduction during this period of low food supplies. 
I postulate that paired females require large endogenous reserves on arrival at the colony to fuel early season activities at the nest, to provide fat and protein for egg production, and probably to fuel much of their search for calcium-rich prey or specific fats during the exodus (Chapter 3). Males arrive at the colony before females, spend approximately $3 \mathrm{~d}$ longer there (presumably digging and defending the nest site), depart on an exodus which is $5 \mathrm{~d}$ shorter than the female (Chapter 2), and then return to take the longest, first incubation shift reported in this species $(\sim 10 \mathrm{~d}$; Chapter 6). For males, therefore, the energetic demands from arrival through the end of the first incubation shift are undoubtedly greater than experienced by male fulmars at southern colonies. With few opportunities to replenish body nutrient supplies, it would be a clear advantage to arrive with large endogenous reserves.

My results on fulmarine petrels shows some similarities to work done on larids. For example, male great black-backed gulls (Larus marinus) also lose considerable mass, fat and protein between pre-breeding and egg-laying like male fulmars, but female gulls increase in body mass, in part due to feeding by the male (Mawhinney et al. 1999). This was interpreted as a result of more intense behaviour by the male (territorial defense, courtship, feeding) compared to the female during the pre-laying period. In fulmars, activities while at the nest appear to be equally intense and shared (i.e., both members of the pairs were observed engaged in all of the activities). However, the male arrives at the nest earlier and leaves later in most pairs, and thus may have more "up-front" investment in the clutch than the female (Mawhinney et al. 1999). As well, the male may compensate somewhat for the 
female's investment in egg production by spending more time incubating the clutch (Chapter 2). Thus, endogenous reserve and behavioural data are consistent with Hatch's (1990:97) statement that "In fulmars, the major differences between the sexes appear to be in the timing and form of parental investment, rather than the total amount."

My study is not the first to show that early season body mass (or in this case, endogenous nutrient reserves) is important for breeding petrels. The relationship between pre-laying body condition and reproductive success has been noted in other species, including grey-headed, Diomedea chrysostoma, and black-browed albatrosses, D. melanophris (Prince et al. 1981), and snow petrels, Pagodroma nivea (Barbraud and Chastel 1999). In those and other studies, it has been suggested that better pre-laying body condition helps birds deal with unpredictably poor annual food supplies (i.e., environmental stochasticity). However, at Cape Vera, the low availability of food early in the season is highly predictable, and makes it imperative that fulmars arrive with large endogenous nutrient reserves to be able to meet their energetic demands until the sea-ice breaks up and a pulse of marine productivity provides abundant food resources during incubation and chick-rearing. In other petrels, the decision to breed may be influenced by pre-breeding body condition, that is, there may be a threshold body condition, which, if not attained, may lead birds to skip breeding (e.g., Chastel et al. 1995). I currently lack a sufficient population of marked birds to assess whether such a threshold exists in Arctic fulmars. 
Northern fulmars of the Canadian High Arctic arrive at their breeding colonies with large endogenous reserves (i.e., energetic capital), a breeding strategy required to deal with the low marine production, cold temperatures, and a compressed prelaying period afforded them at these locations. They then depart on their exodus to acquire other resources for breeding (i.e., energetic income). Climate amelioration is underway in the Arctic marine system (ACIA 2004), and fulmars can respond positively to changes in climate-mediated sea-ice conditions (Gaston et al. 2005). I expect that in the future, High Arctic fulmars may be able to initiate breeding with somewhat smaller endogenous reserves than appear to be required at present, as reductions in annual sea-ice will allow for the bloom of more abundant prey earlier in the breeding season. 


\section{CHAPTER 5}

\section{Flexible incubation rhythm in northern fulmars: a comparison between oceanographic zones}

This chapter formed the basis for the following publication:

Mallory, M. L., A. J. Gaston, M. R. Forbes, H. G. Gilchrist, B. Cheney, S. Lewis, and P. M. Thompson. 2008. Flexible incubation rhythm in northern fulmars: a comparison between oceanographic zones. Marine Biology 154: 1031-104. 


\begin{abstract}
Variation in the timing and abundance of marine food resources is known to affect the breeding behaviour of many seabirds, constraining our understanding of the extent to which these behaviours vary in different parts of a species' range. I studied the incubation shifts of northern fulmars (Fulmarus glacialis) breeding at two colonies in Arctic Canada (High Arctic oceanographic zone) and one colony in the United Kingdom (Boreal oceanographic zone) between 2001-2005. Fulmars in Arctic Canada had longer incubation shifts than previously reported at more southern colonies, presumably because marine productivity is lower early in the breeding season in the Arctic. Shift durations were particularly long at one colony in years with abnormally late, extensive sea-ice cover, although at the other Arctic colony, where sea-ice cover is predictably late every year, the duration of shifts was shorter than expected. At the Boreal colony, incubation shifts were much longer than expected, similar to Arctic colonies, and likely attributable to poor marine food supplies in the North Sea in recent years. Collectively, these data suggest that fulmars can adjust their incubation rhythm to compensate for poor marine feeding conditions, although this may incur a cost to body condition or reproductive success.
\end{abstract}




\section{Introduction}

Oceans exhibit a variety of natural cycles and anthropogenic stressors that induce changes in marine food webs (Aebischer et al. 1990, Pauly and Maclean 2003, ACIA 2004, Frederiksen et al. 2006). One way to track these effects is to monitor seabirds, which are often regarded as effective indicators of the condition of marine ecosystems (Cairns 1987, Furness and Camphuysen 1997, Frederiksen et al. 2007). Because these birds rely on resources from the ocean, changes in marine productivity or specific food supplies may be detected by monitoring seabird reproduction. For example, in response to local reductions in marine food supplies, breeding seabirds may exhibit lower colony attendance, fewer breeding attempts, delayed egg-laying, reduced clutch or egg size, reduced reproductive success, or altered behaviour during breeding (e.g., Schreiber 2002, Frederiksen et al. 2006). Even when marine conditions are "normal", aspects of seabird breeding behaviour may differ between colonies where the type, distribution, and availability of principal prey items differ (e.g., Lewis et al. 2004a, 2006, Wilson et al. 2005). Therefore, in situations where annual marine food supplies differ predictably, we might expect to see concordant differences or local adaptation in the typical behaviour of seabird conspecifics at their colonies.

One aspect of breeding behaviour that should be sensitive to food availability is the incubation rhythm of nesting pairs. For pelagic seabirds, and notably the petrels, incubation behaviour has been well-studied (Warham 1990). Incubation is energetically-demanding for petrels, with one mate losing 2-20\% of its body mass 
during an incubation shift (e.g., Warham 1990, Chaurand and Weimerskirch 1994, Chastel et al. 1995), while the other mate may travel long distances to find sufficient food to replenish energy stores before returning to the nest (Chaurand and Weimerskirch 1994, Weimerskirch 1995, 1998). Thus, incubation shift length is affected both by the time required to search for food and the physical condition of each mate. Reduced availability of food or increased effort to find food may result in longer incubation shifts in petrels (e.g., Johnstone and Davies 1990).

Some aspects of incubation have been studied in northern fulmars (Fulmarus glacialis), the only petrel found in the Boreal, Low Arctic and High Arctic oceanographic zones (Salomonsen 1965, Hatch and Nettleship 1998). Fulmars exhibit both individual and seasonal variation in incubation rhythms (Hatch 1990a,b). Some of this variation is likely attributable to age and breeding experience (Ollason and Dunnet 1978, Hatch 1990b), but annual conditions in the marine environment also appear to influence incubation scheduling (Hatch 1990b, Gaston et al. 2005).

I studied incubation rhythms of northern fulmars nesting at two colonies in the Canadian High Arctic, as well as one colony in temperate waters around the United Kingdom. The Arctic sites were near the northern limit of the species' breeding range, where ambient temperatures and sea-ice cover present a markedly different environment from that experienced by the majority of fulmars breeding elsewhere in the North Atlantic or North Pacific oceans (Fisher 1952). At the Arctic colonies, extensive sea-ice can cover local foraging areas until ice breaks up, requiring that fulmars travel farther and incur higher energetic costs to find open water in which to 
feed. Consequently, I predicted that fulmars in the High Arctic would typically take longer incubation shifts than fulmars breeding in the Boreal oceanographic zone, where potential foraging areas were available close by breeding colonies. Moreover, these two Arctic colonies differed in the predictability with which sea ice covered local foraging areas. At Cape Vera, fulmars had to cross $200 \mathrm{~km}$ of sea ice throughout incubation and into chick-rearing each year, before they reached open water to feed (Chapter 2). In contrast, at Prince Leopold Island, sea ice cover of surrounding marine waters varied considerably among years (Gaston et al. 2005), and typically there was open water adjacent to the colony through much of incubation. Hence I predicted that, in normal ice years, Cape Vera fulmars would have longer incubation shifts than those breeding on Prince Leopold Island, but that in years when ice conditions adjacent to Prince Leopold Island resembled those found every year at Cape Vera, shift lengths at the two colonies would be similar.

\section{Materials and Methods}

Physical data

Research was conducted at two breeding colonies in Arctic Canada (Cape Vera and Prince Leopold Island) in the High Arctic oceanographic zone, and one colony in the UK (Eynhallow, Orkney) in the Boreal oceanographic zone (Fig. 5.1). At Prince Leopold Island $\left(74^{\circ} \mathrm{N}, 90^{\circ} \mathrm{W}\right)$, field crews observed fulmar breeding ecology between 16 June - 21 August 2001, 1 June - 25 August 2002, and 31 May - 21 August 2003 (see also Gaston et al. 2005), while at Cape Vera $\left(76^{\circ} 15^{\prime} \mathrm{N}, 89^{\circ} 15^{\prime} \mathrm{W}\right.$ ), 


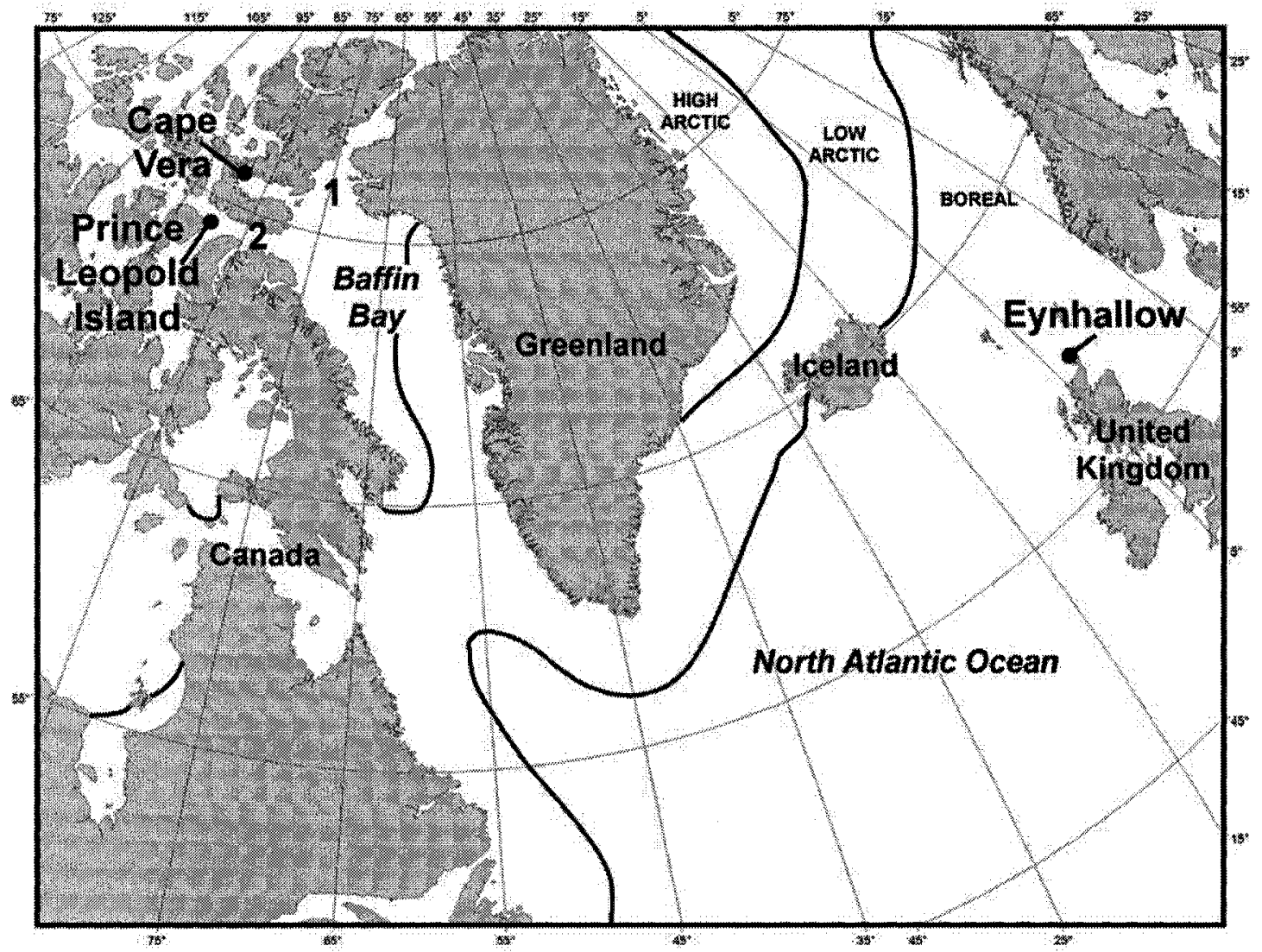

Figure 5.1. The three northern fulmar colonies examined in this study were located in Arctic Canada (Cape Vera, Prince Leopold Island) and the United Kingdom (Eynhallow). Thick lines separate the High Arctic, Low Arctic and Boreal oceanographic zones (after Salomonsen 1965). In Arctic Canada, the North Water Polynya is indicated by "1" and Lancaster Sound is shown by " 2 ". 
northern Devon Island, observations were made during 26 May - 22 August 2003, 14 May - 9 August 2004, and 20 April -10 August 2005 (incubation data were collected only in 2005). On Eynhallow (59 $08^{\prime} \mathrm{N}, 3^{\circ} 08^{\prime} \mathrm{W}$ ) research on breeding ecology has been conducted since 1950 (Dunnet 1991, Thompson and Ollason 2001), but specific research on incubation was carried out from 3 June - 8 July 2003, 30 May - 14 July 2004, and 18 May - 8 July 2005.

At Cape Vera, nearby Jones Sound remains ice-covered from October through July of the following year, although there is open water immediately beside the colony in the Hell Gate - Cardigan Strait Polynya (Smith and Rigby 1981). However, breeding fulmars at Cape Vera do not feed in the local polynya, and instead fly to foraging areas $>200 \mathrm{~km}$ to the east (Mallory et al. 2008). Prince Leopold Island is at the junction of Parry Channel (Lancaster Sound and Barrow Strait) and Prince Regent Inlet. Ice typically covers this region from October through at least April of the following year, but the annual extent of ice cover varies substantially (Gaston and Nettleship 1981, Gaston et al. 2005). Both colonies are situated on extensive, sedimentary cliffs rising to $300 \mathrm{~m}$ or more above sea level, with the majority of fulmars nesting along the upper third of the cliff faces (Gaston et al. 2006). Waters around Eynhallow are ice-free throughout the year, and potential open water foraging areas are found $<1 \mathrm{~km}$ from nest sites that are found among the grassy turfs, old buildings and low lying cliffs around the island (Dunnet et al. 1963). Approximate colony sizes during the study period were 11,000 apparently occupied sites (AOS) at Cape Vera and 22,000 AOS at Prince Leopold Island (Gaston et al. 2006). In both 
cases the nearest fulmar colonies were $>100 \mathrm{~km}$ away. Eynhallow formed a much smaller colony ( $\leq 125$ breeding pairs), but was one of many local colonies within the Orkney archipelago where $>90,000$ AOS occurred within $50 \mathrm{~km}$ of the study site in 2000 (Mitchell et al. 2004).

I used weather data collected at the Resolute Bay airport weather station (approximately $125 \mathrm{~km}$ west of both Arctic field sites;

http://www.weatheroffice.ec.gc.ca; accessed 24 January 2008) as indicative of general weather conditions near the Arctic colonies during incubation. Summary data for Eynhallow were acquired from the North Isles Weather Archive http://www.northisles-weather.co.uk (accessed 24 January 2008). Ice conditions near the Arctic colonies were obtained from the Environment Canada - Canadian Ice Service climate archives http://ice-glaces.ec.gc.ca (accessed 24 January 2008).

\section{Biological data}

Northern fulmars are long-lived, monogamous petrels that lay a single egg, and do not replace the egg if it is lost (Hatch and Nettleship 1998). At the Arctic colonies, fulmars are polymorphic for plumage colour, with birds ranging in colour on the head and body from pure white to dull slate grey, as well as differing in bill markings (Hatch and Nettleship 1998). Consequently, individual members of a pair could be distinguished if pair members were of contrasting morphs. The presence of these distinguishable pairs was identified at the start of each season by observing both pair members together at the site. Once identified, the colour morph of the sitting 
bird was recorded each day during breeding checks, allowing me to detect incubation changeovers to within \pm 1 day. If an exchange took place during a period when $>1$ day elapsed between observations (due to inclement weather), the exchange was estimated to have taken place half way between the two observations. Data were not used if $>3$ days had elapsed between observations.

At the Boreal colony on Eynhallow, all birds were light-phase morphs, but approximately $60-70 \%$ of study pairs could be distinguished visually from colour rings that had been applied previously (see Dunnet 1991). Most data were collected in the 2004 season, when daily breeding checks allowed me to detect incubation changeovers to within \pm 1 day. The incubation patterns of a subset of these birds were also recorded using data loggers (Francis Scientific Instruments, Cambridge, UK) following the procedures outlined in Weimerskirch et al. (2001). Briefly, both pair members had been captured on the nest in a previous breeding season and had a small transponder ("PIT tag") attached to a metal leg band. A loop antenna connected to a data logger was placed around the nest, and whenever the bird returned to or left the nest in subsequent seasons, the data logger recorded its arrival or departure. This provided precise measurements of times spent on and off the nest by each member of a smaller sample of pairs. Where gaps occurred in the visual sighting records, exchanges were assumed to have taken place half way between the detections of the two pair members.

For some years and colonies, monitoring of nest attendance was begun shortly after birds had initiated incubation. I wanted to maximize use of these data but 
minimize bias associated with using incomplete incubation schedules (e.g., due to having only partial, first incubation shifts by the male). Thus, I used the approach of Gaston et al. (2005) and analysed a sub-sample of shifts, specifically those that were in progress at 10-day intervals preceding the date of hatching (date of hatching for sites where eggs did not hatch was estimated as the median for the year concerned). Analysis of incubation shift duration was based on a maximum of four shifts for each nest from each study region: those in progress $30,20,10$ and 0 days before hatching.

Data on body mass were also collected at Arctic sites to explore the effects of inter-annual variation in incubation schedules. In each year at Prince Leopold Island, and in 2003 and 2004 at Cape Vera, fulmars were captured using noose poles. At this time, fulmars were weighed $( \pm 10 \mathrm{~g})$ and measured $( \pm 0.1 \mathrm{~g})$, and gender was ascertained either through morphometrics or dissection (for further details of methods, see Gaston et al. 2005, Mallory and Forbes 2005). I used body mass of fulmars measured during incubation (June or July) to compare mass among years and colonies. Body mass data from the incubation period were not available from Eynhallow.

To analyse incubation parameters of fulmars, I used $F$-ratio tests, ANOVAs (with Tukey-Kramer Multiple Comparisons tests), and Kruskal-Wallis tests (with post-hoc Dunn's Multiple Comparisons tests), depending on whether data could be square-root transformed to approximate normal distributions (Kolmogorov-Smirnov tests; GraphPad Software 1998). Sample coefficients of variation (CoV) and their 
standard errors were calculated and compared with Levene's test, according to Sokal and Braumann (1980). All means are presented \pm 1 SE.

\section{Results}

Weather

During the typical incubation period (approximately 6 June to 25 July at Arctic colonies), the mean daily temperature over five years (2001-2005) was $2.3 \pm 0.2^{\circ} \mathrm{C}$ $\left(\mathrm{n}=255\right.$ days, range $-7.3^{\circ} \mathrm{C}$ to $\left.12^{\circ} \mathrm{C}\right)$. In the same years, the position of open water near the colonies differed greatly. In the first week of July (half way through incubation), fulmars at Cape Vera had to fly $188 \pm 6 \mathrm{~km}(\mathrm{CV} 7 \%)$ over sea ice to reach open water in the North Water Polynya, whereas at Prince Leopold Island, fulmars had to fly $15 \pm 70 \mathrm{~km}$ (CV 139\%). The annual variation in ice position was significantly higher at Prince Leopold Island ( $F$-ratio test, $F_{8}=60.3, P=0.0008$ ). At Eynhallow in 2004 and 2005 , mean daily temperatures were approximately $9^{\circ} \mathrm{C}$ warmer than at the Arctic sites $\left(10.0^{\circ} \mathrm{C}-11.9^{\circ} \mathrm{C}\right.$, similar to the 30 year average).

\section{Incubation}

Pooling data within colonies for all years, typical incubation shift duration differed among sites $(K W=33.9, P<0.0001)$, with the mean duration of incubation shifts from the one season at Cape Vera ( $5.7 \pm 0.2$ days, median 6 days, $n=152$ shifts) being significantly shorter than for three seasons at Prince Leopold Island ( $7.5 \pm 0.2$ days, median 8 days, $n=272$; Dunn's Multiple Comparisons Test, $P<0.001$ ) or three 
seasons at Eynhallow ( $6.8 \pm 0.4$ days, median 7 days, $n=69 ; P<0.05)$. However, there was clearly annual variation within sites (Fig. 5.2). Using colony-years for which I had measurements of $\geq 50$ incubation shifts, mean shift duration differed among the Cape Vera (2005), Prince Leopold Island (2001-2003) and Eynhallow (2004) colonies among years $(K W=143.6, P<0.0001$; Table 5.1). In 2002, mean incubation shifts undertaken by fulmars at Prince Leopold Island were longer than in any other year (Table 5.1; Dunn's Multiple Comparisons test, $P \mathrm{~s}<0.001$ ). Mean incubation shift length at Eynhallow in 2004 was similar to that at Cape Vera or at Prince Leopold Island in $2001\left(P_{\mathrm{S}}>0.05\right)$, but was longer than was found at Prince Leopold Island in $2003(P<0.01)$. In 2003, 20\% of the fulmar incubation shifts at Prince Leopold Island lasted $\leq 2$ days, compared to 4 and $1 \%$ of the shifts recorded in 2001 and 2002, respectively. At Cape Vera in $20059 \%$ of shifts were $\leq 2$ days, and at Eynhallow in 2004, 14\% of shifts were $\leq 2$ days.

Using only data for Prince Leopold Island and Eynhallow (i.e., those years approximating normal distributions), fulmars exhibited higher variability in incubation shift duration at Eynhallow ( $\mathrm{CoV} 43 \pm 5 \%)$ and Prince Leopold Island (2003) (48 $\pm 4 \%)$ than at Prince Leopold Island in $2001(31 \pm 3 \%)$ or $2002(30 \pm 3 \%)$, although these differences were not statistically significant (Levene's test; $F_{3,319}=$ $1.97, P=0.11$ ). The longest incubation shift recorded at both Cape Vera and Eynhallow was 14 days, whereas one shift lasted 18 days at Prince Leopold Island in 2002. 


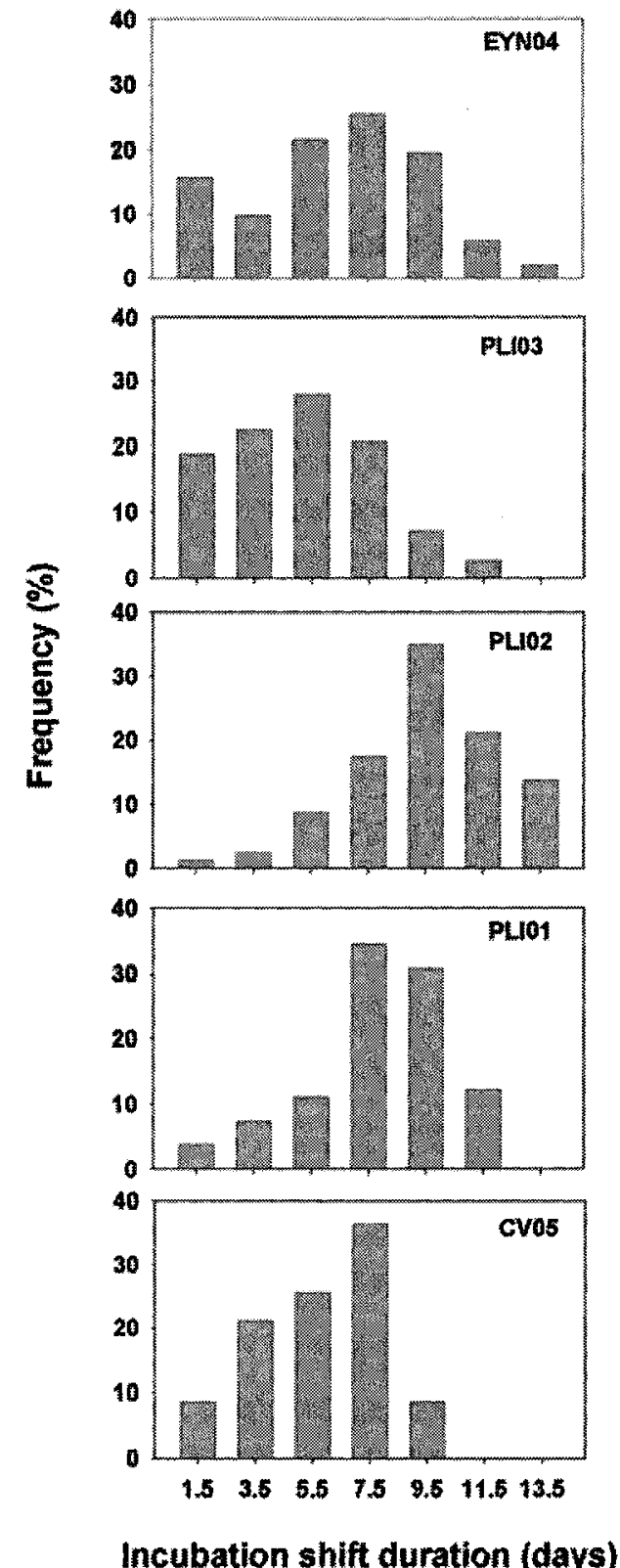

Figure 5.2. The distribution of incubation shift durations differed among years and colonies at Cape Vera (CV05), Prince Leopold Island (PLI01, PLI02, PLI03) and Eynhallow (EYN04). 
Table 5.1. Characteristics of incubation shifts reported for northem fulmars in relation to colony location and oceanographic zone.

"HA" refers to High Arctic and " $B$ " refers to Boreal for oceanographic zones.

\begin{tabular}{cccccccc}
\hline Location (year) & Oceanographic & Colony size & \multicolumn{3}{c}{ Incubation shift (days) } & \multicolumn{2}{c}{ Reference } \\
\cline { 6 - 8 } & zone & (AOS) & Mean (SE) & N (shifts) & Min & Max \\
\hline Cape Vera, Canada (2005) & HA & 11000 & $5.7(0.2)$ & 152 & 1 & 14 & 1 \\
Prince Leopold Island, Canada (2001) & HA & 22000 & $8.0(0.3)$ & 81 & 2 & 12 & 1 \\
Prince Leopold Island, Canada (2002) & HA & 22000 & $9.9(0.3)$ & 80 & 2 & 18 & 1 \\
Prince Leopold Island, Canada (2003) & HA & 22000 & $5.3(0.2)$ & 11 & 1 & 12 & 1 \\
Mallemukfjeld, Greenland (1993) & HA & 1400 & $6.1(0.4)$ & 81 & 1 & 13 & 2 \\
Eynhallow, UK (2003) & B & 90000 & $8.8(1.6)$ & 7 & 2.5 & 13.8. & 1 \\
Eynhallow, UK (2004) & B & 90000 & $7.0(0.4)$ & 51 & 1.6 & 13.5 & 1 \\
Eynhallow, UK (2005) & B & 90000 & $5.0(0.8)$ & 12 & 0.9 & 11.2 & 1 \\
Fair Isle, UK (1952) & B & 28000 & $2.8(0.3)$ & 56 & 0.3 & 8.7 & 3,4 \\
Sands of Forvie, UK (1966) & B & 6400 & $3.7(0.2)$ & 71 & 1 & 11 & 5,6 \\
Foula, Unst, UK (1998, 1999)* & B & & 1.5 & & & 1 & 7 \\
Semidi Islands, Alaska (1976-1981) & B & 220000 & $4.6(0.02)$ & 6954 & 1 & 16 & 8 \\
\hline
\end{tabular}

* $<50 \%$ of the incubation period of breeding fulmars was recorded in this study

1-This study, 2-Falk and Moller (1995a), 3 - Willamson 1952,4 - Shaw et al, 2002,5 - Mougin 1967,6 - Mitchell et al, 2004, 7

- Ojowski et al. 2001; 8-Hatch 1990a 


\section{Body mass at Arctic colonies}

Body mass of incubating male fulmars differed among colony-years at Cape Vera and Prince Leopold Island (ANOVA, $F_{4,92}=8.7, P<0.0001$; Fig. 5.3). Mean mass of males at Prince Leopold Island in $2003(859 \pm 25 \mathrm{~g})$ was significantly heavier than males at that colony in $2001(714 \pm 19 \mathrm{~g}$; Tukey-Kramer, $P<0.001)$ or $2002(754 \pm$ $11 \mathrm{~g} ; P<0.05)$. Males at Cape Vera in $2004(812 \pm 17 \mathrm{~g})$ were also heavier than Prince Leopold Island males in $2001(P<0.01)$. Among female fulmars, incubation body mass also differed among colony-years $\left(F_{4,62}=7.7, P<0.001\right)$. Like males, body mass of females at Prince Leopold Island in $2003(726 \pm 12 \mathrm{~g})$ was higher than females in $2001(620 \pm 20 \mathrm{~g} ; P<0.01)$ or in $2002(634 \pm 13 \mathrm{~g} ; P<0.001)$. Also, female fulmars at Cape Vera in 2003 were heavier $(731 \pm 24 \mathrm{~g})$ than Prince Leopold Island females in 2001 or $2002\left(P_{\mathrm{S}}<0.01\right)$.

\section{Discussion}

The northern fulmar exhibits a flexible incubation rhythm in response to a broad range of climatic and marine environmental conditions. For example, fulmars had a similar range of the length of incubation shifts undertaken, irrespective of whether they bred in the High Arctic (Falk and Møller 1995a, this study), Alaska (Hatch 1990a) or the UK (this study). As predicted, High Arctic fulmars took relatively longer incubation shifts than elsewhere (Table 5.1), but fulmars breeding at Eynhallow had longer incubation shifts than previously observed in Boreal fulmars breeding at sites in the Pacific (Hatch 1990a). 


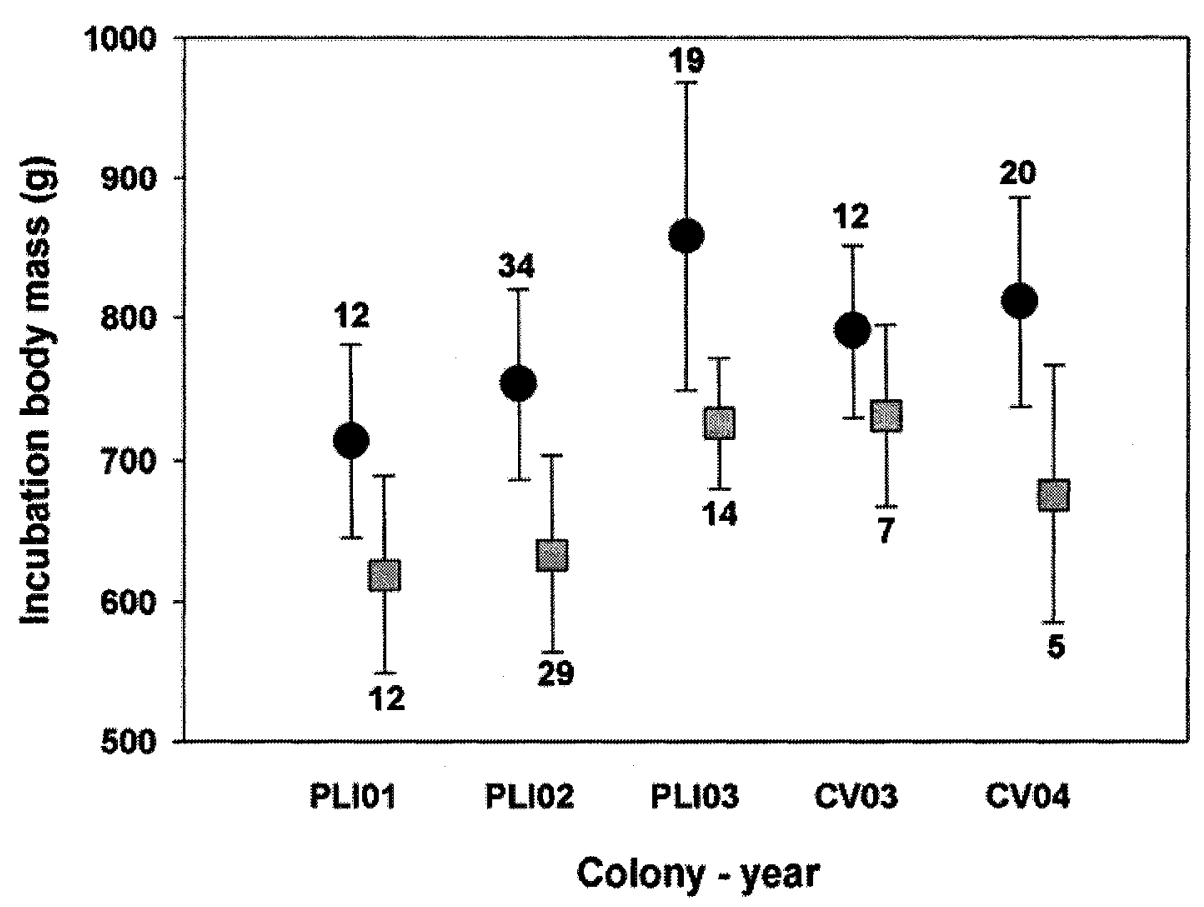

Figure 5.3. In Arctic Canada, body masses (g) of incubating male (black circle) and female (gray square) fulmars differed among colony-years at Cape Vera (CV 03, CV04) and Prince Leopold Island (PLI01, PLI02, PLI03). Sample sizes indicated above (male) and below (female) SE bars. 


\section{Incubation in the Arctic}

Most incubation shifts by fulmars breeding in the High Arctic (Cape Vera or Prince Leopold Island) lasted $\geq 5.3$ days, which was similar to the average of 6.1 day shifts found by Falk and Møller (1995a) at a High Arctic colony in east Greenland. However, during periods of extensive sea-ice at Prince Leopold Island (2001, 2002), typical shifts increased to $>8$ days, $51-185 \%$ longer than reported for any other northern fulmar colonies (shift duration determined using differing techniques; Table 5.1). I expected fulmars in the High Arctic to take longer incubation shifts for three reasons: (1) during June and much of July, many marine areas remain ice-covered in this region, so fulmars have to travel farther to find foraging habitat; (2) birds foraging in this region during incubation may experience lower marine productivity compared to birds at more southern colonies (Behrenfeld et al. 2001); and (3) Arctic fulmars cannot rely on fisheries discards, that were believed to have been important food source in Boreal waters (Fisher 1952, but see also Phillips et al. 1999, Thompson 2006). Importantly, marine productivity has a strong influence on seabird reproductive success (Frederiksen et al. 2007). Thus, as suggested by Falk and Møller (1997), it probably requires more foraging time and effort for High Arctic fulmars to find sufficient food to replenish energy reserves and undertake the next incubation shift (even though they operate in 24-hr daylight), compared to Boreal fulmars. However, the $2.3-4.3$ day difference in mean shift duration between fulmars at Cape Vera and Prince Leopold Island in some years was surprising, and counter to my predictions. 
Fulmars at Cape Vera during a "typical" ice year faced a similar distance of sea-ice to cross as fulmars at Prince Leopold Island in extensive ice years, which is why I expected fulmars at Cape Vera to have relatively long shifts. However, the duration of their shifts averaged approximately one half day longer (but not statistically different) than shifts at Prince Leopold Island during a year when open water was close to that colony (2003), and incubation body masses in these colonyyears were similar. This suggests that routinely traversing $200 \mathrm{~km}$ of sea-ice to reach potential feeding sites may not impose an abnormally increased energetic cost for fulmars, unlike sympatric Arctic seabirds (Gaston et al. 2005). Fulmars can fly hundreds of kilometers to feed (Falk and Møller 1995, Mallory et al. 2008) and 200 $\mathrm{km}$ represents only a $4 \mathrm{hr}$ flight under calm conditions (Hatch and Nettleship 1998). Such a flight would be even faster and consume less energy with some wind (Furness and Bryant 1996), and wind is almost always present at these colonies (Gaston and Nettleship 1981).

Instead, I interpret these differences in incubation shift duration as local adaptation by fulmars at Cape Vera to predictable conditions, compared to environmental stochasticity at Prince Leopold Island. Annually at Cape Vera, birds can rely on a similar travel distance to open water near the North Water Polynya, a productive, ice-free region which recurs every year due to the physical oceanography of that marine area (Smith and Rigby 1981). Because age and experience play a dominant role in reproductive success (Ollason and Dunnet 1978), experienced, breeding fulmars at Cape Vera could sustain a schedule of relatively long incubation 
trips and maintain suitable body condition provided they can access distant but predictable foraging areas (Brown and Nettleship 1981, Weimerskirch et al. 1997).

In contrast, sea ice conditions are quite variable at Prince Leopold Island (Gaston et al. 2005), with 70\% of the years between 1996 and 2005 having open water immediately adjacent to the colony in mid-incubation. However, in the three years when the sea-ice was late and extended east through Lancaster Sound, approximately $13,000 \mathrm{~km}^{2}$ of ice-free ocean were unavailable for foraging compared to years when the ice edge was at the island. In three years when the sea-ice was 150 $\mathrm{km}$ west of the island, an additional $10,000 \mathrm{~km}^{2}$ of foraging habitat was available. Perhaps more importantly, Lancaster Sound is undoubtedly more productive in years when ice breaks up earlier, allowing sea surface temperatures to warm and light to penetrate, stimulating primary production (Welch et al. 1992). That incubation shifts were longer in extensive ice years suggests that at least some fulmar pairs had the behavioural flexibility and body reserves to withstand these conditions, although there appeared to be a cost to the parents in terms of reduced body condition (Fig. 5.3). Nonetheless, Gaston et al. (2005) noted higher egg neglect during incubation in 2001 and 2002, suggesting some birds had to abandon nests during an incubation shift before their mate returned. This was rarely observed in two years at Cape Vera, but has been observed commonly amongst Boreal fulmars in recent breeding seasons on Eynhallow (P. M. Thompson, unpubl. data).

Gaston et al. (2005) also showed that the reduced reproductive success in 2001 and 2002 came principally through reduced fledging success. However, late or 
extensive sea ice might not always result in poor reproductive success for fulmars. In 2001 , the reduced success was attributable principally to late season snowstorms that killed chicks (Gaston et al. 2005), which can happen in any year. In 2001, thickbilled murre (Uria lomvia) reproductive parameters were below normal, but not nearly as poor as in 2002 , when they were the poorest ever recorded at this colony. Given that High Arctic fulmars can adjust incubation schedules to accommodate late ice years, rather than simply abandoning reproduction as would be expected if the chances of breeding successfully were predictably low (Trivers 1972, Chaurand and Weimerskirch 1994), I suspect that marine production was dramatically low in 2002, perhaps because of two consecutive, late ice years, resulting in marginal feeding conditions (e.g., Reid and Croxall 2001).

In addition to individual variation in incubation behaviour (Hatch 1990b), I suggest that fulmars breeding at Prince Leopold Island are predisposed to exploiting nearby feeding areas in typical, open water years, whereas most fulmars at Cape Vera are forced to make long foraging trips for most of the breeding season. At Cape Vera, surveys and satellite tracking indicate that few breeding fulmars forage in the nearby polynya, presumably because it does not provide suitable quantity or quality of food resources, and instead they fly $>200 \mathrm{~km}$ to the North Water Polynya (Mallory et al. 2008). Thus, annual environmental conditions at Cape Vera constrain the behavioural options available to fulmars for incubation scheduling, whereas at Prince Leopold Island, more opportunities exist for expression of individual variation in 
incubation schedules in ice-free years, but these fulmars are severely constrained during extensive ice years.

\section{Incubation at the Boreal colony}

There are no comparable studies of fulmar incubation patterns at other Boreal colonies within the Atlantic. Instead, previous studies of nest attendance have focused on the chick rearing period, when foraging trips tend to be shorter, and are likely to be shaped by the chick's energetic requirements (e.g., Weimerskirch et al. 2001). Other work has been limited to just a portion of the incubation period (e.g., Dunnet et al. 1963, Ojowski et al. 2001) or to observations of a few pairs in a single season (Williamson 1952, Mougin 1967). The most extensive data on attendance throughout incubation by Boreal fulmars comes from Hatch's (1990a) study at a Pacific colony in Alaska. There, shifts averaged 4.6 days, and only in one of five years was the annual mean shift duration $>5.0$ days (Hatch 1990a). In my study, fulmars exhibited annual average incubation shifts of 5.0 to 8.8 days at Eynhallow, albeit on smaller datasets. Although I used slightly different techniques for calculating average shifts, my sub-sample approach meant that these averages excluded the long, first shift by the male (Hatch 1990a), and therefore these averages may be biased somewhat low. Nonetheless, average shifts on Eynhallow were markedly longer than reported by Hatch (1990a) or any other Boreal colonies, and more similar to incubation at Arctic colonies (above). 
Although the small sample sizes from Eynhallow in 2003 and 2005 provided limited power for detecting inter-annual variation in average incubation shifts, available data indicate that these longer shifts were typical through most of this study period. My observations coincide with a period when seabird reproduction at many sites around the United Kingdom was poor (Proffitt 2004, Mavor et al. 2006), an effect attributed to reduced food supplies probably induced by a combination of changing climate and fishery effects on the marine ecosystem (Frederiksen et al. $2004 b, 2006$ ). In fact, 2004 saw the lowest reproductive success recorded on Eynhallow during $>50$ years of study. Occasional, long incubation shifts seem to be a regular feature of some fulmars breeding in the Boreal zone (Mougin 1967, Hatch 1990a, this study). However, I suggest that the relatively long, average shifts observed recently at Eynhallow may represent a behavioural adjustment by the fulmars to altered or reduced food supplies, not unlike the adjustments made by fulmars breeding at Prince Leopold Island in 2001 and 2002. On Prince Leopold, this strategy was associated with reduced body condition. Further work is now required to assess whether Boreal fulmars also incur a similar cost from these long incubation shifts through changes in body condition or future reproductive or survival prospects.

\section{Colony size}

Lewis et al. (2001) found that mean foraging trip duration by northern gannets (Morus bassanus) was longer at larger colonies, probably due to density-dependent effects of competition for depleted food resources at these colonies. While fulmar 
colony size can vary greatly (Table 5.1), fulmars generally fly vast distances on incubation recesses, with trip duration measured in days, and thus are probably less susceptible to the effects of density-dependence that can influence foraging trip duration in other seabirds (Birt et al. 1987, Lewis et al. 2001, Gaston et al. 2007). In fact, using the 2003 data for Prince Leopold Island (i.e., a normal year), there was no significant relationship between mean incubation shift duration and fulmar colony size (square root transformed) where incubation rhythms have been measured (Table $\left.5.1 ; r_{7}=0.03, P=0.94\right)$. This suggests that regional or annual variation in marine food supplies probably have an overriding influence on incubation shift duration in fulmars, as suggested by Hatch (1990a), and as found by Lewis et al. (2006) in cape gannets (M. capensis).

\section{Central place foraging}

One question of interest is why foraging trips are not longer in all years, given that some fulmar pairs are capable of reproducing successfully by adjusting foraging trips for longer durations? Minimizing travel time should be advantageous for central place foragers (Orians and Pearson 1979). I suspect that in more productive years, fulmars can replenish energetic stores in trips of shorter duration, and probably reach a threshold mass enabling them to persist through a normal or even abnormally long, upcoming incubation shift. As well, efficient flight is critical for effective foraging in this species (Furness and Bryant 1996), so it also may be advantageous for breeding fulmars to maintain relatively lower body mass to improve flight efficiency (Rayner 
1999). Moreover, pairs undoubtedly derive benefits by establishing a synchronized, sustainable rhythm for both mates (Hatch 1990b), which also helps reinforce pair bonding, and which should be more attainable with shorter incubation shifts. This aspect may be critical, as age and breeding experience are the dominant factors influencing annual reproductive success in fulmars (Ollason and Dunnet 1978, Hatch 1990b).

\section{Conclusions}

This study, and the previous work by Falk and Møller (1995) suggest that the typical incubation behaviour of High Arctic northern fulmars differs from that of fulmars nesting in the southern part of the breeding range (Williamson 1952, Mougin 1967, Hatch 1990a). These differences are thought to accommodate lower marine productivity early in the breeding season, and the physical impediments posed by seaice. However, in both the Boreal and High Arctic oceanographic zones, fulmars are capable of adjusting their incubation schedules to meet variation in environmental conditions. During years of food scarcity, some pairs can lengthen incubation shifts to accommodate the increased time required to find sufficient food, a strategy accompanied by a reduction in body condition. Given that Arctic marine ecosystems are experiencing rapid changes due to global warming (ACIA 2004), including earlier breakup of sea-ice and increased sea surface temperatures, Arctic fulmars should find future marine conditions more favourable for foraging during incubation, and may respond by adopting incubation rhythms with shorter shifts, more typical of fulmars 
at southern colonies. In contrast, breeding fulmars around the UK and other North Sea coasts may in the future need to compensate for decreasing food supplies by adjusting their incubation rhythms towards a more Arctic pattern. 


\section{CHAPTER 6}

\section{Incubation scheduling by northern fulmars (Fulmarus glacialis) in the Canadian High Arctic}

This chapter formed the basis for the following publication:

Mallory, M. L. 2008. Incubation scheduling by northern fulmars (Fulmarus

glacialis) in the Canadian High Arctic. Journal of Ornithology 150: 175-181. 


\begin{abstract}
Northern fulmars (Fulmarus glacialis) are a ubiquitous seabird of the North Atlantic and North Pacific oceans, and breed at colonies surrounded by markedly different marine environmental conditions. I studied the incubation behaviour of fulmars at a remote colony in the Canadian High Arctic, where birds had to cross $200 \mathrm{~km}$ of seaice through early incubation to get to feeding areas. Fulmars completed incubation in fewer shifts and had a longer mean incubation shift duration (5.3 days) than fulmars breeding in the Boreal oceanographic zone. In particular, the mean duration of the first incubation shift by males in successful pairs (10.3 days) was 2 days longer than for males in unsuccessful pairs, and was longer than reported at any other colony. This exceptionally long shift by the male may be required at this site to give females enough time to recoup energetic reserves after egg-laying, at a time when marine productivity in the Arctic is still seasonably low.
\end{abstract}




\section{Introduction}

Patterns of incubation behaviour in birds reflect trade-offs between current reproductive effort (e.g., protecting the eggs from risk), and future survival and reproductive opportunities (e.g., self-maintenance needs of each parent; Trivers 1972). On- and off-nest activities must be scheduled so that the heat and respiration needs of the embryos are met (Drent 1975), while allowing parents to meet their own energetic requirements (e.g., Drent et al. 1985). Thus, increased investment in incubation by the parent to enhance embryonic development can only be achieved at a cost to the parent's physical condition or susceptibility to predation, and will be influenced in part by the availability of food resources during breeding (e.g., Cairns 1987, Charaund and Weimerskirch 1994).

Incubation patterns (or rhythms) have been well-studied in the Procellariiformes (petrels; Warham 1990). In this group, incubation is shared by both parents, and incubation shifts may be measured in days or weeks, due in part to the large distances petrels may have to fly to find sufficient food (Pennycuick et al. 1984, Chaurand and Weimerskirch 1994, Weimerskirch 1995). Incubation places considerable demands on petrels to manage their energetic reserves (e.g., Chastel et al. 1995). For example, in blue petrels (Halobaena caerulea) and Manx shearwaters (Puffinus puffinus), incubating birds may lose 5 and $10 \mathrm{~g} /$ day of their body mass, respectively (Harris 1966, Chaurand and Weimerskirch 1994), and petrels can lose up to $20 \%$ of their body mass compared to when an incubation shift started (Warham 1990). There also appears to be a threshold value of body condition below which a 
bird will abandon the nest even if the partner has not returned to relieve its mate (Boersma and Wheelwright 1979, Chaurand and Weimerskirch 1994). When food resources are harder to acquire, petrels may increase the length of each incubation shift (e.g., Johnstone and Davies 1990, Ojowski et al. 2001, Gaston et al. 2005). I studied incubation rhythms of northern fulmars (Fulmarus glacialis), the only petrel found in the Boreal, Low Arctic and High Arctic oceanographic zones (Salomonsen 1965, Hatch and Nettleship 1998). There is individual and seasonal variation in fulmar incubation rhythms, which may be affected in part by annual food supplies in the marine ecosystem (e.g., Hatch 1990a, b, Gaston et al. 2005). The schedule of nest attendance for the complete fulmar incubation period is known from only a few studies (Mougin 1967, Hatch 1990a, Falk and Møller 1995). I examined fulmars nesting at a remote colony at the northern limit of the species' breeding range in the Canadian High Arctic, where typical climatic and marine ice conditions present a different environment than that experienced by the majority of the North Atlantic or North Pacific fulmar populations (Fisher 1952). For this reason, I expected that fulmars would exhibit differences in incubation from fulmars elsewhere, given that the breeding schedule of fulmars at this colony differs from their southern conspecifics (Chapter 2). Earlier studies had demonstrated that Arctic fulmars took long incubation shifts (Falk and Møller 1995, Gaston et al. 2005), due either to higher energetic costs of commuting long distances over sea-ice, or reduced food availability during years of prolonged sea-ice cover. For this reason, my overall goal was to describe incubation patterns at this colony, with the expectation that these fulmars 
would have longer incubation shifts than fulmars breeding elsewhere. In particular, male fulmars take the first significant incubation shift, to allow the female to recover energetic reserves after egg-laying. Because High Arctic females take the longest pre-laying exodus recorded in this species (Chapter 2), presumably because marine food supplies are relatively limited early in the breeding season, I predicted that the first male shift at this colony would be longer than that taken by males at any other colonies.

\section{Methods}

Research was conducted between 20 April to 10 August 2005 at Cape Vera $\left(76^{\circ} 15^{\prime}\right.$ $\mathrm{N}, 89^{\circ} 15^{\prime}$ W; Fig. 2.1), Nunavut, Canada. Weather data were collected at the field site using a Davis ${ }^{\circledR}$ Vantage Pro weather station, and data on sea ice were available online from the Environment Canada - Canadian Ice Service climate archives ( $<$ http://ice-glaces.ec.gc.ca $>$ ). During the incubation period (6 June to 25 July 2005 at Cape Vera; Chapter 2), the mean daily temperature was $2.0 \pm 0.3^{\circ} \mathrm{C}(n=49$ days, range $-2.8^{\circ} \mathrm{C}$ to $7.1^{\circ} \mathrm{C}$ ). In the first week of June, open water was $190 \mathrm{~km}$ east of the colony (excluding the small polynya adjacent to the colony where fulmars do not feed; M. L. Mallory, unpubl. data). By the last week of July, the ice edge was still $110 \mathrm{~km}$ east of the colony.

Details on the physical structure of the Cape Vera fulmar colony, as well as monitoring protocols (e.g., selection of breeding pairs by plumage differences, days 
with missing data) for fulmar plots have already been described in Chapter 2. For incubation studies in 2005 , I initiated studies six weeks before egg-laying, conducted intensive, daily observations of birds, and missed few days to inclement weather. For this reason, I was able to get virtually complete records of incubation on a portion of the $>600$ fulmar nest sites monitored daily. These data were similar to those collected by Mougin (1967), Hatch (1990a) and Falk and Møller (1995), and thus the total incubation record and all incubation shifts are presented.

I defined two categories of breeding success for fulmars at Cape Vera: (a) successful breeders - fulmars at nests that produced a chick which was still alive at the post-guard stage (when both adults depart the nest to provision the chick, approximately 12-14 d after hatch; Hatch and Nettleship 1998); (b) failed breeders fulmars at nests that produced an egg, but either the egg or chick were lost.

To analyse incubation parameters of fulmars, I used $t$-tests (Welch correction) and ANOVAs (with Tukey-Kramer Multiple Comparisons tests). Note that ANOVA comparisons of shift lengths (Table 1) used values from summary data, so the distribution of data could not be tested. Because I did not have a priori expectations of the direction of differences in pairwise comparisons, I used conservative sequential Bonferroni adjustments (Rice 1989, Moran 2003) to $P$-values in Table 6.1. To describe the overall pattern of incubation shift duration through the incubation period, I calculated the standardized slope from incubation shift length regressed on shift number for each pair, and then calculated mean slope across pairs. I also separated shifts for males and females for each pair, calculated the sex-specific slopes (as 
above), and then compared male and female slopes using a Wilcoxon matched-pairs signed ranks test. Finally, I calculated the average slopes of incubation shift length through the incubation period at four colonies, and I used Kendall Tau-b nonparametric tests for trend to assess the statistical significance of those slopes (Systat Software Inc 2002). All means are presented \pm SE.

\section{Results}

\section{Incubation rhythms}

Fulmar pairs that successfully completed incubation to produce a chick had a mean incubation period of $49.0 \pm 0.2$ days (range $46-52, n=65$ ). Among successful pairs where I could distinguish males and females $(n=38$ ), males spent $56 \pm 1 \%$ (range 48 $-64 \%$ ) of their time incubating, while females spent significantly less time incubating (44 $\pm 1 \%, 35-53 \%$; Welch's $\left.t_{73}=13.3, P<0.001\right)$.

For 453 incubation shifts observed on 63 pairs, the mean shift duration was $5.7 \pm 0.1$ days (range 1-14 days; Fig. 6.1a). However, this overall mean was biased high, because it included a higher proportion of long shifts from early incubation (Table 6.1) for pairs that subsequently failed. Restricting the analysis to 355 incubation shifts of 38 successful pairs, mean shift duration was $5.3 \pm 0.2$ days (Table 6.1). In 35 of these 38 pairs (95\%), incubation shift duration (excluding the first egglaying shift by the female) declined as incubation proceeded (overall mean 

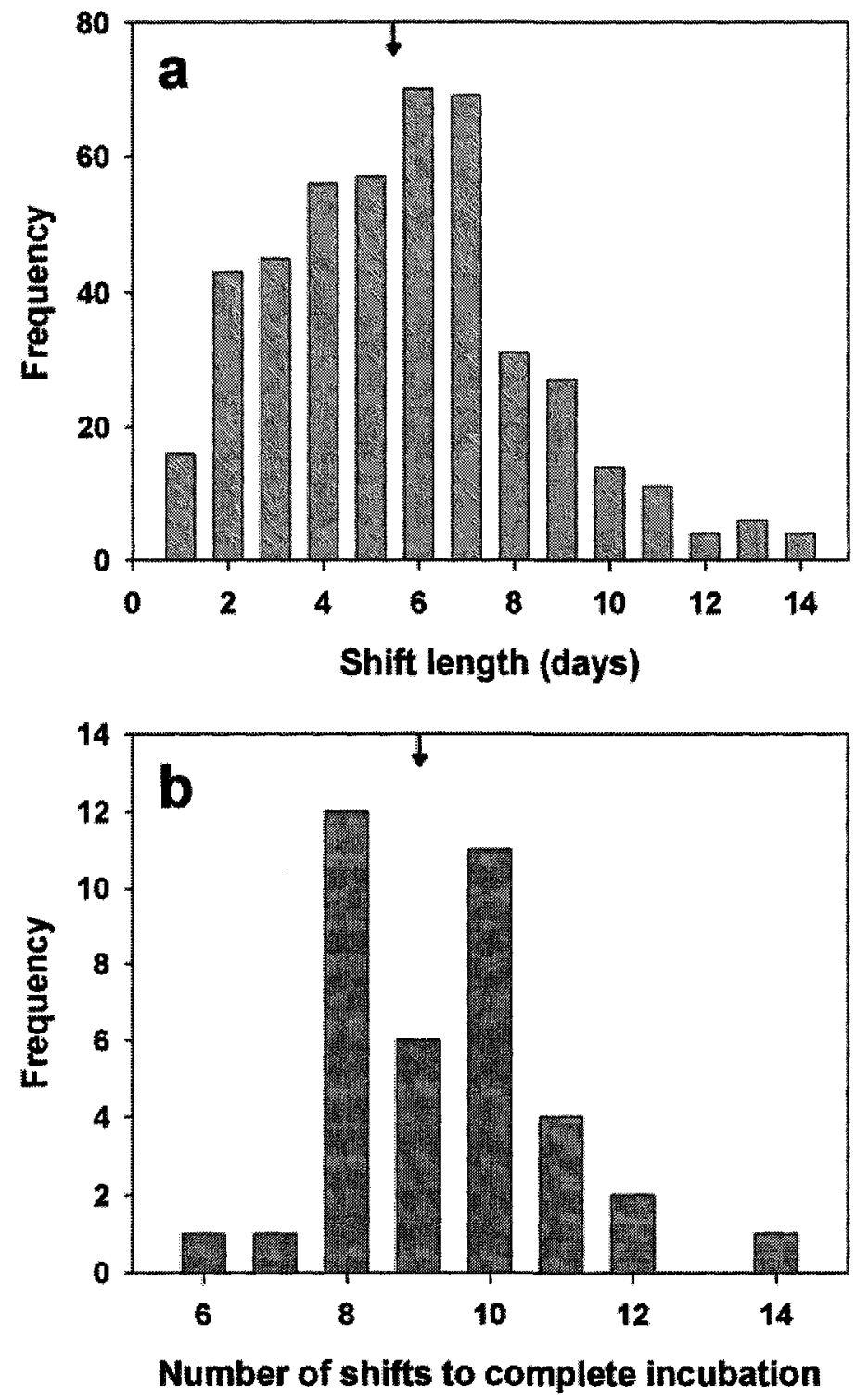

Figure 6.1. The distribution of incubation shifts in northern fulmars at Cape Vera, showing (a) the frequency of incubation shifts of different duration (days; arrow represents mean), and (b) the frequency of the required number of shifts to complete incubation (arrow represents median). 
Table 6.1. Duration of incubation shifts (days) by northern fulmars breeding at Cape Vera, Nunavit, Canada in 2005, compared to previously reported values from other studies, $P$-values followed by (ns) are considered non-significant after applying sequential

Bonferroni corrections for the number of tests, and $n$ refers to number of pairs.

\begin{tabular}{|c|c|c|c|c|c|c|c|c|c|c|c|}
\hline \multirow{2}{*}{$\begin{array}{c}\text { Incubation } \\
\text { Shift }\end{array}$} & \multicolumn{3}{|c|}{ Cape Vera } & \multicolumn{2}{|c|}{ Greenland } & \multicolumn{2}{|c|}{ Alaska } & \multicolumn{2}{|c|}{ Sands of Forvie ${ }^{3}$} & \multicolumn{2}{|c|}{ ANOVA } \\
\hline & Mean (SE) & $\mathrm{n}$ & Range & Mean (SE) & $\mathrm{n}$ & Mean (SE) & n & Mean (SE) & n & $F$ & $P^{4}$ \\
\hline 19 & $1.6(0.1)$ & 38 & $1-4$ & - & & $10(0.1)$ & 1031 & $15(0.3)$ & 6 & & \\
\hline 28 & $10.3(0.4)$ & 38 & $4-14$ & $69(0.9)$ & 9 & $54(0.1)$ & 914 & $6.8(1.1)$ & 6 & 510 & $80.001^{\mathrm{a}}$ \\
\hline 39 & $6.8(0.4)$ & 38 & $1-11$ & $63(13)$ & 7 & $43(0.1)$ & 867 & $3.7(0.5)$ & 6 & 259 & $<0.001^{\circ}$ \\
\hline 48 & $6.3(0.3)$ & 38 & $1-10$ & $4.8(1.3)$ & 9 & $49(0.1)$ & 809 & $5.0(0.8)$ & 6 & 5.9 & $<0.001^{\mathrm{c}}$ \\
\hline 59 & $59(0,3)$ & 38 & $1-9$ & $6.8(1.5)$ & 8 & $43(0.1)$ & 728 & $38(10)$ & 6 & 167 & $<0,001^{b}$ \\
\hline 60 & $5,1(0,3)$ & 38 & 18 & $83(1.4)$ & 7 & $4.8(0.1)$ & 677 & $33(0.3)$ & 6 & 10.0 & $<0001^{\circ}$ \\
\hline 79 & $4.8(0.3)$ & 37 & 18 & $5.5(1.9)$ & 6 & $4.5(0,1)$ & 630 & $2.8(0.8)$ & 6 & 36 & 0.01 (ns) \\
\hline 86 & $43(0.3)$ & 36 & $1-9$ & $45(2.2)$ & 4 & $48(0.1)$ & 594 & $30(0.4)$ & 6 & 6.2 & $0.002^{e r}$ \\
\hline 99 & $36(0.4)$ & 24 & $1-7$ & $47(1.7)$ & 3 & $43(0.1)$ & 549 & $4.0(0.7)$ & 6 & 2.8 & $0.06(\mathrm{~ns})$ \\
\hline $10 \%$ & $3.5(0.4)$ & 18 & 210 & $3.0(2.0)$ & 3 & $4.2(0.06)$ & 499 & $43(1.2)$ & 6 & 2.3 & $0.10(\mathrm{~ns})$ \\
\hline 119 & $3.1(0.6)$ & 7 & $1-5$ & $5 S(2,5)$ & 4 & $38(0.07)$ & 391 & $25(0.6)$ & 6 & 34 & $0.03(\mathrm{~ns})$ \\
\hline 128 & $50(1.0)$ & 3 & $4-7$ & $9.5(15)$ & 2 & $3.4(0.07)$ & 296 & $2.7(0.6)$ & 6 & & \\
\hline 139 & 2 & 1 & & 110 & 1 & & & $26(0.4)$ & 5 & & \\
\hline 148 & 2 & 1 & & & & & & & & & \\
\hline
\end{tabular}

TFalk and Moller (1995. Table 1), ${ }^{2}$ Hatch (1990: Table 3), Mougin (1967. Table 5 )

4 Superseript letters refer to Tukey-Kramer Multiple Comparisons $(P<0.05)$ as follows: a - Cape Vera significantly different from all others, b-Cape Vera and Greenland different from Alaska and Sands of Forvie, c-Cape Vera different from Alaska; d-Greenland different from all others; e - ANOVA excludes Greenland data; $\mathrm{f}$ - Alaska different from Forvie 
standardized slope: $-0.66 \pm 0.05$ days/shift, $95 \% \mathrm{CI}:-0.77--0.55, n=38$; Table 6.1). The decline in the duration of successive incubation shifts was greater for males (mean standardized slope: $-0.76 \pm 0.04$ days/shift, $95 \% \mathrm{CI}:-0.85--0.66, n=38$ ) than for females (mean standardized slope: $-0.53 \pm 0.09$ days/shift, $95 \%$ CI: $-0.72-$ $0.35, n=38$; Wilcoxon matched-pairs signed ranks test, $P=0.0054$ ). In 27 pairs (71\%), the longest incubation shift undertaken by the male was followed immediately by the longest shift taken by the female, and in a different subset of 27 pairs, the shortest shift taken by the male was followed consecutively by the shortest shift taken by the female. Most (76\%) successful pairs completed incubation in eight, nine or ten shifts (Fig. 6.1b), and 71\% undertook an equal number of shifts for each mate (including the first egg-laying shift by the female).

The mean duration of the first shift by the male in successful nests $(10.3 \pm 0.4$ days, range $4-14, n=38$ pairs) was longer than that of first male shifts in failed nests ( $\left(8.3 \pm 0.6\right.$ days, range $3-13, n=25$ pairs; Welch's $\left.t_{47}=2.8, P=0.008\right)$. However, none of the remaining incubation shifts (3-10) differed in duration between successful and failed breeders ( $t$-tests, all $P>0.1)$.

\section{Comparisons to other colonies}

Differences in typical shift duration were evident for fulmars at Cape Vera compared to Alaska, Greenland or the UK. At all colonies, mean shift length tended to decline as fulmars got closer to completing incubation (Table 6.1; mean standardized slope: $-0.70 \pm 0.08$ days/shift, $n=4$ ), although on summary data these 
trends were only significant for Alaska and Cape Vera (Kendall Tau tests, $P<0.05$ ). For fulmars that completed incubation, overall mean shift length in Alaska was $4.3 \pm$ 0.04 days (based on means per pair, $n=562$ pairs, Hatch 1990a), which was significantly shorter than at either Cape Vera $(5.9 \pm 0.2$ days, $n=38$ pairs $)$ or Greenland ( $6.0 \pm 1.4$ days, $n=7$ pairs; ANOVA on summary data, $F_{2,604}=71.8, P<$ 0.001; Tukey-Kramer Multiple Comparisons tests, $P<0.001$ ). For the entire incubation period (excluding the first shift by the female), fulmars nesting at the Sands of Forvie, UK, had a mean incubation shift duration of $3.7 \pm 0.2$ days $(n=71$ shifts for six pairs; Mougin 1967), similar to the mean of $2.8 \pm 0.2$ days ( $n=3$ pairs) found by Williamson (1952) in the UK. Thus, average fulmar incubation shifts per breeding pair at Arctic colonies were $37-114 \%$ longer than at Boreal colonies.

Excluding the egg-laying shift, the first two incubation shifts undertaken each by the male and by the female at Cape Vera (hence, shifts 2-5) were longer than those taken by fulmars at Alaska or the UK, and more similar to fulmar incubation in Greenland (Table 6.1). However, the first incubation shift by Cape Vera male fulmars averaged 3 days longer than Greenland or UK males, and 5 days longer than Alaskan males.

\section{Discussion}

Geographical variation in the northern fulmar has been a source of intrigue for seabird biologists and biogeographers for decades (Fisher 1952, Salomonsen 1965, 
Hatch and Nettleship 1998). While regional differences in morphometrics and appearance of fulmars have long been known (Fisher 1952, van Franeker and Wattel 1982), more recent studies have demonstrated marked variation in diurnal colony attendance (Falk and Møller 1995), breeding schedules (Chapter 2), breeding success (Ollason and Dunnet 1986, Hatch 1990b, Falk and Møller 1995), molt chronology (Chapter 9), and diet (Mehlum and Gabrielsen 1993, Phillips et al. 1999). The present study, along with those of Falk and Møller (1995) and Gaston et al. (2005), collectively suggest that incubation behaviour by Arctic fulmars is typically different from that of fulmars nesting in the Boreal oceanographic zone.

The duration of incubation shifts in fulmars is affected by the energetic needs of incubating parents, and these in turn are influenced by the ability of parents to acquire and store energetic reserves during foraging bouts when the other mate is incubating. As central place foragers, longer foraging bouts (and hence longer incubation shifts) should be favoured when food is far from the colony, to minimize the proportion of time spent commuting to and from the feeding area (Orians and Pearson 1979, Hatch 1990a). This effect may be exacerbated in the Arctic breeding season, because extensive sea ice and associated low marine productivity early in the season should make it more difficult to find sufficient food (Raymont 1976, Welch et al. 1992). At Cape Vera, the closest feeding area (open water) is consistently $200 \mathrm{~km}$ to the east through the early breeding season each year (Chapter 2), and better feeding areas may be $>400 \mathrm{~km}$ east of the colony, in the more productive, east side of the North Water Polynya (Lewis et al. 1996). 
Considering these effects, I postulate that at no other colony site are breeding fulmars under as many predictable, annual constraints on incubation shift duration as at Cape Vera (except during severe ice years in Lancaster Sound; Gaston et al. 2005). At Cape Vera, most fulmars complete incubation in fewer shifts $(8-10)$ than at colonies in the Boreal oceanographic zone $(\geq 10)$, and consequently overall mean shift duration is $1.5-2$ days longer than at southern colonies (Williamson 1952, Mougin 1967, Hatch 1990a). Moreover, the most noticeable differences in shift duration are early in incubation, particularly the first two shifts by the male and female (excluding the first, egg-laying shift), which are significantly longer at High Arctic colonies (Falk and Møller 1995, this study) than early shifts taken by Boreal fulmars. In early June, marine production should be lower and food supplies harder to find in Arctic waters than later in the season.

There was also a strong pattern of decreasing shift duration as incubation proceeded at Cape Vera. Only one fulmar took a shift lasting $>9$ days at Cape Vera after the fifth incubation shift, but shifts $\geq 11$ days were undertaken after the fifth shift by incubating fulmars in Alaska (Hatch 1990a) and Greenland (Falk and Møller 1995). It is likely that increasing marine production through the breeding season allows High Arctic fulmars to replenish energetic stores in less time, and consequently return from a foraging bout more quickly. However, data from studies across the breeding range show that fulmars take shorter shifts near the end of incubation (Williamson 1952, Hatch 1990a, Gaston et al. 2005). Selection may favour this behaviour, irrespective of marine food supplies, because a parent 
completing a relatively long shift would be unlikely to have sufficient stored food to feed its chick upon hatching (Imber 1976). Alternately, because a parent has to guard the chick for $\geq 10$ days after hatch, short shifts at the end of incubation would be adaptive so that the chick does not have to wait long for a parent to depart and return with its first meal. Nonetheless, the mean shift duration at Cape Vera was still $3.5-$ 4.3 days for shifts $8-10$, the period when most fulmars were completing incubation. These shifts were longer than the $\leq 2.6$ days found in the UK (Williamson 1952, Mougin 1967) and similar to fulmars in Alaska (Hatch 1990a), although at Cape Vera incubation may be completed in four less shifts than in Alaska.

Both Hatch (1990a) and Falk and Møller (1995) found no difference between shift lengths of fulmars that were either successful or unsuccessful. In contrast, I found that the first male shift at Cape Vera was typically 2 days longer in successful pairs compared to pairs that failed, although there were no differences in the duration of other shifts. Moreover, first shifts by the male were $50-90 \%$ longer than reported for other fulmar colonies, and even longer than the 9 day average reported for Prince Leopold Island, Canada (Hatch and Nettleship 1998), but High Arctic male fulmars contributed the same amount of time (56\%) to incubation as elsewhere $(55 \%$; Mougin 1967, Hatch 1990a). At Cape Vera, the female takes a much longer pre-laying exodus than at any other colony (Chapter 2), and females lose body mass during the exodus (Chapter 3). Furthermore, some female fulmars in Alaska contributed up to $60 \%$ of the incubation time, whereas at Cape Vera, maximum female contributions were $53 \%$, or 3.5 days less total time than in Alaska. This pattern suggests a greater 
energetic constraint on breeding females at Cape Vera, for which the exceptionally long, first shift by males may be required to allow females sufficient time to recoup resources after egg-laying at a time when food supplies are low (Welch et al. 1992). In support of this hypothesis, regional surveys suggest that fulmars may depart the Canadian High Arctic entirely during the pre-laying exodus (McLaren 1982), presumably because food supplies are difficult to find, and this occurs shortly before the female's first recuperative foraging bout (Chapter 2).

Like many other aspects of their ecology, incubation scheduling of northern fulmars exhibits consistent regional differences, with longer incubation shifts typical of High Arctic colonies. However, there also appears to be colony-specific differences within the High Arctic oceanographic zone, which are probably influenced by the annual variability (North East Water Polynya - Falk and Møller 1995; Lancaster Sound - Gaston et al. 2005) or stability (Cape Vera - Chapter 2) of nearby sea ice cover. Reductions in the timing and extent of Arctic ice (ACIA 2004) should increase the variability of annual foraging conditions in the early season at Cape Vera, but presumably in a direction that stimulates more production earlier in the season. This should alleviate some of the constraints that the birds now experience, and lead to shorter incubation shifts. The observed range in duration of each incubation shift suggests that there is already the behavioural flexibility within the colony to adapt to these altered sea ice conditions, as found at Prince Leopold Island (Gaston et al. 2005). 


\section{CHAPTER 7}

Predation, nest shelter and nesting behaviour: are they correlated in High Arctic northern fulmars?

This chapter formed the basis for the following publication:

Mallory, M. L., and M. R. Forbes. Predation, nest shelter and nesting behaviour: are they correlated in High Arctic northern fulmars? Journal of Ornithology, in preparation. 


\begin{abstract}
The physical characteristics of nest sites can influence the outcome of breeding attempts and breeding behaviour in colonial seabirds. I examined the relationship between nest shelter, reproductive success, and time spent in different behaviours at the nest by breeding northern fulmars (Fulmarus glacialis) at the remote Cape Vera colony on Devon Island, Nunavut, Canada. As predicted, fulmars nesting in sheltered caves experienced lower predation pressure and produced more chicks than fulmars nesting on exposed ledges. However, fulmars nesting on ledges experienced more insolation and heating hours than fulmars nesting in caves, suggesting a greater thermoregulatory cost to cave-nesting. However, I failed to detect a difference in laying dates, incubation shifts, incubation period, or the time that fulmars in different nest locations allocated to behaviours at the nest. Incubating fulmars exhibited apparently suboptimal allocation of time to different behaviours, particularly for cave-nesters. I postulate that patterns learned from previous, successful breeding experience may be more important factors influencing the behavioural repertoire of incubating fulmars than costs associated with physical characteristics of their nest site.
\end{abstract}




\section{Introduction}

Research into how birds apportion their time to different activities has provided much insight into their ecology and energetic needs (e.g., Walsberg 1983, Weathers et al. 1984). In the breeding season, time allocation to various activities is a key factor that potentially limits avian annual reproductive success and survival (King 1974). Parental investment theory posits that a breeding bird must balance its use of time and energetic stores to successfully reproduce, while maintaining its own body condition to evade predators, avoid disease, and survive to reproduce the following year (Trivers 1972, Montgomerie and Weatherhead 1988). Thus, we expect breeding birds to minimize time spent in activities not directly related to reproduction (e.g., selfmaintenance, agonistic interactions, predatory interactions), because these reduce the time available for behaviours that may maximize annual reproductive success (e.g., nest building and maintenance, pair bonding, incubation). For long-lived birds, reproductive success improves with age and breeding experience, presumably in part due to practice in successfully balancing time and energy allocation (e.g., Ollason and Dunnet 1988, Warham 1990).

Among colonial seabirds, detailed analyses of time-activity budgets during breeding have focused on sex-specific roles on and off the nest (e.g., Hatch 1990a, b), and the relationship between time and activities while out at sea, adult body condition, and breeding success (e.g., Warham 1990, Weimerskirch 1995, Stahl and Sagar 2006). Much less is reported on how birds apportion time while at the nest site (but see Grant et al. 1982, Maxon and Bernstein 1985, Verspoor et al. 1987). It is 
clear that behaviour and reproductive success can vary with nest location in a seabird colony (e.g., Gaston and Nettleship 1981, Pierotti 1982, Gaston and Elliot 1996), and that behavioural factors such as breeding synchronization, incubation scheduling, and predator defense typically correlate with reproductive success (Coulson 2002, Hamer et al. 2002). As well, physical characteristics of the nest site can result in large microclimatic differences (Kim and Monaghan 2005a, b), and these can influence body condition and hence energetic needs (Gaston et al. 2002, Fast et al. 2007). Further, nest site characteristics may influence the frequency of agonistic interactions from disturbance, or predation (e.g., Hudson 1982, Gaston and Elliot 1996, Gilchrist and Gaston 1997). For example, nesting in higher densities may confer advantages of mutual defense (Gilchrist and Gaston 1997), but this might also expose breeders to disturbance from other breeders or non-breeding, prospecting birds (Kim and Monaghan 2005a). In turn, disturbed birds may spend more time vigilant or defending their nest, potentially reducing both energy stores and the time spent incubating (Drent 1975, Hatch and Nettleship 1998). Thus, there is a potential tradeoff between nest site location and behavioural time allocation at the nest in seabird colonies which could affect annual reproductive success (Kim and Monaghan 2005a, b).

I studied the relationship between nest site characteristics and time allocation to different behaviours by northern fulmars (Fulmarus glacialis Linnaeus, 1761) breeding in the Canadian High Arctic. While studies in the United Kingdom and Alaska have shown that age, breeding experience, and variation in marine 
productivity are the principal factors influencing annual breeding success in fulmars (e.g., Ollason and Dunnet 1978, Hatch 1990a, b, c, Gray et al. 2003), no one has examined the possible role of nest location on reproductive success. In general, less is known about fulmars nesting in the High Arctic (Falk and Møller 1997, Hatch and Nettleship 1998), although it appears that annual climatic factors have a significant influence on reproductive timing and success (Gaston et al. 2005, Chapter 2).

In the cold climate of the Arctic, some studies have hypothesized that nest site selection by breeding birds represents a trade-off between energetic (thermoregulatory) costs to adults (i.e., effects on parental body condition) against the risk of predation on the clutch (Lyon and Montgomerie 1987, Fast et al. 2007). In this study, I extend this hypothesis to include time allocation to more energeticallyexpensive activities at the nest as part of energetic costs. At Arctic fulmar colonies, nest locations vary from highly sheltered caves to broad, exposed ledges (Hatch and Nettleship 1998). The most sheltered nests (caves) should experience a lower risk of nest failure (predation, rockfall), inclement weather (snowfall, ice), or disturbance from conspecifics, but may represent a colder microclimate than exposed sites (Lyon and Montgomerie 1987). If fulmar nest site selection is influenced by microclimate and predation risk, I predicted: (1) fulmars nesting in the most sheltered sites would have the highest reproductive success, and that these sites would be occupied first in the breeding season; (2) fulmars in the most sheltered sites would spend less time in energetically-costly behaviours (i.e., less time disturbed by conspecifics or predators) compared to fulmars nesting in exposed sites; and (3) if sheltered caves are colder 
than exposed ledges, then fulmars nesting in caves would take longer incubation shifts or have a longer incubation period, as more time would be needed to recoup energetic supplies lost due to higher costs of thermoregulation.

\section{Materials and Methods}

\section{Study location}

The timing of my research, and the geographic characteristics of the study site are described in Chapter 2. Therefore, below I provide details specific to the study conducted in Chapter 7.

The cliff face at Cape Vera is composed of fractured, unstable, sedimentary rock. Erosion of the cliff has created differing levels of nest shelter for breeding fulmars (similar to Gaston and Nettleship 1981), depending on the presence of an overhang ("roof"), shelter on sides of the nest ("walls"), and the width of ledges. Unsafe climbing conditions precluded us from descending to and measuring each nest site. Instead, I used a Canon ${ }^{\circledR} 20 \mathrm{D}$ digital camera with a $400 \mathrm{~mm}$ lens to produce an 8 megapixel photograph of selected nest sites, and from these photographs I determined the presence of a partial or complete roof and walls. Ledge widths were estimated as body lengths of incubating birds. Using these characteristics, I defined three categories of decreasing nest site shelter as follows: (a) caves - sites protected by a roof $<2$ body lengths above the nest, usually with walls on both sides (Fig. 7.1a); (b) 

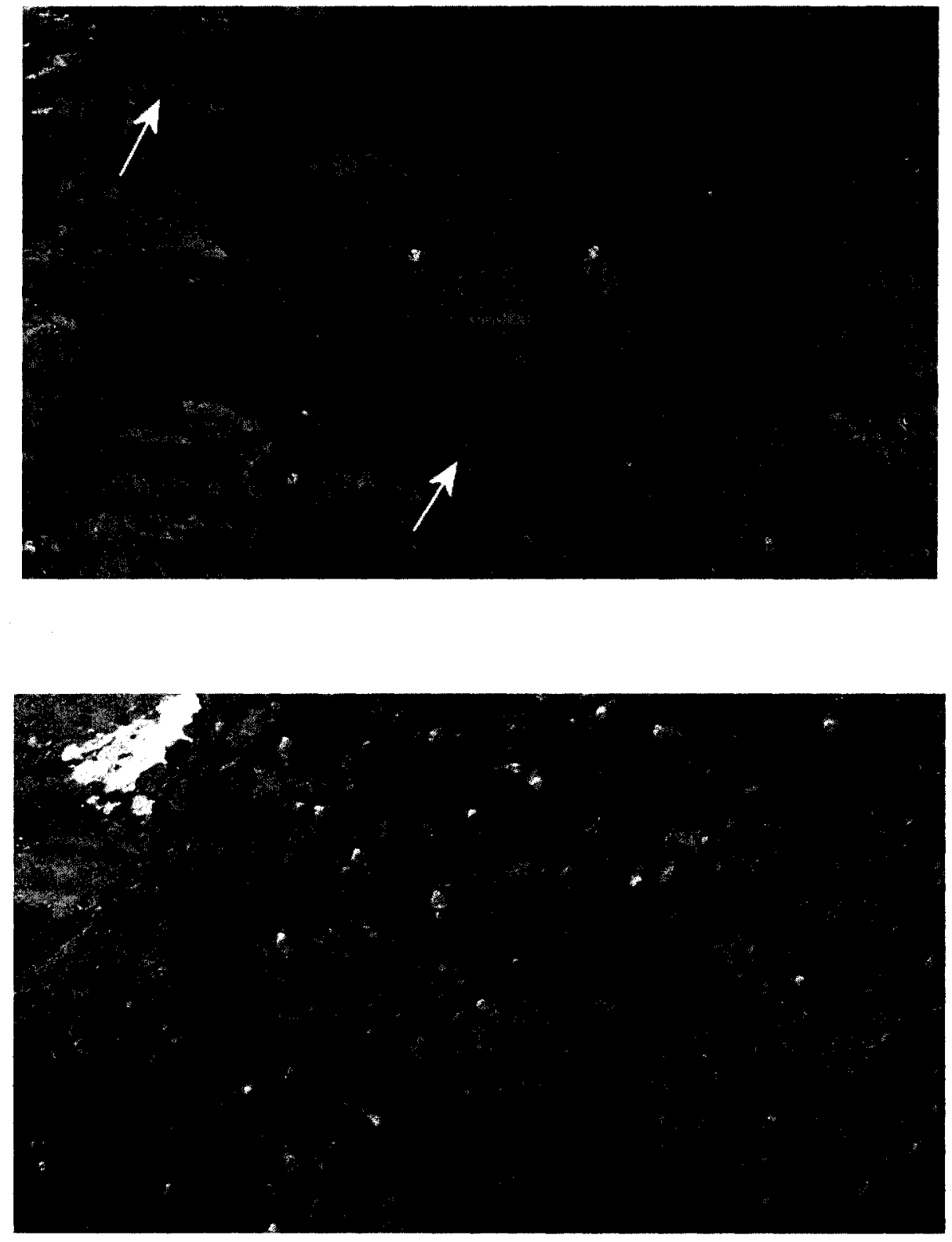

Figure 7.1. Different types of nesting locations of northern fulmars (Fulmarus glacialis) used in this study. In the upper panel, "cave" sites are noted by arrows, whereas other fulmar nests are on "narrow ledges". In the lower panel, all sites were on a "broad ledge". 
narrow ledges - sites $\leq 3$ body lengths wide, with only one nest between the cliff face and ledge edge, with no or partial roof ( $>2$ body lengths above), and with varying numbers of walls ( $0-2$; Fig. 7.1a); and c) broad ledges - sites $\geq 3$ body lengths wide (typically sloping down towards the ocean from the cliff fact to ledge drop off), with no roof and multiple nests between the cliff and edge (Fig. 7.1b).

\section{Egg predation experiments}

Northern fulmars are long-lived, monogamous petrels that lay a single egg in a dirt scrape, and do not relay if that egg is lost (Hatch and Nettleship 1998). I conducted an experiment to assess the intensity of predation on fulmar eggs by placing eggs in artificial nests at various locations around the colony, similar to the methodology of Rowe and Jones (2000). I used large chicken eggs as proxies as they are the same colour but slightly smaller than fulmar eggs. Eggs were placed at different types of nesting locations on the cliffs (caves, narrow ledges, broad ledges). All artificial nests were checked at least once within $24 \mathrm{hr}$ to determine their fate.

I also observed occasions when eggs were naturally neglected by fulmars because the egg rolled out of the nest, parents abandoned the nest site, or severe weather caused a temporary departure from the nest. I recorded how long it took for those eggs to be depredated. 
Nest site temperatures

Because microclimate could play an important role in nest site choice or success for Arctic birds (e.g., Fast et al. 2007), I recorded temperatures at nest level using three IButton ${ }^{\circledR}$ thermistor data loggers (accuracy $\pm 1^{\circ} \mathrm{C}$ ). My goal was to depict the daily variation in microclimate among sites, so I placed one thermistor in each of a cave, narrow ledge and broad ledge on the cliffs at Cape Vera, all in similar, east-facing locations. They were set to collect simultaneous data, once every hour, and ran from $1815 \mathrm{hr}$ on 13 June to $1515 \mathrm{hr}$ on 17 July 2004 (i.e., most of the fulmar incubation period; Chapter 2).

I recorded ambient temperatures using a Davis ${ }^{\circledR}$ weather station at Cape Vera. I was unable to account for windchill at nest sites, a factor which could be important at cool temperatures (Kim and Monaghan 2005a). However, predominant winds came from the west and north, meaning they blew off of the plateau and across the water, and not directly on the cliffs. This meant that under most conditions, except easterly winds, fulmars along the cliff face appeared to be quite protected from any strong winds. For this reason, I suspect that differential windchill effects on nest locations were small.

\section{Incubation}

In 2005 , fulmar nests were observed from first arrival of pairs at the colony through early chick-rearing. Successful nests were defined as those where a chick was 
observed in the nest on 9 August or later ( $\geq 2$ weeks old). Details of incubation monitoring protocols are described in Chapters 2 and 6.

\section{Behaviour at the nest}

To assess patterns of disturbance by conspecifics, I conducted daily counts of fulmars during incubation on two plots between 8 June and 27 July 2005 . One plot consisted of nests on narrow ledges, and the other of nests on a broad ledge. Because cave sites were uncommon and scattered, I could not conduct similar counts in these sites. Plot counts were usually conducted between 1300 and $1900 \mathrm{hrs,} \mathrm{depending} \mathrm{on} \mathrm{weather}$ conditions. I also conducted a 24-hr count on 18-19 June 2005, recording numbers of birds on each plot every two hours. I examined whether variation in numbers of birds at the plots was higher on the broad ledge, which would represent greater numbers of failed and non-breeding fulmars visiting the plot (Hatch 1989).

I also conducted time-activity budgets on nesting fulmars for 1-4 hour periods in 2003. Details of activity (behavioural) data collection are described in Chapter 4. Activity data were converted to proportions for each sample period.

\section{Statistical treatment}

I used Fisher Exact tests to compare proportions of eggs lost from different nest types. Distributions of all other data were examined using Kolmogorov-Smirnov normality tests, and if data approximated normality, I proceeded with planned comparisons of means using $t$-tests or ANOVAs. In cases where data distributions 
did not meet requirements for parametric tests, I used non-parametric Kruskal-Wallis tests or Spearman rank correlations. Variation in plot counts was compared using an $F$-ratio test. For activity data, I performed an arcsine square root transformation of proportions of time spent in each behaviour. I then conducted a MANOVA on behaviours (excluding time spent preening, so the procedure was not bounded by the same total time for each sample), using nest location as the independent treatment. All means are presented $\pm \mathrm{SE}$, and statistical tests report two-sided $P$ values.

\section{Results}

\section{Breeding Success}

I determined reproductive success in 232 nests (Table 7.1). Approximately half of the fulmars nesting on ledges (narrow or broad) failed to produce a chick, whereas only $20 \%$ of the nests in caves failed (Fisher Exact test, $P=0.006$ ). Nest initiation was generally synchronous across the colony, and fulmar pairs nesting in caves or ledges laid eggs on similar dates (Table $7.1 ; F_{2,82}=0.3, P=0.7$ ).

\section{Predation}

The Cape Vera fulmar colony appears to experience relatively intense predation pressure. An arctic fox den was located at the south end of the colony, and fulmar eggs, chicks and adults were all observed being brought back to the den by adult 
Table 7.1. Comparison of breeding success (\%), laying date (mean $\pm \mathrm{SE}$ ), incubation shift (median days, range) and incubation period (mean \pm SE days) of northern fulmars (Fulmarus glacialis) in 2003-2005 nesting in parts of the cliff which varied in their protection from weather and predators.

\begin{tabular}{cccc}
\hline Nest parameter & \multicolumn{3}{c}{ Nest location } \\
\cline { 2 - 4 } & Cave $(n)$ & Narrow ledge $(n)$ & Broad ledge $(n)$ \\
\hline Successful (\%) & $82(22)$ & $49(53)$ & $50(157)$ \\
Laying date (ordinal day) & $158.6 \pm 2.0(5)$ & $157.6 \pm 0.4(30)$ & $157.8 \pm 0.4(50)$ \\
Incubation shift (days) & $5,1-14(71)$ & $6,2-14(91)$ & $6,1-13(111)$ \\
Incubation period (days) & $50.1 \pm 0.5(8)$ & $49.4 \pm 0.4(11)$ & $49.3 \pm 0.5(14)$ \\
\hline
\end{tabular}


foxes to feed their young. Glaucous gulls (Larus hyperboreus) and common ravens (Corvus corax) were also observed carrying eggs and chicks. Both gyrfalcon (Falco rusticolus) and peregrine falcon (Falco peregrinus) were seen at the colony, but I never recorded an attack by these species on fulmars.

Using eggs placed at artificial nest sites on the cliff, most eggs disappeared within $24 \mathrm{hr}$ from narrow or broad ledges, in similar proportions for both experimental and natural nests (Table 7.2; $P \mathrm{~s}>0.1$ ), and thus I pooled data from different ledge types. Eggs on ledges were depredated more quickly than those in caves $(P<0.001)$. Despite the propensity for eggs to disappear rapidly after being left exposed by adult fulmars, some neglected eggs remained in caves, narrow or broad ledges for $>10$ days (also observed by Falk and Møller 1997).

During the three years of study (293 field days), I never observed a predation attempt on fulmars nesting in caves. In contrast, I observed 17 predation attempts on fulmars nesting on ledges.

\section{Nest site temperatures}

Ambient mean daily temperatures during fulmar incubation ranged from $-7.3^{\circ} \mathrm{C}$ to $12.0^{\circ} \mathrm{C}$ during the three study years, but nest-level temperatures differed across breeding locations on the cliff. From 34 days of simultaneous thermistor records, the median temperature in the cave $\left(2^{\circ} \mathrm{C}\right.$, range -1 to $\left.23, n=815\right)$ was lower than that at a narrow ledge $\left(3^{\circ} \mathrm{C}\right.$, range -1 to $\left.28, n=815\right)$, or at a broad ledge $\left(5^{\circ} \mathrm{C}\right.$, range 0 to 31 , $n=815 ; K W=332.9, P<0.001$ ). During sunny conditions on 16 June 2004 , nests were 
Table 7.2. A comparison of predation rates on white eggs placed or observed exposed at various northern fulmar (Fulmarus glacialis) nest locations around the Cape Vera fulmar colony between 2003-2005.

\begin{tabular}{ccc}
\hline Trial location & Eggs placed $(n)$ & Eggs remaining in 24 hr (n) \\
\hline Experimental nesting locations & 10 & 0 \\
Narrow ledge & 22 & 6 \\
Broad ledge & 7 & 5 \\
Cave & & 1 \\
Natural nesting locations & 5 & 1 \\
Narrow ledge & 14 & 4 \\
Broad ledge & 5 & \\
Cave & 5 & \\
\hline
\end{tabular}


$23^{\circ} \mathrm{C}$ warmer on the broad ledge than in the cave (Fig. 7.2a), and the daily maximum temperature on the ledge was $26^{\circ} \mathrm{C}, 20^{\circ} \mathrm{C}$ warmer than the maximum of $6^{\circ} \mathrm{C}$ recorded in the cave. As the overall maximum daily ambient temperature warmed through the recording period (Fig. $7.2 \mathrm{~b} ; r_{\mathrm{s} 34}=0.47, P=0.005$ ), this differential between thermal conditions at nest sites ameliorated. For example, the median hourly temperature difference between the cave thermistor and the broad ledge thermistor for eight sunny days in June $\left(4^{\circ} \mathrm{C}\right.$, range $\left.-2-24, n=192\right)$ was higher than that for four sunny days in July $\left(3^{\circ} \mathrm{C}\right.$, range $-2-15, n=96$; Mann-Whitney test, $\left.U=5839, P<0.001\right)$. Similarly, the median hourly temperature difference for nine cloudy days in June $\left(3^{\circ} \mathrm{C}\right.$, range 0 $-14, n=216)$ was higher than that for ten cloudy days in July $\left(2^{\circ} \mathrm{C}\right.$, range $-2-7$, $n=240$; Mann-Whitney test, $U=15886, P<0.001)$.

Over the thermistor recording period, a fulmar nest in the cave would have experienced $2654^{\circ} \mathrm{C} \cdot \mathrm{hrs}$, whereas a nest on the narrow ledge would have felt $4137^{\circ} \mathrm{C} \cdot \mathrm{hrs}(56 \%$ more heat than the cave), and the nest on the broad ledge would have felt $5310^{\circ} \mathrm{C} \cdot h r s$ ( $28 \%$ more heat than the narrow ledge and $100 \%$ more than the cave).

\section{Incubation}

Using only nests where incubation was successful (i.e., hatched a chick), fulmars nesting in caves took incubation shifts of similar duration as fulmars nesting on narrow ledges or broad ledges (Table 7.1; $K W=1.6, P=0.4$ ). Similarly, the mean 

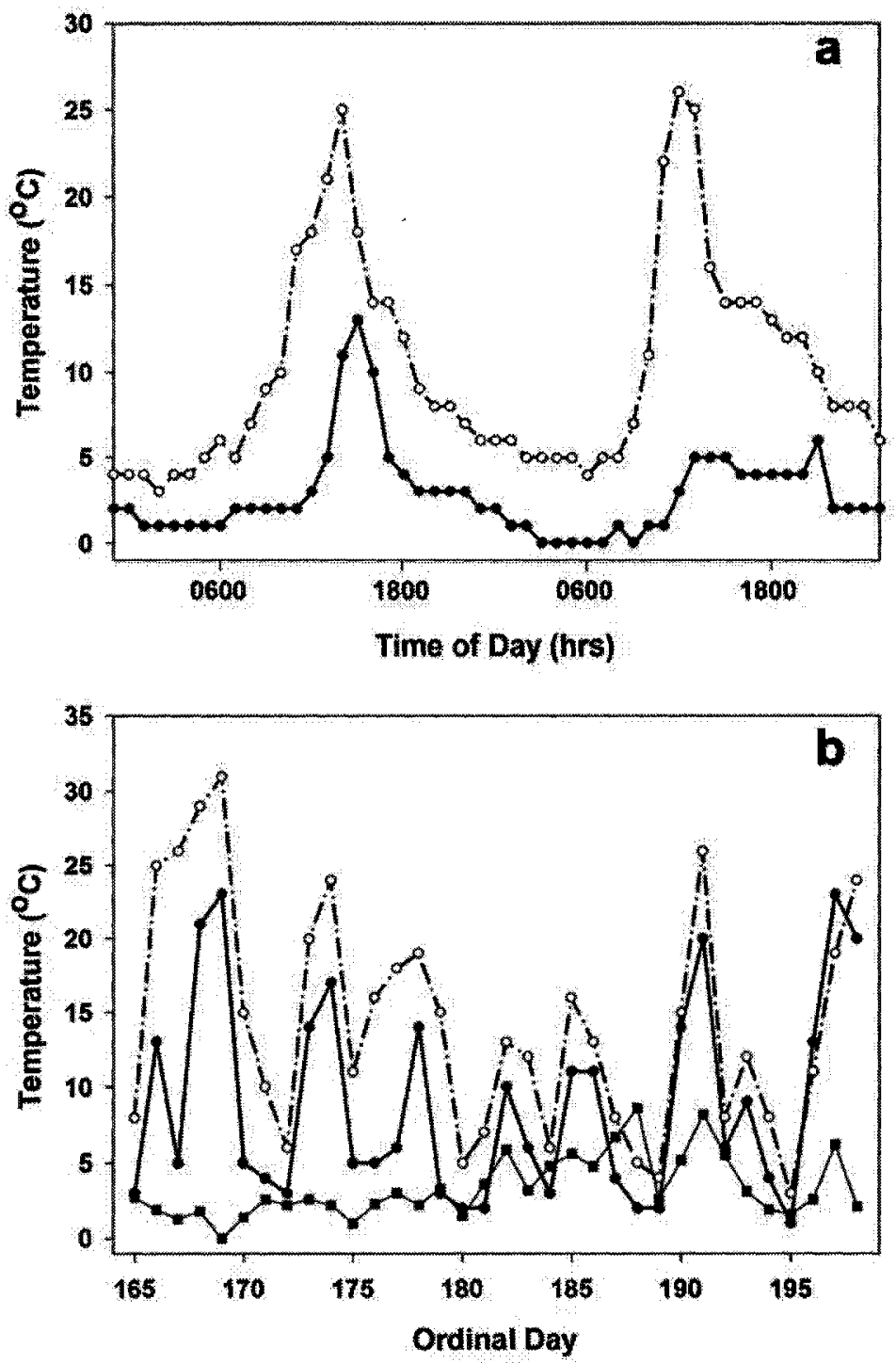

Figure 7.2. Records of temperatures at nest sites on the Cape Vera cliffs in 2004. (a) Hourly temperature records for thermistors set at a nest site on a broad, exposed ledge (open circles) and a cave (filled circles) on 15 - 16 June, 2004. (b) Daily maximum temperate records for thermistors set on the broad ledge (open circles), the cave (filled circle), and mean daily ambient air temperatures (filled squares). 
incubation period did not differ significantly among fulmar nesting locations (Table $\left.7.1, F_{2,30}=0.7, P=0.5\right)$.

\section{Behaviour}

Throughout incubation, I rarely observed disturbance of cave-nesting fulmars by visiting birds, although these observations were not quantified. However, variation in numbers of fulmars counted daily at the broad ledge plot (mean $108 \pm 3$ birds) was higher than variation at the narrow ledge plot $(32 \pm 1 ; F$-ratio test on variance, $\left.F_{76}=12.4, P<0.001\right)$. Similarly, in the 24-hour count, number of fulmars attending the broad ledge plot ( $94 \pm 3$ birds) was more variable than at the narrow ledge plot (30 \pm $\left.1 ; F_{28}=11.8, P<0.001\right)$. Collectively, counts suggested that fulmars nesting on broad ledges were at higher risk of disturbance by visiting non-breeders than birds on narrow ledges, and probably birds in caves.

Between 12 June and 6 July 2003, we recorded 200 hours of time-activity budgets $(n=150)$ on incubating fulmars. Nest location appeared to have little influence on fulmar behaviour. Using MANOVA, Wilk's Lambda test criterion showed that fulmars allocated similar time to each behaviour irrespective of whether they nested in caves, narrow ledges or broad ledges (Table $7.3 ; F_{10,288}=1.3, P=0.26$ ). 
Table 7.3. Comparison of time spent in each activity by incubating northern fulmars (Fulmarus glacialis) nesting in different microhabitats on the cliffs in 2003 (sample sizes are number of observation periods of individual birds nesting in each habitat type).

\begin{tabular}{lccc}
\hline Behavior & \multicolumn{3}{c}{ Mean (SE) time spent in each activity (\%) } \\
\cline { 2 - 4 } & Cave (36) & Narrow Ledge (37) & Broad Ledge (77) \\
\hline Rest & $74.9(4.6)$ & $66.0(4.8)$ & $74.4(2.8)$ \\
Preen & $3.0(1.0)$ & $3.3(0.8)$ & $2.8(0.5)$ \\
Vigilant & $16.6(3.2)$ & $20.1(4.2)$ & $14.7(2.3)$ \\
Pair bond & $4.3(1.0)$ & $8.6(1.6)$ & $7.1(1.0)$ \\
Agonistic & $0.6(0.2)$ & $1.6(0.5)$ & $0.6(0.2)$ \\
Adjust nest & $0.6(0.4)$ & $0.4(0.3)$ & $0.4(0.2)$ \\
\hline Total Time (hr) & 53.6 & 40.6 & 105.8 \\
\hline
\end{tabular}




\section{Discussion}

Annual reproductive success of northern fulmars varies between $12-48 \%$, depending on colony location and yearly local environmental conditions (e.g., Ollason and Dunnet 1988, Hatch and Nettleship 1998). Partitioning out the independent effects of various environmental stressors on reproductive success is difficult for long-lived seabirds (e.g., Ainley et al. 1995, Barbraud and Chastel 1999, Gaston et al. 2005), because prior breeding experience, and thus the ability of birds to adjust to these stressors, is considered the principal factor influencing breeding success (e.g., Ollason and Dunnet 1988, Warham 1990). In the Arctic, however, more extreme weather conditions are experienced by breeding fulmars than elsewhere in their range, which constrains the timing of breeding (Chapter 2), can reduce nest success directly (Hatch and Nettleship 1998, Chapter 8), or can have indirect effects on body condition and behaviour (Gaston et al. 2002, Fast et al. 2007). As well, physical characteristics of nest sites affect the level of disturbance from predators (Lima and Dill 1990) or nonand failed breeding birds visiting the colony (Gaston and Nettleship 1981, Hudson 1982, Hatch and Nettleship 1998). Thus, given the potential costs of nesting in more exposed sites in Arctic colonies, I hypothesized that nest shelter would have a strong effect on both reproductive success and fulmar behaviour during breeding. In support of my prediction, significantly more fulmars hatched their eggs when nesting in protected sites, and I suspect that if I had followed nests until fledging, this difference would have been more pronounced, as exposed chicks may die after burial during late-season snowstorms (Hatch and Nettleship 1998, Chapter 8). Despite this, I could 
not discern any corresponding differences in behaviour at the nest which might explain the variation in nesting success.

\section{Variation in predation}

Predation pressure on nesting fulmars at Cape Vera varied with nest location. Most eggs left exposed on cliff ledges were quickly depredated by glaucous gulls, whereas those left exposed in caves persisted longer without being eaten. A similar result was found by Rowe and Jones (2000) studying predation of razorbill (Alca torda) nests on ledges and in crevices, although overall levels of predation in their study appeared to be lower. Large gulls require suitable wind conditions to successfully maneuvre and snatch eggs (Gilchrist et al. 1998), and probably find it unprofitable or dangerous to try and depredate eggs from sheltered caves (Gilchrist and Gaston 1997). Moreover, fulmars can projectile vomit stomach oil which can seriously reduce the survival of predators that get hit (Hatch and Nettleship 1998). Thus, gulls may avoid depredating fulmar nests in caves, because they have few options for avoiding oil spit at them.

\section{Variation in microclimate}

Overall, both ambient and nest-level temperatures I recorded in the High Arctic were lower than those found during recent studies in the low Arctic. Ambient temperatures at Cape Vera were $<10^{\circ} \mathrm{C}$ for the recording period, with a nest-level maximum of $31^{\circ} \mathrm{C}$ on one day, whereas Gaston et al. (2002) had more than $50 \%$ of daily ambient maxima $>15^{\circ} \mathrm{C}$ and recorded $46^{\circ} \mathrm{C}$ on the back of one breeding bird. Similarly, nest- 
level maximum temperatures were $>27^{\circ} \mathrm{C}$ for five consecutive days on Southampton Island (Fast et al. 2007). I also observed different patterns of nest heating compared to the low Arctic. Fast et al. (2007) found that eiders nesting on the ground in artificial shelters had more moderate heating conditions (temperatures were neither as low nor as high) than eiders in exposed sites. I found that the microclimate of fulmar nest sites varied across the cliff face, but my thermistor results suggested that cavenesting fulmars experienced lower minimum and mean daily temperatures, and rarely reached the same daily maximum as fulmars nesting in exposed sites. Cave nests may be colder because the rock surrounding caves stays cold longer into the breeding season, and may also trap cool air (Lyon and Montgomerie 1987). For example, I regularly observed ice or snow remaining in the back of caves long after it had disappeared from the rest of the cliff face. Fulmars nesting in caves would also experience less insolation and consequently lower heating hours compared to fulmars nesting on broad ledges, although as ambient temperatures rose, this difference apparently declined.

These temperature differences suggest that cave-nesting fulmars incur a higher thermoregulatory cost during incubation compared to ledge-nesters, which could affect body condition. Both Kilpi and Lindström (1997) and Fast et al. (2007) found that incubating female common eiders nesting in exposed sites lost more weight than those in sheltered sites, which they attributed to increased thermoregulatory costs in these capital breeders. However, relatively few eiders nested in naturally sheltered sites in the colony (Fast et al. 2007), whereas I noticed 
that almost all caves were occupied by nesting fulmars. Unlike fulmars, eiders lack strong defenses against predators, and could feel trapped at sheltered nests during a predation attempt. Therefore, Fast et al. (2007) proposed that the microclimatic advantages offered by sheltered sites were offset by the increased vulnerability of eiders to predators.

I propose the opposite for High Arctic fulmars, that is, the microclimatic disadvantages of nesting in the most sheltered sites (caves) are offset by the reduced risk of predation or effects of severe inclement weather at these sites. This hypothesis fits other aspects of the ecology and energetics of fulmars. For example, these petrels have a low metabolic rate and efficient thermoregulatory capabilities (Gabrielsen et al. 1988) allowing them to fast up to 14 days while incubating (Hatch 1990b). Therefore, a reduction in body condition to meet increased energy costs of thermoregulation seems well within the species' tolerances, and a separate study has shown that Arctic fulmars can operate with reduced body condition during times of environmental stress (Gaston et al. 2005). At the same time, the major factor causing reproductive failure at Arctic fulmar colonies is severe weather, particularly snowstorms during the chick-rearing stage (Hatch and Nettleship 1998, Chapter 8), so choosing cave sites should substantially improve breeding success.

If cave-nesting fulmars have higher annual breeding success but incur greater energetic costs of breeding, I predict the following: (1) fulmars nesting in caves are in better physical condition at the initiation of incubation, and maintain relatively higher body condition through incubation, than fulmars on ledges; (2) over their breeding 
history, fulmars nesting in caves will skip breeding more frequently than fulmars nesting on ledges; or (3) cave-nesting fulmars will have a shorter lifespans than ledge-nesting fulmars (Ollason and Dunnet 1988).

\section{Behaviour and nest location}

Incubating fulmars spent similar amounts of time engaged in each of the various behaviours I observed at the nest, irrespective of where they nested in the colony. Moreover, I found no evidence that incubation parameters (initiation date, mean shift length, incubation period) differed significantly among nest locations. These results were surprising given that predation pressure and disturbance from visiting birds appeared to be higher for fulmars nesting on broad ledges, or that microclimates were cooler in caves. Previous studies on ground-nesting gulls found that birds at more sheltered nest sites had earlier egg-laying dates, heavier eggs, higher hatching success, more fledglings, or spent more time sleeping and less time alert than gulls at less sheltered sites (e.g., Burger 1977, Kim and Monaghan 2005a, b).

My results suggest a strong linkage between the physical characteristics of the nest site and nest success, but no evidence of corresponding behavioural differences among birds nesting in these different locations. Why does fulmar behaviour appear to be suboptimal when there should be thermal and social benefits associated with the physical characteristics of the nest site, especially when energetic constraints appear critical for fulmar reproductive success in the Arctic (Gaston et al. 2005, Chapters 24)? I consider two possible explanations. 
I studied fulmar behaviour over a few seasons, and despite being in an extreme environment (High Arctic), most of my behavioural observations were recorded during moderate weather (e.g., sun, cloud, fog, rain). It may be that any differences in behaviour related to nest site characteristics are manifested most during more extreme conditions (e.g., snow, strong wind), as suggested by Kim and Monaghan (2005a) for gulls. Fulmars are well-adapted to withstand cool temperatures (Gabrielsen et al. 1988), can recover and store fat reserves quickly (Hatch 1990c, Phillips and Hamer 1999), and appear to have sufficient reserves to incubate for more days than a typical incubation shift (Chapter 4). Under the moderate weather conditions during most study days, the differences in energetic costs associated with nest locations may be relatively minor. For example, I did not record time budgets during periods of heavy snowfall (for safety reasons), although such events occurred (e.g., 29 June and 14 July 2004). Had those been included in the sample, my analysis would probably have shown that fulmars on ledges spent more time active than fulmars in caves, because the birds on ledges would have been digging snow from around their nest (Hatch and Nettleship 1998). However, even if I had recorded activities during inclement weather and this supported my nest location and behavioural predictions, it still would not explain why cave-nesting fulmars spent as much time active as ledge-nesting fulmars during moderate weather, when social and thermal conditions should favour less activity at caves.

Thus, an alternate explanation may indeed lie in the quality or experience of individuals breeding at different nest locations, as Kim and Monaghan (2005a, b) 
showed for gulls. Simply, my expectation of a correlation between nest site characteristics and Arctic fulmar behaviour may be incorrect. Instead, successful, practiced patterns of time and energy allocation by each pair (Hatch 1990a) may be influenced far more by energetic consequences of travel and foraging time during incubation recesses (e.g., Furness and Bryant 1996, Shaffer et al. 2001) than by the comparatively minor energetic costs of different activities at the nest during moderate weather (Warham 1990, Ellis and Gabrielsen 2002). Perhaps as importantly, the observed variation in successful fulmar breeding behaviours (Ollason and Dunnet 1978, 1988, Hatch 1990a) could be driven in part by individual, adaptive differences in suites of behavioural repertoires in these long-lived birds (e.g., Sih et al. 2004).

Acquiring a more sheltered nest location increases the chances of nest success in Arctic fulmars, presumably by reducing the risks of failure due to predation or inclement weather. Nonetheless, time allocation to incubation or different behaviours at the nest showed little relation to nest shelter, perhaps reflecting the low energetic costs of nest site activities compared to foraging and flight, and the constraints on breeding phenology at this colony (Chapter 2). Overall, behavioural repertoires at the nest may be influenced more by differences among individual birds, or the experience of breeding pairs, than by nest site characteristics. A similar study on a marked, known-age population which followed behaviours through the entire breeding season is required to discern the potential effects of age, experience, or behavioural repertoires in explaining suboptimal time and energy allocation in breeding fulmars. 


\section{CHAPTER 8}

\section{Influence of weather on reproductive success of northern fulmars in the Canadian High Arctic}

This chapter formed the basis for the following publication:

Mallory, M. L., A. J. Gaston, M. R. Forbes, and H. G. Gilchrist. 2009. Influence of weather on reproductive success of northern fulmars in the Canadian High Arctic. Polar Biology 32: in press. 


\begin{abstract}
The northern fulmar (Fulmarus glacialis) is a common seabird of the North Atlantic Ocean, with breeding colonies broadly dispersed between $45^{\circ} \mathrm{N}$ and $80^{\circ} \mathrm{N}$. At higher latitudes, breeding fulmars experience extensive sea-ice and presumably snow and low temperatures which do not affect fulmars in the southern part of the breeding range. I studied the relationship between weather and reproductive success of northern fulmars breeding at two colonies in the Canadian High Arctic. Collectively, hatching success, fledging success, and productivity (chicks fledged per egg laid) were similar between my study and results from colonies located south of the Arctic. However, a larger proportion of fulmars at apparently occupied sites (AOS) in High Arctic colonies appeared to forego egg-laying, resulting in lower proportions of chicks fledged per AOS. Extreme inclement weather was the major factor influencing nesting success, resulting in pulses of egg or chick loss during or immediately following major storms, although the mechanism of effects appeared to differ between the two colonies. For Arctic fulmars, the risks of nest failure due to stochastic, deleterious weather events may be offset by the predictable abundance of food supplies during chick-rearing in Arctic waters.
\end{abstract}




\section{Introduction}

Many bird species exhibit phenotypic plasticity in life history characteristics across their breeding range, presumably in response to differing physical or biological selective pressures experienced over the gradient of environmental conditions (Welty and Baptista 1988). For example, avian breeding phenology, clutch size, egg hatchability, and reproductive success may vary significantly with increasing altitude or latitude (e.g., Koenig 1982, Fortescue 1999, Dunn et al. 2000). Thus, studies of the reproductive ecology of a species from one part of its range may not accurately reflect its ecology elsewhere, which may be the case for the northern fulmar (Fulmarus glacialis; Chapter 2, Chapter 4).

The fulmar is a petrel with a circumpolar distribution, breeding across $35^{\circ}$ of latitude (to $80^{\circ} \mathrm{N}$; Hatch and Nettleship 1998). It is a generalist predator and scavenger, feeding on marine invertebrates, small fish, carrion and industrial fisheries discards (if available; Fisher 1952). This long-lived seabird lays a single egg which is not replaced if lost and exhibits synchronous breeding within colonies, but nesting dates are delayed at higher latitudes (Chapter 2). Most northern fulmars inhabit the Low Arctic and Boreal oceanographic zones year round (Salomonsen 1965, Hatch and Nettleship 1998), but birds from High Arctic colonies only overwinter in this region.

Among seabirds, reproductive success is strongly linked to annual productivity of the marine food web (Furness and Camphuysen 1997). This has been shown for Boreal fulmars (Ollason and Dunnet 1988, Gray et al. 2003), and may be 
linked to long-term climatic and oceanographic cycles (Thompson and Ollason 2001). However, for High Arctic fulmars, breeding phenology and success also may be affected by additional physical aspects of the marine environment, and specifically sea ice cover. In this region, more extensive sea ice, or ice that is delayed in breakup, constitutes a barrier to fulmar foraging, and also delays production in the marine food web (Welch et al. 1992). In years with late sea ice, fulmar reproductive success is reduced (Gaston et al. 2005).

Given that High Arctic fulmars experience some additional constraints on breeding compared to Boreal fulmars, I was interested in determining if the typical reproductive success of High Arctic birds differed from that of conspecifics nesting in the Boreal zone. Falk and Møller (1997) provided some information on fulmars breeding in one season in northeast Greenland, and some summary data for northern Canada are found in Hatch and Nettleship (1998). However, there are no detailed, published accounts of the reproductive ecology of this species across sites and years in the High Arctic, and particularly there are no accounts of how fulmars are affected by the more extreme weather events typical of this region. An assessment of Arctic fulmar ecology is timely, as sea ice and weather patterns are changing rapidly in the Arctic (ACIA 2004).

I studied the breeding ecology of northern fulmars at two colonies in the Canadian High Arctic. Fulmars breeding at these latitudes exhibit a compressed breeding schedule (Chapter 2) and experience subzero temperatures and potential snowfall throughout the nesting period. They cannot exploit industrial fisheries 
during the breeding season (Chapter 1), making them more reliant on natural ecosystem processes. Collectively, these differences may create stresses not faced by fulmars breeding farther south. Consequently, I predicted that mean annual reproductive success of fulmars in the Canadian High Arctic should be lower compared to fulmars nesting in the Low Arctic and Boreal oceanographic zones. Moreover, while some fulmar nests fail at all breeding colonies for a variety of reasons (e.g., predation, abandonment by one member of pair; Ollason and Dunnet 1988), I expected that nest failures of Arctic fulmars would be associated with particularly severe weather events.

\section{Materials and Methods}

The spatial and temporal characteristics of work at the Cape Vera and Prince Leopold Island study sites are described in Chapter 5, with locations depicted in Fig. 5.1. Additional protocols specific to Chapter 8 are described below.

Weather data were recorded at Cape Vera (2003-2005) and at Prince Leopold Island (2005) using a Davis ${ }^{\circledR}$ Vantage Pro weather station, set to record hourly. In other years, Prince Leopold Island weather was recorded once daily using a handheld weather station. However, in most years observations at Prince Leopold Island were initiated after fulmars began laying eggs. Ice conditions near both colonies were obtained from the Environment Canada - Canadian Ice Service climate archives $<$ http://ice-glaces.ec.gc.ca $>$. 
I used "apparently occupied sites" (AOS; Lloyd et al. 1991) as my assessment of birds considering breeding at each site. This method excludes obvious nonbreeding birds on ledges unsuitable for nesting. Northern fulmars have very high fidelity to breeding sites ( $>90 \%$ if no mortality; Hatch and Nettleship 1998), and thus I assumed that observations through the season at a nest were observations of the same pair. Long-term population monitoring plots each supporting $25-300$ nests were established at both Cape Vera $(n=8)$ and Prince Leopold Island ( $n=7)$ (Mallory and Gaston 2005). Nest sites were viewed using $10 \times 42$ binoculars or a $60 \mathrm{X}$ spotting scope from vantage points $30-300 \mathrm{~m}$ distant along the cliff top, so birds were not disturbed during counting. Due to poor weather (below), data were not necessarily collected on all plots each day.

Detailed, daily observations ( $\leq 4 \mathrm{hrs}$ ) were conducted on selected nest sites to determine which mate was attending the nest, and to identify whether an egg or chick was in the nest. It is not easy to determine if a fulmar is on an egg, as non-breeders often appear to be incubating for periods of hours, but then leave the nest site (Fisher 1952, Gaston et al. 2006). I had the same personnel monitor the same plots as much as possible within each year, which allowed observers to become familiar with the individual bird's appearance and behaviors. Occasionally nest failures occurred during periods when I could not view the nest (e.g., fog), or when prolonged observations of adults still could not determine if the adult bird was on an egg (although behavioral cues often helped deduce nest status). In these cases, I ascribed 
nest failure date as the midpoint between the previous and next conclusive assessment of nest contents (typical error \pm 1 day).

Using daily observation data, I calculated mean daily egg or chick survival to compare among sites and years. For all calculations, dates were converted to ordinal dates, with 1 January $=001$. Methodologies used to study fulmars were similar at both sites, but more field assistants were used at Cape Vera, particularly in 2005. For this reason, and because some of the Prince Leopold Island data has been presented previously (Gaston et al. 2005, 2006), I refer principally to Cape Vera data for certain analyses, but use data from both sites and/or all years where possible.

Depending on the distribution of data, I used $t$-tests, ANOVAs, Pearson or Spearman rank correlations to compare data among years or colonies (Systat Software Inc. 2002). To examine relationships between nest failure and weather, I grouped data by 3 day periods (to capture the full extent of some storms), and used Spearman rank correlations to compare numbers of eggs lost in that period to average weather conditions over that period. Means are presented $\pm \mathrm{SE}$, and all statistical tests report two-tailed probabilities.

\section{Results}

Weather and ice

At Cape Vera, temperatures were below $-10^{\circ} \mathrm{C}$ when fulmars arrived at the breeding cliffs (Fig. 8.1a). Temperatures warmed during the breeding season (3-yr mean daily 


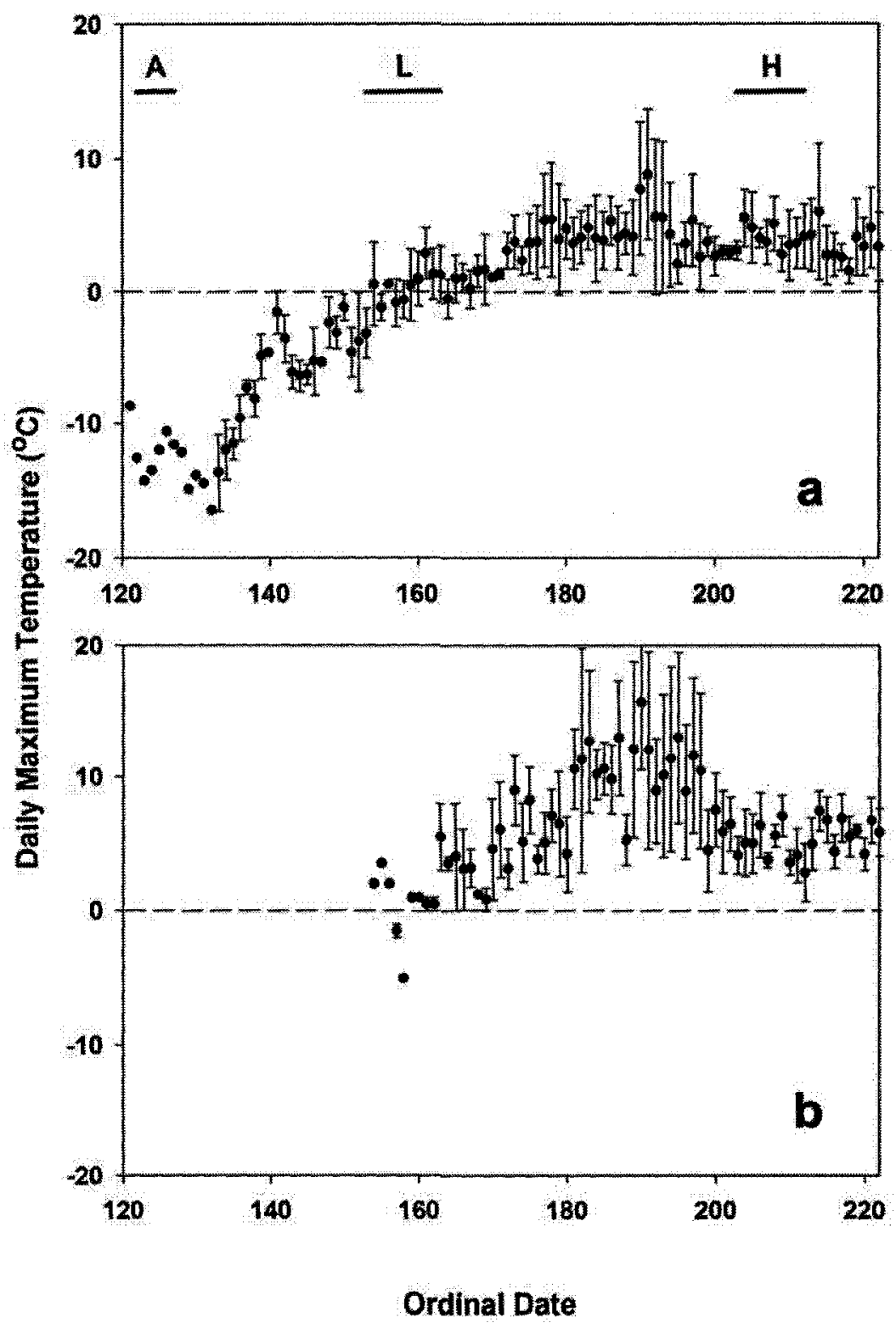

Figure 8.1. Mean $( \pm$ SE) daily temperature at (a) Cape Vera, Devon Island, 20032005, and (b) Prince Leopold Island, 2002, 2003, 2005. Lines above the temperature graph indicate the periods of arrival at the colony by fulmars (A), laying (L) and hatching $(\mathrm{H})$ at Cape Vera, which are similar at Prince Leopold Island. 
means; $r_{83}=0.74, P<0.001$ ), but overall maximum temperatures during incubation and early chick-rearing ( 8 June -11 August) were $\operatorname{cool}\left(3.4 \pm 0.4^{\circ} \mathrm{C}, n=65\right.$ days, range $\left.2.7-14.0^{\circ} \mathrm{C}\right)$. The mean daily maximum wind speed was $13.2 \pm 1.6 \mathrm{~km} / \mathrm{h}(8.0-62.8$ $\mathrm{km} / \mathrm{h} ; n=65$ ), and gusts exceeded $100 \mathrm{~km} / \mathrm{h}$ at least once each month. Fog was frequent ( $>25 \%$ of days each year), and snowfall occurred every month, with significant wet snow accumulation $(>10 \mathrm{~cm})$ in July of each year. At Cape Vera (and probably Prince Leopold Island), the laying period coincided with the point at which ambient mean daily temperatures rose above $0^{\circ} \mathrm{C}$ (Fig. 8.1).

Weather conditions were similar at Prince Leopold Island (Fig 8.1b), but mean daily maximum temperatures during incubation and chick-rearing were warmer $\left(6.5 \pm 0.4^{\circ} \mathrm{C}, n=65\right.$, range $\left.-0.8-26.3^{\circ} \mathrm{C}\right)$. Blizzards occurred on 18-20 August 2001, and again on 13 June, 23 July, and 13 August 2003. In the breeding seasons of 20012005 , mean daily maximum wind speed was $18.3 \pm 1.0 \mathrm{~km} / \mathrm{h}(0-70 \mathrm{~km} / \mathrm{h} ; n=174$ days). Fog was common ( $>25 \%$ of days) in all years, but in 2005, 22 of 51 (43\%) days at the field site were too foggy or snow was too heavy to safely conduct fulmar observations.

In early June 2001 and 2002 (i.e., egg-laying), sea-ice was >90\% solid cover from Prince Leopold Island to the nearest open water $200 \mathrm{~km}$ to the east, whereas in 2003 and 2005 there was open water immediately beside the colony in early June. In contrast, at Cape Vera there was a pocket of open water (polynya) located immediately beside the colony in early June, but sea-ice extended for approximately $200 \mathrm{~km}$ to the west in Jones Sound, which remained through much of July before 
breaking up in August. During the previous decade (1996-2005), the mean distance to open water at Cape Vera (excluding the Hell Gate Polynya) in the second week of June was $190 \pm 5 \mathrm{~km}$, a distance that was consistent across years (coefficient of variation 9\%). In contrast, at Prince Leopold Island the mean distance was $42 \pm 39$ $\mathrm{km}$ and was much more variable (coefficient of variation $292 \% ; F$-ratio test, $\left.F_{18}=50.5, P<0.001\right)$.

\section{Weather and timing of reproductive failure}

Reproductive failure occurred throughout the breeding season at both colonies (Fig. 8.2a). Of 346 nest failures observed at Prince Leopold Island or Cape Vera during 2001-2005, 67\% occurred during incubation, and 33\% occurred during chick-rearing. At Cape Vera, six of $216(3 \%)$ nest attempts failed because the pair pushed the egg out of the nest cup. At Prince Leopold Island, 22 of $306(7 \%)$ nest attempts failed because eggs did not hatch (i.e., eggs were observed in the nest after the latest hatch date in the colony), a proportion significantly larger than was observed in two years at Cape Vera ( 2 of 216 [1\%]; Fisher Exact test, $P=0.0005$ ).

At Prince Leopold Island in 2003, mean daily egg survival rate from 6 June to 24 July (typical fulmar incubation period) was $0.9894 \pm 0.0023$. Of the 61 eggs lost on the monitoring plots that year, nine $(15 \%)$ were confirmed lost during blizzards, and a further 10 eggs $(16 \%)$ were only observed after the snow cover had melted, suggesting fulmars abandoned nests during the storms and eggs were buried. Collectively, eggs tended to be lost during periods of low barometric pressure 


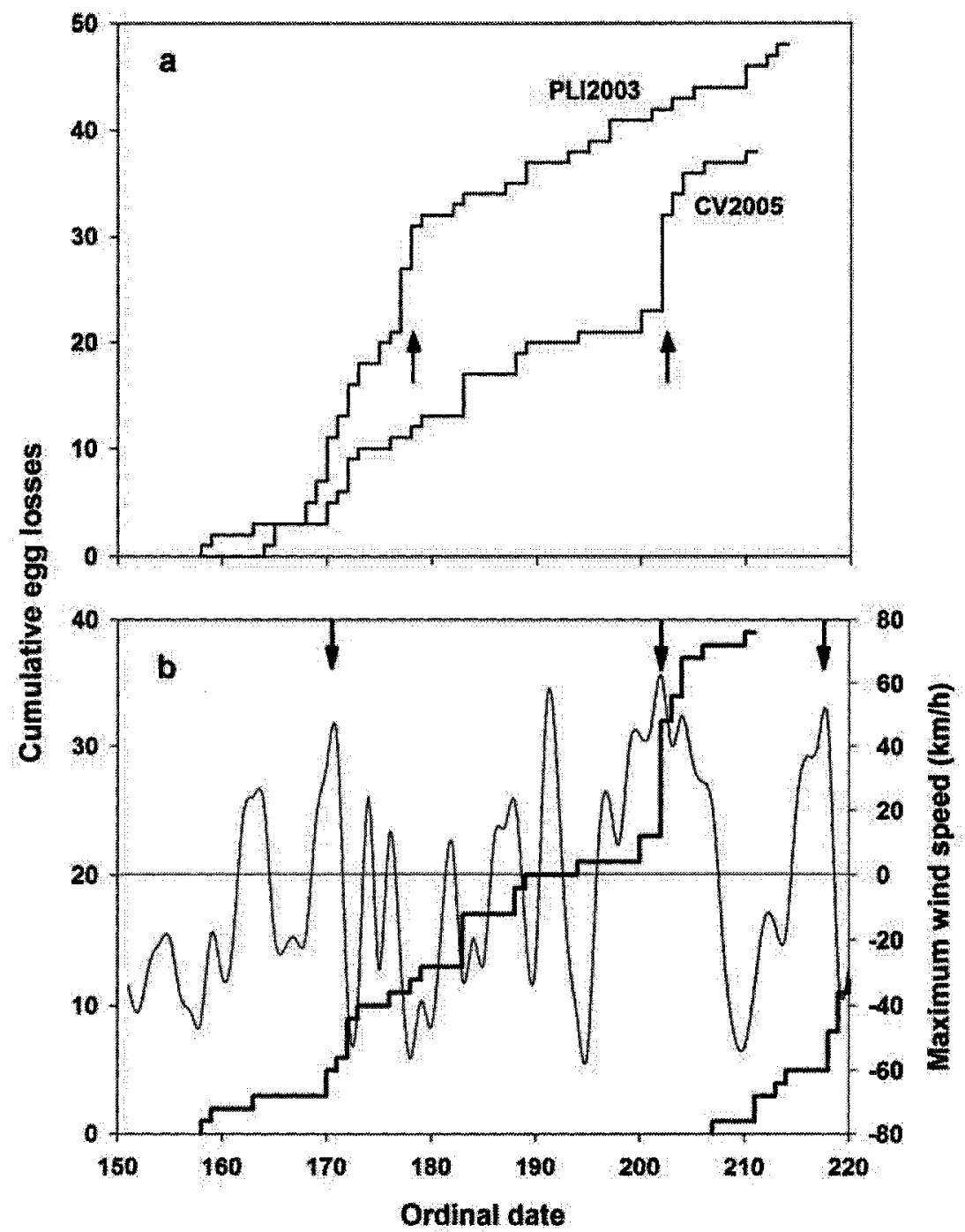

Figure 8.2. Cumulative mortality of fulmar eggs or chicks at Prince Leopold Island in 2003 (PLI03) and Cape Vera in 2005 (CV05). The upper panel (a) depicts the timing of egg losses, with pulses of mortality noted by arrows. In the lower panel (b), the thin line is maximum daily wind speed at Cape Vera, the thick lines are cumulative egg (left) or chick (right) loss, and arrows represent storms with easterly wind gusts > $70 \mathrm{~km} / \mathrm{h}$. 
(associated with snowstorms; $r_{\mathrm{s} 16}=-0.54, P=0.03$ ) but not necessarily during periods of greater wind velocity $\left(r_{\mathrm{s} 16}=-0.20, P=0.45\right)$. Furthermore, $16 \%$ of the chicks in monitoring plots died (blew off or were depredated) during the snowstorm on 13 August 2003, representing 58\% of total chick mortality. In 2001, 26\% of monitored chicks appeared to be killed by a snowstorm on 19-20 August (not all these deaths could be verified before the field party left), representing a minimum of $45 \%$ of total chick mortality. However, in 2005, when no blizzards occurred during the portion of the nestling period observed, the mean daily chick survival rate for the first 14 days after hatch was very high $(0.9984 \pm 0.0016, n=44$ nests $)$.

At Cape Vera in 2005, mean daily egg survival rate was similar to that of Prince Leopold Island (above) for the incubation period ( $0.9915 \pm 0.0026, n=49$ days; Mann-Whitney $U=1069, P=0.34)$. However, in contrast to Prince Leopold Island, eggs tended to be lost during periods of high wind $\left(r_{\mathrm{s} 15}=0.59, P=0.02\right)$, but not lower barometric pressure $\left(r_{\mathrm{s} 15}=-0.19, P=0.50\right)$. Three storms supporting sustained east winds $>40 \mathrm{~km} / \mathrm{h}$ (peak gusts $>70 \mathrm{~km} / \mathrm{h}$ ) led to $62 \%$ of the 52 nest failures, including one on 6 August during which $46 \%$ of monitored chicks disappeared (presumably all depredated). Interestingly, a major snowstorm on 12-14 July 2005 (193-195; > 20 $\mathrm{cm}$ ), with westerly winds $>40 \mathrm{~km} / \mathrm{h}$, did not result in substantial egg loss (Fig. 8.2b). Mean daily chick survival rate was $0.9739 \pm 0.0099$ ( $n=38$ nests) in 2004 and 0.9814 \pm 0.0058 in 2005 ( $n=59$ ), both of which were significantly lower than the daily chick survival rate at Prince Leopold Island in 2005 (paired $t$-tests, $t_{13}>2.6, P_{\mathrm{S}}<0.05$ ). 
Over two years at Cape Vera, mean daily chick survival rates were lower in the first 10 days after hatch than in the second 10 days (Fig. 8.3), as more chicks were lost by day 10 (23 chicks) than between day 11 and 20 (three chicks; Binomial test, $P<0.001)$. Higher chick survival after day 10 corresponds to the start of the rearing period when both parents leave the chick alone while they forage.

\section{Annual reproductive success}

Annual reproductive success varied at Cape Vera and Prince Leopold Island (Table 8.1). For both sites, approximately $70 \%$ of the pairs at AOS produced an egg, but annually $40-81 \%$ of those eggs hatched, and $42-88 \%$ of hatched chicks survived to the post-guard stage. The greater values for chick survival in 2004 and 2005 may be related to the field schedule, because chicks were monitored for approximately 10 days less than in the earlier years. Nonetheless, chick mortality appears to be uncommon once parents stop guarding the young around day 14 (Fig. 8.3). Because I have no records of local weather at either site after the end of observations, and local weather differs from conditions at the nearest weather station in Resolute Bay (M. L. Mallory, unpubl. data), I could not model fledging success reliably.

If no significant storms occurred after our observations ceased, fulmars produced an estimated 0.27 fledglings/AOS in 2004 and 0.36 fledglings/AOS in 2005 at Cape Vera. At Prince Leopold Island in 2005, fulmars produced 0.26 fledglings/AOS. Over these five breeding seasons and two sites, 231 of 901 fulmar 


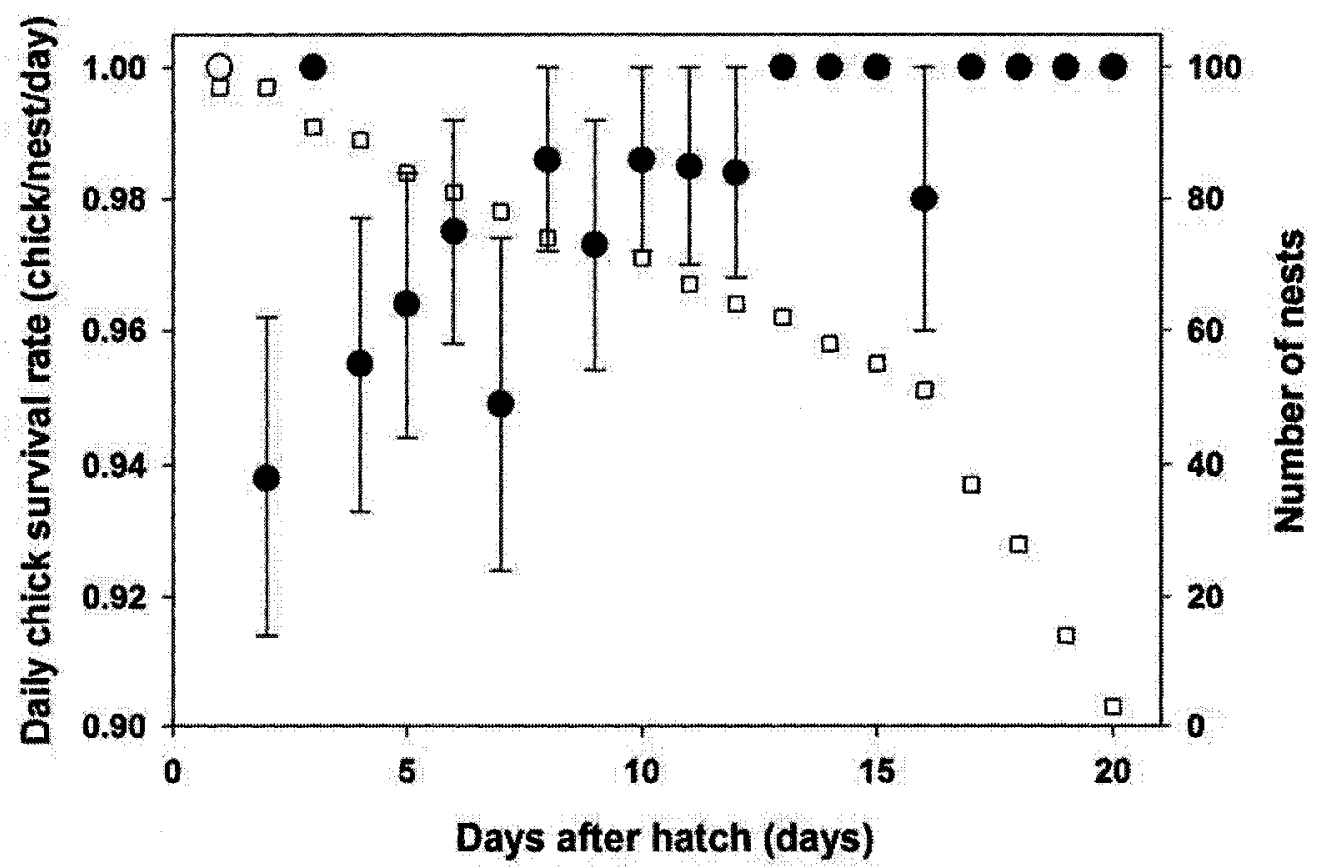

Figure 8.3. Mean (SE) daily fulmar chick survival rates at Cape Vera, pooled for 2004 and 2005. The open circle on day 1 corresponds to day of hatching, and was $100 \%$ survival because we could not account for chicks that may have been lost on that day before our observations. Daily sample sizes (open squares, right hand $\mathrm{Y}$ axis) declined with increasing age, due both to mortality, or the end of our observation period. 
Table 8.1. Measures of reproductive perfomance of northern fulmars from Prince Leopold Island (PLI) and Cape Vera (CV) in the Canadian high Arctic, 2001-2005. AOS refers to apparently occupied sites. Estimates of maximum fledging success and productivity assume that all chicks reaching the post-guard stage survived to fledge.

\begin{tabular}{|c|c|c|c|c|c|c|c|c|c|}
\hline \multirow[t]{2}{*}{ Site Year } & \multirow[t]{2}{*}{ AOS } & \multirow{2}{*}{$\begin{array}{l}\text { Eggs } \\
\text { laid }\end{array}$} & \multirow{2}{*}{$\begin{array}{l}\text { Chicks } \\
\text { hatched }\end{array}$} & \multirow{2}{*}{$\begin{array}{l}\text { Median date } \\
\text { of hatching }\end{array}$} & \multirow{2}{*}{$\begin{array}{l}\text { Chicks } \\
\text { reaching } \\
\text { post-guard }\end{array}$} & \multicolumn{4}{|c|}{ Proportion $(\%)$} \\
\hline & & & & & & $\begin{array}{c}\text { Pairs that } \\
\text { laid }\end{array}$ & $\begin{array}{l}\text { Eggs that } \\
\text { hatched }\end{array}$ & $\begin{array}{l}\text { Maximun } \\
\text { hatched chicks } \\
\text { that could fledge }\end{array}$ & $\begin{array}{l}\text { Maximum prodictivity } \\
\text { (max chicks fledged / egg } \\
\text { 1aid) }\end{array}$ \\
\hline PLI 2001 & 172 & 127 & 103 & 28 July & 431 & 74 & 81 & 42 & 34 \\
\hline PLI 2002 & 132 & 87 & 39 & $28 \mathrm{Iny}$ & 171 & 66 & 45 & 44 & 45 \\
\hline PLI 2003 & 124 & 102 & 41 & 28 July & 281 & 82 & 40 & 68 & 40 \\
\hline PL 2005 & 182 & 96 & 51 & $26 \mathrm{July}$ & $45^{2}$ & 53 & 53 & 88 & 47 \\
\hline CV 2004 & 154 & 112 & 54 & 25 Iuly & 462 & 73 & 48 & 85 & 41 \\
\hline CV 2005 & 137 & 104 & 65 & 25 July & 522 & 76 & 62 & 80 & 50 \\
\hline \multicolumn{6}{|c|}{ Mean (SE) } & $71(4)$ & $55(6)$ & $68(8)$ & $43(2)$ \\
\hline
\end{tabular}

${ }^{1}$ Maximum fledging (chicks observed to -20 days old)

2 Nests were monitored for 10 days longer at PLI in 2001-2003 than in other years, values represent chicks surviving $>10$ days (11 nests at PLI in 2005 were only 4-8 days in the ehick guard period). 
pairs at AOS (26\%) produced a chick that reached the post-guard stage and probably survived (or $37 \%$ of the 628 fulmar pairs that laid an egg).

\section{Discussion}

The northern fulmar colonies at Cape Vera and Prince Leopold Island share many similarities, including their nesting structure, body size, proportion of different color morphs, and breeding schedule (Hatch and Nettleship 1998, Mallory and Forbes 2005, Gaston et al. 2006, Chapter 2). I identified some additional similarities between these colonies that differ from colonies elsewhere in the species' range, but discovered notable differences in fulmar reproductive success at these sites.

\section{Reproductive success and weather}

Consistent with my prediction, northern fulmar colonies in the Canadian High Arctic exhibited lower annual reproductive success than Boreal fulmar colonies (Table 8.2), although the pattern and timing of reproductive failure was similar (most losses during incubation; Dunnet et al. 1979, Hatch and Hatch 1990). Although hatching success, estimated fledging success, and chick survival (Greenland, 100\% after 20 days; Falk and Møller 1997) in this study was similar to previous work (Table 8.2), I found that only $26 \%$ of AOS in the Canadian High Arctic produced a chick that fledged (range $13-32 \%$ per year). This contrasted with higher annual reproductive success reported for Alaska, Greenland, and across the United Kingdom (up to twofold difference; Table 8.2). 


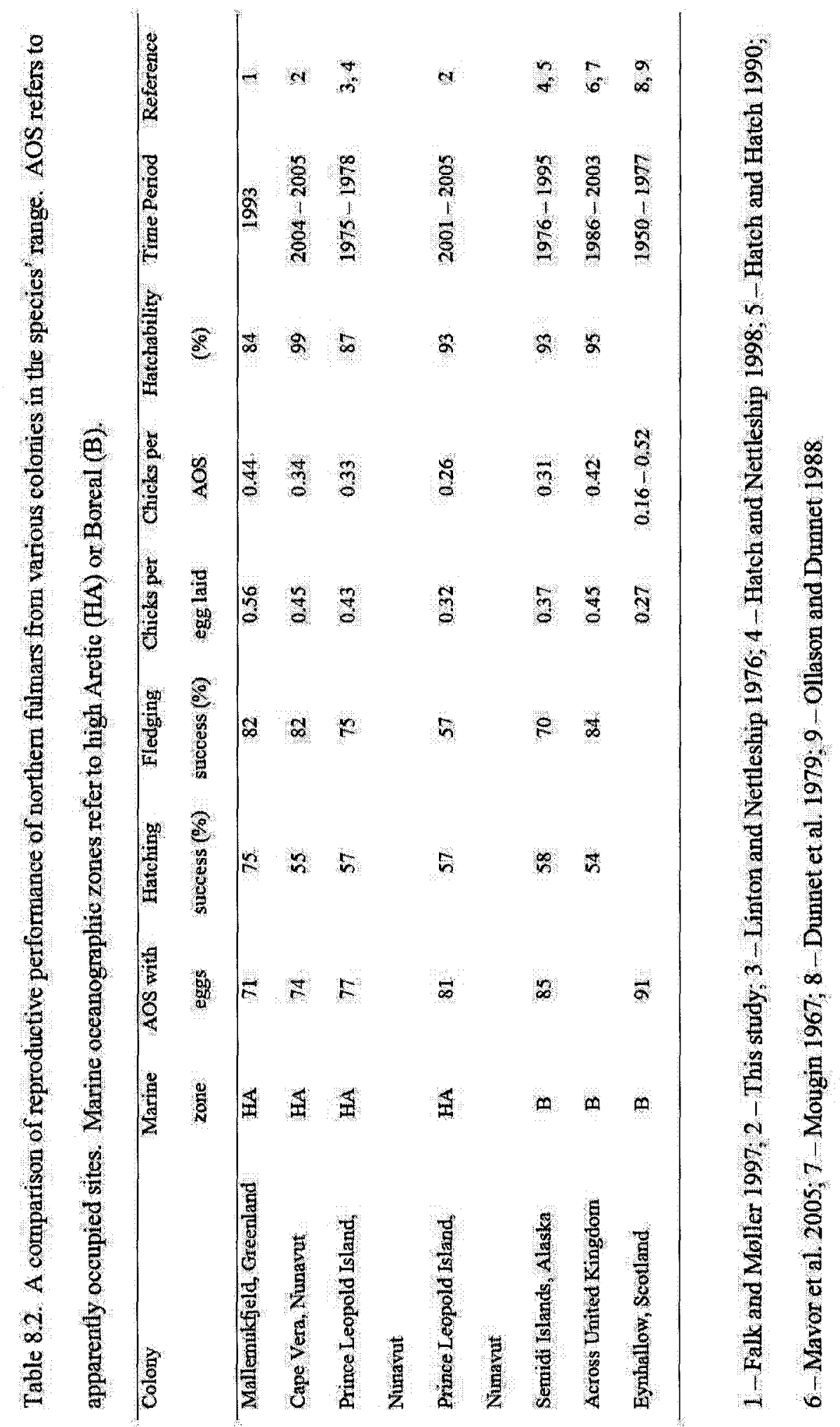


These proportional differences are not explained by lower success per egg laid. The mean annual number of chicks fledged per egg in my study $(43 \pm 2 \%, n=6$ colony-years) did not differ from that in Alaska ( $37 \pm 5 \%, n=15$ years; Hatch and Nettleship 1998) or previously at Prince Leopold Island ( $40 \pm 4 \%, n=4$ years; Hatch and Nettleship 1998; ANOVA, $F_{2,22}=0.32, P=0.7$ ), and was similar to the $27 \%$ average for Eynhallow, Scotland, although values for Greenland in 1993 were higher (Table 8.2). Instead, the lower success per AOS in Canadian High Arctic colonies must be related to a larger proportion of birds attending sites that do not attempt to breed.

Studies in Greenland and the Canadian High Arctic suggest that up to 20\% more fulmar pairs attending nest sites did not lay an egg compared to fulmars breeding in Alaska or the United Kingdom (Table 8.2). In my study, results could have been biased by data from Prince Leopold Island in 2001 and 2005, where nest observations were initiated after the median laying date, and thus I could have underestimated true laying attempts. However, I paid particular scrutiny to the laying period at Cape Vera in 2005, to ensure that I recorded all laying attempts, and eggs laid per AOS was similar in 2005 to most other years (Table 8.1). Fulmars have very high nest site fidelity (Hatch and Nettleship 1998), and I observed that 33 pairs continued to attend their nest site for 17.0 \pm 1.7 days (range 5-39 d) after nest failure. Thus, I posit that my potential bias would have reduced the measure of chicks produced per egg laid, but not productivity per AOS. 
Like other fulmarine petrels breeding at high latitudes (Hodum 2002;

Creuwels et al. 2008), High Arctic fulmars have a short window of opportunity in which to breed (Chapter 2). When environmental conditions or their own physical condition are insufficient to meet the necessary breeding schedule, selection should favour birds that skip breeding rather than incurring stress that might reduce future chances of reproduction in these long-lived birds (Trivers 1972), particularly in late or extensive ice years when marine production, and consequently fulmar reproductive success, are reduced (Welch et al. 1992, Gaston et al. 2005). Thus, I speculate that in any year in the High Arctic, a larger proportion of fulmars may find environmental conditions unsuitable and skip breeding, compared to fulmars breeding at colonies farther south.

Hatchability of fulmar eggs (i.e., the proportion of eggs incubated to full term that hatch) varied markedly by colony and year. I observed high hatchability in both years at Cape Vera, but rates were lower in Alaska, Greenland, and at Prince Leopold Island (Table 8.2). Observed hatchability differences seem unrelated to colony size, latitude or nest initiation date (see Koenig 1982), and likely do not reflect infertility differences within the same species at different colonies (Warham 1990). Instead, I suggest two possible mechanisms that might account for colony-specific differences in hatchability. First, Prince Leopold Island receives more heavy snowfall through the season, whereas Cape Vera is colder (due to the proximity of the ice cap; Fig. 3.1.) Blanketing snow may lead to increased egg neglect (absence by both adults from the nest during incubation). Despite considerable chill tolerance in fulmar eggs 
(Warham 1990), inexperienced fulmar pairs may not attend nests enough during snowstorms to provide the required incubation, and the egg may die, even though parents return after the storm to incubate, and continue past term before abandoning the breeding attempt. Second, exposed fulmar eggs appear to be depredated very quickly at Cape Vera by glaucous gulls (Larus hyperboreus), presumably because these are the only seabird prey available to the gulls. At Prince Leopold Island, however, gulls can also prey on thick-billed murres (Uria lomvia) and black-legged kittiwakes (Rissa tridactyla). If the costs of foraging on these other species are lower than risking contamination by fulmar stomach oil (potentially lethal; Swennen 1974), then predation pressure may be relatively lower on fulmars at Prince Leopold Island than at Cape Vera. Hence, neglected eggs may remain uneaten for longer, allowing absent parents to return and continue incubation.

Weather at High Arctic colonies may affect hatchability of eggs, but more importantly it is the major factor influencing nest failure at both colonies I studied, in contrast to results of Boreal fulmars in Alaska (Hatch and Hatch 1990). Wind storms were associated with pulses of nest failure at Cape Vera, as were snowstorms with peaks of nest failure at Prince Leopold Island. In contrast to the "pulses" of nest failure observed at High Arctic colonies, failure at Boreal colonies may be more gradual unless storms are profoundly intense. For example, Gray et al. (2003) noted that a nine day period of bad weather resulted in $36 \%$ mortality of fulmar chicks being monitored, and $53 \%$ of total chick mortality, a proportion similar to what I observed in storms lasting one or two days. 
Typical weather and sea-ice patterns may also explain some of the differences between our study and the results of Falk and Møller (1997), studying fulmars at the Northeast Water Polynya (High Arctic) near Greenland. They found that the fulmar breeding schedule was timed to coincide with the breakup and reforming of sea ice in the nearby polynya, presumably because many fulmars foraged in this area. Falk and Møller (1997) had calm conditions in their study, with only two days where winds were $>36 \mathrm{~km} / \mathrm{h}$ for all of June and July (no mention of significant snowstorms), with one gale preceding egg-laying and another occurring when most chicks were 14 days old. It is unclear how representative these conditions were of most years. They recorded chick survival of $91 \%$, higher than I estimated in this study $(68 \pm 8 \%)$, or at Prince Leopold Island in 1976 (88\%; Linton and Nettleship 1977), or the range observed in the northern United Kingdom (55-87\%; Gray et al. 2003). Thus, the Greenland data demonstrate that not all High Arctic colonies suffer weather-related losses every year.

Gaston et al. (2005) showed that another climate-related variable, late breakup of sea ice, also had a deleterious effect on fulmar reproduction at Prince Leopold Island. However, sea ice distribution is unlikely to influence fulmar reproduction at Cape Vera as strongly, because the floe edge is more predictable at this site (Smith and Rigby 1981, this study). Open water adjacent to the latter colony is always available in the Hell Gate - Cardigan Strait polynya by the time the fulmars arrive, unlike the variable sea ice conditions in early May at Prince Leopold Island. Moreover, satellite telemetry indicates that active and failed breeders at Cape Vera fly 
$>200 \mathrm{~km}$ one way to feed (Mallory et al. 2008), and helicopter transects near Cape Vera have found few fulmars beyond a $2 \mathrm{~km}$ radius from the colony during the breeding season (M. L. Mallory, unpubl. data). In contrast, many fulmars apparently feed closer to Prince Leopold Island during the breeding season $(<50 \mathrm{~km}$; Nettleship and Gaston 1978). Fulmars feeding chicks at Cape Vera typically have few distinguishable parts in regurgitations (suggesting a long retention time), whereas items in regurgitations at Prince Leopold Island can often be identified (Linton and Nettleship 1977, Hatch and Nettleship 1998), again suggestive of relatively longer foraging trips by adults at Cape Vera.

I hypothesize that colony-specific behavioural adaptations may allow fulmars at Cape Vera to successfully breed despite extensive but predictable sea ice near the colony persisting to the chick-rearing period, compared to Prince Leopold Island. These adaptations may include an earlier and more synchronized breeding phenology within and across years (Chapter 2). Although data are available for only two seasons at Cape Vera, the dates for colony arrival (1 May), first egg date (3 June), median date of laying (6 June), median date of hatching ( $25 \mathrm{July}$ ), and latest possible date of hatching (3 August) are generally earlier than observed at Prince Leopold Island (Hatch and Nettleship 1998; Gaston et al. 2005), despite being farther north and more isolated by sea ice for longer. Future monitoring at Cape Vera will determine if phenology and reproductive success are less variable across years compared to Prince Leopold Island. 


\section{Fulmar colonies in the High Arctic}

My study demonstrated that certain aspects of fulmar reproductive ecology are common across the species range. However, fulmars breeding at colonies in the High Arctic have developed a compressed breeding schedule (Chapter 2), and more birds attended colonies without breeding each year, resulting in lower chicks fledged per AOS, compared to Low Arctic and Boreal colonies. Extreme weather events during breeding, such as heavy snowfall or strong winds, led to considerable nest failure.

If the number of fledglings produced per egg laid is similar across the species' range, but High Arctic fulmars experience more weather-induced nest failure, then High Arctic fulmars must experience less fluctuation in marine food supplies, a major factor influencing fulmar reproductive success elsewhere (Hatch and Hatch 1990, Gray et al. 2003). At Cape Vera, fulmars forage in a large, recurrent polynya on natural prey, and thus polynya productivity may be stable across years. Moreover, the pulse of marine production in Arctic waters around these colonies probably peaks during chick-rearing (Welch et al. 1992, Barbraud and Chastel 1998), making acquisition of food relatively easy for provisioning young, and perhaps offsetting losses caused by random, catastrophic storms. In contrast, Boreal fulmars may have more dietary options, including fish and fisheries discards (Fisher 1952, Gray et al. 2003), but prey availability may vary more in relation to climate cycles and economics. Given that High Arctic and Boreal fulmars overlap in wintering conditions in the North Atlantic Ocean (Mallory et al. 2008), a simultaneous investigation of colony attendance, and the proximate causes of nest failure at 
colonies in both oceanographic zones would help identify the relative importance of factors influencing reproductive success. 


\section{CHAPTER 9}

\section{Prebasic molt initiation and progress in northern fulmars of the High Arctic: do molt and breeding overlap?}

This chapter formed the basis for the following publication:

Allard, K. A., M. L. Mallory, K. L. Wilcox, and M. R. Forbes. 2008. Prebasic molt initiation and progress in northern fulmars of the High Arctic: do molt and breeding overlap? Polar Biology 31: 181-188. 


\begin{abstract}
I examined feather molt progress of northern fulmars (Fulmarus glacialis) at Cape Vera in the Canadian High Arctic through opportunistic observation of individuals in flight from 2003 to 2006 , and examination of bodies and wings of 127 individuals collected at the site, from 2003 to 2005 . I found no evidence suggesting that fulmars shed primary feathers during breeding. Prebasic molt was initiated in the head, neck, sides, belly and back approximately one week before hatch. I failed to detect a sex effect on molt progress, but molt among breeders was delayed compared to molt in non- or failed breeders. This study constitutes a baseline I feel may be useful to: 1) researchers interested in feather replacement chronology, wherein feathers are used as sources of biological information; and 2) researchers interested in eventual assessment of relationships among large-scale environmental processes and molt progress in this species, especially in light of predicted changes to Arctic regions.
\end{abstract}




\section{Introduction}

Characteristics of local breeding bird populations, such as timing of breeding, measures of body condition and their proxies, as well as reproductive output in birds, are commonly proposed metrics valuable to investigation of ecological change (e.g., Visser et al. 1998, Frederiksen et al. 2004, Grosbois and Thompson 2005). More recently, increasing numbers of studies use tissues, including feathers, as source material (e. g., work with isotopes) to infer on contaminant burden, diet and geographical distribution within and among species (e.g., Hodum and Hobson 2000). Studies which use feathers in particular rely on knowledge of molt chronology (e.g., Thompson and Furness 1995), often derived from the literature, and are vulnerable to poorly understood potential sources of variation. Also, molt strategies and variation in molt progress (i.e., timing of onset, and rate) often are overlooked and remain largely understudied (Ginn and Melville 1983). Molt, reproduction, migration, and the accumulation of fat reserves are considered energetically-demanding processes for birds (Chu 1984, King and Murphy 1985), and tend to be temporally segregated and timed with periods of food abundance (Payne 1972, Ricklefs 1974). For example, molt of flight feathers and reproduction generally occur at different times, likely to optimise the trade-off between breeding success and survival until the next breeding season (Holmgren and Hedenström 1995, Robertson et al. 1998). Though molt can represent a relatively small net daily expenditure in terms of feather synthesis (King and Murphy 1985, Norstrom et al. 1986), additional costs might also be incurred through reduced flying ability (Beck 1970, Lindström et al. 1994, 
Swaddle and Witter 1997) and reduced foraging efficiency, as well as increased thermoregulatory expenses. According to theory, costs incurred through increased energetic expenditures related to molt would compete with allocation of resources to reproductive effort, and thus selection should favour molt initiation occurring upon completion of breeding.

In some situations, however, where food resources are not limiting, or environmental conditions place constraints on the completion of other life history processes (e.g., migration), molt and breeding may overlap (reviewed by Bridge 2006). For example, Barbraud and Chastel (1998) showed that southern fulmars (Fulmarus glacialoides) breeding in Antarctica initiated primary molt during incubation, presumably due to a short summer season and abundant marine food supplies, and a similar explanation was proposed for molt-breeding overlap in giant petrels (Macronectes spp.; Hunter 1984). Furthermore, the absence or removal of costs of breeding should lead to earlier onset of molt for failed breeders, non-breeding adults and juveniles, which has been observed in many species (Ginn and Melville 1983).

I studied molt in northern fulmars (Fulmarus glacialis), the only petrel (Procellariiformes) found in the Boreal, Low Arctic and High Arctic oceanographic zones (Salomonsen 1965). The timing of molt and reproduction typically are segregated in the petrels (Warham 1996), including fulmars (Hatch 1979, Hatch and Nettleship 1998), although Bridge (2006) recently suggested that that Procellariiformes were more likely to overlap molt and reproduction than other 
seabirds, especially in sedentary or dispersive populations. Fulmars undergo a single, complete molt (Hatch and Nettleship 1998), the timing of which varies primarily in relation to breeding status. Non-breeders enter molt earlier than breeders, and primary molt is initiated by failed breeders approximately two weeks after nest loss (Hatch and Nettleship 1998). However, many earlier studies of molt in this and other species failed to distinguish effectively breeders from non- or failed breeders. Furthermore, incorrectly qualifying failed or non- breeders as breeders can lead to the false conclusion that overlap exists between molt and reproduction. This stresses the importance of individual-based information in molt studies and the challenge inherent to comparison with some earlier studies. Molt has been documented in fulmars principally occupying colonies in the Boreal oceanographic zone (Duffey 1950, Carrick and Dunnet 1954, Dott 1973, Hatch 1979). Body molt in breeding individuals at Alaskan colonies was observed as early as late incubation, with onset of primary molt occurring rarely near the end of chick-rearing (Hatch 1979, Hatch and Nettleship 1998). The observation that some breeders initiate primary molt in late incubation (Hatch 1979) might be attributable to high food resource abundance (Carrick and Dunnet 1954).

I observed molt by fulmars breeding at the remote Cape Vera colony in the Canadian High Arctic (Mallory and Fontaine 2004) and assessed molt progress at both the individual and colony levels, to compare to these previous studies. Little information on molt chronology exists for the large fulmar populations associated with colonies in this region, except for some observations of molting fulmars at sea 
(Brown 1988). Polar regions are characterized by having: (1) shortened seasonal opportunities for reproduction; (2) extreme winter conditions and sea ice cover which collectively impose the need to migrate; and (3) spatially and temporally concentrated food resources (Hamer et al. 2002). At Cape Vera, fulmars exhibit a compressed and adjusted breeding schedule (Chapter 2) and relatively long incubation shifts (Chapters 5,6 , which presumably reflect behavioural adaptations to low marine productivity (i.e., food supplies) during the early part of the breeding season (Raymont 1976).

The principal objectives of this study on northern fulmars in the Canadian High Arctic were to: (1) establish the first baseline chronology of body molt for this species in this region; (2) determine whether incubation and molt overlap, as seen for southern fulmars (Barbraud and Chastel 1998); (3) assess how molt differs among breeders and non-breeders; and (4) determine whether there are sex-specific differences in molt patterns.

\section{Materials and Methods}

The study was undertaken at Cape Vera, Devon Island, Nunavut, Canada (Fig. 2.1) where 71,32 , and 24 individual fulmars were collected during 2003, 2004, and 2005, respectively, as part of a larger project examining the ecology of fulmars at this remote site. The 2003 sample included breeders, failed breeders and likely nonbreeders captured between 10 June and 18 August. The remaining fulmars were breeders collected 18 May and 16 July 2004, and 4 May and 11 June 2005, respectively. Birds were captured on the nest using poles equipped with nooses, and 
were quickly euthanized by decapitation. Those birds captured during pre-laying were assumed to be breeders (Chapter 2), while those captured after egg-laying were classed as breeders if they were incubating an egg. The 2003 sample also included individuals shot with shotguns in the vicinity of the colony (following Canadian Council on Animal Care guidelines). These birds were principally non- or failed breeders, based on telemetry work conducted at the site (M. L. Mallory, unpubl. data), as well as information from dissection (below). Fulmars varied in color from dark (DD) to light (LL), although the majority were in the intermediate categories (D and L; Hatch and Nettleship 1998).

All birds sampled were sexed through dissection and direct examination of gonads. Presence and size of a post-ovulatory follicle, determined through dissection, allowed me to further classify females as non- versus failed breeders. Also, telemetry evidence suggests breeders leave the colony to forage hundreds of kilometers to the east (Mallory et al. 2008), thereby spending less time at or near the colony shoreline area, where fulmars were observed and shot. I was otherwise unable to age individuals. Northern fulmars at the site exhibited high breeding synchrony, thus limiting the need for correcting for differences in breeding phenology among individuals (i.e., number of days after clutch initiation), a potentially important covariate in other circumstances and in other species.

I determined intensity of feather replacement through counts of blood quills in 20 feather region (Titman et al. 1990, Thompson and Drobney 1995): crown, cheek, chin-throat, neck, upper back, scapulars, lower back, rump, upper tail coverts, 
rectrices, undertail coverts, collar, breast, belly, side, flank, primaries, secondaries, tertials, and wing coverts. Each feather region was subject to three grab samples. Molt intensity initially was obtained by calculating a percentage of the number of pin and/or growing feathers compared to completed molted feathers within each of the 20 individual regions. For each individual, I then calculated a mean total molt intensity value which represented the mean of all feather region molt intensities, with values of 0 representing no molt, $0.01-1.0$ representing light molt, and values $\geq 1.01$ representing intermediate or heavy molt (Thompson and Drobney 1995).

I used the method of Ashmole (1962) to obtain Primary Molt Scores (PMS), calculated as the sum of molt scores obtained from each primary feather $(0=$ old feather in place, to $5=$ new feather fully grown), from innermost P1 to outermost P10, in each wing. Although primary molt is typically thought to be symmetrical (Weimerskirch 1991), I examined and calculated molt scores for both right and left wings. Also, from 2003 to 2006, through the breeding season I recorded opportunistically the proportion of flying fulmars observed in primary wing molt, by counting at least 100 birds at one viewing each day, and recording how many of those birds exhibited wing molt. I conducted the same procedure at a separate fulmar colony (Prince Leopold Island, $74^{\circ} \mathrm{N}, 90^{\circ} \mathrm{W}$ ) in 2005 .

\section{Statistical analyses}

I used paired $t$-tests, Mann-Whitney U tests, Kruskal-Wallis tests, and Fisher's Exact tests to assess possible differences in molt symmetry between sexes, breeding status, 
or months, or to compare proportions of molting birds. An ANCOVA was used to test for differences in primary molt scores between sexes, with sex as a main effect and date of collection as a covariate. Trends in proportion of birds exhibiting primary molt were assessed using Pearson correlation. All dates were converted to Ordinal dates $(1$ January $=001)$ for analysis. Means are reported $\pm \mathrm{SE}$, and all tests were twotailed and use a significance level of 0.05 (Systat Software Inc. 2002).

\section{Results}

\section{Breeding chronology}

The timing of breeding was consistent among years, with mean date of egg-laying occurring on 6 June in 2004 (Ordinal date 157.1 $\pm 0.6, n=16)$ and 2005 (157.9 \pm 0.2 , $n=103$ ).

\section{Wing molt}

Pooling data from three years, 71 breeding adults were captured on the colony between nine and 83 days prior to the median hatch date at the colony (i.e., pre-laying through $66 \%$ of incubation). Of these, none showed any evidence of wing feather molt in primary, secondary, tertiary, axillary, or alulae regions, including inner and outer wing coverts (Table 9.1). I did not collect any known breeders later in the season, but I observed no primary molt in 47 adults provisioning chicks during 1-14 August 2003. In contrast, non- or failed breeders in 2003 exhibited molt in 
Table 9.1. Mean (SE) percentage of molt intensity of 20 feather regions from northern fulmars collected during the breeding seasons of 2003-2005 at Cape Vera, Nunavut, Canada. Only birds with complete data for all feather regions are included. Note: Inferences should not be drawn from comparisons between breeders and nonor failed breeders.

\begin{tabular}{lcccc}
\hline Feather Tract & \multicolumn{2}{c}{ Breeders } & \multicolumn{2}{c}{ Non- or Failed Breeders } \\
& Male (35) & Female (29) & Male (23) & Female (23) \\
\cline { 2 - 5 } & & & & \\
\hline Crown & 0 & 0 & $0.1(0.1)$ & $1.4(0.6)$ \\
Cheek & 0 & 0 & $0.9(0.6)$ & $5.5(2.4)$ \\
Chin/throat & 0 & 0 & $1.0(0.7)$ & $2.6(2.0)$ \\
Neck & $0.1(0.1)$ & $0.1(0.1)$ & $0.6(0.4)$ & $3.4(1.6)$ \\
Upper Back & $0.6(0.4)$ & $0.1(0.1)$ & $2.1(1.1)$ & $3.4(1.4)$ \\
Scapulars & $0.1(0.1)$ & 0 & $1.7(0.9)$ & $4.5(1.9)$ \\
Lower Back & $0.8(0.6)$ & 0 & $1.4(1.0)$ & $3.4(1.3)$ \\
Rump & $0.3(0.3)$ & 0 & $1.3(0.9)$ & $5.9(2.4)$ \\
Upper Tail Coverts & $0.7(0.5)$ & 0 & $0.5(0.5)$ & $3.3(1.6)$ \\
Rectrices & 0 & 0 & 0 & $1.2(1.2)$ \\
Undertail Coverts & 0 & 0 & $1.8(1.2)$ & $2.1(1.0)$ \\
Collar & $0.9(0.6)$ & 0 & $0.3(0.3)$ & $3.8(1.8)$ \\
Breast & $0.04(0.04)$ & 0 & $0.5(0.5)$ & $0.02(0.02)$ \\
Belly & $0.1(0.1)$ & 0 & $0.3(0.3)$ & $0.2(0.2)$ \\
Side & $0.8(0.5)$ & 0 & $0.4(0.3)$ & $0.7(0.7)$ \\
Flank & $1.6(1.3)$ & $0.3(0.3)$ & 0 & $0.4(0.4)$ \\
Primaries & 0 & 0 & $19.6(3.7)$ & $27.8(3.7)$ \\
Secondaries & 0 & 0 & $0.7(0.4)$ & $1.6(0.8)$ \\
Tertials & 0 & 0 & $42.0(9.4)$ & $47.8(9.8)$ \\
Wing Coverts & 0 & 0 & $0.3(0.2)$ & $1.8(0.9)$ \\
& & & & \\
Total Molt Score & $0.05(0.03)$ & $0.03(0.02)$ & $0.22(0.04)$ & $0.40(0.06)$ \\
\hline
\end{tabular}


various wing feather regions. During August, an average of $36 \pm 4$ of 100 birds observed at the shoreline were in obvious primary molt, a significantly higher proportion than among confirmed breeders (Fisher Exact test, $P<0.0001$ ).

The proportion of fulmars exhibiting primary wing molt increased through the breeding season (Fig. 9.1), both at Cape Vera $\left(r_{67}=0.88, P<0.001\right)$ and Prince Leopold Island $\left(r_{38}=0.88, P<0.001\right)$. Fulmars were first observed losing primary feathers on day 174 (23 June), approximately two weeks after the mean egg-laying date for the colony. The proportion of birds observed in primary molt from $14-19$ July was similar each year: $2003-12 \%, 2004-13 \%, 2005-12 \%, 2006-16 \%(K W=1.4$, $P=0.7$ ). Peak counts of molters, averaging $43 \%$ of birds observed at the shoreline, occurred between day 223 and 226 (11 to 14 August), although I cannot exclude the possibility that higher proportions occurred after this date, as observations ended then.

Individuals observed flying along the breeding cliffs near the mean hatch date for the colony were less likely to show signs of molt than conspecifics observed flying along the shoreline away from the colony $(\geq 1 \mathrm{~km})$. Between 23 July and 9 August at Cape Vera, only $6.0 \pm 1.8 \%$ of birds flying near the cliffs showed primary molt ( $n=7$ counts), whereas during this same period, $28.6 \pm 3.5 \%$ of birds near the coast were in wing molt ( $n=18$; Mann-Whitney test, $U=3.0, P<0.001$; Fig. 9.1). 


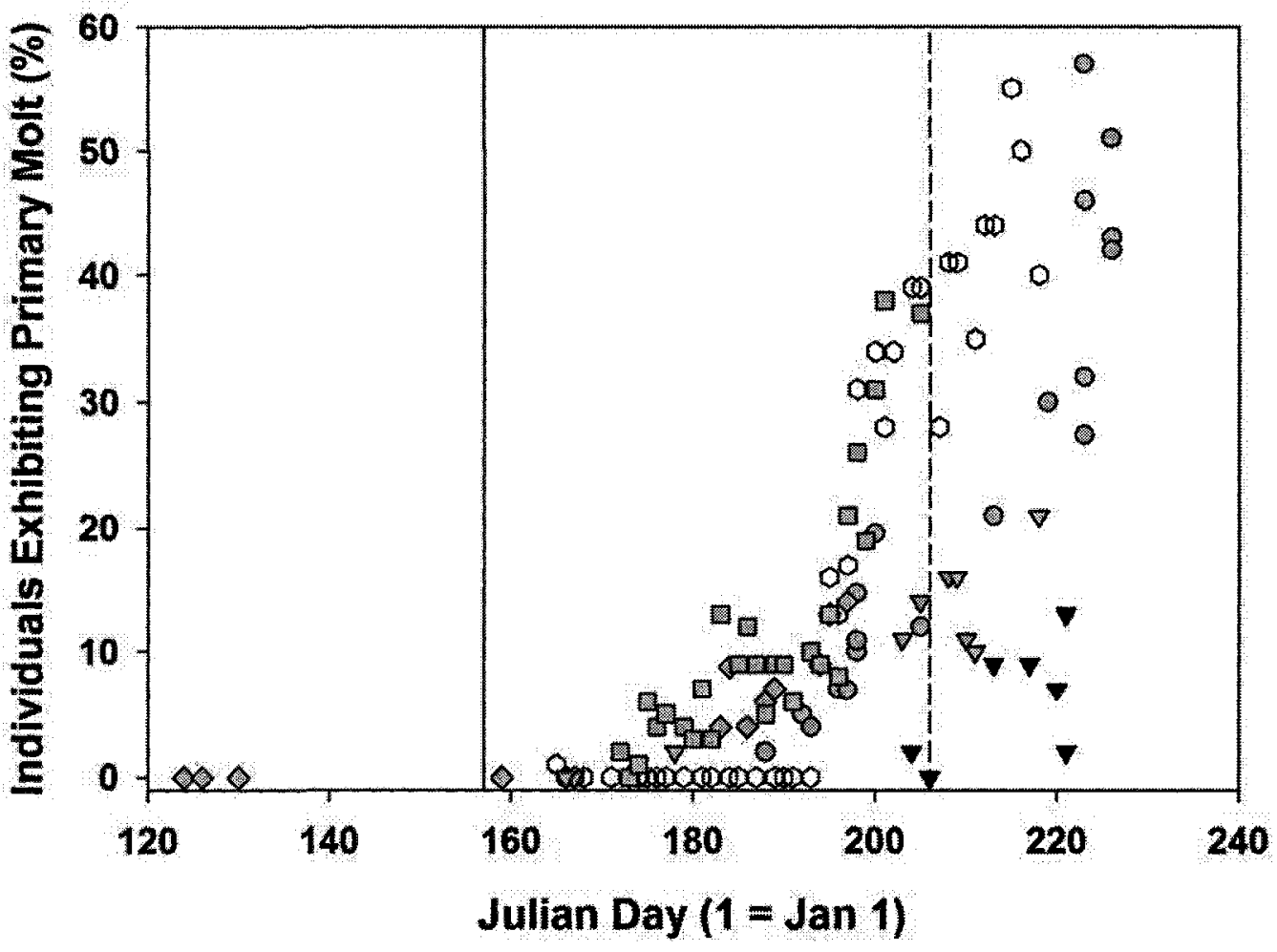

Figure 9.1. Sampled proportions of 11,500 individuals in flight exhibiting primary molt. Each point represents a sample of 100 birds observed from either a colony or shoreline position. Points differ by year and location as follows: (1) Cape Vera 2003 (filled circles), 2004 (filled triangles; black are counts made from the cliffs), 2005 (filled diamonds), 2006 (filled squares); (2) Prince Leopold Island 2005 (open circles). 
Primary molt scores

I detected considerable variability in primary molt scores (PMS) in my sample of birds known to contain non- or failed breeders from 2003 measured between 7 July and 18 August (PMS range 0-12). Of these birds, many non-zero PMS were obtained prior to hatch at the colony.

For birds in primary molt, I did not detect a difference between mean PMS for the left wing $(3.7 \pm 0.6, \mathrm{n}=36)$ and right wing $\left(3.4 \pm 0.6\right.$; paired $\left.t_{35}=1.24, P=0.2\right)$. Primary molt scores were perfectly symmetrical in $64 \%$ of the birds examined, and nearly symmetrical (PMS difference $\leq 1$ ) in $80 \%$ of all individuals not identified as known breeders (Fig. 9.2). Only one individual exhibited a PMS difference greater than $2($ PMS difference $=6)$.

I tested whether $\log _{10}$-transformed PMS in non- or failed breeding males differed from females, but there was a significant interaction effect of sex with date for both right and left wings $\left(F_{1,34}>5.5, P<0.03\right)$. Instead, I compared PMS values between sexes in July and in August, using Mann-Whitney tests. I did not detect a significant difference in PMS between males and females for either month (all $P>0.15$ ), except for a tendency for August males to have lower PMS than females ( $P=0.082)$, although samples sizes were small (Fig. 9.3). I could not test for a sex difference in PMS for the sample of individuals known to be breeders as none had initiated primary molt.

Molt of primary feathers was initiated at the second primary (P2), followed by P3, P1, P4 and P5 (Fig. 9.2), as indexed by the development scoring pattern from 


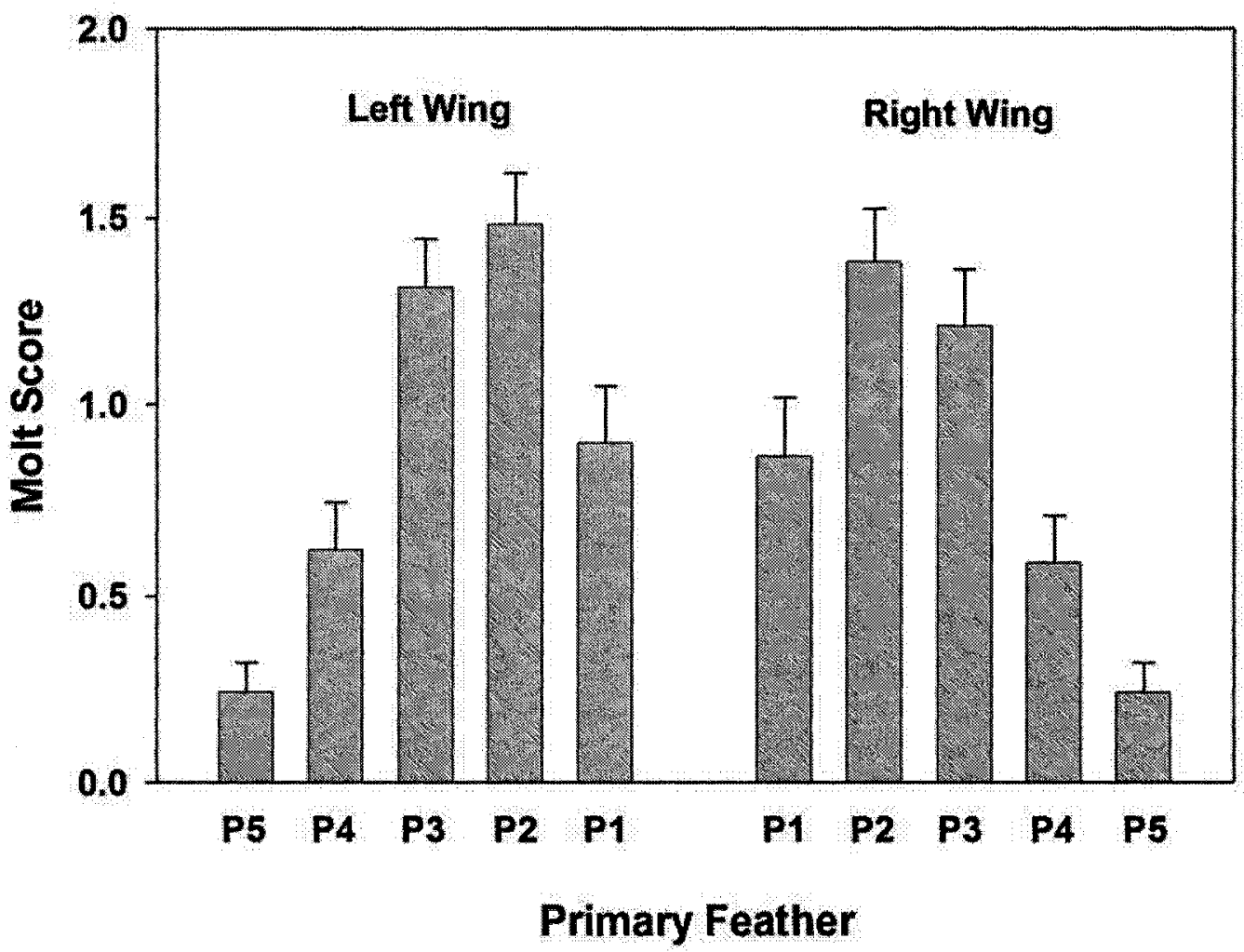

Figure 9.2. Mean (SE) primary molt score of individual primary feathers using the Ashmole (1962) method, for the left and right wings of 29 northern fulmars exhibiting primary molt. Molt initiation was never observed for feathers P6-P10 in any birds at the colony. 


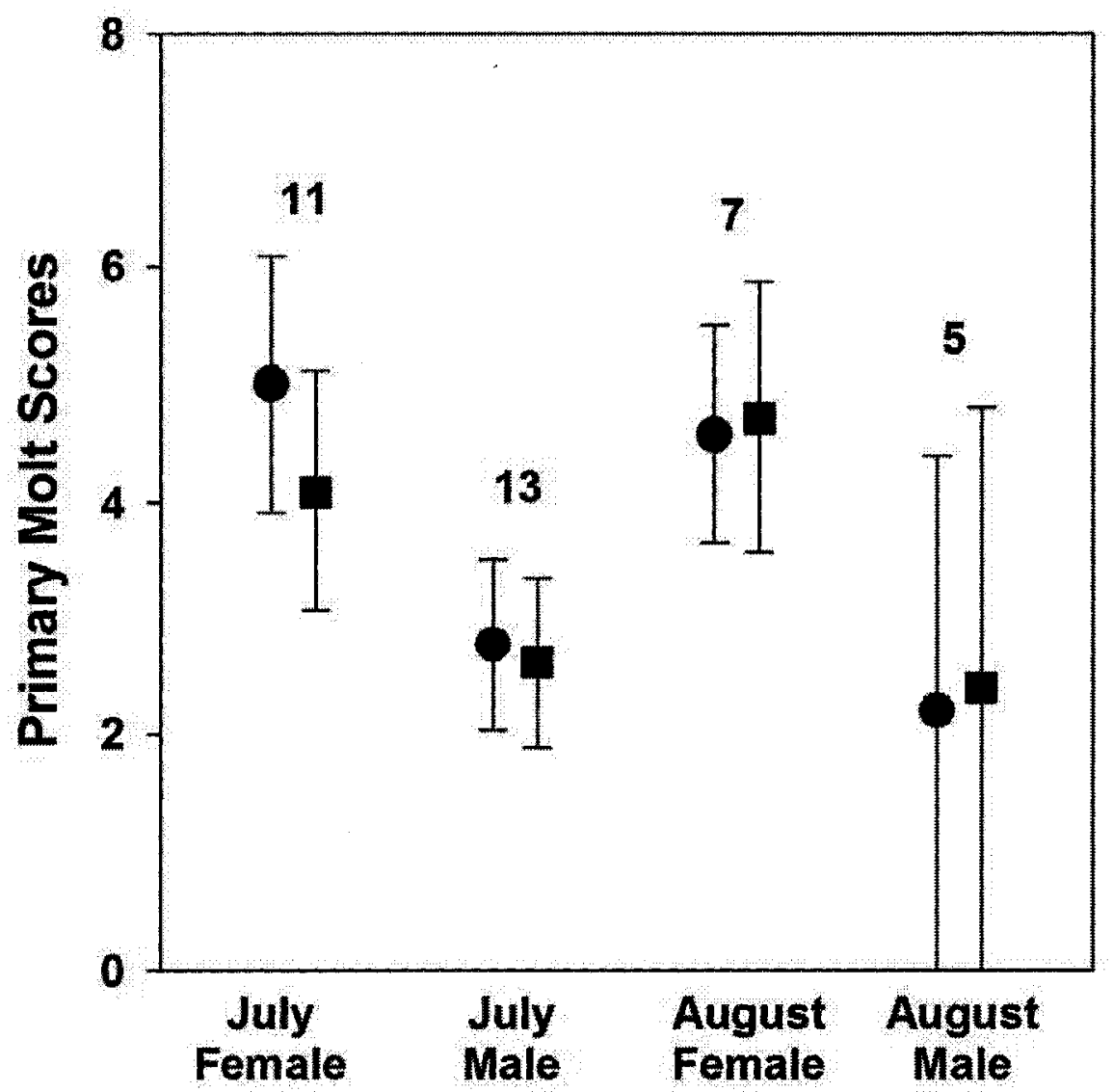

Figure 9.3. Total primary molt scores for left (circle) and right (square) wings of failed and non-breeding fulmars. 
Ashmole (1962). No fulmars at the colony were observed molting feathers in the P6 to $\mathrm{P} 10$ positions. For 19 fulmars with molt in the secondary feather tracts, molt was initiated at an inner node, with $89 \%$ having blood quills in the S21 position, $68 \%$ in $\mathrm{S} 20$ and $\mathrm{S} 19,10 \%$ in S18, and $5 \%$ in S15. The maximum number of primary feathers being replaced per wing at a given time in any individual sampled was five $(n=7)$. Of these, no single feather obtained a molt score greater than three (i.e. vane more than two thirds grown), which suggests that an even greater number of feathers undergoing replacement in an individual is possible.

\section{Body molt}

Although breeders showed no evidence of molt in flight feather regions in any year, molt onset was detected on other parts of the body in 13 of 64 adults (20\%) captured at the nest. However, only those individuals captured near the end of the incubation period (four of five individuals captured within two weeks of hatch) exhibited mean molt intensity greater than $1 \%$ (mean $6.2 \%$, range $2-11 \%$ ). Among these individuals, molt had been initiated in the capital, side, collar, back, scapular, leg, and tail areas (Table 9.1).

Unlike active breeders, molt was initiated by non- or failed breeding fulmars in all feather regions examined in females, and all but the rectrices and flank feathers in males (Table 9.1). For these birds, molt had progressed most in the scapular and primary feather regions, as well as the head. 
I did not detect a significant difference in the mean molt intensity between breeding male and female fulmars (Table 9.1; Mann-Whitney tests, all $P>0.1$ ). However, female non- or failed breeding fulmars tended to have higher mean molt intensity in the crown $(P=0.07)$, cheek $(P=0.06)$, neck $(P=0.04)$ and wing covert $(P=0.06)$ feather regions than male non-breeders (Table 9.1). Overall, non-breeding females had a higher total molt score than non-breeding males $(P=0.02)$.

\section{Discussion}

Northern fulmars breeding in the Canadian High Arctic did not initiate primary feather molt during incubation or early chick-rearing, consistent with most observations from studies in the Boreal part of the fulmar's range (Wynne-Edwards 1939, Duffey 1950, Fisher 1952, Hatch and Nettleship 1998). However, failed or non-breeding birds were observed in primary molt as early as 23 June, approximately two weeks after the mean egg-laying date for the colony, as found elsewhere (Hatch and Nettleship 1998). Some breeding fulmars did initiate molt in other parts of their body, notably the neck, upper back, and flank regions. Nonetheless, total molt scores for breeding and non-breeding birds indicated no molt to light molt (Thompson and Drobney 1995). Molt may be energetically-expensive in petrels; Chu (1984) found that shearwaters lost $12 \%$ body mass during molt. Thus, in the High Arctic, fulmars appear to temporally segregate primary molt and reproduction.

My results confirm the unusual molt pattern suggested by Thompson et al. (2000), whereby fulmars, sooty shearwaters (Puffinus griseus) and certain albatrosses 
(Tickell 2000) initiate primary molt at P2. In fulmars, the progression was rapid, with P2-P3 and then P1 and P4 almost molting as a block. This pattern is different from most other seabirds, notably the other procellariids, where the typical primary molt sequence initiates at P1. Also consistent with Thompson et al. (2000), I found that secondary molt was initiated at an inner node, with considerable changeover of S1821. However, none of the fulmars I examined had initiated secondary molt at a second node, despite being in the process of replacing up to four of the innermost secondaries. Thompson et al. (2000:50) stated that "shortly after molt begins at the inner node, secondary molt begins at a middle node (S5)...”. The rate of feather replacement may differ between High Arctic and Boreal fulmar populations, but at present I lack data to evaluate this possibility.

The timing of primary molt clearly differs among northern fulmar colonies, which is probably related to differences in nesting dates (Chapter 2). Fulmars nesting in different parts of the British Isles may exhibit large differences in molt chronology (Ginn and Melville 1983). On 10 July 1960, Bourne (1966) observed 33\% of the fulmars at St. Kilda, UK in primary molt, while around this date only $6 \%$ of fulmars at Cape Vera were in primary molt (Fig. 9.1). However, mean egg-laying dates at these colonies differ by approximately one month (Chapter 2 ). Thus, at the same stage of the breeding season, about $26 \%$ of fulmars at Cape Vera were exhibiting primary molt (Fig. 9.1). In contrast, Hatch (1979) found a peak of approximately $75 \%$ of fulmars at the Semidi Islands, Alaska colony exhibiting primary molt in midJuly in 1977, and the first week of August in 1976. Moreover, the earliest birds in 
primary molt were seen 24 May. The highest proportion of molters observed at Cape Vera was $57 \%$ on 11 August, with primary molt first observed on 23 June. Typical mean egg-laying and hatch dates differed by only two days between Hatch's Alaskan site and Cape Vera, yet primary molt initiation and peak proportional occurrence were observed 1-4 weeks earlier in Alaska. I speculate that either colony attendance dynamics of non-breeders (outlined below), or the timing of molt in relation to mean egg-laying dates or migratory habits (Bridge 2006) differ for fulmars in the North Pacific and North Atlantic populations.

Harris (1971) and Verbeek (1977) have hypothesized that differences in food availability and/or changes in foraging strategies during some years might explain differences in molt initiation dates between populations and years. For most bird species, reproduction occurs in synchrony with maximum food availability, due to high energetic costs to breeding adults. Hence, reproduction and molt may only be temporally exclusive in situations where food resources are limited or when specific ecological constraints otherwise determine allocation of energy budgets. In years with abundant food, parent birds might be able to both feed young and initiate molt earlier than expected. If this is the case, changes in patterns of molt chronology, both within and between populations over time, might serve as indicators of ecological conditions in the marine environment.

Furthermore, timing of molt may be related to environmental conditions or energetic requirements that are specific to given populations or locations. For example, local availability of, and access to, natural or anthropogenic food resources 
(Harris 1971), geographic constraints (i.e., migration duration and distance; Holmgren and Hedenström 1995), photoperiod (Lesher and Kendeigh 1941, Lindström et al. 1994), and ice conditions could lead to regionally-specific molt timing. Environmental conditions that vary widely within the fulmar's distribution range might explain the variability in molt chronologies among colonies reported in the literature.

Hatch $(1979,1989)$ surmised that seasonal and annual patterns of fulmar colony attendance, including the timing of molt, were linked to annual marine productivity. If we assume that the relative timing of nest failure was similar between these colonies, then I propose two possible explanations for the difference in the timing of molt compared to breeding in Alaska and Cape Vera. First, proportionally more non-breeding birds exhibiting wing molt may attend Alaskan colonies relatively earlier in the breeding season, compared to High Arctic fulmars. This may be possible, but Hatch (1989) speculated that many non-breeding birds arrived at the Alaskan colonies in August. Second, non-breeding High Arctic fulmars may delay entering wing molt until later in the season when local marine productivity is higher (Raymont 1976). Although I lack data to test these two hypotheses, I note that low marine productivity early in the breeding season probably accounts for the relatively long pre-laying exodus (Chapter 2) and incubation shifts (Chapters 5 and 6) in High Arctic fulmars.

A difference in the proportion of birds showing signs of molt between those observed near nesting ledges and those observed farther away from the colony, 
suggests that individuals visiting the colony, probably breeders and recently failed breeders, were slower to initiate wing molt than other conspecifics (see Fig. 9.1). It therefore is likely that, in addition to known breeders, a significant proportion of the sampled birds shot along the shoreline near the colony consisted of failed breeders and non-breeding juveniles. This finding is in agreement with results of telemetry studies conducted at the site, where breeding birds all left the colony to feed hundreds of kilometres to the east (Mallory et al. 2008), and also was confirmed in part through internal examination of carcasses. Also, this result highlights the importance of colony-specific information for use in intercolony comparisons. I cannot rule out the possibility that some of the variation in molt proportions observed among fulmar colonies could be related to differences in local, unreported movements of breeding, non-breeding and failed breeders.

I found that non- or failed breeding female fulmars were somewhat more advanced in molt than non- or failed breeding males, but there was little progression of molt between July and August in non-breeders. This observation is probably attributable to more advanced, non-breeding molters leaving the colony for pelagic zones to molt their outer primaries (Brown 1988) while new molters (recently failed breeders) enter the near-colony molting group, resulting in little apparent change in molt progress. Also, the overall percentage of molt intensity was low in both sexes (Table 9.1). I suspect that this pattern is driven by failed breeders, and may be attributable to the timing of contributions to incubation by each sex. For example, a female may lay her egg and then find herself in relatively poor physical condition, 
and abandon the nesting attempt (and thus, could potentially shift resources towards molt). Because her partner takes the first incubation shift for up to two weeks, the male may not realize that the attempt has been abandoned until the female fails to return. Similarly, if a female returns to find that the nest has been lost during the male's first shift, she would be in relatively good condition, and could immediately switch resource allocation towards molt. In contrast, the male may first have to recover resources lost during the incubation shift before being in suitable condition to initiate molt.

The factors that determine molt progress in fulmars remain to be explored fully. Despite advances in knowledge of fulmar reproduction, diet, and body condition, I consider that the potential for molt chronology to serve as an ecological metric remains presently dubious, in the absence of studies at other sites. Nonetheless, this study documented consistent patterns over three years at one High Arctic site, and similar patterns at a second site. These should serve as a suitable baseline set against which future comparisons can be made. Documenting this baseline is timely, as ecological conditions are changing in the Arctic, and fulmars respond to these environmental changes (Thompson and Ollason 2001, Gaston et al. 2005). Given the ease with which primary molt can be observed and recorded, I suggest that investigation of ecological factors affecting timing and duration of molt in many seabird species could lead to the use of molt, especially primary molt, as a possible indicator of ecological change. Therefore, I recommend that all studies at fulmar colonies include regular (at least weekly), standardized surveys of molting 
birds within the core colony to detect date of first primary molt, and the proportion of molting birds in relation to date of egg-laying and hatching. Such quantitative studies of molt timing and rate in relation to sex, age, breeding success, and foraging considerations, among different populations and using common methodologies, are clearly warranted for this and other broadly-distributed species. 


\section{CHAPTER TEN}

\section{General Discussion}


My thesis focused on constraints on breeding for northern fulmars in High Arctic Canada, and particularly the causes and consequences of variation in phenotypic traits exhibited by the breeding birds. This chapter summarizes the general findings of the preceding chapters, highlights the novelty of this research, and identifies avenues for further study.

\section{Salient findings and novelty}

Prior to this study, there were only two investigations on some aspects of the reproductive ecology of High Arctic fulmars. Falk and Møller $(1995,1997)$ conducted a single-season study of fulmars breeding on the northeast coast of Greenland, while Nettleship (in Hatch and Nettleship 1998) examined some aspects of fulmar reproduction at Prince Leopold Island over several seasons in the 1970s, although most of those data remain unpublished. Otherwise, the vast majority of information on this species came from studies in the Boreal oceanographic zone, notably in Alaska (Hatch 1990a, b, c) and the United Kingdom (Fisher 1952, Ollason and Dunnet 1978, 1980, 1986, 1988). These earlier studies provided the baseline data against which my work could be compared, particularly the research in Alaska. However, my thesis research developed or extended our knowledge on wild populations of this species, and particularly how the physical environment of the Arctic marine ecosystem has shaped the reproductive ecology of fulmars breeding at this latitude. These results lead to some interesting avenues for future environmental and behavioural research on fulmars (see Future Directions). 
As an underlying theme throughout the thesis, the timing and extent of sea ice cover in the Arctic places a major constraint on the breeding ecology of High Arctic fulmars, because it forms a physical barrier to birds accessing food, and also blocks light penetration into the water column, delaying marine production (Raymont 1976, Welch et al. 1992). These birds have a short window of opportunity in which to breed, and yet require a comparably long breeding season to successfully fledge young (Hatch and Nettleship 1998). In Chapter 2, I showed how fulmars breeding at high latitudes have adjusted the breeding schedule of conspecifics in the Boreal zone, by compressing the amount of time pairs spend together at the colony between arrival from migration and undertaking the pre-laying exodus, and then taking the longest known exodus from any colony. Moreover, this exodus had no "breaks" in it (whereby birds might return briefly to check their nest site), another difference from more southerly colonies. A second key difference that I observed was that High Arctic fulmars have relatively invariant annual arrival and egg-laying dates, particularly when compared to sympatrically-breeding gulls and auks (Gaston et al. 2005). Furthermore, they exhibited higher synchrony in their timing of breeding compared to fulmars at southern colonies. This Chapter summarized how there was little variation in the timing of breeding by High Arctic fulmars, and this scheduling constraint formed the basis for the following chapters, examining the energetic and behavioural consequences of this schedule.

In Chapter 3, I examined the function of the pre-laying exodus in fulmars. This unique behaviour among the petrels accommodates "income breeding" in this 
species (Drent and Daan 1980), whereby the female was thought to require the exodus to gain nutrients for egg production, and the male departed to gather fat reserves for undertaking the first incubation shift (Warham 1990). However, no one had ever tested these assumptions. I showed that female, High Arctic fulmars have enough fat and protein reserves for egg production prior to departing for the exodus, but that they lack sufficient mineral reserves to form the eggshell, thereby necessitating the exodus. Using energetic models, I also showed that males endogenous reserves were insufficient for him to remain at the nest while the female was away and still initiate incubation, and thus he must also undertake an exodus. These results are the first empirical confirmation of the "income breeding hypothesis" for the function of the petrel exodus, although the potential limiting function of mineral reserves was an unexpected finding.

Energetic nutrient reserves are not only important for fulmars to lay their egg. At High Arctic colonies, fulmars arrive at their nest sites while they are still snowcovered and while the surrounding sea is mostly frozen. Thus, in Chapter 4 I demonstrated how High Arctic fulmars must arrive at the breeding grounds with large endogenous nutrient reserves, to fuel their energetically-costly activities at their nest site prior to the exodus, because they cannot leave for brief periods to gather food (energy) supplies. Chastel et al. (1995) proposed a similar argument for the importance of early season body condition for a burrow-nesting petrel, and similarly Barbraud and Chastel (1999) linked early season body condition to higher reproductive success in snow petrels. High Arctic fulmars arrive with much larger 
endogenous reserves than fulmars in Alaska, where it is warmer, with no snow covering nests, and where birds can depart the colony for short refueling trips. Both Chapter 3 and 4 highlighted the strong relationship between the constraints imposed on the fulmar breeding schedule by sea ice, and the consequent physiological adaptations of fulmars to accommodate these environmental (distant food) and scheduling (short window) constraints.

Among the petrels, the synchronization of shared incubation duties is one of the key aspects influencing reproductive success, and is a strong reason why older, experienced birds have higher reproductive success (Ollason and Dunnet 1988). Following the laying of their egg, High Arctic fulmar pairs must take turns incubating the egg while their mate is away from the nest foraging, at a time when much of their breeding grounds are still ice-covered. In Chapters 5 and 6, I showed that fulmars do this by taking fewer but longer incubation shifts compared to conspecifics at southern colonies. This is probably attributable to longer search times and a lower availability of food supplies early in the breeding season for Arctic fulmars, as suggested by Falk and Møller (1995). Unlike the timing of breeding or the size of energetic reserves, I found considerable variation in incubation scheduling by fulmars. Incubation behaviour appears to be an aspect of reproduction where individual (or pair) variation can be accommodated in Arctic conditions. However, there are still certain constraints placed on this variation. In particular, pairs with males that stayed on the nest for a longer initial incubation shift had greater nesting success than pairs that had 
shorter initial shifts, which suggests that larger male reserves permitting a longer incubation shift after the exodus may be beneficial.

Aside from phenological and behavioural constraints on fulmar reproduction influenced principally by Arctic sea ice, I also examined some finer scale constraints on breeding at the nest site, namely nest shelter and its relationship with weather and predation, all of which were novel investigations on fulmars. In Chapter 7 I showed that fulmars nesting in the most sheltered nest sites had the highest reproductive success, which may have been related to lower predation pressure or more shelter from storms. Despite this difference in nesting success, fulmars in sheltered sites did not acquire these sites earlier for breeding (as would be expected if they were higher quality; Coulson 2002), nor did they devote less time to energetically-costly activities like agonistic interactions as fulmars in exposed sites, counter to my expectations. There was much variation in the allocation of time by incubating fulmars at their nest, irrespective of qualities of their nest site, and I posited that further investigation of these behaviours with known age birds is required to understand this apparently suboptimal behaviour.

In Chapter 8, I analysed one of the key comparative questions from this study, namely "is there a difference in reproductive success of High Arctic fulmars compared to Boreal fulmars". There was high (e.g., two-fold) variation in measures of annual reproductive success among sites and years, but overall hatching success, apparent fledging success, and productivity were similar across the species' range. However, I found two key differences between High Arctic and more southern 
colonies. First, there were more pairs that attended nest sites in the High Arctic but that failed to lay an egg, which meant that Arctic colonies have a lower proportion of eggs laid per apparently occupied nest site compared to southern colonies. Because energetic stores prior to egg-laying appear to be very important in Arctic fulmars, I posit that more birds in the Arctic did not lay an egg because their endogenous reserves were insufficient for breeding, compared to fulmars in the Boreal zone. Second, most nest failure at Arctic colonies was associated with major weather events (wind or snow storms), which led to temporary abandonment of nests, and consequent weather-facilitated nest predation by gulls. At Boreal colonies, weather obviously has an effect on nesting success, but variation in marine food supplies seem to play a more dominant role (Hatch 1990c, Gray et al. 2003). A key and novel implication, then, is that High Arctic fulmars may be trading-off a higher risk of stochastic, catastrophic storm events during incubation and chick-rearing (which could lead to nest failure) against a more abundant and predictable food supply (Welch et al. 1992) during chick-rearing (which would make rearing chicks comparably easier).

In the final Chapter (9), I returned to the question of energetic reserves and life cycle processes, and showed that in the High Arctic, fulmars show complete temporal segregation of the energetically-costly activities of breeding and molting wing feathers. Overlap of these processes has been observed in fulmars of the Southern Ocean (Barbraud and Chastel 1998), or in other petrels when food supplies are superabundant (Bridge 2006), as well as occasionally at Alaskan fulmar colonies (Hatch 1979). However, in the High Arctic, the pulse of abundant food appears to 
come relatively later in the breeding season than in the Southern Ocean, and thus overlapping these activities would put breeding fulmars in a significant energy deficit, at a time when their flying ability would be compromised (Rayner 1999).

Collectively, the various chapters provided different insights into phenotypic variation and constraints on Arctic-breeding fulmars. The selective pressures imposed by sea ice favour high synchrony (i.e., little variation) in the breeding schedule of fulmars, and similarly favour large endogenous nutrient reserves on arrival at the breeding colony. The scheduling of molt also is highly constrained by the energetic consequences for fulmars of early season sea ice cover, and I found no birds entering wing molt while their nest still had an egg or chick. There appeared to be less constraint on incubation behaviour, with many varied attendance schedules observed in successful nests. Nonetheless, Arctic fulmars generally had a longer mean incubation shift duration compared to fulmars at southern colonies. Also, despite higher nest success in sheltered nest sites, incubating fulmars exhibited much variability in their allocation of time to different activities at the nest site, irrespective of nest location. These latter two findings may reflect the over-riding importance of experience and learning among breeding pairs of these long-lived organisms (Wilson 1998, Sih et al. 2004). If a pair develops an incubation schedule or nest defense pattern that is successful, that may be more important for breeding success than taking advantage of small energetic gains that I perceived could exist for different nest sites. 
Given the variation I observed in behaviours and reproductive success at the colonies, I can make some predictions about the future conditions at these sites, which I discuss in the following section.

\section{Future directions}

As I stated in Chapter 1, variation existing within populations is of interest because we need to know how wild populations may adjust to environmental change (Sih et al. 2004). At its simplest level, to manage these populations, and our activities that might affect them, we need to understand whether the phenotypic traits that we observe can compensate for the environmental changes, and whether this relates to underlying genotypic variation for population-level adjustments to long-term environmental changes. This is particularly important for Arctic bird populations, because the Arctic marine environment is changing more rapidly than many other environments anywhere around the world (ACIA 2004).

\section{Climate change}

Perhaps the most obvious avenue for future study is how climate change will affect Arctic fulmar populations. From the data I gathered during this study, I can make some predictions based on effects at the colony, and effects remote from the colony.

The information on fulmars from Cape Vera and Prince Leopold Island suggests that there is already considerable variation in structural size and mass (Mallory and Forbes 2005), incubation scheduling (Gaston et al. 2005, Chapters 5 and 
6), and at-nest behaviours (Chapter 7) at these colonies. Assuming that this phenotypic variation represents underlying genotypic variation, then I expect that parts of the fulmar populations breeding at these colonies will be able to adapt to long-term changes in sea ice patterns, and the consequent changes in the distribution and abundance of food supplies, either through phenotypic plasticity, or through selection of preferred genotypes. Given the observed, inter-annual variation in incubation patterns at Prince Leopold Island (Chapter 5), I expect that the typical incubation pattern at Arctic colonies may become more like Boreal colonies. Furthermore, with a reduction in sea ice cover and earlier breakup (ACIA 2004), phytoplankton blooms may appear earlier in the year or be more prolonged, leading to earlier marine production of food. This situation may mean that Arctic fulmars could attempt breeding despite having smaller endogenous reserves, again following a pattern typical of Boreal fulmars.

Stenseth and Mysterud (2002) suggested that climate change can lead to a deleterious, progressive mismatch of the timing of peak food supplies and timing of avian reproduction, and to some extent, this is already evident for thick-billed murres in Hudson Bay (T. Gaston, unpubl. data). Given the synchrony in egg-laying that I observed (Chapter 2), it is unclear whether Arctic fulmars can adjust their breeding earlier in the season, but perhaps more importantly, they may not need to do so. Although the timing of murre reproduction varies annually in response to ice conditions (Gaston et al. 2005), with peak food availability corresponding to chickrearing, fulmars currently initiate nests and hatch eggs before murres, with an 
invariant breeding schedule. In fact, Fisher (1952) found that fulmars at North Atlantic colonies showed low variation in their annual nesting schedule compared to other seabirds (although more variation than at High Arctic fulmar colonies; Chapter 2). Thus, I hypothesize that the current timing of breeding by Arctic fulmars is more constrained by fitting their relatively long breeding season into the available open water period, instead of trying to match peak food abundance for chick-rearing, like murres. If this hypothesis is correct, then irrespective of whether they adjust their breeding schedule, Arctic fulmars should find foraging conditions better if sea ice breakup is earlier.

Thus, in these instances, long-term losses of sea ice due to climate change may provide some benefits for these High Arctic colonies.

In contrast, my data suggest that a potentially major problem for High Arctic fulmars could be an increase in storm frequency or intensity, another expected consequence of climate change (ACIA 2004). Given that winds and snow were the main factors leading to fulmar nest failure (Chapter 8), an intensification of these effects could result in more catastrophic losses of fulmar nests annually. I predict that changes in Arctic storm patterns will be the major, deleterious effect of climate change on Arctic fulmar populations, and thereby merits further study.

I also acquired other data that were not used directly in this thesis, but which point to other effects of climate change on Arctic fulmar populations. In the North Atlantic Ocean, studies have shown that northern fulmar survival is negatively correlated with the winter North Atlantic Oscillation, and thus fulmars fare poorer 
during warmer, wetter winters, with a five year lag in effects (Thompson and Ollason 2001). The preliminary data collected from Prince Leopold Island since the mid1970s suggests that this may also be true for Arctic fulmars (Fig. 10.1). Counts of fulmars attending nests on the breeding plots were significantly lower three years after winters with a low winter Arctic Oscillation Index (i.e., a warmer, wetter winter). This probably means that survival of young Arctic fulmars is lower in these winters (attributable to low winter food supplies), resulting in lower colony counts three years later, when young fulmars first return to their natal colony (Lyngs 2003). However, a reliable assessment of this pattern requires that we follow marked individuals for capture - recapture measurements, and conduct appropriate survival analyses (e.g., Grosbois and Thompson 2005). Presently we lack such a population in Arctic Canada. 


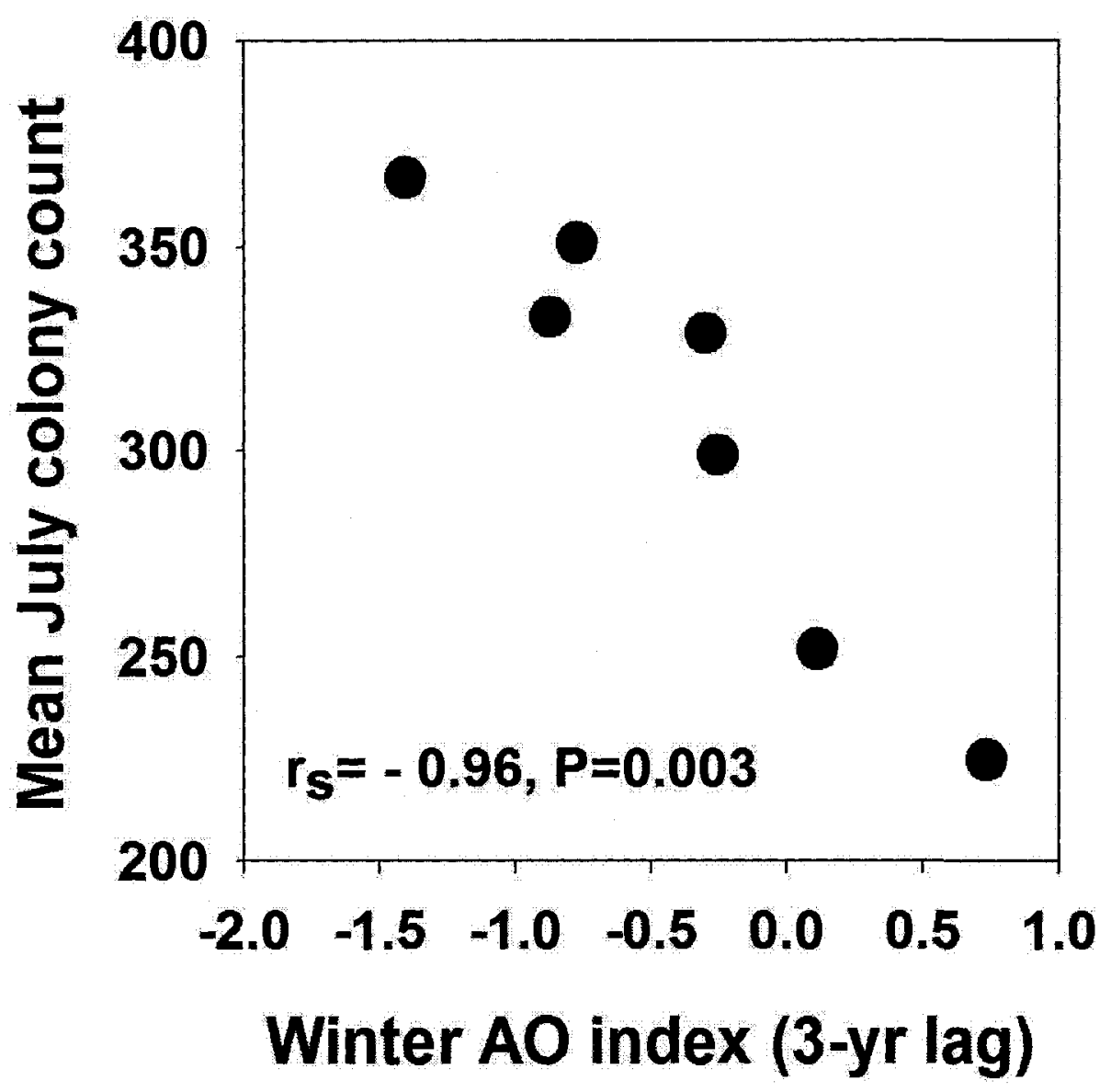

Figure 10.1. Annual means of daily plot counts of northern fulmars attending the breeding plots at Prince Leopold Island, 1976 - 2005. Methodologies for counts are described in Chapters 2 and 8. Data on Arctic Oscillation Index values came from http://www.cgd.ucar.edu/cas/jhurrell/indices.html. 


\section{Fulmars as bioindicators}

A second area suitable for future research is the expanded use of fulmars as bioindicators of the health of the marine ecosystem. For example, studies in the Barents Sea have shown that gull species show aberrant parasite burdens and incubation behaviour when they have higher levels of contaminants in their tissues (Sagerup et al. 2000, Bustnes et al. 2001), and some similar patterns have been found in Canadian eiders (Wayland et al. 2001). Fulmars are currently part of the Canadian monitoring program of contaminants in Arctic seabirds, and they show high levels of some contaminants in their tissues (Braune et al. 2001, Mallory et al. 2006a), but additionally they consume plastic garbage which lodges in their digestive tract and is slowly digested (Mallory 2008). With limited access to food resources early in the breeding season and thus a reliance on stored nutrients for activities at the nest (Chapters 3 and 4), increased stress from pollution could have a deleterious effect on Arctic fulmar populations, either directly, or synergistically by affecting allocation of reserves to other body functions such as immunity. Changes in contaminant sources and uptake, along with ongoing climate amelioration and the consequent possibility of more intense parasitic infections at higher latitudes (Mallory et al. 2006b, 2007) could collectively place new stresses on Arctic populations. A controlled, experimental study on fulmar body condition, parasites and contaminants would be a useful contribution to help interpret some of the energetic data presented in my thesis. 


\section{Fulmar behaviour}

My work also suggested three interesting areas of behavioural research that should be followed in fulmars. First, fulmars in the Boreal oceanographic zone have a much longer time to pair bond at the nest site and take a shorter exodus from the colony (Hatch and Nettleship 1998), and this leads to opportunities for extra-pair copulations over a long period (Hunter 1998). However, Arctic fulmars have a very short window to pair-bond and copulate before departing for the long exodus. Moreover, the female stores sperm in glands (Hatch 1983), but in Boreal fulmars she would release these sperm and fertilize her egg before departing for the exodus, while in Arctic fulmars, the female would already be on her exodus looking for food before releasing stored sperm. In the High Arctic, male fulmars spent more time during prelaying with their mate than Boreal fulmars (Hatch 1990c, Chapter 2), which may reflect efforts by the male for more copulations, or to prevent extra-pair copulations. Thus, as I noted in Chapter 2, I predict that levels of extra-pair copulations at High Arctic colonies will be more strongly correlated with male attendance during prelaying than at more southern colonies. Furthermore, there might be lower egg hatchability at Arctic colonies, because more females would be using older, potentially degraded sperm released during the exodus to fertilize eggs.

A second behavioural question is that of the role of learning and experience in successful reproduction. High Arctic fulmars begin returning to their colonies when they are three years old (Lyngs 2003), but probably do not start breeding until they are more than seven years old (Hatch and Nettleship 1998). In this intervening 
period, young birds are learning how to land on cliffs, and presumably following other birds to learn the colony schedule, where to go to feed, and how to defend nests (Coulson 2002). My study showed that there is much variation in incubation scheduling, nest site use, and behaviours at the nest within the colony. A fascinating follow up study would be to attach transmitters to both experienced (old) and inexperienced (young) birds occupying the same ledge area of a cliff face, to examine whether colony ledges are acting as information centres (Ward and Zahavi 1973, Gaston and Nettleship 1981). Certain types of evidence for this could be gleaned from observing marked birds (e.g. synchrony of departure and arrival, direction of travel), but satellite tracking would give insights into the important aspects of foodfinding away from the colony.

The possibility that behavioural syndromes may operate in a fulmar colony also appears to be a fertile topic for future investigation. Behavioural syndromes are linked suites of behavioural repertoires that are consistently exhibited by individuals across different conditions (Wilson 1998, Sih et al. 2004). In other long-lived animals, different behavioural repertoires are favoured under varying environmental pressures, and thus may be adaptive (e.g., Réale et al. 2003). For example, if higher aggression is generally favoured in the feeding grounds and during competition for nest sites in fulmars, this may explain why successful, cave-nesting fulmars exhibited similar amounts of agonistic activity as ledge-nesters, despite experiencing less disturbance from conspecifics. When I captured fulmars, I observed marked differences in their responses, with some birds highly aggressive, and others shy. In 
future studies, I recommend that reactions of birds to capture or when interacting with neighbours or predators be scored. In this way, researchers could test for correlations between these indicators of individual personalities and other factors influencing reproductive success, such as body condition, mate personality type, nest site characteristics, and incubation scheduling.

Nutrient reserve dynamics of High Arctic marine birds

Perhaps the most novel finding from my research was the pattern of nutrient reserve dynamics in breeding fulmars. First, the data confirm that the fulmar exodus serves to allow females to gather nutrients to form the egg. An interesting study now would be to assess pre- and post-exodus nutrients in fulmars from the Boreal oceanographic zone, to determine if this pattern is consistent across the species' range, or whether other nutrients are more limiting south of the Arctic.

A second and broader question comes from observation of high nutrient reserves in fulmars when they arrive at the field site, which I argued were necessary to fuel early season activities at a time of low and distant food supplies. Klaassen et al. $(2001,2006)$ showed that some shorebirds also arrive with large, early season reserves to fuel activities other than egg-laying. This strategy should benefit species of Arctic migrants whose breeding schedule is tightly constrained, as seasonal phenology of snowmelt and food availability are unpredictable, but food can consistently be expected to be low early in the season, particularly in the marine environment. Thus, I predict that investigations on other species which are 
distributed across many degrees of latitude (e.g., certain waterfowl, black-legged

kittiwakes, Rissa tridactyla) will show that conspecifics breeding in the Arctic generally have larger endogenous reserves at the start of the breeding season, compared to those nesting at more southern locations. 


\section{LITERATURE CITED}

Abraham, C. L., and W. J. Sydeman. 2004. Ocean climate, euphausiids and auklet nesting: inter-annual trends and variation in phenology, diet and growth of a planktivorous seabird, Ptychoramphus aleuticus. Marine Ecology Progress Series 274:235-250.

ACIA. 2004. Impacts of a warming arctic: arctic climate impact assessment. Cambridge University Press.

Aebischer, N. J., J. C. Coulson, and J. M. Colebrook. 1990. Parallel long-term trends across our marine trophic levels and weather. Nature 347: 753-755.

Ainley, D. G., W. J. Sydeman, and J. Norton. 1995. Upper trophic level predators indicate interannual negative and positive anomalies in the California Current food web. Marine Ecology Progress Series 118: 69-79.

Ainley, D. G. 2002. The Adélie Penguin: bellwether of climate change. Columbia University Press, New York.

Ainley, D. G., R. E. LeResche, and W. J. L. Sladen. 1983. Breeding biology of the Adélie Penguin. University of California Press, Los Angeles.

Alisauskas, R. T., and C. D. Ankney. 1985. Nutrient reserves and the energetics of reproduction in American Coots. Auk 102: 133-144.

Alisauskas, R. T., and C. D. Ankney. 1992. The cost of egg laying and its relationship to nutrient reserves in waterfowl. Pp 30-61 in B. D. J. Batt, A. D. Afton, M. G. Anderson, C. D. Ankney, D. H. Johnson, J. A. Kadlec and G. L. 
Krapu (eds.). Ecology and management of breeding waterfowl. University of Minnesota Press, Minneapolis.

Ankney, C. D. 1977. Feeding and digestive organ size in breeding lesser snow geese. Auk 94: 275-282.

Ankney, C. D., and C. D. MacInnes. 1978. Nutrient reserves and reproductive performance in female lesser snow geese. Auk 95: 459-471.

Ashmole, N. P. 1962. The black noddy (Anous tenuirostris) on Ascension Island. Ibis 103: 235-273.

Astheimer, L. B., and C. R. Grau. 1985. The timing and energetic consequences of egg formation in Adélie Penguins. Condor 87: 256-267.

Baldwin, S. P., and S. C. Kendeigh. 1938. Variations in the weight of birds. Auk 55: 416-467.

Barbraud, C., and O. Chastel. 1998. Southern fulmars molt their primary feathers while incubating. Condor 100: 563-566.

Barbraud, C. and O. Chastel. 1999. Early body condition and hatching success in the snow petrel Pagodroma nivea. Polar Biology 21: 1-4.

Barbraud, C., and H. Weimerskirch. 2001a. Contrasting effects of the extent of seaice on the breeding performance of an Antarctic top predator, the snow petrel Pagodroma nivea. Journal of Avian Biology 32: 297-302.

Barbraud, C., and H. Weimerskirch. 2001b. Emperor Penguins and climate change. Nature 411: 183-186.

Barbraud, C., and H. Weimerskirch. 2006. Antarctic birds breed later in response to 
climate change. Proceedings of the National Academy of Sciences USA 103: $6248-6251$.

Beck, J. R. 1970. Breeding seasons and moult in some smaller Antarctic petrels. In: Holdgate, M. W. (ed.) Antarctic ecology. Vol. 1. Academic Press, London. Behrenfeld, M. J., J. T. Randerson, C. R. McClain, G. C. Feldman, S. O. Los, C. J. Tucker, P. G. Falkowski, C. B. Field, R. Frouin, W. E. Esaias, D. D. Kolber, and N. H. Pollack. 2001. Biospheric primary production during an ENSO transition. Science 291: 2594-2597.

Bêty, J., G. Gauthier, and J. -F. Giroux. 2003. Body condition, migration, and timing of reproduction in snow geese : a test of the condition-dependent model of optimal clutch size. American Naturalist 162: 1101-1121.

Bêty, J., J. -F. Giroux, and G. Gauthier. 2004. Individual variation in timing of migration: causes and reproductive consequences in greater snow geese (Anser caerulescens atlanticus). Behavioral Ecology and Sociobiology 57: 18.

Birkhead, T. R., and D. N. Nettleship. 1981. Reproductive biology of thick-billed murres (Uria lomvia): an inter-colony comparison. Auk 98: 258-269.

Birt, V. L., T. P. Birt, D. Goulet, D. K. Cairns, and W. A. Montevecchi. 1987. Ashmole's halo: direct evidence for prey depletion by a seabird. Marine Ecology Progress Series 40: 205-208.

Blem, C. R. 1990. Avian energy storage. Current Ornithology 7: 59-113. Boersma, P. D., and N. T. Wheelwright. 1979. Egg neglect in the Procellariiformes: 
reproductive adaptations in the fork-tailed storm petrel. Condor 81: 157-165.

Boersma, P. D., G. A. Rebstock, and D. L. Stokes. 2004. Why penguin eggshells are thick. Auk 121: 148-155.

Bourne, W. R. P. 1966. The plumage of the fulmars of St. Kilda in July. Bird Study 13: $209-213$.

Boyd, I., S. Wanless, and C. J. Camphuysen. 2006. Top predators in marine ecosystems. Their role in monitoring and management. Cambridge University Press, Cambridge, UK.

Braune, B. M., G. M. Donaldson, and K. A. Hobson. 2001. Contaminant residues in seabird eggs from the Canadian Arctic. I. Temporal trends 1975-1998. Environmental Pollution 114: 39-54.

Brenninkmeijer, A., M. Klassen, and E. W. M. Stienen. 1997. Sandwich terns Sterna sandvicensis feeding on shell fractions. Ibis 139:397-400.

Bridge, E. S. 2006. Influences of morphology and behavior on wing-molt strategies in seabirds. Marine Ornithology 34: 7-19

Brooke, M. 1978. Some factors affecting the laying date, incubation and breeding success of the Manx Shearwater, Puffinus puffinus. Journal of Animal Ecology 47:477-495.

Brown, R. G. B. 1988. The wing-moult of fulmars and shearwaters (Procellariidae) in Canadian arctic waters. Canadian Field-Naturalist 102: 203-208.

Brown, R. G. B. 1991. Marine birds and climatic warming in the northwest Atlantic. Pp 49-54 In W. A. Montevecchi, and A. J. Gaston, eds. Studies of high 
latitude seabirds. 1. Behavioural, energetic and oceanographic aspects of seabird feeding ecology. Canadian Wildlife Service Occasional Paper No. 68. Ottawa.

Brown, R. G. B., and D. N. Nettleship. 1981. The biological significance of polynyas to arctic colonial seabirds, p. 59-65. In I. Stirling and H. Cleator [eds.], Polynyas in the Canadian Arctic. Canadian Wildlife Service Occasional Paper 45.

Brown, R. G. B., D. N. Nettleship, P. Germain, C. E. Tull, and T. Davis. 1975. Atlas of eastern Canadian seabirds. Canadian Wildlife Service, Ottawa. 220 pp.

Bryant, D. M., and R. W. Furness. 1995. Basal metabolic rates of North Atlantic seabirds. Ibis 137: 219-226.

Buckland, S. T. 1982. A mark-recapture survival analysis. Journal of Animal Ecology 51: 833-847.

Burger, J., and M. Gochfield. 2002. Effects of chemicals and pollution on seabirds. Pp 428-525 In Biology of Marine Birds. Edited by E.A. Schreiber and J. Burger. CRC Press, New York.

Burnham, K. P., and D. R. Anderson. 2002. Model Selection and Multimodel Inference: A Practical Information-theoretic Approach, $2^{\text {nd }}$ edition. SpringerVerlag, New York.

Burger, J. 1977. Role of visibility in nesting behaviour of Larus gulls. Journal of Comparative Physiology and Psychology 91: 1347-1358.

Bustnes, J. O., V. Bakken, K. E. Erikstad, F. Mehlum, and J. U. Skaare. 2001. 
Patterns of incubation and nest-site attentiveness in relation to organochlorine (PCB) contamination in glaucous gulls. Journal of Applied Ecology 38, 791801.

Cairns, D. K. 1987. Seabirds as indicators of marine food supplies. Biological Oceanography 5: 261-271.

Carrick, R., and G. M. Dunnet. 1954. Breeding of the fulmar, Fulmarus glacialis. Ibis $96: 356-370$.

Chastel, O., H. Weimerskirch, and P. Jouventin. 1995. Influence of body condition on reproductive decision and reproductive success in the blue petrel. Auk 112: 964-972.

Chaurand, T. and H. Weimerskirch. 1994. Incubation routine, body mass regulation and egg neglect in the blue petrel Halobaena caerulea. Ibis 136: 285-290.

Cherel, Y., and V. Ridoux. 1992. Prey species and nutritive value of food fed during summer to King Penguin Aptenodytes patagonica chicks at Possession Island, Crozet Archipelago. Ibis 134: 118-127.

Cherel, Y., J. B. Charrassin, and Y. Handrich. 1993. Comparison of body reserve buildup in prefasting chicks and adults of King Penguins (Aptenodytes patagonicus). Physiological Zoology 66: 750-770.

Cherel, Y., J. B. Charrassin, and E. Challet. 1994a. Energy and protein requirements for molt in the king penguin Aptenodytes patagonicus. American Journal of Physiology 266: 182-1188.

Cherel, Y., J. Gilles, Y. Handrich, and Y. Le Maho. 1994b. Nutrient reserve 
dynamics and energetics during long-term fasting in the king penguin (Aptenodytes patagonicus). Journal of Zoology (London) 234: 1-12.

Chu, E. W. 1984. Sooty shearwaters off California: diet and energy gain. Pp. 64-71 In D. N. Nettleship, G. A. Sanger, and P. F. Springer (eds.) Marine birds: their feeding ecology and commercial fisheries relationships. Canadian Wildlife Service Special Publication, Ottawa.

Clarke, A., and P. A. Prince. 1980. Chemical composition and calorific value of food fed to mollymauk chicks Diomedea melanophris and D. chrysostoma at Bird Island, South Georgia. Ibis 122: 488-494.

Clutton-Brock, T. H. (ed.). 1988. Reproductive Success. University of Chicago Press, Chicago.

Coulson, J. C. 2002. Colonial breeding in seabirds. Pp. 87-113 in E. A. Schreiber and J. Burger (eds.). Biology of marine birds. CRC Press, New York.

Coulson, J. C., and J. M. Horobin. 1972. The annual reoccupation of breeding sites by the fulmar. Ibis $114: 30-42$.

Creuwels, J. C. S., J. A. van Franeker, S. J. Doust, A. Beinssen, B. Harding, and O. Hentschel. 2008. Breeding strategies of Antarctic petrels Thalassoica antarctica and southern fulmars Fulmarus glacialoides in the high Antarctic and implications for reproductive success. Ibis 150: 160-171.

Darwin, C. D. 1859. The Origin of Species. Penguin, London.

Dobush, G. R., C. D. Ankney, and D. G. Krementz. 1985. The effect of apparatus, extraction time, and solvent type on lipid extractions of snow geese. Canadian 
Journal of Zoology 63: 1917-1920.

Dott, H. E. M. 1973. Fulmars at land in summer and autumn. Bird Study 22: 255259.

Drent, R. H. 1975. Incubation. Pp. 333-420 In D. S. Farner and J. R. King (eds.), Avian biology, Vol. 5. pp. 333-420. Academic Press, New York.

Drent, R. H., and S. Daan. 1980. The prudent parent: energetic adjustments in avian breeding. Ardea 68: 225-252.

Drent, R. H., J. M. Tinbergen, and H. Biebach. 1985. Incubation in the starling, Sturnus vulgaris: resolution of the conflict between egg care and foraging. Netherlands Journal of Zoology 35: 103-123.

Drobney, R. D. 1984. Effect of diet on the visceral morphology of wood ducks. Auk 101: 93-98.

Duffey, E. 1950. Non-breeding in the fulmar Fulmarus glacialis. Scottish Naturalist 62: 111-121.

Dunn, P. O., K. J. Thusius, K. Kimber, and D. W. Winkler. 2000. Geographic and ecological variation in clutch size of tree swallows. Auk 117: 215-221.

Dunnet, G. M. 1991. Population studies of the Fulmar on Eynhallow, Orkney Islands. Ibis 133 (Suppl. 1): 24-27.

Dunnet, G. M., A. Anderson, and R. M. Cormack. 1963. A study of the survival of adult fulmars with observations on the pre-laying exodus. British Birds 56: 218.

Dunnet, G. M., J. C. Ollason, and A. Anderson. 1979. A 28-year study of breeding 
fulmars Fulmarus glacialis in Orkney. Ibis 21: 293-300.

Ellis, H. I., and G. W. Gabrielsen. 2002. Energetics of free-ranging seabirds. Pp. 359-408 in E. A. Schreiber and J. Burger (eds.). Biology of marine birds. CRC Press, New York.

Endler, J. A. 1986. Natural selection in the wild. Princeton University Press, Princeton.

Falk, K., and S. Møller. 1995. Satellite tracking of high arctic northern fulmars. Polar Biology 15: 495-502.

Falk, K., and S. Møller. 1997. Breeding ecology of the fulmar Fulmarus glacialis and the kittiwake Rissa tridactyla in high-arctic northeastern Greenland, 1993. Ibis 139: 270-281.

Fast, P. L. F., H. G. Gilchrist, and R. G. Clark. 2007. Experimental evaluation of nest shelter effects on weight loss in incubating common eiders Somateria mollissima. Journal of Avian Biology 38: 205-213.

Fisher, J. 1952. The fulmar. Collins, London.

Fortescue, M. 1999. Temporal and spatial variation in breeding success of the little penguin Eudyptula minor on the east coast of Australia. Marine Ornithology 27: 21-28.

Freuchen, P., and F. Salomonsen. 1958. The Arctic year. G. P. Putnam and Sons, New York.

Frederiksen, M., M. P. Harris, F. Daunt, P. Rothery, and S. Wanless. 2004a. Scaledependent climate signals drive breeding phenology of three seabird species. 
Global Change Biology 10: 1214-1221.

Frederiksen, M., S. Wanless, M. P. Harris, P. Rothery, and L. J. Wilson. 2004b. The role of industrial fisheries and oceanographic change in the decline of North Sea black-legged kittiwakes. Journal of Applied Ecology 41: 1129-1139.

Frederiksen, M., M. Edwards, A. J. Richardson, N. C. Halliday, and S. Wanless. 2006. From plankton to top predators: bottom-up control of a marine food web across four trophic levels. Journal of Animal Ecology 75: 1259-1268.

Frederiksen, M., R. Mavor, and S. Wanless. 2007. Seabirds as environmental indicators: the advantages of combining datasets. Marine Ecology Progress Series 352: 205-211.

Furness, R. W. 1993. Birds as monitors of pollutants. Pp. 86-143 In Birds as monitors of environmental change. Edited by R.W. Furness and J.J.D. Greenwood. Chapman \& Hall, London.

Furness, R. W., and C. M. Todd. 1984. Diets and feeding of fulmars Fulmarus glacialis during the breeding season: a comparison between St. Kilda and Shetland colonies. Ibis 126: 379-387.

Furness, R.W., and D. M. Bryant. 1996. Effect of wind on field metabolic rates of breeding northern fulmars. Ecology 77: 1181-1188.

Furness, R. W., and C. J. Camphuysen. 1997. Seabirds as monitors of the marine environment. ICES Journal of Marine Science 54: 726-737.

Gabrielsen, G. W., F. Mehlum, and H. E. Karlsen. 1988. Thermoregulation in four species of arctic seabirds. Journal of Comparative Physiology B 157: 703- 
708.

Garthe, S. 1997. Influence of hydrography, fishing activity, and colony location on summer seabird distribution in the southeastern North Sea. ICES Journal of Marine Science 54: 566-571.

Garthe, S., W. A. Montevecchi, U. Ojowski, and I. J. Stenhouse. 2004. Diets of northern fulmar (Fulmarus glacialis) chicks in the northwest Atlantic Ocean. Polar Biology 27: 277-280.

Gaston, A. J., and I. L. Jones. 1998. The auks. Oxford University Press, Oxford.

Gaston, A. J., and D. N. Nettleship. 1981. The thick-billed murres of Prince Leopold Island. Canadian Wildlife Service Monograph Number 6.

Gaston, A. J., and R. D. Elliot. 1996. Predation by ravens Corvus corax on Brünnich's guillemot Uria lomvia eggs and chicks and its possible impact on breeding site selection. Ibis 38: 742-748.

Gaston, A. J., and J. M. Hipfner. 1998. The effect of ice conditions in northern Hudson Bay on breeding by Thick-billed Murres (Uria lomvia). Canadian Journal of Zoology 76: 480-492.

Gaston, A. J., J. M. Hipfner, and D. Campbell. 2002. Heat and mosquitoes cause breeding failures and adult mortality in an Arctic-nesting seabird. Ibis 144: 185-191.

Gaston, A. J., H. G. Gilchrist, and M. L. Mallory. 2005. Variation in ice conditions has strong effects on the breeding of marine birds at Prince Leopold Island, Nunavut. Ecography 28: 331-344. 
Gaston, A. J., M. L. Mallory, H. G. Gilchrist, and K. O'Donovan. 2006. Status, trends and attendance patterns of the northern fulmar Fulmarus glacialis in Nunavut, Canada. Arctic 59: 165-178.

Gaston, A. J., R. C. Ydenberg, and G. E. J. Smith. 2007. Ashmole's halo and population regulation in seabirds. Marine Ornithology 35: 119-126.

Gauthier, G., J. Bêty, and K. A. Hobson. 2003. Are greater snow geese capital breeders? New evidence from a stable isotope model. Ecology 84: 32503264.

Gilchrist, H. G. 1999. Declining thick-billed murre Uria lomvia colonies experience higher gull predation rates: an inter-colony comparison. Biological Conservation 87: 21-29.

Gilchrist, H. G. and A. J. Gaston. 1997. Effects of murre nest site characteristics and wind conditions on predation by glaucous gulls. Canadian Journal of Zoology 75: 518-524.

Gilchrist, H. G., A. J. Gaston, and J. N. M. Smith. 1998. Wind and prey nest sites as foraging constraints on an avian predator, the glaucous gull. Ecology 79: 2403-2414.

Ginn, H. B., and D. S. Melville. 1983. Moult in birds. Tring: British Trust for Ornithology.

Grant, G. S. 1984. Energy cost of incubation to the parent bird. Pp. 59-72 in Seabird energetics (G. C. Whittow and H. Rahn, eds.). New York, Plenum Press.

Grant, G. S., T. N. Pettit, H. Rahn, G. C. Whittow, and C. V. Paganelli. 1982. Water 
loss from Laysan and black-footed albatross eggs. Physiological Zoology 55: 405-414.

GraphPad Software Inc. 1998. GraphPad Instat Ver. 3.00. GraphPad Software, San Diego, CA.

Grau, C. R. 1984. Egg formation. Pp. 33-58 in Seabird energetics (G. C. Whittow and H. Rahn, eds.). New York, Plenum Press.

Gray, C. M., R. A. Phillips, and K. C. Hamer. 2003. Non-random nestling mortality in northern fulmars: implications for monitoring marine environments. Journal of Zoology (London) 259: 109-113.

Griminger, P. 1986. Lipid metabolism. Pp. 345-358 In: Sturkie PD (ed) Avian physiology. Springer Publishers, New York.

Grosbois, V., and P. M. Thompson. 2005. North Atlantic Ocean climate variation influences survival in adult fulmars. Oikos 109: 273-290.

Groscolas, R., L. Schreiber, and F. Morin. 1991. The use of tritiated water to determine protein and lipid utilization in fasting birds: a validation study in incubating great-winged petrels, Pterodroma macroptera. Physiological Zoology 64: 1217-1233.

Guillemain, M., J. Elmberg, C. Arzel, A. R. Johnson, and G. Simon, 2008. The income-capital breeding dichotomy revisited : late winter body condition is related to breeding success in an income breeder. Ibis 150: 172-176.

Hamer, K. C., E. A. Schreiber, and J. Burger. 2002. Breeding biology, life histories, and life history-environment interactions in seabirds. Pp. 217-261 in E. A. 
Schreiber and J. Burger (eds.). Biology of marine birds. CRC Press, New York.

Harris, M. P. 1966. Breeding biology of the Manx Shearwater Puffinus puffinus. Ibis 108: 17-33.

Harris, M. P. 1971. Ecological adaptations of moult in some British gulls. Bird Study 18: 113-118.

Hatch, S. A. 1979. Breeding and population ecology of northern fulmars (Fulmarus glacialis) at Semidi Islands, Alaska. M.Sc. Thesis, University of Fairbanks, Alaska.

Hatch, S. A. 1983. Mechanism and ecological significance of sperm storage in the northern fulmar with reference to its occurrence in birds. Auk 100: 593-600.

Hatch, S. A. 1987. Copulation and mate guarding in the northern fulmar. Auk 104:450-461.

Hatch, S. A. 1989. Diurnal and seasonal patterns of colony attendance in the northern fulmar, Fulmarus glacialis, in Alaska. Canadian Field-Naturalist 103: 248-260.

Hatch, S. A. 1990a. Individual variation in behavior and breeding success of northern fulmars. Auk 107: 750-755.

Hatch, S. A. 1990b. Time allocation by northern fulmars Fulmarus glacialis during the breeding season. Ornis Scandinavica 21: 89-98.

Hatch, S. A. 1990c. Incubation rhythm in the fulmar Fulmarus glacialis: annual variation and sex roles. Ibis 132 : 515-524. 
Hatch, S. A., and D. N. Nettleship. 1998. Northern fulmar (Fulmarus glacialis) In The Birds of North America, No. 361 (A. Poole and F. Gill, eds.). The Birds of North America Inc., Philadelphia, PA.

Hatch, S. A., and M. A. Hatch. 1990. Breeding seasons of oceanic birds in a subarctic colony. Canadian Journal of Zoology 68:1664-1679.

Hobson, K. A. 1993. Trophic relationships among high arctic seabirds: insights from tissue-dependent stable-isotope models. Marine Ecology Progress Series 95: 7-18.

Hodum, P. J. 2002. Breeding biology of high-latitude Antarctic fulmarine petrels (Procellariidae). Journal of Zoology (London) 256:139-149.

Hodum, P. J., and K. A. Hobson. 2000. Trophic relationships among Antarctic fulmarine petrels: insights into dietary overlap and chick provisioning strategies inferred from stable-isotope $\left(\delta^{15} \mathrm{~N}\right.$ and $\left.\delta^{13} \mathrm{C}\right)$ analyses. Marine Ecology Progress Series 198: 273-281.

Holmgren, N., and A. Hedenström. 1995. The scheduling of molt in migratory birds. Evolutionary Ecology 9: 354-368.

Houston, D. C., P. J. Jones, and R. M. Sibly. 1983. The effect of female body condition on egg laying in Lesser Black-backed Gulls Larus fuscus. Journal of Zoology (London) 200: 509-520.

Hudson, P. J. 1982. Nest site characteristics and breeding success in the razorbill Alca torda. Ibis 124: 355-359.

Hunt, G. L., Jr. 1991. Marine ecology of seabirds in polar oceans. American 
Zoologist 31: 141-142.

Hunter, F. M. 1998. Timing of pair and extra-pair copulations in the northern fulmar. Condor 100: 141-145.

Hunter, S. 1984. Moult of the giant petrels Macronectes halli and M. giganteus at South Georgia. Ibis 126: 119-132.

Imber, M. J. 1976. Breeding biology of the grey-faced petrel Pterodroma macroptera gouldi. Ibis 118: 51-64.

Jenouvrier, S., C. Barbraud, and H. Weimerskirch. 2003. Effects of climate variability on the temporal population dynamics of southern fulmars. Journal of Animal Ecology 72: 576-587.

Johnstone, R. M., and L. S. Davies. 1990. Incubation routines and foraging trip regulation in the grey-faced petrel Pterodroma macroptera. Ibis 132: 14-20.

Keer, D. C., C. D. Ankney, and J. S. Millar. 1982. The effect of drying termperature on extraction of petroleum ether soluble fats of small birds and mammals. Canadian Journal of Zoology 60: 470-472.

Kilpi, M., and K. Lindström. 1997. Habitat-specific clutch size and cost of incubation in common eiders, Somateria mollissima. Oecologia 111:297301 .

Kim, S.-Y., and P. Monaghan. 2005a. Interacting effects of nest shelter and breeder quality on behaviour and breeding performance of herring gulls. Animal Behavior 69: 301-306.

Kim, S.-Y., and P. Monaghan. 2005b. Effects of vegetation on nest microclimate 
and breeding performance of lesser black-backed gulls (Larus fuscus). Journal of Ornithology 146: 176-183.

King, J. R. 1974. Seasonal allocation of time and energy resources in birds. In: Paynter, R. A. (eds.). Avian energetics. Publication of the Nuttall Ornithologists' Club No 15, pp 4-85.

King, J. R., and M. E. Murphy. 1985. Periods of nutritional stress in the annual cycles of endotherms: fact or fiction? American Zoologist 25: 955-964.

Klaassen, M., A. Lindström, H. Meltofte, and T. Piersma. 2001. Arctic waders are not capital breeders. Nature 413: 794 .

Klaassen, M., K. F. Abraham, R. L. Jefferies, and M. Vrtiska. 2006. Factors affecting the site of investment, and the reliance on saving for arctic breeders: the capital-income dichotomy revisited. Ardea 94: 371-384.

Koenig, W. D. 1982. Ecological and social factors affecting hatchability of eggs. Auk 99: 526-536.

Krementz, D. G., and C. D. Ankney. 1986. Bioenergetics of egg production by female house sparrows. Auk 103: 299-305.

Lack, D. 1954. The natural regulation of animal numbers. Clarendon Press, Oxford.

Lack, D. 1966. Populations studies on birds. Clarendon Press, Oxford.

Lack, D. 1968. Ecological adaptations for breeding in birds. Methuen Press, London.

Lawson, J. W., A. M. Magalhaes, and E. H. Miller. 1998. Important prey species of marine vertebrate predators in the northwest Atlantic: proximate composition 
and energy density. Marine Ecology Progress Series 164: 13-20.

Lesher, S. W., and S. C. Kendeigh. 1941. Effect of photoperiod on molting of feathers. Wilson Bulletin 53: 169-180.

Lewis, E. L., D. Ponton, L. Legendre, and B. LeBlanc. 1996. Springtime sensible heat, nutrients and phytoplankton in the Northwater polynya, Canadian Arctic. Continental Shelf Research 16: 1775-1792.

Lewis, S., T. N. Sherratt, K. C. Hamer, and S. Wanless. 2001. Evidence of intraspecific competition for food in a pelagic seabird. Nature 412: 816-819.

Lewis, S., E. A. Schreiber, F. Daunt, G. A. Schenk, S. Wanless, and K. C. Hamer. 2004. Flexible foraging patterns under different time constraints in tropical boobies. Animal Behavior 68: 1331-1337.

Lewis, S., D. Gremillet, F. Daunt, P. G. Ryan, R. J. M. Crawford, and S. Wanless. 2006. Using behavioral and state variables to identify proximate causes of population change in a seabird. Oecologia 147: 606-614.

Lima, S. L., and L. M. Dill. 1990. Behavioral decisions made under risk of predation: a review and prospectus. Canadian Journal of Zoology 68: 619-640.

Lindstrom, A., S. Daan, and G. H. Visser. 1994. The conflict between moult and migratory fat deposition: a photoperiodic experiment with bluethroats. Animal Behaviour 48: 1173-1181.

Linton, A., and D. N. Nettleship. 1977. Biological investigation of northern fulmars (Fulmarus glacialis) at Prince Leopold Island, NWT, summer 1976. Studies on Northern Seabirds Report No 53. Available from Environment Canada, 
Sackville, NS.

Lloyd, C., M. L. Tasker, and K. Partridge. 1991. The status of seabirds in Britain and Ireland. T \& AD Poyser, London.

Lyngs, P. 2003. Migration and winter ranges of birds in Greenland. Dansk Ornitologisk Forenings Tidsskrift 97.

Lyon, B. E., and R. D. Montgomerie. 1987. Ecological correlates of incubation feeding: a comparative study of high arctic finches. Ecology 68: 713-722.

MacDonald, M. A. 1977. The pre-laying exodus of the Fulmar Fulmarus glacialis (L.). Ornis Scandinavica 8: 33-37.

MacDonald, M. A. 1980. The winter attendance of Fulmars at land in NE Scotland. Ornis Scandinavica 11:23-29.

Mallory, M. L. 2008. Marine plastic debris in northern fulmars from the Canadian High Arctic. Marine Pollution Bulletin 54: in press.

Mallory, M. L., and A. J. Fontaine. 2004. Key marine habitat sites for migratory birds in Nunavut and the Northwest Territories. Canadian Wildlife Service Occasional Paper 109

Mallory, M. L., and M. R. Forbes. 2005. Sex discrimination and measurement bias in northern fulmars (Fulmarus glacialis) from the Canadian Arctic. Ardea 93: $25-36$.

Mallory, M. L., and A. J. Gaston. 2005. Monitoring northern fulmars in the Canadian Arctic: plot locations and counts at selected colonies. Canadian Wildlife Service Technical Report 432. 
Mallory, M. L., B. M. Braune, and M. R. Forbes. 2006a. Breeding and contaminant concentrations in northern fulmars (Fulmarus glacialis L.) from the Canadian high arctic. Chemosphere 64: 1541-1544.

Mallory, M. L., M. R. Forbes, and T. D. Galloway. 2006b. Ectoparasites of northern fulmars Fulmarus glacialis (Procellariformes: Procellariidae) from the Canadian Arctic. Polar Biology 29: 353-357.

Mallory, M. L., J. D. McLaughlin, and M. R. Forbes. 2007. Breeding status, contaminant burden and endoparasites of northern fulmars (Fulmarus glacialis) from the Canadian high arctic. Ibis 149: 338-344.

Mallory, M. L., J. Akearok, D. B. Edwards, K. O’Donovan, and C. D. Gilbert. 2008. Autumn migration and wintering of northern fulmars (Fulmarus glacialis) from the Canadian High Arctic. Polar Biology 31:745-750.

Marshall, A. J., and D. L. Serventy. 1956. The breeding cycle of the Short-tailed Shearwater, Puffinus tenuirostris (Temminck), in relation to trans-equatorial migration and its environment. Proceedings of the Zoological Society of London 127: 489-510.

Mavor, R. A., M. Parsons, M. Heubeck, and S. Schmitt. 2005. Seabird numbers and breeding success in Britain and Ireland, 2004. Joint Nature Conservation Committee, Peterborough, UK.

Mavor, R. A., M. Parsonsm, M. Heubeck, and S. Schmitt. 2006. Seabird numbers and breeding success in Britain and Ireland, 2005. UK Nature Conservation No. 30, Peterborough, UK. 
Mawhinney, K., A. W. Diamond, and F. P. Kehoe. 1999. The use of energy, fat, and protein reserves by breeding great black-backed gulls. Canadian Journal of Zoology 77: 1459-1464.

Maxson, S. J., and N. P. Bernstein. 1984. Breeding season time budgets of the southern black-backed gull in Antarctica. Condor 86: 401-409.

McBean, G. 2004. Arctic climate: past and present, p. 21-60. In C. Symon, L. Arris, and B. Heal [eds.], Arctic climate impact assessment. Cambridge University Press, New York.

McLaren, P. L. 1982. Spring migration and habitat use by seabirds in eastern Lancaster Sound and western Baffin Bay. Arctic 35: 88-111.

Mehlum, F., and G. W. Gabrielsen. 1993. The diet of high-arctic seabirds in coastal and ice-covered pelagic areas near the Svalbard archipelago. Polar Research 12: $1-20$.

Meijer, T., and R. Drent. 1999. Re-examination of the capital and income dichotomy in breeding birds. Ibis 141: 399-414.

Michel, P., J. C. Ollason, V. Grosbois, and P. M. Thompson. 2003. The influence of body size, breeding experience and environmental variability on egg size in the northern fulmar (Fulmarus glacialis). Journal of Zoology (London) 261: $427-432$.

Mitchell, P. I., S. F. Newton, N. Ratcliff, and T. E. Dunn. 2004. Seabird populations of Britain and Ireland. T. \& A.D. Poyser, London.

Montevecchi, W. A., and R. A. Myers. 1997. Centurial and decadal oceanographic 
influences on changes in northern gannet populations and diets in the northwest Atlantic: implications for climate change. ICES Journal of Marine Science 54: 608-614.

Montgomerie, R. D., and P. J. Weatherhead. 1988. Risks and rewards of nest defense by parent birds. Quarterly Review of Biology 63: 167-187.

Moran, M. D. 2003. Arguments for rejecting the sequential Bonferroni in ecological studies. Oikos 100: 403-405.

Morrison, R. I. G. and K. A. Hobson. 2004. Use of body stores in shorebirds after arrival on High-Arctic breeding grounds. Auk 121: 333-344.

Mougin, J. - L. 1967. Etude écologique des dues espèces de fulmar: le fulmar Atlantique, Fulmarus glacialis, et le Fulmar Antarctique, Fulmarus glacialoides. Oiseau 37: 57-103.

Nagy, K. A. 1983. The doubly labeled water $\left({ }^{3} \mathrm{HH}^{18} \mathrm{O}\right)$ method: a guide to its use. University of California, Los Angeles Publication No. 12-1417.

National Snow and Ice Data Center [online]. 2007. State of the cryosphere. National Snow and Ice Data Center, University of Colorado, CO. $<$ http://nsidc.org/sotc/sea_ice.html $>$ (10 May 2007).

Nettleship, D. N. and A. J. Gaston. 1978. Patterns of pelagic distribution of seabirds in western Lancaster Sound and Barrow Strait, Northwest Territories, in August and September 1976. ESCOM Report No AI-09, Environment Canada, Ottawa.

Nettleship, D. N., and P. J. Evans. 1985. Distribution and status of the Atlantic 
Alcidae. Pages 53-154 in D. N. Nettleship and T. R. Birkhead (eds.), The Atlantic Alcidae. Academic Press, London, U.K.

Nettleship, D. N., and D. C. Duffy. 1993. Seabird populations. Elsevier Applied Science, London.

Newton, I. 2003. The speciation and biogeography of birds. Academic Press, New York.

Nisbet, I. C. T. 1994. Effects of pollution on marine birds. Pp. 8-25 In Seabirds on islands: threats, case studies, and action plans. Edited by D.N. Nettleship, J. Burger and M. Gochfield. Birdlife International, Cambridge, UK.

Norstrom, R. J., T. P. Clark, J. P. Kearney, and A. P. Gilman. 1986. Herring gull energy requirements and body constituents in the Great Lakes. Ardea 74: 123.

Ojowski, U., C. Eidtmann, R. W. Furness, and S. Garthe. 2001. Diet and nest attendance of incubating and chick-rearing northern fulmars (Fulmarus glacialis) in Shetland. Marine Biology 129: 1193-1200.

Ollason, J. C., and G. M. Dunnet. 1978. Age, experience and other factors affecting the breeding success of the fulmar Fulmarus glacialis in Orkney. Journal of Animal Ecology 47: 961-976.

Ollason, J. C., and G. M. Dunnet. 1980. Nest failures in the fulmar: the effect of observers. Journal of Field Ornithology 51: 39-54.

Ollason, J. C., and G. M. Dunnet. 1986. Relative effects of parental performance and egg quality on breeding success of fulmars Fulmarus glacialis. Ibis 128: 290- 
296.

Ollason, J. C., and G. M. Dunnet. 1988. Variation in breeding success in fulmars. Pp. 263-278 In T. H. Clutton-Brock (ed.) Reproductive Success. Chicago: University of Chicago Press.

Orians, G. H. and N. E. Pearson. 1979. On the theory of central place foraging. Pp. 155-177 In: Horn DJ, Mitchell RD, Stairs GR (eds) Analysis of ecological systems. Ohio State University Press, Columbus, $\mathrm{OH}$.

Pauly, D., and J. Maclean. 2003. In a perfect ocean: the state of fisheries and ecosystems in the North Atlantic Ocean. Island Press, Washington.

Payne, R. B. 1972. Mechanism and control of molt. Pp. 85-113 In: D. S. Farner and J. R. King (eds.) Avian Biology, Vol 11. Academic Press, New York

Pennycuick, C. J. J. P. Croxall, and P. A. Prince. 1984. Scaling of foraging radius and growth rate in petrels and albatrosses (Procellariiformes). Ornis Scandinavica 15: 145-154.

Perrins, C. M. 1970. The timing of birds' breeding seasons. Ibis 112: 242-255.

Phillips, R. A., and K. C. Hamer. 1999. Lipid reserves, fasting capability, and the evolution of nestling obesity in procellariiform seabirds. Proceedings of the Royal Society of London B 266: 1329-1334.

Phillips, R. A., M. K. Petersen, K. Lilliendahl, J. Solmundsson, K. C. Hamer, C. J. Camphuysen, and B. Zonfrillo. 1999. Diet of the northern fulmar Fulmarus glacialis: reliance on commercial fisheries? Marine Biology 135: 159-170.

Pierotti, R. 1982. Habitat selection and its effect on reproductive output in the 
herring gull in Newfoundland. Ecology 63: 854-868.

Pinaud, D., and H. Weimerskirch. 2002. Ultimate and proximate factors affecting the breeding performance of a marine top predator. Oikos 99: 141-150.

Prince, P. A., C. Ricketts, and G. Thomas. 1981. Weight loss in incubating albatrosses and its implications for their energy and food requirements. Condor 83: 238-242.

Proffitt, F. 2004. Reproductive failure threatens bird colonies on North Sea coast. Science 304: 1090 .

Raymont, J. E. G. 1976. Plankton and productivity in the oceans. Pergamon Press, Toronto, Canada.

Rayner, J. M. V. 1999. Estimating power curves of flying vertebrates. Journal of Experimental Biology 202: 3449-3461.

Réale, D., B. Y. Gallant, M. Leblanc, and M. Festa-Bianchet. 2000. Consistency of temperament in bighorn ewes and correlates with behaviour and lift history. Animal Behaviour 60: 589-597.

Réale, D., and M. Festa-Bianchet. 2003. Predator-induced natural selection on temperament in bighorn ewes. Animal Behaviour 60: 589-597.

Reid, K., and J. P. Croxall. 2001. Environmental response of upper trophic level predators reveals a system change in an Antarctic marine ecosystem. Proceeding of the Royal Society of London B 268: 377-384.

Rice, W. R. 1989. Analyzing tables of statistical tests. Evolution 43: 223-225.

Richdale, L. E. 1963. Biology of the Sooty Shearwater Puffinus griseus. 
Proceedings of the Zoological Society of London 141:1-117.

Ricklefs, R. E. 1974. Energetics of reproduction in birds. Pp. 152-292 in Avian energetics (R. A. Paynter, ed.). Cambridge, Massachusetts, Nuttall Ornithological Club.

Ricklefs, R. E. 1983. Some considerations on the reproductive energetics of pelagic seabirds. Studies in Avian Biology 8:84-94.

Ricklefs, R. E., D. C. Hahn, and W. A. Montevecchi. 1978. The relationship between egg size and chick size in the laughing gull and Japanese quail. Auk 95: 135-144.

Ricklefs, R. E., D. D. Roby, and J. B. Williams. 1986. Daily energy expenditure by adult Leach's storm-petrels during the nesting cycle. Physiological Zoology 59: 649-660.

Robertson, G. J., F. Cooke, and I. R. Goudie. 1998. Moult speed predicts pairing success in male harlequin ducks. Animal Behaviour 55: 1677-1684.

Roff, D. A. The evolution of life histories. Chapman \& Hall, New York.

Rowe, S., and I. L. Jones. 2000. The enigma of razorbill Alca torda breeding site selection: adaptation to a variable environment? Ibis $142: 324-327$.

Safina, C. 2002. Eye of the albatross - visions of hope and survival. Henry Holt and Company, New York.

Sagerup, K., E. O. Henriksen, A. Skorping, J. U. Skaare, and G. W. Gabrielsen. 2000. Intensity of parasitic nematodes increases with organochlorine levels in the glaucous gull. Journal of Applied Ecology 37: 532 - 540. 
Salomonsen, F. 1961. The birds of Greenland. Munksgaard, Copenhagen.

Salomonsen, F. 1965. The geographical variation of the fulmar (Fulmarus glacialis) and the zones of marine environment in the North Atlantic. Auk 82: 327-355.

Salomonsen, F. 1979. Ornithological and ecological studies in S. W. Greenland (59 $46^{\prime}-62^{\circ} 27^{\prime} \mathrm{N}$ Lat.). Meddelser Om Greenland 204: 1-214.

Sandberg, R., and F. R. Moore. 1996. Fat stores and arrival on the breeding grounds: reproductive consequences for passerine migrants. Oikos 77: 577-581.

SAS Institute Inc. 2002. SAS 9.1. SAS Institute Inc., Cary, North Carolina.

Schreiber, E. A. 2002. Climate and weather effects on seabirds. Pp. 179-216 In Biology of marine birds. Edited by E.A. Schreiber and J. Burger. CRC Press, New York.

Serventy, D. L. 1963. Egg laying time-table of the Slender-billed Shearwater, Puffinus tenuirostris. Proceedings of the XIII International Ornithological Congress 1: 338-343.

Shaffer, S. A., D. P. Costa, and H. Weimerskirch. 2001. Behavioural factors affecting foraging effort of breeding wandering albatrosses. Journal of Animal Ecology 70: 864-874.

Shaw, D. N., C. A. Holt, H. E. Maggs, and D. de Palacio. 2002. Fair Isle seabird studies. JNCC Report 332, Joint Nature Conservation Committee, Aberdeen, UK.

Sih, A., A. Bell, and J. C. Chadwick. 2004. Behavioral syndromes: an ecological and evolutionary overview. Trends in Ecology and Evolution 19: 372-378. 
Slater, C. A. 1990. First arrival dates at two fulmar Fulmarus glacialis colonies in Norfolk. Bird Study 37:1-4.

Smith, R. L. 1980. Ecology and field biology. $3^{\text {rd }}$ Edition. Harper \& Ross Publishers, New York.

Smith, M., and B. Rigby. 1981. Distribution of polynyas in the Canadian Arctic. In: Stirling I, Cleator H (eds) Polynyas in the Canadian Arctic. Canadian Wildlife Service Occasional Paper 45: 7-28.

Sokal, R. R., and C. A. Braumann. 1980. Significance tests for coefficients of variation and variability profiles. Systematic Zoology 29: 50-66.

Stahl, J. -C., and P. M. Sagar. 2006. Long and short trips in nonbreeding Buller's albatrosses: relationships with colony attendance and body mass. Condor 108: $348-365$.

Stenseth, N. C., and A. Mysterud. 2002. Climate, changing phenology, and other life history traits: nonlinearity and match-mismatch to the environment. Proceedings of the National Academy of Sciences USA 99: 13379-13381.

Stirling, I. 1997. The importance of polynyas, ice edges, and leads to marine mammals and birds. Journal of Marine Systems 10: 9-21.

Swaddle, J. P., and M. S. Witter. 1997. The effects of molt on the flight performance, body mass, and behavior of European starlings (Sturnus vulgaris): an experimental approach. Canadian Journal of Zoology 75: 11351146.

Swennen, C. 1974. Observations on the effect of ejection of stomach oil by the 
fulmar Fulmarus glacialis on other birds. Ardea 62: 111-117.

Systat Software Inc. 2002. Systat 10.2. Systat, Richmond.

Thompson, C. W., S. A. Hatch, M. Leu, K. Brennan, B. Roca, and B. Krausse. 2000.

Novel sequences of flight feather molt in sooty shearwaters and northern fulmars. Pacific Seabirds 27: 50 .

Thompson, D. R., and R. W. Furness. 1995. Stable-isotope ratios of carbon and nitrogen in feathers indicate seasonal dietary shifts in northern fulmars. Auk 112: 493-498.

Thompson, J. E., and R. D. Drobney. 1995. Intensity and chronology of post reproductive molts in male canvasbacks. Wilson Bulletin 107: 338-358.

Thompson, P. M. 2006. Identifying drivers of change; did fisheries play a role in the spread of North Atlantic fulmars? Pp. 143-156 In: Boyd IL, Wanless S, Camphuysen CJ (eds) Top predators in marine ecosystems: their role in monitoring and management. Cambridge University Press, Cambridge.

Thompson, P. M., and J. C. Ollason. 2001. Lagged effects of ocean climate change on fulmar population dynamics. Nature 413: 417-420.

Tickell, W. L. N. 2000. Albatrosses. Yale University Press, New Haven, CT.

Titman, R. D., M. C. Lagrenade, and M. R. Miller. 1990. An evaluation of techniques to measure contour feather molt in ducks. Journal of Wildlife Management 54: 219-222.

Trivers, R. L. 1972. Parental investment and sexual selection. Pp. 136-179 In Sexual selection and the descent of Man 1871-1971. Edited by B. Campbell (ed.), 
Aldine, Chicago.

Van Franeker, J. A. 1986. Arctic and Antarctic seabird studies: fulmarine petrels. Circumpolar Journal 1: 3-13.

Van Franeker, J. A., and J. Wattel. 1982. Geographical variation of the fulmar Fulmarus glacialis in the North Atlantic. Ardea 70: 31-44.

Verbeek, N. A. M. 1977. Timing of primary moult in adult herring gulls and lesser black-backed gulls. Journal of Ornithology 118: 87-89.

Verspoor, E., T. R. Birkhead, and D. N. Nettleship. 1987. Incubation and brooding shift duration in the common murre Uria aalge. Canadian Journal of Zoology 65: $247-252$.

Visser, M. E., A. J. van Noordwijk, J. M. Tinbergen, and C. M. Lessells. 1998. Warmer springs lead to mistimed reproduction in great tits (Parus major). Proceedings of the Royal Society of London B 265: 1867-1870.

Walsberg, G. E. 1983. Avian ecological energetics. Pp. 171-220 In Avian biology, Vol. 7. Edited by D.S. Farner, J.R. King, and K.C. Parkes. Academic Press, New York.

Ward, P., and A. Zahavi. 1973. The importance of certain assemblages of birds as "information centres" for food finding. Ibis 115: 517-534.

Warham, J. 1983. The composition of petrel eggs. Condor 83: 194-199.

Warham, J. 1990. The petrels - their ecology and breeding systems. Academic Press, London.

Warham, J. 1996. The behaviour, population biology and physiology of the petrels. 
Academic Press, London.

Wayland, M., H. G. Gilchrist, D. L. Dickson, T. Bollinger, C. James, R. A. Carreno, and J. Keating. 2001. Trace elements in king eiders and common eiders in the Canadian Arctic. Archives of Environmental Contamination and Toxicology 41: 491-500.

Weathers, W. W., W. A. Buttemer, A. M. Hayworth, and K. A. Nagy. 1984. An evaluation of time-budget estimates of daily energy expenditure in birds. Auk 101: $459-472$.

Weimerskirch, H. 1991. Sex-specific differences in molt strategy in relation to breeding in the Wandering Albatross. Condor 93: 731-737.

Weimerskirch, H. 1995. Regulation of foraging trips and incubation routine in male and female wandering albatrosses. Oecologia 102: 37-43.

Weimerskirch, H. 1998. How can a pelagic seabird provision its chick when relying on a distant food source? Cyclic attendance at the colony, foraging decision, and body condition in sooty shearwaters. Journal of Animal Ecology 67: 99109.

Weimerskirch, H., T. Mougey, and X. Hindermeyer. 1997. Foraging and provisioning strategies of black-browed albatrosses in relation to the requirements of the chick: natural variation and experimental study. Behavioral Ecology 8: 635-643.

Weimerskirch, H., O. Chastel, Y. Cherel, J.-A. Henden, and T. Tveraa. 2001. Nest attendance and foraging movements of Northern Fulmars rearing chicks at 
Bjørnøya Barents Sea. Polar Biology 24: 83-88.

Welch, H.E., M. A. Bergmann, T. D. Siferd, K. A. Martin, M. F. Curtis, R. E. Crawford, R. J. Conover, and H. Hop. 1992. Energy flow through the marine ecosystem of the Lancaster Sound region, Arctic Canada. Arctic 45: 343-357.

Welty, J. C., and L. Baptista. 1988. The life of birds, fourth edition. Harcourt College Publishers, Toronto.

Whittow, G. C. 2002. Seabird reproductive physiology and energetics. Pp. 409-437 in E. A. Schreiber and J. Burger (eds.). Biology of marine birds. CRC Press, New York.

Williamson, K. 1952. The incubation rhythm of the fulmar. Scottish Naturalist 64: $138-147$.

Wilson, D. S. 1998. Adaptive individual differences within single populations. Philosophical Transactions of the Royal Society of London Series B 353: 199205.

Wilson, R. P., J. A. Scolaro, D. Gremillet, M. A. M. Kierspel, S. Laurenti, J. Upton, H. Gallelli, F. Quintana, E. Frere, G. Muller, M. T. Straten, and I. Zimmer. 2005. How do magellanic penguins cope with variability in their access to prey? Ecological Monographs 75: 379-401.

Wynne-Edwards, V. C. 1939. Intermittent breeding of the Fulmar (Fulmarus glacialis (L.)), with some general observations on non-breeding in sea-birds. Proceedings of the Zoological Society of London A 109: 127-132. 